\title{
TRATAMENTO DIGITAL DE FOTOGRAFIAS AÉREAS VERTICAIS COMO UMA ALTERNATIVA À ANÁLISE ESTEREOSCÓPICA DE BACIAS HIDROGRÁFICAS
}

\author{
ANTONIO AMADOR DE SOUSA \\ Engenheiro Agrícola
}

Orientador: Prof Dr. RUBENS ANGULO FILHO

\begin{abstract}
Tese apresentada à Escola Superior de Agricultura "Luiz de Queiroz", da Universidade de São Paulo, para a obtenção do título de Doutor em Agronomia, Área de Concentração: Irrigação e Drenagem.
\end{abstract}

\section{PIRACICABA}

Estado de São Paulo - Brasil

Março de 2000 


\section{ERRATA}

\begin{tabular}{|c|c|c|c|}
\hline$p$. & linha & onde se lê & leia-se \\
\hline 27 & 6 e 9 & $\ldots$...scattergramas... & ...diagramas de dispersão... \\
\hline 27 & 15 & ...scattergrama $\ldots$ & ...diagrama de dispersão... \\
\hline 35 & 27 & ...sendo mais nas filtragens... & ...sendo mais usado nas filtragens... \\
\hline 38 & 14 & $\begin{array}{l}\text {...respectivamente para com do } \\
\text { espaço RGB. }\end{array}$ & ...respectivamente. \\
\hline 44 & 9 & ...GPS (Global Positioning Systems). & ...GPS (Global Positioning System). \\
\hline 45 & 12 & ...onde $\mathrm{x}=$ média da coordenada $\ldots$ & $\ldots$ onde: $\mathrm{x}=$ medida da coordenada $\ldots$ \\
\hline 64 & 25 & ...ER mapp, MGE... & ...ER mapper, MGE... \\
\hline 74 & 5 & $\begin{array}{l}\text {..CYMK (cyan, yellow, magenta, } \\
\text { preto), para... }\end{array}$ & $\begin{array}{l}\text {..CYMK (cyan, yellow, magenta } \\
\text { and black, respectivamente), para... }\end{array}$ \\
\hline \multirow[t]{2}{*}{77} & 5 e 16 & $\ldots 1 / 30$ polegada.. & $\ldots 1 / 50$ polegada $\ldots$ \\
\hline & 6 e 17 & $\ldots 1 / 50$ polegada $\ldots$ & $\ldots 1 / 30$ polegada $\ldots$ \\
\hline 101 & 25 & $\ldots$ França $(1068), \ldots$ & ...França $(1968), \ldots$ \\
\hline 115 & 17 a 18 & $\begin{array}{l}\text {...produtos de um sistema sensor de } \\
\text { resolução espectral limitada (pouco } \\
\text { além do visível) comparado... }\end{array}$ & $\begin{array}{l}\text {...produtos de um sistema sensor de } \\
\text { caráter unidimensional comparado... }\end{array}$ \\
\hline 123 & 1,3 e 5 & MÉTODO 1.......MÉTODO 2 & MÉTODO 2....MÉTODO 3 \\
\hline 127 & 23 & ...podzólicos refle... & ...podzólicos reflete... \\
\hline
\end{tabular}

\section{REFERÊNCIAS BIBLIOGRÁFICAS}

Páginas 153, 155 e 156

onde se lê ...Escola Superior de Agronomia...

leia-se ...Escola Superior de Agricultura... 
Dados Internacionais de Catalogação na Publicação (CIP)

DIVISÃo DE BIBLIOTECA E DOCUMENTAÇÁOO - Campus "Luiz de Queiroz"/USP

Sousa, Antonio Amador de

Tratamento digital de fotografias aéreas verticais como uma alternativa à análise estereoscópia de bacias hidrográficas / Antonio Amador de Sousa. - - Piracicaba, 2000. 167 p. : il.

Tese (doutorado) - Escola Superior de Agricultura Luiz de Queiroz, 2000.

Bibliografia.

1. Bacia hidrográfica 2. Fotográfia aérea 3. Fotointerpretação 4. Geoprocessamento 5. Levantamento do solo 6. Processamento de imagem I. Título

CDD 526.0285

"Permitida a cópia total ou parcial deste documento, desde que citada a fonte - 0 autor"

Data de dopósito junto à CPG/ESALQ

$09 / 03 / 2000$ 
A meus pais,

Sinésio (in memóriam) e Maria;

A minha esposa,

Vânia

e nosso filho, Vinícius,

DEDICO COM AMOR 


\section{AGRADECIMENTOS}

À Universidade Federal da Paraíba pela oportunidade oferecida para realização do curso de Doutorado.

À Coordenadoria de Aperfeiçoamento de Pessoal de Ensino e Pesquisa (CAPES-PICDT-UFPB) pela concessão de bolsa de estudo.

Ao Prof. Dr. Rubens Angulo Filho pela orientação e oportunidade de ampliar meus conhecimentos.

Ao Prof. Dr. Carlos Alberto Vettorazzi pela atenção e valorosas sugestões.

Ao Dr. Maurício Alves Moreira pela atenção e apoio em visitas ao INPE.

Ao Prof. Dr. Jacob Silva Souto pelo apoio irrestrito e amizade inquestionável.

Ao colega Lúcio Valério Coutinho de Araújo pela amizade e agradável convivência em Piracicaba.

Aos colegas Osvaldo e Eder pela atenção e amizade e Parise pela amizade e importante colaboração.

Aos funcionários do Departamento de Engenharia rural e da Divisão de Biblioteca e Documentação da ESALQ.

Enfim, a todos aqueles que, direta ou indiretamente contribuíram para a realização deste trabalho. 


\section{SUMÁRIO}

Página

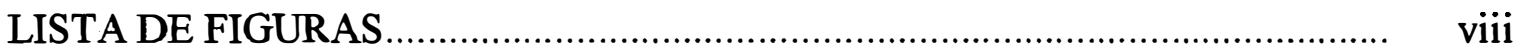

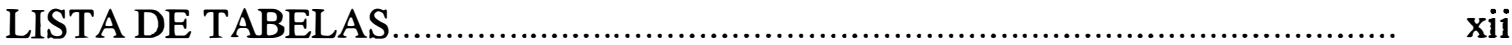

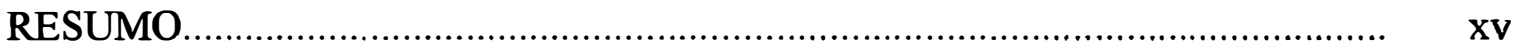

SUMMARY ...................................................................................

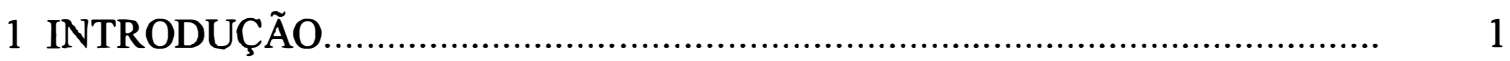

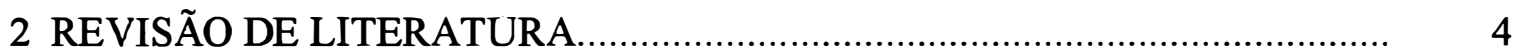

2.1 Fotointerpretação aplicada ao levantamento de solos.................................. 4

2.2 Estudo de bacias hidrográficas e composição de redes de drenagem............... 10

2.3 Padrão de drenagem superficial.................................................... 14

2.4 Processamento e análise de imagens.................................................. 17

2.4.1 Processamento de imagens contínuas.............................................. 18

2.4.2 Processamento de imagens digitais...................................................... 20

2.4.2.1 Digitalização de imagens.......................................................... 22

2.4.2.2 Histogramas de imagens........................................................... 24

2.4.2.3 Técnicas de processamento de imagens digitais.................................... 28

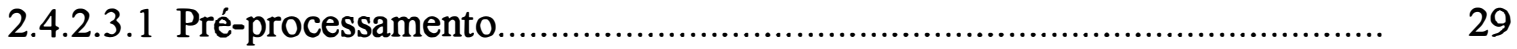

2.4.2.3.2 Realce de imagens.................................................................. 31

2.4.2.3.3 Classificação digital.................................................................. 40

2.5 Conversão de dados e georreferenciamento de imagens............................... 43

3 MATERIAL E MÉTODOS .............................................................. 47

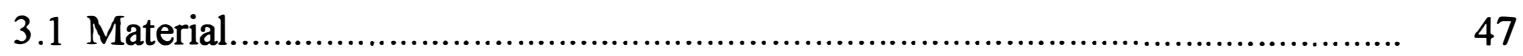

3.1.1 Localização e caracterização da área de estudo....................................... 47

3.1.1.1 Localização geográfica.......................................................... 47

3.1.1.2 Geologia................................................................................ 47

3.1.1.3 Geomorfologia................................................................ 51 
3.1.1.4 Clima

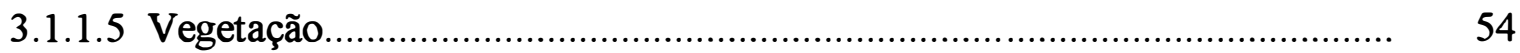

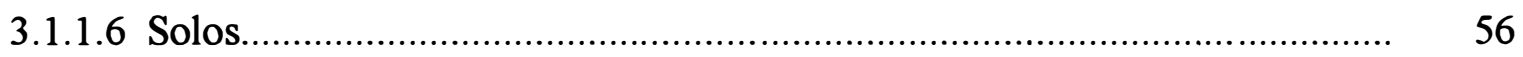

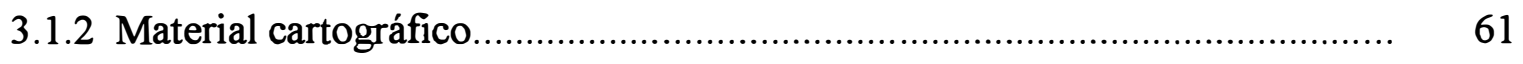

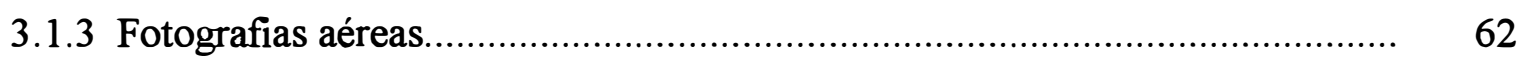

3.1.4 Equipamentos e materiais utilizados na interpretação visual.......................... 63

3.1.5 Equipamentos e sistemas computacionais utilizados no processamento e

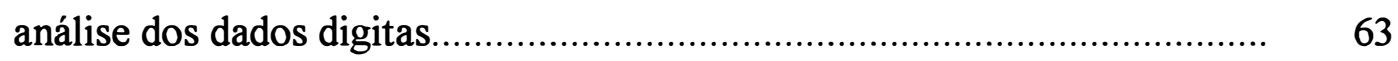

3.2 Métodos.

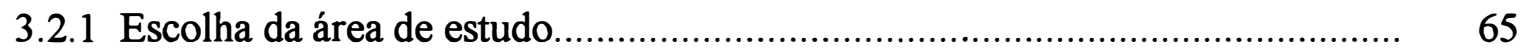

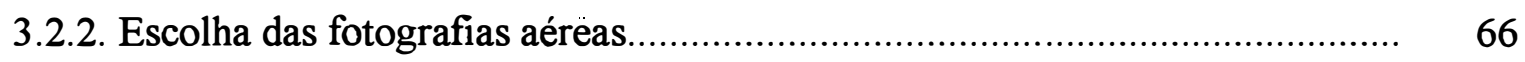

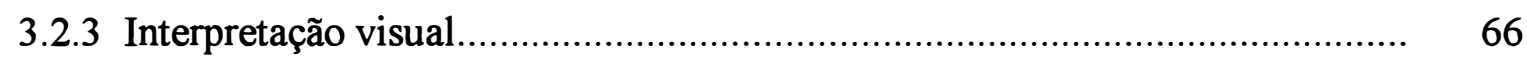

3.2.3.1 Elaboração do mapa básico de drenagem.................................................... 66

3.2.3.2 Determinação das características dimensionais das bacias.......................... 67

3.2.3.3 Seleção das bacias................................................................................. 68

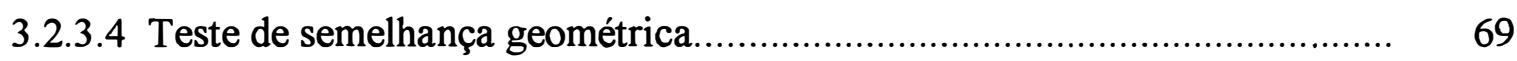

3.2.3.5 Análise da rede de drenagem............................................................. 70

3.2.4 Processamento digital das fotografias...................................................... 72

3.2.4.1 Aquisição dos dados digitais.................................................................. 72

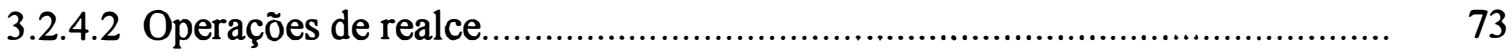

3.2.4.3 Georreferenciamento e correção geométrica das imagens.......................... 74

3.2.4.4 Formação do mosaico e delimitação de áreas de trabalho........................... 78

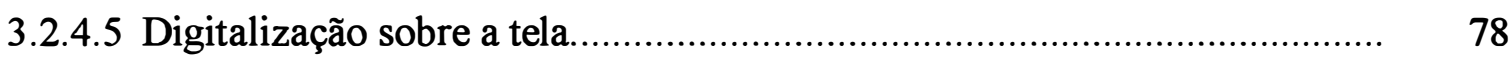

3.2.4.6 Medição dos segmentos de rios, perímetro e área ……………………....... 79

3.2.4.7 Compilação dos resultados...................................................................... 81

3.2.5 Delineamento experimental e análise estatística............................................ 81

4 RESULTADOS E DISCUSSÃO..................................................................... 87

4.1 Interpretação visual.................................................................................. 87 
Página

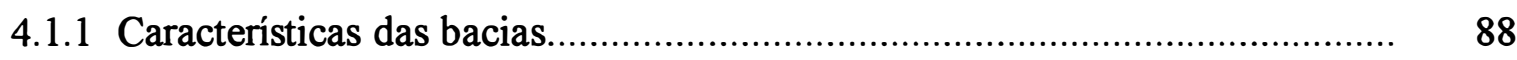

4.1.2 Características da rede de drenagem.......................................................... 97

4.1.2.1 Análise do número de segmentos de rios................................................. 97

4.1.2.2 Análise dos comprimentos dos rios........................................................ 101

4.1.3 Características do padrão de drenagem..................................................... 107

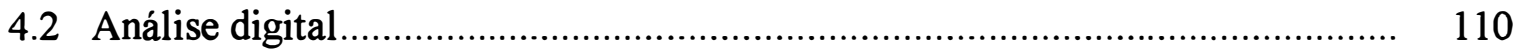

4.2.1 Processamento digital das imagens......................................................... 110

4.2.1.1 Digitalização das fotografias................................................................. 110

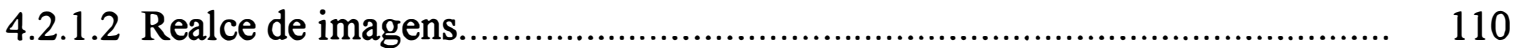

4.2.1.3 Seleção de pontos de controle e georreferenciamento............................... 117

4.2.1.4 Mosaicagem.............................................................................. 119

4.2.1.5 Digitalização da rede de drenagem e das bacia........................................ 119

4.2.2 Composição da rede de drenagem. ........................................................... 124

4.2.3 Características do padrão de drenagem........................................................ 125

4.3 Análise estatística dos dados.................................................................... 128

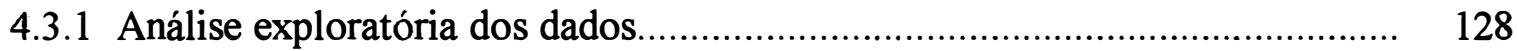

4.3.2 Análise de variância e comparação de médias através do teste de Tukey e do teste F para contrastes......................................................................... 129

4.3.2 Teste exato de Fisher para a variável Razão de textura média das bacias..... 138

5. CONCLUSÕES 140

ANEXO: Características da rede e do padrão de drenagem das bacias estudadas, determinadas pelos três intérpretes, para os Métodos 2 e 3..................... 142 


\section{LISTA DE FIGURAS}

Página

1 Histogramas bimodal (a) e unimodal (b), com a representação dos respectivos valores de moda e média (adaptado de Soares, 1994).

2 Histograma bidimensional ou scattergrama, cuja região de maior freqüência é representada pela pequena área escura na parte superior direita do gráfico (adaptado de Crósta, 1992)

3 Histograma de uma imagem e sua versão com ampliação linear de contraste e respectiva função de transferência (adaptado de Crósta, 1992)

4 Histograma bidimensional mostrando o espaço de atributos de uma imagem multiespectral, em 2 bandas, para três tipos de material ( $A, B$ e $C)$, considerando as intensidades máxima e mínima dos DNs nas bandas 1 e 2 (adaptado de Soares, 1994)

5 Histograma bidimensional mostrando o espaço de atributos de uma imagem multiespectral, em outro par de bandas (2 e 3), para os mesmos tipos de material da Figura 4 (adaptado de Soares, 1994).

6 Localização geográfica da área de estudo

7 Distribuição espacial das unidades litoestratigráficas ocorrentes na área de estudo (Governo do Estado de São Paulo, 1966). 
Página

8 Divisão Geomorfológica do Estado de São Paulo (Almeida, 1974).................. 52

9 Balanço hídrico da região de Piracicaba segundo Thornthwaite

10 Mapa de solos da área de estudo (Governo do Estado de São Paulo, 1989)........

11 Exemplos de tratamentos digitais aplicados às fotografias para realce da rede de drenagem e respectivos histograma: a) sem tratamento de realce; b) equalização de histograma; c) composição colorida (KMC)

12 Bacias hidrográficas dos grupos 1 e 2 , representativas de solos litólicos, distribuídas nas bacias do Ribeirão dos Marins e do Ribeirão Granal.

13 Bacias hidrográficas do grupo 3, representativas de solos litólicos, todas localizadas na bacia do Ribeirão dos Marins

14 Bacias hidrográficas dos grupos 1, 2 e 3, representativas de solos podzólicos, distribuídas nas bacias dos Ribeirões Congonhal, Granal e Marins.

15 Bacias hidrográficas dos grupos 4 e 5, representativas de solos podzólicos, todas localizadas na bacia do Ribeirão Congonhal.

16 Bacias hidrográficas do grupo 6, representativas de solos podzólicos, a primeira localizada na bacia do Ribeirão Pau D'alhinho e, a segunda, na bacia do Ribeirão Congonhal. 
17 Realce de fotografias aéreas digitalizadas por modificação de histogramas: a) fotografia sem realce; b) aumento linear de contraste; c) equalização de histograma.

18 Realce de fotografias aéreas digitalizadas por filtragem digital: a) filtro passa-alta; b) filtro laplaciano (modificados de Walsh et al., 1990).

19 Composições coloridas a partir de transformações no espaço de cores: a) transformação (HLS); b) transformação (KMC).

20 Amostras do mosaico, evidenciando linhas de contato entre fotografias no sentido da linha de vôo e entre faixas a) área de pouca variação do relevo; b) área com maior variação do relevo

21 Detalhe da bacia hidrográfica 27RC na fotografia aérea georreferenciada: a) antes da digitalização da rede de drenagem e dos limites da bacia; b) após a digitalização.

22 Representação da bacia hidrográfica 27RC digitalizada pelos três intérpretes, para os MÉTODOS 2 e 3: a) primeiro intérprete; b) segundo intérprete; c) terceiro intérprete.

23 Médias em função dos Métodos de medição para as variáveis Nwl, N, Lwl e Lt, nas bacias dos dois solos

24 Médias em função dos Métodos de medição para as variáveis Lm1, Lm, A e $\mathrm{P}$, nas bacias dos dois solos. 
25 Médias em função dos Métodos de medição para as variáveis Dd, Fr e T, nas bacias dos dois solos

26 Freqüências observadas para Textura média em função dos Métodos de medição. 


\section{LISTA DE TABELAS}

Página

1 Parâmetros para classificação da textura topográfica com base nos valores de razão de textura média (França, 1968).

2 Propriedades dimensionais de bacias hidrográficas representativas de solos litólicos e podzólicos, e discriminação das unidades de mapeamento.

3 Análise dimensional e de semelhança geométrica aplicada a bacias hidrográficas representativa de solos litólicos e podzólicos.

4 Número de segmentos de rios observados em cada ordem de ramificação e respectiva média ponderada, para bacias representativas de solos litólicos e podzólicos.

5 Equações ajustadas Segundo Maxwell (1955) (logNw = loga - logb.w) para números de segmentos de rios, com os respectivos coeficientes de determinação $\left(\mathrm{R}^{2}\right)$, para bacias representativas de solos litólicos e podzólicos...

6 Valores observados e calculados da Razão de Ramificação $(\mathrm{Rb})$ de redes de drenagem para bacias representativas de solos litólicos e podzólicos

7 Comprimento total de segmentos de rios observados em cada ordem de ramificação e o total em cada bacia, para solos litólicos e podzólicos 
8 Equações ajustadas segundo França (1968) (logLw = loga - logb.w) para comprimentos totais de segmentos de rios, com os respectivos coeficientes de determinação $\left(\mathbf{R}^{2}\right)$, para bacias representativas de solos litólicos e podzólicos...

9 Comprimento médio de rios observados em cada ordem de ramificação e o total, para bacias representativa de solos litólicos e podzólicos

10 Equações ajustadas segundo Vasques Filho (1972) (logLm = loga - blog.w) para comprimentos médios de rios, com os respectivos coeficientes de determinação $\left(\mathrm{R}^{2}\right)$, para bacias representativas de solos litólicos e podzólicos..

11 Características quantitativas do padrão de drenagem e classes de textura topográfica de bacias representativas de solos litólicos e podzólicos.

12 Números de pontos de controle demarcados, descartados e selecionados para cada fotografia e respectivos erros médios quadráticos.

13 Resumo das características quantitativas dos padrões de drenagem e classe de textura topográfica obtidas na interpretação digital das bacias representativas dos dois solos, e resumo geral, incluindo a interpretação visual.

14 Localização espacial de "outliers"

15 Análise da variância e teste F para as variáveis Nwl, N, Lwl, Lt, Lml e Lm... 130

16 Análise da variância e teste F para as variáveis A, P, Dd, Fr e T 
17 Médias de métodos de medição e teste de Tukey para todas as variáveis analisadas nas bacias dos dois solos

18 Teste F para contrastes para as variáveis N1, Lm, A, Dd, Fr e T nas bacias dos solos podzólicos.

19 Estimativas dos contrastes significativos.

20 Coeficientes de correlação parcial e teste $t$, para o cruzamento das variáveis duas a duas nas bacias dos solos litóliocs

21 Coeficientes de correlação parcial e teste $t$, para o cruzamento das variáveis duas a duas nas bacias dos solos podzólicos.

22 Freqüência observada e porcentagem (\%) por total de linha de "razão de textura média" das bacias ( $\mathrm{Tm}$ ) em função dos Métodos estudados 


\title{
TRATAMENTO DIGITAL DE FOTOGRAFIAS AÉREAS VERTICAIS COMO UMA ALTERNATIVA À ANÁLISE ESTEREOSCÓPICA DE BACIAS HIDROGRÁFICAS
}

\author{
Autor: Antonio Amador de Sousa \\ Orientador: Prof. Rubens Angulo Filho
}

\section{RESUMO}

Com o objetivo de avaliar a utilização do processamento digital como técnica auxiliar na fotointerpretação de bacias hidrográficas, desenvolveu-se o presente estudo nas bacias dos Ribeirões dos Marins, Congonhal, Granal e Pau d'Alhinho, no Município de Piracicaba, SP. Foram utilizadas fotografias aéreas verticais de 1995, além de cartas planialtimétricas e mapa de solos da região.

Inicialmente, fez-se a interpretação visual para obtenção da rede de drenagem e dos limites de bacias hidrográficas de $3^{\mathrm{a}}$ ordem. Aplicando princípios de análise dimensional e semelhança geométrica, selecionaram-se grupos de bacias representativas de solos litólicos e podzólicos, para os quais foram realizadas análises das características da rede e do padrão de drenagem.

Os resultados mostraram heterogeneidade quanto às características dimensionais das bacias, principalmente nos solos podzólicos. Contudo, no estudo das características do padrão de drenagem, os índices frequência de rios e densidade de drenagem indicaram diferenças entre as bacias dos dois solos, sendo a frequência de rios o índice mais consistente.

Após a interpretação visual as fotografias foram digitalizadas através de "scanner" e georreferenciadas para formação de mosaico. Foram aplicados tratamentos digitais por aumento de contraste, filtragem e realce. 
Para comparação dos resultados através de análise estatística, foram estabelecidos três métodos de interpretação. A análise visual constituiu o Método 1 e os tratamentos digitais constituíram os outros dois, sendo que o Método 2 correspondeu à utilização das fotografias digitalizadas sem realce e o Método 3 com realce. A rede de drenagem e limites de bacias foram digitalizados em tela, segundo os Métodos 2 e 3, por três intérpretes diferentes, e a média, dos dados levantados, utilizada para análise estatística. A análise visual, considerada padrão para comparação, foi realizada apenas por um intérprete.

A análise de variância dos dados referentes às bacias dos solos litólicos, para comparação dos métodos, mostrou que o teste $\mathrm{F}$ não foi significativo, ao nível de $5 \%$, para nenhuma das variáveis estudadas na composição da rede e características do padrão drenagem. Nas dos solos podzólicos, entretanto, o teste $\mathrm{F}$ para métodos foi significativo apenas para as variáveis número de rios de primeira ordem (Nwl), comprimento médio de rios $(\mathrm{Lm})$ e razão de textura (T) (ao nível de $5 \%$ ) e para área (A), densidade de drenagem $(\mathrm{Dd})$ e frequência de rios $(\mathrm{Fr})$ (ao nível de $1 \%$ ). A comparação de médias pelo teste de Tukey para as bacias destes solos mostrou que para as variáveis Nwl, Lm e T, o Método 1 diferiu do 3, mas ambos não diferiram do Método 2, sendo que para as variáveis Nwl e T, o Método 1 apresentou maior média e, para a variável Lm, a menor média. Para as variáveis A, Dd e Fr o Método 1 diferiu dos métodos 2 e 3 , apresentando maior média para as variáveis $\mathrm{Dd}$ e Fr e a menor média para a variável A.

$\mathrm{Na}$ classificação de textura topográfica para as bacias dos solos litólicos, os métodos permitiram classificar todas as bacias, igualmente, como "textura média", indicando que essa classificação independe do método. No caso das bacias dos solos podzólicos, o Teste exato de Fisher não foi significativo, mostrando que esta classificação independe do método utilizado, também neste caso.

As conclusões finais evidenciam que os os tratamentos digitais aplicados aos dados, de maneira geral, não produziram o efeito esperado em termos de realce das feições de interesse. $O$ realce através da composição colorida, embora tenha 
proporcionado um aspecto visual, aparentemente, melhor que o da fotografia sem realce, isto não se traduziu em resultados significativos na comparação entre os métodos.

A melhor condição para uso da metodologia como alternativa à análise estereoscópica, foi em bacias com rede de drenagem bem definida, geralmente identificada pela presença de vegetação arbustiva, neste caso, mais frequentes nos solos litólicos. Porém, o método da estereoscopia foi imprescindível para a interpretação de bacias hidrográficas situadas em áreas de solos descobertos ou com gramíneas, a exemplo dos solos podzólicos, para permitir a diferenciação entre solos.

A forma de aquisição dos dados digitais via "scanner" foi satisfatória para o desenvolvimento do trabalho, pois as fotografias mantiveram suas características após a digitalização, apresentando definição visual similar às imagens no formato analógico.

A geometria dos pontos de controle selecionados para 0 georreferenciamento apresentaram, em todos os casos, valores de erro abaixo do limite aceitável e níveis de exatidão compatíveis com as exigências do trabalho. A mosaicagem resultou em bons ajustes das linhas de contato entre as fotografias, ocorrendo apenas alguns pontos de discordância nas regiões de relevo mais acidentado. Este fato, entretanto, não prejudicou significativamente a digitalização da rede de drenagem e delimitação das bacias hidrográficas. 


\title{
DIGITAL PROCESSING OF VERTICAL AERIAL PHOTOGRAPHS AS AN ALTERNATIVE TO STEREOSCOPIC ANALYSIS OF WATERSHEDS
}

\author{
Author: Antonio Amador de Sousa \\ Adviser: Prof. Rubens Angulo Filho
}

\section{SUMMARY}

The main objective of this study was to evaluate the utilization of digital processing as a technical approach for watershed photo interpretation. It was developed at Ribeirões dos Marins, Congonhal, Granal and Pau d'Alhinho watersheds in Piracicaba, SP. Vertical aerial photographs from 1995, local soil and topographic maps were used in this study.

First was made the stereoscopic analysis to obtain the drainage network and the third order watersheds limits. Typical watersheds containing litolics and podzolics soils were selected by using dimensional analysis and geometrical similarity, where was performed evaluation of network characteristics and drainage pattern.

Watershed dimensional characteristics were highly variable mainly on podzolics soils, however, among drainage patterns, frequency of rivers and drainage density were significantly different comparing both soil watersheds. Frequency of rivers was the most consistent parameter measured.

Aerial photographs were scanned and control points elected to build the photographic mosaic. In order to enhance photographs features, the following digital processing were applied: contrast stretch, filtering and image enhancement. 
Statistical analysis was based on interpretation methods, which were visual analysis (Method 1), scanned photographs without enhancement (Method 2) and scanned with enhancement (Method 3). Drainage network and watershed limits were digitally identified at the computer monitor, by using methods, 2 and 3. Three interpreters performed the process and measurement data were pooled to averaged to statistical analysis. Method 1 was performed only for a single interpreter.

Variance analysis for comparison of methods among watershed data was performed with $\mathrm{F}$ test. Watersheds containing litolic soils, were not different $(P<0,05)$ for the network characteristics and drainage pattern. For podzolic soils watersheds, however, first order number of rivers $(\mathrm{Nwl})$, length of rivers mean $(\mathrm{Lm})$, ratio texture $(\mathrm{T})(P<0.05)$; area (A), drainage density $(\mathrm{Dd})$ and frequency of rivers $(\mathrm{Fr})(P<0.0 I)$ were different when measured by different methods. Tukey test was used to compare averages from watershed podzolic soils, which revealed the following method vs parameter effects: Nwl, Lm and T were different for Methods 1 and 3. Other comparisons were not significantly different $(P>0.05)$. Nwl and T estimated by Method 1 were the highest and Lm was the lowest measures compared with other methods. For A, Dd and Fr Method 1 was different $P<$ 0.05) from Methods 2 and 3, revealing the highest values for $\mathrm{Dd} \mathrm{e} \mathrm{Fr}$ and lowest for A.

By using a topographic texture classification, litolic soils watersheds were classified as mean texture, which implies no differences among methods. On podzolic soil watersheds, even with additional Fisher test, there were no differences related to mean texture among methods.

Digital processing applied to data did not present expect results. Colored image enhancement did not show a better method when compared with other treatments, as supposed by previous visual appearance.

According to these data, the most appropriate condition to use alternative method for stereoscopic analysis was fitted in well-defined watershed drainage network, containing shrubs, more frequently in litolic soils. For watershed containing podzolic soils, due to the characteristic soil bareness or to sward covering, stereoscopy was considered essential on soil differentiation. 
Image scanning was considered satisfactory for this type of study, once photographs kept their original characteristics after digitalization.

The set of control points to build the photographic mosaic had errors less then allowable RMS (root mean square) errors, what allowed a satisfactory adjustment between aerial photographs interfaces, however some lack of fitting occurred due to relief. In fact, this disturbing effect did not compromise the digitalization of drainage network and definition of watersheds. 
"Se autoridades, cientistas e leigos insistem na importância de preservar e restaurar o ambiente natural, certamente não é por razões simplesmente estéticas ou científicas, mas porque da preservação e da restauração do ambiente natural depende a sobrevivência da humanidade sobre a Terra. Se o ambiente é de fato imprescindivel à vida dos homens, significa isto que a natureza tem limites, ao contrário do que pensam os possibilistas. Isto, contudo, não significa retornar aos postulados do determinismo."

(Arthur Soffiati) 


\section{INTRODUÇÃO}

Diante da necessidade de conhecer cada vez melhor o meio que o envolve, o homem tem investido progressivamente no desenvolvimento de técnicas que visam facilitar os seus trabalhos na busca constante desse conhecimento. Entre outras, as que utilizam o sensoriamento remoto, têm assumido importância cada vez maior no estudo de recursos terrestres, onde se destacam os levantamentos geológicos, geomorfológicos, climatológicos, hidrológicos, pedológicos e de vegetação. Nestes levantamentos são estudados e mapeados fatores do ambiente físico de interesse, visando à orientação para a forma mais racional de sua exploração e/ou ocupação, de acordo com suas potencialidades.

O conhecimento pedológico de uma região tem vital importância na avaliação das suas potencialidades para atividades agropecuárias e florestais, visto que $o$ planejamento de uso, manejo e conservação do solo, onde se promova o mínimo de degradação, deve ter como base o conhecimento de suas características potenciais e limitantes.

A maneira convencional de se realizar levantamentos de solos implica em exaustivos trabalhos de campo, laboratório e escritório, envolvendo uma série de atividades, como: descrição morfológica de perfis; coleta de material dos horizontes em inúmeros pontos de amostragem; análises físicas, químicas e mineralógicas; processamento e análises de dados; classificação das unidades de mapeamento e, finalmente, confecção da carta pedológica, com a definição dos seus limites.

Atualmente, a interpretação de imagens representa uma ferramenta de utilidade incontestável neste campo, com a utilização de fotografias aéreas, imagens de 
satélite e de radar, em conjunto ou separadamente. Esta técnica permite dividir uma região de estudo em áreas homogêneas quanto ao padrão fisiográfico, possibilitando, desta maneira, o planejamento global das atividades de campo, a redução do número de análises (devido à redução do número de pontos de amostragem), além de aumentar a precisão no traçado dos limites entre as unidades de solo. Evidentemente, essas simplificações de tarefas implicam em rapidez e menor custo do levantamento.

Entre os elementos de fotointerpretação usualmente empregados na identificação e análise de recursos naturais (tonalidade, padrão, textura, relevo, vegetação natural, rede de drenagem etc.), o estudo do relevo e da drenagem superficial tem sido bastante difundido entre os pesquisadores. Neste estudo, a rede de drenagem apresenta vantagens sobre o relevo, principalmente com relação aos índices morfométricos, que são de obtenção relativamente fácil e permitem boa inferência sobre as condições do solo.

Evidentemente, o resultado deste tipo de estudo sobre fotografias aéreas verticais, mesmo fundamentado nas melhores técnicas de fotointerpretação, depende, em grande parte, de fatores humanos ligados à acuidade visual e experiência do fotointérprete, além do bom conhecimento sobre o tema analisado.

Quando se analisam dados coletados no formato digital, o volume e a qualidade de informações presentes, fogem a essa capacidade do sistema visual humano, carecendo, portanto, de outras técnicas ou ferramentas que facilitem a identificação e extração dessas informações. Segundo Crósta (1992), o processamento digital tem a função principal de fornecer essas ferramentas, para posterior interpretação, devendo, portanto, ser encarado como um estágio preparatório, embora quase sempre obrigatório, da atividade de interpretação das imagens de sensoriamento remoto.

Ao mesmo tempo, sabe-se que qualquer imagem no formato analógico pode ser transformada em imagem digital, através do processo conhecido como digitalização. Neste caso, para evitar distorções geométricas, deve-se utilizar equipamento apropriado para a digitalização de mapas e fotografias aéreas. Com a fotografia convertida para o formato digital, tem-se a possibilidade de leitura e 
manipulação por sistemas de processamento digitais, da mesma forma que as imagens de satélite.

No intuito de contribuir para a melhoria de técnicas de extração de informações sobre fotografias aéreas, através da obtenção e análise da rede de drenagem por meio de processos digitais, é que se planejou este trabalho, tendo com principais objetivos:

- avaliar o emprego de tratamentos digitais de fotografias aéreas verticais na obtenção e análise da rede de drenagem de bacias hidrográficas;

- comparar os resultados obtidos por este processo àqueles obtidos através da análise visual das fotografias aéreas com o uso de estereoscópio;

- analisar a viabilidade do emprego de mosaicos fotográficos georreferenciados para a digitalização da rede de drenagem de bacias hidrográficas. 


\section{REVISÃO DE LITERATURA}

Por se tratar o presente trabalho de uma investigação sobre a utilização de processamento digital em fotografias aéreas como técnica auxiliar na fotointerpretação de bacias hidrográficas, esta revisão será apoiada inicialmente nos conhecimentos produzidos sobre a interpretação visual de fotografias com auxilio do estereoscópio, referindo-se tanto ao desenvolvimento das técnicas, como à utilização destas em trabalhos realizados em nossas condições. Em seguida, serão apresentadas as considerações inerentes ao processamento digital e georreferenciamento de imagens.

\subsection{Fotointerpretação aplicada ao levantamento de solos}

Fotografias aéreas foram inicialmente utilizadas em levantamentos de solos como mapa básico para facilitar a orientação em campo, proporcionando, consequentemente, um aumento de rendimento no trabalho. Conforme relata Simonson (1950), o primeiro mapeamento de solos utilizando fotografias aéreas foi realizado nos Estados Unidos, em 1929, por Bushnell e colaboradores.

Posteriormente, técnicos e cientistas começaram a perceber que, além de servir como mapa básico, as fotografias também podiam ser interpretadas, aproveitandose a riqueza de detalhes das cenas registradas como fonte de informação adicional. Com o desenvolvimento de técnicas de interpretação e experiência adquirida pelos fotointérpretes, as fotografias aéreas passaram a ser utilizadas também como uma forma alternativa de apresentação dos mapas de solos, fazendo-se a delimitação das unidades de mapeamento diretamente sobre mosaicos fotográficos, e este produto enviado para 
impressão. Para Simonson (1950), o maior avanço em levantamento de solos nas duas décadas anteriores a 1950, foi a utilização de fotografias aéreas.

Atualmente, estas constituem excelente ferramenta de trabalho neste campo, comprovado pelo grande número de trabalhos encontrados na literatura especializada, onde os autores evidenciam a sua utilidade e ressaltam as vantagens e restrições a que estão sujeitas.

Colwell (1952) define fotointerpretação como o ato de se examinar imagens fotográficas de objetos com o propósito de identificá-los e avaliar o seu significado. Para este autor, a fotointerpretação deve apoiar-se no "princípio da convergência de evidências", segundo o qual vários elementos de reconhecimento levam a uma determinada conclusão, que provavelmente será a correta.

De maneira mais ampla, Summerson (1954) define fotointerpretação como a previsão do que não pode ser realmente visto. Esta definição é normalmente aceita pelos autores como a que melhor se ajusta à interpretação fotográfica de solos, uma vez que as fotografias não mostram todo o corpo do solo, mas apenas sua superficie e, ainda, recoberta por vegetação. Por outro lado, são os variados aspectos de ocorrência na superficie, tais como vegetação, formas topográficas, drenagem, erosão, tonalidade fotográfica e uso da terra, que podem indicar a presença de solos diferentes.

Creswick \& Rockwell (1959) afirmam que as fotografais aéreas apresentam as diversas informações que devem aparecer num mapa de solos, no entanto, dependendo do nível de estudo, um mínimo de verificação local se faz necessário.

Segundo Bomberger \& Dill (1960), as fotografias aéreas mostram apenas a superficie do solo, que muitas vezes não está visível. Por outro lado, salientam que a presença de padrões, tais como os de relevo, drenagem, erosão e vegetação, permite ao fotointérprete fazer inferências sobre a distribuição dos solos e material de origem. Contudo, advertem que o trabalho de campo não pode ser substituído completamente.

Vários autores, entre os quais se incluem Rourke \& Austin (1951), Creswick \& Rockwell (1959), Bomberger \& Dill (1960), Buringh (1960), reconhecem 
que as fotografias aéreas não substituem completamente o trabalho de campo, embora aumentem a exatidão e o rendimento dos mapeamentos de solos. Estes autores também reconhecem que a fotointerpretação é mais útil em levantamentos de reconhecimento do que em levantamentos detalhados. Contudo, Bastos (1966) comenta trabalho descrito por Vera (1964), referente ao Projeto Aerofotogramétrico OEA-CHILE, no qual $120.000 \mathrm{~km}^{2}$ de terras agrícolas tiveram seus solos levantados a nível detalhado num período de 18 meses. $\mathrm{O}$ autor ainda chama a atenção para o fato de que as informações obtidas neste curto espaço de tempo, sem o uso de técnicas aerofotogramétricas e fotointerpretativas, levaria tempo superior ao de uma vida humana.

Para Amaral \& Audi (1972), a fotografia aérea apresenta-se como material de trabalho indispensável no levantamento de solos, proporcionando ganho de tempo, precisão de limites e real visão global da paisagem com riqueza de detalhes. Desta maneira, não serve apenas como base cartográfica preliminar, para auxiliar os trabalhos de campo e traçado de roteiros mais interessantes, mas também possibilita a separação das unidades de solo diretamente sobre ela.

Raben (1960) explica que há duas maneiras para estudar imagens aerofotográficas. Uma, totalmente empírica, consiste no exame minucioso de todo o material fotográfico existente, sem omitir nada. A outra, utiliza-se de probabilidades, ou seja, o intérprete pesquisa apenas as áreas nas quais os objetos de interesse podem ser encontrados, desprezando grande número de fotografias que não tem probabilidade de conter as informações desejadas. Isto é "pesquisa lógica", uma combinação de visão geral e estudo intensivo, que exige maior experiência, já que o intérprete terá de decidir onde os estudos terão melhores resultados, mas é mais produtiva em termos de tempo e esforço desprendidos. $\mathrm{O}$ autor ainda sugere o "princípio da convergência de evidência", desenvolvido por Colwell (1952), como técnica a ser utilizada pelo intérprete para identificar objetos nunca vistos anteriormente, ou para entender o significado de objetos já identificados.

Frost (1960) coloca três princípios importantes a serem utilizados na interpretação de solos em fotografias aéreas: 1) solos semelhantes aparecem nas 
fotografias com padrões semelhantes; 2) solos diferentes aparecem com padrões diferentes; 3) desde que as características da imagem fotográfica tenham sido correlacionadas com propriedades do solo observadas no campo e no laboratório, muitas propriedades importantes de solos semelhantes podem ser inferidas por fotointerpretação.

O estudo de fotografias aéreas é geralmente feito em duas etapas, conforme sugeriram Ray (1963), Ricci \& Petri (1965) e Raben (1969). A primeira consiste na observação, coleta de dados, medição e identificação das imagens tridimensionais nas fotografias aéreas. A segunda consiste na indução e ou dedução de fenômenos ou de relações, incluindo a aplicação das informações obtidas na solução de problemas.

Para a fotointerpretação aplicada ao levantamentos de solos, Goosen (1968) preconizou três métodos de análise:

- Método da análise dos padrões: proposto por Frost (1960), este método se baseia na identificação das maiores unidades da paisagem e na divisão destas em unidades menores, caracterizadas pelos chamados "elementos padrões locais", que serão examinados em estereoscopia. São considerados como "elementos padrões", a forma do terreno, a drenagem, os canais de erosão, a vegetação, a tonalidade fotográfica $e$ o uso da terra. O princípio do método parte da suposição de que cada "elemento padrão" está relacionado com certas condições do solo. Entretanto, este método exige grandes conhecimentos de Geomorfologia por parte do fotointérprete, ou que o mesmo tenha uma grande coleção de representações adequadas de formas de terreno, ou seja, uma boa chave de fotointerpretação.

- Método da análise fisiográfica: método que classifica o terreno em unidades fisiográficas, as quais correspondem a uma associação única de solos. Este método requer amplo conhecimento dos processos geomorfométricos (intemperização, erosão, sedimentação etc.), bem como sua influência na paisagem, que se manifestará na imagem. Sugerido por Buringh (1960) e desenvolvido por Goosen 
(1968), este método é tido por diversos autores como o mais eficiente na caracterização de solos através de fotointerpretação.

- Método da análise de elementos: este método consiste em analisar sistematicamente aqueles elementos da paisagem que se relacionam com as condições do solo (Buringh, 1960). Esta análise baseia-se no princípio de que qualquer elemento (tipo de terreno, relevo, condições de drenagem, vegetação natural, cor, uso da terra etc.) pode estar relacionado a uma certa unidade de solo e, portanto, uma diferenciação no elemento pode estar relacionada com um limite de solo. Quanto maior o número de vezes que uma linha estiver evidenciada por elementos diferentes, maior será a certeza de que aquela realmente será uma linha de solo. Resumidamente, é o que se convencionou como "convergência de evidências" sugerido por Colwell (1952). Por estas características, o método pode ser aplicado universalmente, inclusive por fotointérpretes ainda inexperientes.

Apesar desses três métodos de fotointerpretação terem sido citados de forma individual pelo autor, o mesmo comenta que esta divisão é relativamente artificial. Dependendo da maneira como for conduzido o levantamento, os três métodos poderão ser utilizados simultaneamente.

Utilizando os princípios propostos pelo método da "análise de elementos", vários trabalhos foram realizados no Brasil, entre eles França (1968), Marchetti (1969), Fadel (1972), Vasques Filho (1972), Leão (1973), Gevaerd (1974), Souza (1975), Carvalho (1977), Freire (1977), Nogueira (1979), Politano (1980), Angulo Filho (1981), Manechini (1981), Valério Filho (1984), Vettorazzi (1985), Angulo Filho (1986), Demattê (1992) e outros. Estes autores estabeleceram parâmetros para a identificação de algumas unidades de solo nas condições brasileiras.

Além destes, outros autores têm contribuído para o desenvolvimento da fotointerpretação no Brasil, seja avaliando outras técnicas ou a aplicabilidade de outros produtos do sensoriamento remoto para fins de mapeamento de solos. 
No INPE (Instituto Nacional de Pesquisas Espaciais) as pesquisas realizadas nesta área tiveram início no ano de 1975. Um dos primeiros resultados desta iniciativa foi o trabalho sobre "Avaliação de imagens orbitais (LANDSAT-1) como base para o levantamento de solo", em duas áreas correspondentes às regiões de Ribeirão Preto-SP e Dourados-Amambai-MT (Valério Filho et al., 1976). Na análise, foram utilizados elementos de fotointerpretação, como: vegetação natural, uso da terra, relevo e drenagem, além da tonalidade aparente das imagens.

Neste mesmo período, outra pesquisa foi desenvolvida por Koffler (1976), sob o tema "Utilização de imagens aerofotográficas e orbitais no estudo do padrão de drenagem em solos originados do Arenito de Bauru". Este estudo teve como objetivo analisar com maior detalhe as relações entre rede de drenagem e solo.

Vettorazzi (1988), fez a interpretação de imagens TM/LANDSAT - 5, em duas escalas, com vistas à caracterização fisiográfica para mapeamento de solos. Dentre suas conclusões, o autor menciona que os critérios rede de drenagem e relevo tiveram comprovada, mais uma vez, sua grande utilidade em trabalhos de interpretação visual de imagens, na estratificação regional em áreas fisiograficamente distintas.

Pfeifer (1995), analisou a aplicabilidade de produtos de sensores remotos na caracterização fisiográfica para mapeamento de solos e concluiu que os critérios rede de drenagem e relevo, mostraram-se úteis na interpretação visual dos diversos produtos de sensoriamento remoto, na separabilidade de unidades morfogeneticamente distintas. Também concluiu que, no traçado da rede de drenagem, as maiores contribuições são dadas pelas fotografias aéreas, seguidas da imagem orbital, em relação à imagem de radar.

Souza (1997), estudou a utilização de dados digitais TM/LANDSAT e análise de agrupamentos na delimitação das unidades de solos da planície de inundação do Rio Ivai - PR. Diante dos resultados, o autor concluiu que a análise de agrupamento, associada à metodologia utilizada e acrescida das modificações feitas no seu trabalho, mostrou-se eficiente na identificação de diferentes classes de solos, tomando-se por base 
a análise dos níveis de cinza de áreas homogêneas, no caso, consideradas as unidades de mapeamento.

Pissarra (1998), fez uma avaliação quantitativa das características geomórficas de microbacias de $1^{a}$ ordem em posições diferentes do sistema de drenagem e verificou que as microbacias localizadas a montante no sistema, possibilitam uma melhor representatividade das microbacias hidrográficas. Isto mostra que a adoção de um critério, fixando uma mesma posição da microbacia no sistema de drenagem, é necessário para melhorar a qualidade da amostragem das microbacias no âmbito da unidade de solo.

\subsection{Estudo de bacias hidrográficas e composição de redes de drenagem}

Os sistema fluviais foram estudados inicialmente por geólogos, fisiógrafos e geomorfólogos, sendo mais recentes os estudos realizados por pedólogos. Esses pesquisadores verificaram que as redes de drenagem refletem certas características dos materiais superficiais sobre os quais se desenvolvem. No entanto, seus trabalhos foram desenvolvidos quase que exclusivamente em bases descritivas, uma vez que se preocupavam em descrever as formas do relevo atual ou identificar a natureza dos solos ou das rochas subjacentes. Como resultado desses estudos, muitos padrões de drenagem foram descritos e classificados, sempre procurando correlacioná-los à natureza dos solos e dos substratos rochosos e/ou à presença de estruturas geológicas.

Horton (1945), explicou o desenvolvimento de sistemas hidrográficos e suas bacias de drenagem por processos de erosão hídrica que, para um determinado ambiente, depende em primeiro lugar da proporção entre infiltração e deflúvio do local. Desta forma, para que ocorra uma concentração de volume de deflúvio suficiente para iniciar a formação de canais em um determinado terreno, deve existir um comprimento mínimo de escoamento sobre a superficie ("comprimento crítico"), que depende da sua declividade, da velocidade do deflúvio, da capacidade de infiltração e resistência do solo à erosão. Para o mesmo autor, a resistência do solo à erosão é o mais importante fator 
envolvido no fenômeno da erosão e que, em períodos relativamente longos, exerce efeito dominante no desenvolvimento dos sistemas hidrográficos e suas bacias de drenagem.

Para Lueder (1959), a principal justificativa para a análise da drenagem superficial é que ela fornece indicações sobre a relação infiltração/deflúvio, capacidade de infiltração, permeabilidade e textura dos materiais presentes em uma área. Trata-se, no entanto, de uma regra geral, onde exceções existem, como por exemplo, fatores de controles gerais ou localizados e a existência e profundidade do substrato rochoso ou de camadas densas no subsolo.

Deste ponto de vista, Ray (1963) comenta que onde o controle estrutural atinge o seu mínimo, as características da rede de drenagem podem ser influenciadas pela espessura e natureza do material exposto.

Gravelius, citado por Horton (1945), estabeleceu o sistema europeu de classificação de rios em ordem. Neste sistema, o rio principal ou tronco é designado como de $1^{\mathrm{a}}$ ordem e seus tributários imediatos como de $2^{\mathrm{a}}$ ordem e assim sucessivamente, de maneira que os tributários menores, não ramificados, constituem a ordem mais elevada. Horton (1945) inverteu esta seqüência de numeração, considerando os tributários não ramificados como sendo de $1^{\text {a }}$ ordem e atribuindo a ordem mais elevada ao rio principal.

Strahler (1952) modificou o sistema de Horton (1945), classificando segmentos de rios, de modo que toda nascente é um segmento de primeira ordem; quando dois segmentos de primeira ordem se juntam, formam um de segunda; quando dois de segunda ordem se juntam, formam um de terceira e assim por diante.

A padronização na notação trouxe vantagens e facilidades para a análise e comparação das redes de drenagem, uma vez que somente são comparáveis entre si, os elementos de mesma ordem de ramificação.

Horton (1945) chamou de "composição da rede de drenagem", ao número e comprimento de rios e tributários de diferentes classes ou ordens, independente do padrão. Este autor afirma que a composição da rede de drenagem tem alto grau de 
significância hidrológica, enquanto o padrão isolado tem pouca significância hidrológica. Por outro lado, reconhece que o padrão de drenagem é altamente significativo como indicador de controle geológico.

Vários pesquisadores adotaram o sistema de Horton (1945), como Strahler (1952), Maxwell (1955) Schumm (1956), França (1968), Marchetti (1969), Fadel (1972), Vasques Filho (1972), Leão (1973), Gevaerd (1974), Souza (1975), Carvalho (1977), Freire (1977), Angulo Filho (1981), Valério Filho (1984), Vettorazzi (1985), Angulo Filho (1986), Demattê (1992) entre outros.

Na continuidade do seu estudo sobre a composição de redes de drenagem, Horton (1945) propôs a lei dos números e a dos comprimentos de rios. A "lei dos números de rios" expressa a relação entre o número de rios de cada ordem e a ordem de ramificação em termos de uma série geométrica inversa, que tem como base a razão de ramificação. A "lei dos comprimentos de rios", expressa a relação entre os comprimentos médios de rios de cada ordem e a ordem de ramificação, em termos de uma série geométrica direta na qual o primeiro termo é o comprimento médio dos rios de primeira ordem.

Segundo Maxwell (1955), existe uma relação linear entre o logaritmo dos números de segmentos de rios de cada ordem e as respectivas ordens de ramificação, com pequena dispersão, ou seja, dando coeficientes de correlação com significância estatística em alto nível de probabilidade, que seria a forma de se medir a dispersão dos dados. Na sua forma explícita, esta relação é dada pela equação $\log N \mathbf{N}=\mathbf{a}-\mathbf{b} . \mathbf{w}$, onde Nw é o número de rios. Desta equação, o autor ainda propôs a expressão $\mathbf{R b}=$ antilog b, como sendo a melhor expressão empírica da razão de ramificação.

Strahler (1957) relacionou os logaritmos dos comprimentos totais de segmentos de rios com as respectivas ordens e obteve uma regressão exponencial do tipo $\mathbf{L w}=\mathbf{a} \cdot \mathbf{w}^{\mathbf{t b}}$ que, expressa na forma $\operatorname{logarítmica}$ é $\log \mathbf{L w}=\log \mathbf{a}-\mathbf{b} \log \mathbf{w}$, onde $\mathbf{L w}$ é o comprimento total de rios na ordem $\mathbf{w}$. $\mathbf{O}$ mesmo autor sugeriu que a inclinação $\mathbf{b}$ da linha de regressão forneceria uma medida útil da variação dos comprimentos dos rios ao se passar de uma ordem para outra. Todavia, observou também que a variação dos dados 
de comprimento de rios não é linear, concluindo que a semelhança geométrica não é preservada com o aumento da ordem de grandeza de bacias hidrográficas.

França (1968), considerando além da semelhança geométrica, a homogeneidade de solos e de substratos rochosos, verificou que o melhor ajuste seria uma equação exponencial do tipo $L w=a b^{-w}$ que, expressa na forma logarítmica fica $\log L w=\log \mathbf{a}-\mathbf{w} \log b$, onde $\mathbf{L} w$ é o comprimento total de segmentos de rios na ordem w. O antilog de b da equação de França (1968) representa a razão de comprimentos totais (R1w).

Segundo Strahler (1957), a razão de ramificação é um número sem dimensão, que expressa a composição do sistema de drenagem, sendo altamente estável, com pequena amplitude de variação de uma região para outra, exceto onde domina poderoso controle geológico. Por outro lado, a análise dos comprimentos de rios mostra que as relações não apresentam tanta significância como a lei dos números de rios.

Para os comprimentos médios de rios, Vasques Filho (1972) ajustou a equação $\operatorname{logarítmica} \log \mathbf{L m}=\log \mathbf{a}-\mathbf{w} \log \mathbf{b}$ e também verificou a validade da equação $R 1=\log ^{-1} b$, onde $R 1$ é a razão de comprimentos médios.

França (1968), Fadel (1972), Leão (1973), Gevaerd (1974) e Souza (1975), observaram variações na razão de ramificação em diferentes solos de diferentes regiões do País, sendo que o primeiro trabalhou com bacias de $4^{\mathrm{a}}$ ordem e, os demais, com bacias de $3^{\mathrm{a}}$ ordem. Os mesmos autores estudaram as razões de comprimentos totais e de comprimentos médios, onde também encontraram variações.

A relação R1/Rb foi considerada por Horton (1945) como sendo um fator importante, relacionado tanto à composição como ao estágio de desenvolvimento da rede de drenagem. França (1968), com base nos resultados obtidos, demonstrou que o valor $\mathbf{R} 1$ se relaciona com as razões de ramificação e de comprimento total da seguinte forma: $\mathbf{R b}=\mathbf{R} 1 / \mathbf{R} 1 \mathbf{w}$.

Parâmetros quantitativos da rede de drenagem foram estudados com o auxílio de fotografias aéreas por Carvalho et al. (1978), onde concluíram que a razão de 
ramificação foi o melhor parâmetro para diferenciar duas unidades de solo: Terra Roxa Estruturada Eutrófica e uma associação de Solos Podzólicos Vermelho-Amarelos variação Piracicaba + Litossolo fase substrato argilito/folhelho.

\subsection{Padrão de drenagem superficial}

Parvis (1950) comenta que a relativa simplicidade com que os canais de drenagem podem ser observados em fotografias aéreas, facilita o reconhecimento de seus padrões de drenagem, o estudo analítico de seus elementos e a avaliação de sua significância na interpretação de solos e substratos rochosos. Este autor considera que, enquanto os padrões de rios de ordens inferiores informam a respeito de solos ou substratos rochosos, os padrões de rios de ordem mais elevadas mostram a influência de controle estrutural.

Para Lueder (1959) a drenagem superficial é provavelmente o mais seguro indicador das condições do terreno que o fotointérprete possui. Porém, a significância de um padrão de drenagem não é fácil, pois envolve, além da apreciação teórica, a aplicação da fotoexperiência (experiência adquirida no processo de correlacionar detalhes do terreno com sua imagem fotográfica).

Segundo Frost (1960), os padrões de drenagem refletem a maneira pela qual a água que atinge a superficie do solo se distribui, em termos de deflúvio e infiltração, fornecendo, assim, indícios da origem e da composição dos materiais dos solos do local.

Para expressar quantitativamente o grau de desenvolvimento da rede de drenagem, Horton (1945) propôs duas relações: a densidade de drenagem e a freqüência de rios. Segundo esse autor, a densidade de drenagem vem a ser o comprimento médio dos rios por unidade de área, sendo expressa pela equação $\mathrm{Dd}=\mathrm{Lt} / \mathrm{A}$, onde $\mathrm{Dd}$ é a densidade de drenagem, $\mathrm{Lt}$ é o comprimento total de rios das diversa ordens e A é a área da bacia de drenagem, todos os termos expressos no mesmo sistema. 
A freqüência de rios $(\mathrm{Fr})$ refere-se à relação entre o número total de rios das diversas ordens $(\mathrm{N})$ pela área da bacia de drenagem, ou seja, $\mathrm{Fr}=\mathrm{N} / \mathrm{A}$.

Para Horton (1945) e Strahler (1957), a densidade de drenagem e a freqüência de rios variam com o tamanho da área de drenagem, não podendo ser diretamente comparáveis, através dessas duas relações, as pequenas com as grandes bacias. Segundo Strahler (1957), é indispensável comparar bacias que tenham a mesma ordem de ramificação para se obter dados significativos.

Strahler (1957) propôs como requisito para que duas bacias de drenagem sejam comparáveis, que elas devam ser geometricamente semelhantes. Se existir a similaridade geométrica, todos os correspondentes números admensionais, como ângulos e razões entre medidas de comprimento, serão iguais; ainda assim existirão várias diferenças significativas entre elas.

França (1968) atribuiu as variações verificadas no padrão de drenagem, em primeiro lugar, à natureza do solo e, depois, à posição topográfica e à natureza e profundidade do substrato rochoso. Este autor concluiu ainda que a análise e interpretação do padrão de drenagem permitiram a distinção entre os solos estudados.

O padrão de drenagem é influenciado pela profundidade do substrato rochoso e pelas declividades das suas superficies. De maneira geral, com a diminuição da profundidade do substrato rochoso e com o aumento das declividades, ocorre aumento no número de rios e diminuição em seus comprimentos médios, além de alterar a distribuição desses rios, segundo Souza (1975), Carvalho (1977) e Freire (1977).

Silva (1977) atribuiu ao relevo, em primeiro lugar e ao controle geológico em seguida, o grau de desenvolvimento das redes de drenagem, através da alteração da relação infiltração/deflúvio.

Para Angulo Filho (1981), as características do padrão de drenagem foram condicionadas pela natureza e propriedades dos solos estudados, pela natureza e propriedades do substrato rochoso, posição que ocupa no relevo regional e, também, pela vegetação e uso da terra. 
Estudando as características dos padrões de drenagem de 5 mapas de solos, utilizando fotografias aéreas e amostras circulares, Silva (1986) determinou os componentes do sistema de drenagem para separar as unidades de solo. Neste estudo, diferenças foram observadas nos padrões de drenagem, distinguindo os solos bem desenvolvidos dos fracamente desenvolvidos.

Em estudo de bacias hidrográficas com o auxilio de fotografias aéreas, França \& Demattê (1990) trabalharam em duas formações de solo: Oxisols desenvolvidos de rochas básicas e Ultisols formados de arenito. Neste estudo, a densidade de drenagem parece ter sido o melhor parâmetro para diferenciar o solo, quando as unidades mapeadas foram comparadas.

Demattê (1992) estudou solos desenvolvidos de rochas eruptivas básicas e ácidas, no estado do Paraná, mediante metodologia proposta por França (1968). Os solos foram caracterizados qualitativa e quantitativamente pela "densidade de drenagem", "freqüência de rios" e "razão de textura média", utilizando bacias hidrográfica e amostras circulares.

Smith (1950), estudando a topografia de regiões dissecadas por rios, utilizou um índice semelhante ao da "freqüência de rios" de Horton (1945), ao qual denominou de "razão de textura", para expressar o espaçamento entre os canais de drenagem. A "razão de textura"(T), é expressa por $\mathrm{T}=\mathrm{N} / \mathrm{P}$, onde $\mathrm{N}$ é o número de crênulas na curva de nível escolhida e $\mathrm{P}$ é o perímetro da bacia, expresso em milhas. $\mathrm{O}$ mesmo autor estabeleceu um valor médio ponderado para caracterizar a textura topográfica, tomando em consideração o tamanho de cada bacia, sendo calculado pela seguinte expressão: $\operatorname{Tm}=\Sigma(\operatorname{TxA}) / \Sigma \mathrm{A}$, onde $\mathrm{Tm}$ é o valor médio ponderado da razão de textura, $\mathrm{T}$ a razão de textura e $\mathrm{A}$ a área, de cada bacia.

Considerando que os sistemas de drenagem podem ser melhor estudados em mapas básicos de drenagem obtidos pelo exame estereoscópico de fotografias aéreas, conforme recomendado por Ricci \& Petri (1965), França (1968) fez a determinação da textura topográfica considerando $\mathrm{N}$ como sendo o número total de rios da bacia. Nesta modificação, o autor ainda adaptou os componentes da equação de Smith (1950) para o 
sistema métrico e estabeleceu os seguintes parâmetros: Tm menor que 2,5 km (classe grosseira); Tm entre 2,5 km e 6,2 km (classe média) e Tm maior que 6,2 km, (classe fina).

\subsection{Processamento e análise de imagens}

O termo "imagem" tem significado bastante amplo na nossa linguagem, podendo referir-se às vezes ao simples reflexo de objetos no espelho, na água ou qualquer superficie polida, ou então se concretizar nas formas de expressão artística, como a pintura, a escultura, a fotografia etc., e pode até mesmo significar apenas a representação mental de uma forma qualquer.

No domínio do sensoriamento remoto, o termo se refere ao registro contínuo ou discreto de uma vista bidimensional (Curran, 1988). O registro é feito por um sensor geralmente acoplado a uma plataforma aérea ou orbital. Dependendo das características do sistema sensor utilizado na aquisição dos dados (sistema fotográfico, imageamento eletro-óptico), a imagem será registrada na forma contínua ou discreta.

Quando se trata de imagem contínua, significa que a informação é registrada como um sinal contínuo que representa a exposição sobre a cena observada por um sensor fotográfico, cujo produto final apresentado para análise são dados analógicos, como as imagens em cópias de papel ou transparências. Historicamente, várias técnicas de processamento têm sido implementadas nesta fase, dando origem ao que se denominou de "processamento de imagens contínuas".

Diferentemente do formato contínuo, na imagem discreta os detalhes são mantidos em unidades digitais ou discretas, que não podem ser vistas, mas que podem ser tratadas e manipuladas quantitativamente (Curran, 1988). Isto significa que a informação da cena observada pelo sensor (sistema eletro-óptico) é registrada em várias parcelas discretas, que são transformadas em impulsos elétricos e então codificadas e armazenadas em meio magnético na forma digital, onde somente podem ser tratadas e manipuladas por programas de computador. $\mathrm{O}$ conjunto de técnicas e procedimentos 
utilizados para processar essas informações, com a finalidade de torná-las adequadas à interpretação, é conhecido como "processamento digital de imagens".

Um exemplo de imagem contínua é a fotografia aérea, na qual os detalhes são registrados e exibidos como um sinal contínuo que podemos ver e interpretar (Curran, 1988). Já as imagens multiespectrais adquiridas pelo sensor TM do satélite Landsat, por exemplo, são registradas no formato digital. Neste caso, porém, a imagem pode ser transformada para o formato contínuo, onde cada banda registrada pelo sensor é convertida em níveis de cinza e/ou composições coloridas, a critério do usuário. Portanto, o produto é disponibilizado nos dois formatos.

Assim como as imagens podem ser adquiridas tanto como registro contínuo quanto discreto, o seu processamento também pode ser implementado de maneira específica para cada formato. Na verdade, as técnicas de processamento tiveram origem com a manipulação de imagens contínuas (dados analógicos), tendo-se desenvolvido vários procedimentos e equipamentos específicos, sempre buscando melhorar a qualidade dos dados e facilitar a sua interpretação.

Diz-se que os sinais detectados pelo sensor são processados opticamente, quando são transformados em uma imagem bidimensional da cena. Segundo Novo (1995), diferentes técnicas de extração de informações através da inspeção de imagens processadas opticamente podem ser encontradas nos numerosos manuais de fotointerpretação.

\subsubsection{Processamento de imagens contínuas}

Este tipo de processamento envolve uma série de técnicas e equipamentos que foram desenvolvidos com o objetivo de possibilitar correções, realces e classificações dessas imagens.

Curran (1988) refere-se a cinco técnicas de correção e realce, como as mais conhecidas e utilizadas, enumerando-as na seguinte ordem: 
1) ampliação seletiva - para facilitar a observação de detalhes dentro de uma cena ou permitir isolar uma área ou feição de estudo;

2) modificação de contraste - um meio de otimizar a escala de tons de cinza da imagem, às vezes envolvendo aumento de contraste para auxiliar na localização de mudanças tonais sutis, ou diminuição de contraste para revelar detalhes em áreas que apresentam tons muito escuros ou muito claros;

3) realce de bordas - para mapeamento de falhas geológicas, mudanças bruscas de declividade do terreno e limites de textura;

4) produção de composições coloridas - um meio de manipulação e exibição de várias imagens multibanda de uma cena, como uma imagem colorida;

5) filtragem espacial e direcional - para remoção de feições irregulares na imagem, tais como linha de varredura e bandas de nuvem, e realçar os detalhes remanescentes.

Dentre vários equipamentos citados pelo autor, utilizados para implementar essas técnicas, destacam-se o ampliador fotográfico (photographic enlarger), que pode ser usado com as quatro primeiras técnicas e mais a classificação de imagens, e o processador óptico (optic processor), único equipamento usado para filtragem.

Ainda de acordo com Curran (1988), a técnica de classificação de imagens contínuas mais freqüentemente usada é a de fatiamento (density slicing), onde tons específicos dentro de uma imagem de sensoriamento remoto são isolados, de acordo com cada nível de densidade. Esta técnica tem mostrado ser particularmente útil para a localização de limites de densidade (Ranz \& Schineider) e para correlacionar visualmente áreas não contíguas de tom similar (Rohde \& Olson; Frazee et al.), todos citados por Curran (1988).

Atualmente, a tendência é de se utilizar, com maior freqüência, técnicas de processamento digital de imagens, face à necessidade de se processar quantidades cada vez maiores de dados provenientes de imagens multiespectrais. Esta tendência tem se firmado com a tecnologia dos novos sensores que, se por um lado oferecem 
capacidade de coleta de imagens numa maior quantidade de regiões do espectro, por outro, aumentam a complexidade de análise dos dados, de modo que as técnicas de inspeção visual tornaram-se insuficientes para processá-los, exigindo o desenvolvimento de técnicas computacionais.

\subsubsection{Processamento de imagens digitais}

Em princípio, o processamento digital de imagens refere-se à utilização de um conjunto de procedimentos e técnicas de computação, que tem o objetivo de facilitar a identificação e extração de informações específicas a partir de uma enorme quantidade de dados geralmente contidos nas imagens, para posterior interpretação.

Um conceito bastante simples e objetivo é apresentado por Quintanilha (1990), onde o autor explica que o processamento de imagens digitais pode ser entendido como o conjunto de procedimentos relativos à manipulação e análise de imagens através do computador, compreendendo basicamente a entrada de dados, o realce (manipulação do contraste), a análise estatística e a geração de saídas que podem ser imagens em tons de cinza ou coloridas.

Como foi visto anteriormente, o enorme volume de informação presente nas imagens de várias regiões do espectro extrapola a capacidade de análise do sistema visual humano. Além disto, vários tipos de degradação e distorção, inerentes aos processos de aquisição, transmissão e visualização de imagens contribuem para limitar ainda mais esta capacidade. Segundo Crósta (1992), o objetivo principal do processamento digital de imagens é o de remover essas barreiras, inerentes ao sistema visual humano, facilitando a extração de informações a partir das imagens. Neste contexto, o processamento digital deve ser encarado como um estágio preparatório, embora quase sempre obrigatório, da atividade de interpretação das imagens de sensoriamento remoto.

Para Quintanilha (1990), embora o interesse pelas técnicas de processamento de imagens digitais remonte ao início da década de 20 , quando figuras 
digitalizadas foram inicialmente transmitidas por cabo submarino entre Nova York e Londres, as aplicações dos conceitos de imagens digitais só tiveram um maior desenvolvimento na segunda metade da década de 60 . Segundo o autor, este avanço foi proporcionado pelo advento da terceira geração de computadores digitais, cuja tecnologia disponibilizou aos usuários, velocidade e capacidade de armazenamento compatíveis com aquelas necessárias à implementação de algoritmos de processamento de imagens.

Embora os computadores tenham sido incorporados rapidamente à tecnologia do sensoriamento remoto, tanto na programação dos sensores que operam à bordo de satélites e aeronaves, como na análise de dados, a sua utilização ficou inicialmente restrita aos centros especializados em pesquisa e tecnologia de sensoriamento remoto, tendo em vista o grande custo então envolvido nessa nova tecnologia e o requerimento de computadores de grande porte para realizar o processamento.

Todo esse avanço, por sua vez, criou a necessidade de pessoal qualificado, treinado em técnicas de análise de imagens digitais. Para Handerson et al. (1983), esse treinamento deveria ser implementado a nível de universidade, como parte da educação em sensoriamento remoto, porém, os custos associados a muitos dos sistemas (grandes computadores) ficavam além do orçamento de uma instituição acadêmica. Uma solução econômica para este dilema, conforme relatam os autores, seria o uso de sistemas de análise de imagens baseado em microcomputadores.

Em tempos mais recentes, a evolução das técnicas de processamento tem sido cada vez mais rápida. Segundo Crósta (1992), os anos 80 trouxeram a explosão tecnológica dos processadores digitais e uma queda acentuada nos custos envolvidos, causando fortes reflexos na computação gráfica, na qual se baseia o processamento digital de imagens. Isto fez com que os sistemas especializados no processamento de imagens de sensoriamento remoto ficassem ao alcance de uma comunidade muito maior de usuários, sendo comum encontrá-los hoje nas universidades, instituições públicas, empresas e até mesmo escolas. 


\subsubsection{Digitalização de imagens}

Apesar de seus processos de registros serem totalmente diferentes, não há divisão rígida entre cada tipo de imagem, de maneira que uma imagem digital pode ser convertida numa imagem contínua e vice-versa.

Segundo Nichols (1983), em sua discussão sobre "dispositivos de aquisição de dados", é fundamental a conversão de dados ambientais para a forma digital, sendo que no caso da maior parte dos dados de satélite, este processo já ocorre longe do controle do analista de sensoriamento remoto. Entretanto, existe uma grande massa de dados disponíveis que precisa ser digitalizada, no sentido de facilitar o seu processamento posterior ou fusão com dados de sensoriamento remoto.

Curran (1988) menciona que as exigências básicas de muitos procedimentos de processamento de imagem é a capacidade de ransformação da imagem entre os estados contínuo e discreto. Por exemplo, uma imagem contínua pode ser convertida em dados discretos para análise digital e, em seguida, convertida de volta à forma contínua para análise visual.

Quintanilha (1990), descrevendo "fluxo de dados em processamento de imagens", analisa o processo de digitalização dos sistemas sensores, como a discretização (ou amostragem) da cena imageada através da superposição de uma malha hipotética, e a atribuição de valores inteiros (que correspondem aos níveis de cinza) a cada ponto dessa malha, ao que chama de processo de quantização.

Novo (1995) comenta que dados digitais normalmente provêm de sistemas de varredura multiespectral, que permitem a saída de dados em fitas magnéticas, ressalvando, porém, que produtos obtidos através de sensores fotográficos, como fotografias aéreas, podem ser digitalizados e processados através de computadores.

Crósta (1992) comenta que o processo de digitalização de imagem analógica (fotografias, mapas, etc.) pode ser implementado através de um "scanner", 
periférico que transforma a imagem em uma matriz bidimensional com o número de linhas e colunas e tamanho de cada célula pré-definidos, atribuindo a cada célula um valor de nível de cinza proporcional à tonalidade da imagem original. Esta matriz é então convertida para o formato digital gráfico, podendo ser lida e manipulada por sistemas de processamento digitais.

É importante compreender que a matriz bidimensional referida acima, formada por linhas e colunas, eqüivale à malha hipotética citada por Quintanilha (1990), assim como os pequenos elementos da imagem chamados de pontos de malha e células, respectivamente, que carregam valores de níveis de cinza associados, são mais freqüentemente referidos como "pixels" ("pixel" no singular, que representa uma forma abreviada de "picture element").

Como a cada "pixel" corresponde uma única combinação de linha e coluna, associou-se um sistema de coordenadas $(\mathrm{x}, \mathrm{y})$ para o espaço bidimensional da imagem, com origem no seu canto superior esquerdo, onde cada "pixel" tem um endereço único definido pelas distâncias ao longo da linha (x) e da coluna (y), a partir da origem. Além disso, o valor de intensidade, ou nível de cinza associado a cada "pixel" é registrado como um número digital ou DN ("Digital Number").

Segundo Mascarenhas (1987), freqüentemente uma imagem consiste de $512 \times 512$ ou $1024 \times 1024$ "pixels", cada um quantizado com 6 "bits" (64 níveis) a 10 "bits" (1024 níveis).

Curran (1988) comenta que o valor do DN depende do nível de energia eletromagnética proveniente da superficie da terra que o sensor recebe e do número de níveis de intensidade que tiver sido usado para descrever a escala de intensidade da imagem. Muitas das imagens de sensoriamento remoto são codificadas em 8 "bits" $\left(2^{8}\right)$, que representa uma amplitude de intensidade de 256 níveis de cinza, distribuídos no intervalo de 0 a 255 , que deve abranger do mais baixo ao mais alto nível de radiância ou retorno de radar recebidos pelo sensor. 
Para imagens digitalizadas por meio de "scanner", o princípio de atribuição de DN's não é diferente, ou seja, a quantidade de níveis de cinza será sempre representada por uma potência de 2 . Portanto, uma fotografia digitalizada e codificada em 8 "bits" será exibida com 256 níveis de cinza. Já uma fotografia digitalizada com apenas 2 níveis de cinza ( 1 "bit"), resulta numa imagem digital binária da fotografia original, onde só se distinguem áreas totalmente pretas ou totalmente brancas. Segundo Graça (1990), este nível de digitalização seria suficiente para o arquivamento de desenhos monocromáticos e em bom estado de conservação.

\subsubsection{Histogramas de imagens}

A utilização de conceitos estatísticos em imagem digital é uma necessidade básica à estrutura e tratamento dos dados, com a finalidade de permitir a sua leitura e manipulação em computador, através dos diversos algoritmos dedicados a tarefas de processamento digital.

Segundo Paradella (1990), uma forma simples de representação paramétrica de uma imagem digital, comumente usada em processamento de imagens digitais de sensoriamento remoto, é a construção de histogramas. Para Quintanilha (1990), este é um dos primeiros passos para a análise e entendimento de uma imagem digital.

Os histogramas são gráficos que representam a freqüência de ocorrência de "pixels" para cada valor possível de DN. Em outras palavras, os histogramas descrevem graficamente a distribuição dos níveis de cinza de uma imagem, através da freqüência absoluta ou relativa dos mesmos. Desta maneira, fornecem a informação sobre quantos "pixels" na imagem possui cada nível de cinza (valor de DN) ou, de forma equivalente, que proporção da imagem cada nível de cinza representa.

Os histogramas também são conhecidos como distribuição de intensidades e função de densidade de probabilidade (fdp), sendo que o último termo advém do fato de que, estatisticamente, o histograma representa, neste caso, a 
probabilidade de se achar um DN de um dado valor dentro de uma imagem (Crósta, 1995).

Considerando-se uma cena completa de imagem de satélite (TM-Landsat, por exemplo), seria inconveniente representar a contagem total dos valores assumidos de cada um dos vários milhões de "pixels" no histograma. Por isto, comumente se usa o histograma normalizado, no qual o valor máximo da ordenada corresponde ao valor digital com maior freqüência, sendo as freqüências restantes escalonadas proporcionalmente, ou seja, ajustadas em relação a esse máximo, como percentagens de máxima contagem. No caso das abscissas, normalmente usam-se 256 níveis, distribuídos eqüitativamente no intervalo de 0 a 255, que é a amplitude exata para imagens concebidas em sistema de 8 "bits".

Deste modo, podem ser definidas algumas estatísticas importantes como: o total de "pixels" na imagem, a intensidade média e a variância dessa imagem (Quintanilha, 1990). Segundo Crósta (1992), a média e a moda são conceitos básicos de estatística úteis ao se tratar com histogramas (Figura 1) e podem ser definidas da seguinte forma:

- média - representa a média aritmética de um conjunto de valores (DN's, por exemplo); num histograma, corresponde ao seu "centro de gravidade";

- moda - representa o valor mais comum de um conjunto de valores; num histograma, é o ponto mais alto do gráfico.

Conforme exemplifica Crósta (1992), a importância da moda num histograma de imagem pode ser avaliada comparando-se os histogramas das seguintes cenas: uma imagem que possui uma parte da área coberta por água e o restante coberto por solo (região costeira, por exemplo), e uma imagem homogênea (monocultura em terreno plano, por exemplo). A primeira imagem produzirá um histograma tipicamente bimodal (Figura 1a), com "pixels" mais escuros (correspondentes à água) agrupados próximo à origem, enquanto os demais deverão se espalhar de forma menos pronunciada pelo restante do intervalo de DN's. A segunda imagem, que apresenta baixo contraste, 
produzirá um histograma com um único e proeminente pico, ou seja, um histograma unimodal (Figura 1b). Consequentemente, imagens com diferentes tipos de cobertura superficial apresentarão múltiplos picos no seu histograma, ou seja, histogramas multimodais. Quando houver diferenças significativas entre os valores médios de resposta espectral desses picos, os mesmos serão claramente separados no histograma.

Quanto ao conceito de variância da imagem, referido por Quintanilha (1990), esta indica o espalhamento dos níveis de cinza ao longo do seu eixo, sendo, portanto, uma medida de contraste da imagem. Neste caso, quanto maior for o espalhamento, maior será o contraste e vice-versa.

Um outro aspecto importante a ser considerado nos histogramas de imagens digitais diz respeito à dimensão dos dados que eles podem representar, ou seja, o número de bandas espectrais.

No caso da distribuição de freqüência de "pixels" de uma única banda, tem-se o histograma unidimensional, cuja representação pode ser uma tabela ou um

a)

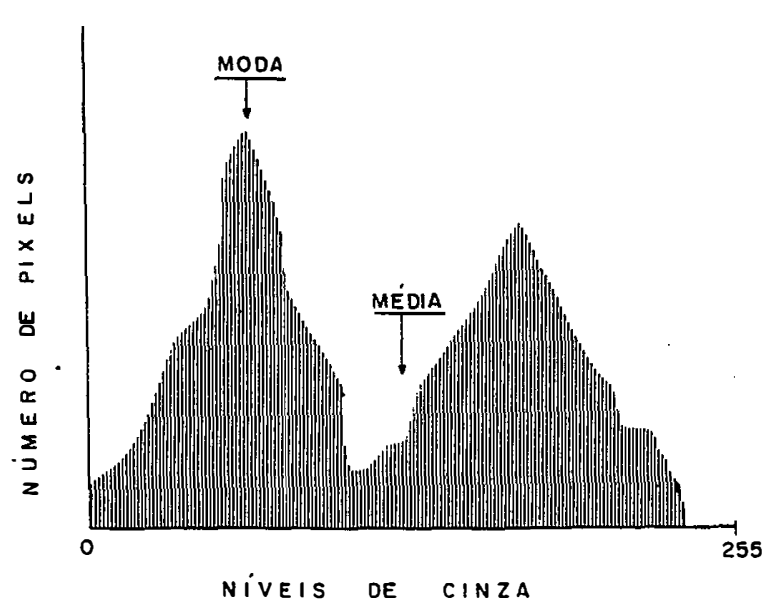

b)

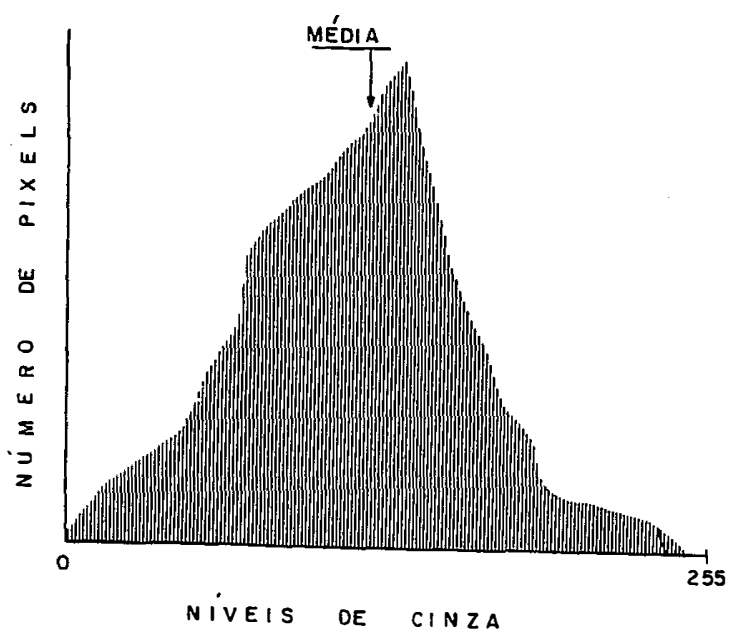

Figura 1 - Histogramas bimodal (a) e unimodal (b), com a representação dos respectivos valores de moda e média (adaptado de Soares, 1994). 
gráfico contendo o número de "pixels" atribuídos a cada um dos possíveis DN's, conforme visto até agora.

Quando se trata de imagens multiespectrais, o conceito utilizado é o de histogramas multidimensionais, sendo o bidimensional o mais simples deles. Estes são "plots" bivariados dos DN's de uma banda contra os de outra, conhecidos como scattergramas (Figura 2). Eles mostram visualmente o grau de correlação entre as duas bandas consideradas e identificam as situações em que a superficie mostra claramente diferentes tipos de respostas nas duas bandas (Crósta, 1992).

Ainda segundo o autor, os scattergramas são úteis não apenas na avaliação do grau de correlação entre pares de imagens e na decisão sobre tipos de técnicas de aumento de contraste na produção de imagens coloridas realçadas, mas principalmente pelo fato de que eles podem ser descritos estatisticamente e manipulados para servir de base para classificação estatística e para análise estatística multivariada de imagens multiespectrais de sensoriamento remoto.

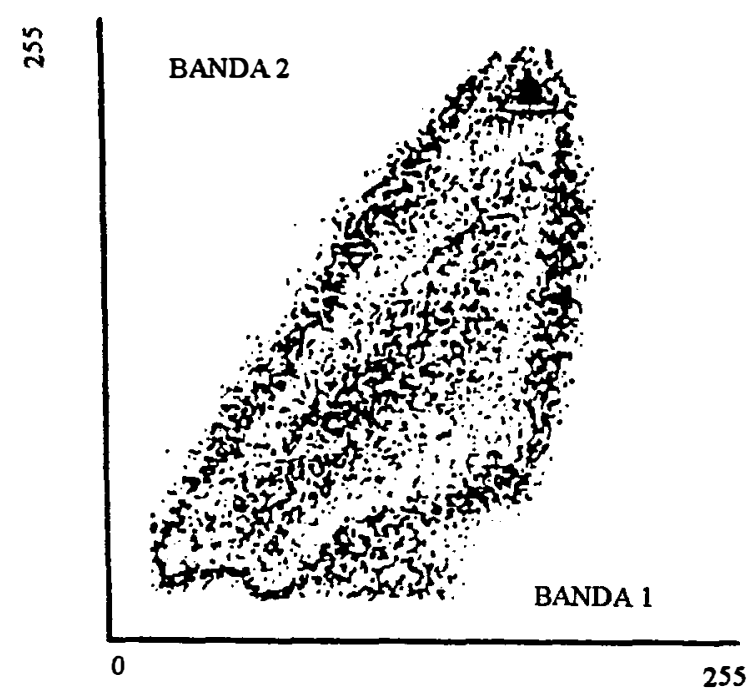

Figura 2 - Histograma bidimensional ou scattergrama, cuja região de maior freqüência é representada pela pequena área escura na parte superior direita do gráfico (adaptado de Crósta, 1992). 


\subsubsection{Técnicas de processamento de imagens digitais}

Lillesand \& Kiefer (1994) consideram que as formas possíveis de manipulação de imagens digitais são literalmente infinitas. Entretanto, todos os procedimentos realmente utilizados podem ser reunidos em cinco tipos gerais de operações assistidas por computador, que são: 1) retificação e restauração de imagens; 2) realce; 3) classificação; 4) fusão de dados em Sistema de Informações Geográfica, $e$ 5) modelagem biofísica

Curran (1988) considera que entre as muitas formas de processamento de imagens discretas existem seis operações que são mais utilizadas por cientistas que estudam o meio ambiente. Estas operações correspondem basicamente aos quatro primeiros tipos de classificação de Lillesand \& Kiefer (1994), mais as operações de compressão de imagem e visualização colorida, que na verdade, é apenas um desdobramento das operações de realce de imagem.

Novo (1995) reúne as técnicas de processamento de imagens digitais em três categorias: 1) técnicas de pré-processamento (preparação da imagem); 2) técnicas de realce e 3) técnicas de classificação. Estas categorias, portanto, correspondem aos três primeiros tipos de operações classificados por Lillesand \& Kiefer (1994), onde os próprios autores esclarecem que os procedimentos de retificação e restauração de imagens são freqüentemente denominados de operação de pré-processamento, uma vez que eles normalmente precedem as manipulações e análises dos dados da imagem, que têm o objetivo de extrair informações específicas.

Talvez pelo fato da maioria dos trabalhos em sensoriamento remoto estar direcionada para a análise e monitoramento dos recursos terrestres, é comum se encontrar na literatura referências que tratam das técnicas de processamento de imagens digitais apenas em termos de pré-processamento, realce e classificação, como Mascarenhas (1987), Godoy Júnior \& Novo (1989), Mascarenhas (1990), Paradella (1990), Quintanilha (1990), entre outros. 
As técnicas de pré-processamento referem-se a um conjunto de operações realizadas com o objetivo de corrigir distorções e degradações dos dados da imagem para criar uma representação mais fiel da cena original. Além de correções geométricas e radiométricas, a correção dos efeitos atmosféricos (remoção de bruma) também é uma operação típica da fase de pré-processamento.

As técnicas de realce, em geral visam melhorar a qualidade da imagem sob os critérios subjetivos de avaliação do observador humano, ou seja, são operações que preparam a imagem para subsequente interpretação visual.

O objetivo das técnicas de classificação é substituir a análise visual da imagem pela análise quantitativa dos níveis de cinza, possibilitando o reconhecimento automático de objetos da cena.

\subsection{Pré-processamento}

\section{a) Correção radiométrica}

Quintanilha (1990) explica que as correções radiométricas são usadas para eliminar ruídos presentes na imagem e que influenciam não só o aspecto das imagens, como também o resultado dos processamentos porventura utilizados. Esses ruídos podem ser causados, por exemplo, pela descalibração do(s) detetor(es) do sistema sensor, pela presença de muitos valores fora da sua faixa de detecção, ou ainda, pela interferência da atmosfera.

Segundo Novo (1995), a função dos programas de correção radiométrica é minimizar diferenças entre níveis de cinza registrados por uma matriz de detetores. Essas diferenças decorrem de problemas de calibração dos detetores ou em função da não-linearidade da resposta dos detetores à radiância da cena. Neste caso, o processamento envolve a transformação da resposta original do detetor (não-linear) numa resposta linear. 
Filtros de média e de mediana são exemplos de técnicas usadas para correção radiométrica de imperfeições causadas pela resposta do instrumento.

\section{b) Correção geométrica}

A correção geométrica tem como objetivo minimizar as distorções geométricas provenientes das características do sensor utilizado e das variações decorrentes do seu movimento durante a captação da imagem. São, por exemplo, deformações devido às variações da altitude, posição e velocidade de vôo da plataforma do sensor, efeito da curvatura da terra, refração atmosférica e deslocamento do relevo.

Este tipo de correção é feita por programas específicos que têm a função de organizar os "pixels" da imagem em relação a determinados sistemas de projeção cartográfica, através de técnicas de reamostragem. Segundo Novo (1995), isto implica numa reformatação da cena em uma base cartográfica, onde são utilizados pontos de controle no terreno, facilmente identificáveis na base cartográfica e na cena a ser corrigida geograficamente. $\mathrm{Na}$ imagem, os pontos de controle são localizados pelas coordenadas (x,y) e, na base, pela coordenadas geográficas (latitude, longitude). A função que relaciona a posição do ponto $\mathrm{x}, \mathrm{y}$ com sua respectiva posição geográfica é determinada pelo método dos mínimos quadrados.

Após o ajuste geométrico, se faz necessário o cálculo dos novos níveis de cinza da imagem corrigida. Existem diferentes procedimentos para resolver este problema. Os mais comuns, citados em Quintanilha (1990), Lillesand \& Kiefer (1994) e Novo (1995), são: alocação do vizinho mais próximo (nearest neighbour), interpolação bilinear e convolução cúbica.

\section{c) Correção atmosférica}

Um outro fator que afeta a qualidade dos dados da imagem na fase de aquisição é o efeito atmosférico. Por isto, técnicas de correção atmosférica são utilizadas com o objetivo de reduzir o efeito da interferência da atmosfera sobre os valores de nível de cinza registrados numa dada cena. 
Existem métodos de correção atmosférica que baseiam-se em aproximações para o efeito atmosférico e admitem algumas generalizações, tais como: isotropia do campo de radiação; homogeneidade atmosférica; constância do ângulo de incidência de radiação, etc.

Segundo Quintanilha (1990), o método mais simples de correção neste caso é o chamado principio da reflectância zero. Este método supõe que os valores de nível de cinza mais baixos de uma cena estão associados às regiões com sombra de relevo ou de nuvem, ou ainda corpos de água limpa, e cujos valores de nível de cinza sejam não nulos. Neste caso, devem-se subtrair os valores de nível de cinza mais baixos de todos os pixels da imagem.

Novo (1995), comenta que os métodos mais sofisticados de correção baseiam-se na transferência radiativa e usam programas para o cálculo de transmitância atmosférica. Estes métodos apresentam, também, certas desvantagens no tocante ao tempo computacional, dependendo dos cálculos.

Há ainda outros métodos como o de correlação de canais, ou o da análise de histogramas. Maiores informações sobre os métodos de correção atmosférica podem ser encontradas em Morimoto (1980) e Dias (1982).

\subsection{Realce de imagens}

Existem várias formas de apresentação do assunto na literatura, sendo que as diferenças básicas se prendem ao nível de detalhamento ou algumas variações de termos, conforme se pode constatar em Moik (1980), Curran (1988), Quintanilha (1990), Crósta (1992), Lillesand \& Kiefer (1994) e Novo (1995). De maneira geral, podem-se reunir as técnicas de realce basicamente em três conjuntos de operações, que são: manipulação de contraste, filtragem digital e realce espectral.

A forma apresentada por Quintanilha (1990) abrange todo esse conjunto de operações e permite uma boa compreensão. Neste caso, as técnicas de realce são 
vistas na seguinte seqüência: a) transformações por manipulação de histogramas (manipulação de contrastes); b) filtragens digitais; c) realces espectrais.

a) transformações por manipulação de histogramas

Os equipamentos de sensoriamento remoto são projetados para registrar intensidades de radiação eletromagnética, seja proveniente de radiância ou retroespalhamento, sob uma faixa de variação muito ampla de condições. Por exemplo, os sensores Landsat - MSS e TM têm de registrar radiância desde regiões fracamente iluminadas como os oceanos árticos, até regiões muito bem iluminadas como os desertos. Como resultado, apenas uma porção relativamente pequena da sua escala de medidas será usada em uma cena particular (Curran, 1988). Por esta razão, as imagens de satélite normalmente apresentam um baixo contraste.

Quintanilha (1990) comenta que a técnica de modificação de histograma é a primeira atividade ou manipulação a ser conduzida sobre a imagem, cujo objetivo é modificar os níveis de cinza de tal modo que se obtenha um histograma com a forma desejada pelo usuário. A idéia é redistribuir os valores de níveis de cinza na imagem de modo a melhorar a qualidade da visualização da informação nela contida.

O cálculo dos valores do novo histograma na transformação é realizado através de uma função conhecida como função de transferência, que correlaciona os valores de DN's do histograma original aos do histograma modificado.

Segundo Crósta (1992), no processamento digital, a implementação da função de transferência é feita por meio de uma processo chamado "Look-up Table" (LUT), que evita a especificação da função de transferência matematicamente e sua aplicação a cada um dos "pixels" da imagem para calcular as novas intensidade. A grande vantagem deste processo é, sem dúvida, a eficiência computacional, uma vez que o algoritmo realiza o cálculo para cada um dos 256 possíveis valores de níveis de cinza antes de modificar o histograma e armazena os resultados numa tabela. Em seguida, o DN de cada "pixel" da imagem original é usado simplesmente como um endereço para localizar o valor do DN modificado na tabela. 
As transformações por modificação de histograma mais conhecidas são: ampliação linear de contraste ("linear contrast stretch"), transformação linear por segmentos ("piecewise linear transformation"), equalização de histograma e classificação por fatiamento.

A ampliação linear de contraste é a forma mais simples de se aumentar o contraste de uma imagem. Neste tipo de realce, a função de transferência é uma reta cuja inclinação controla a quantidade de expansão das intensidade da imagem original, e o histograma modificado tem a mesma forma do histograma original (Figura 3 ).

Uma das aplicações mais comuns do aumento de contraste é na preparação de composições coloridas usando 3 bandas de um sensor (Crósta, 1992). Neste caso, o aumento de contraste permite uma maior variação de matizes nas 3 cores básicas (vermelho, azul e verde) às quais são atribuídas as 3 bandas, proporcionando uma boa distribuição de cores na composição resultante.

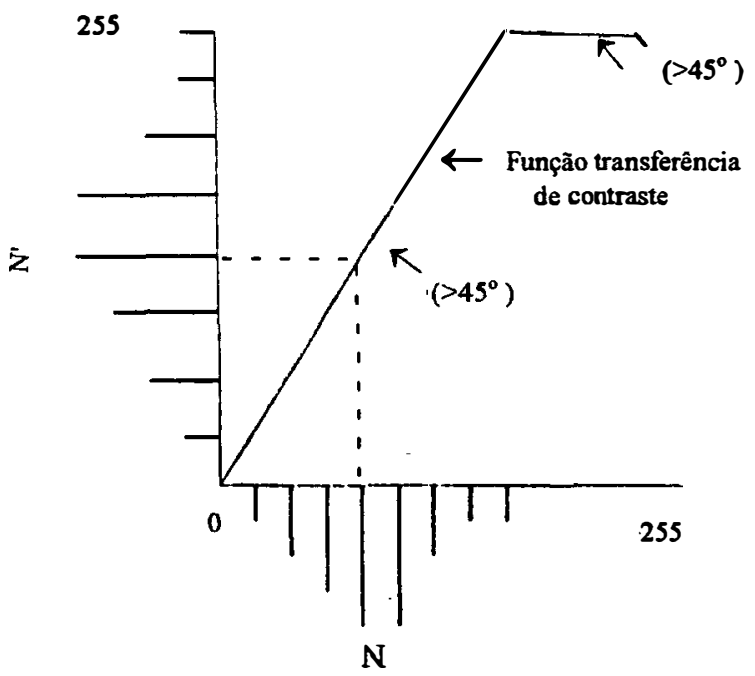

Figura 3 - Histograma de uma imagem e sua versão com ampliação linear de contraste e respectiva função de transferência (adaptado de Crósta, 1992). 
Segundo Quintanilha (1990), quando o histograma da imagem não é simétrico, fica impossível se controlar ao mesmo tempo os níveis de cinza de saída e a saturação nas pontas dos histogramas apenas com uma transformação linear. Neste caso, pode-se utilizar a transformação linear por segmentos, que ajusta diferentes segmentos de reta a diferentes partes do histograma.

Dependendo da aplicação ou problema inerente às imagens, outros tipos de transformação podem ser realizadas sobre o histograma, inclusive não-lineares. A equalização de histogramas é uma transformação não linear bastante comum.

Crósta (1992) explica que esta transformação parte do princípio de que o contraste de uma imagem seria otimizado se todos os 256 possíveis níveis de intensidade fossem igualmente utilizados, ou seja, todas as barras verticais que compõem o histograma fossem iguais. Evidentemente isto não é possível devido à natureza discreta dos dados digitais. Todavia, uma aproximação pode ser conseguida ao se espalhar os picos do histograma da imagem, deixando intocadas as partes mais achatadas do mesmo.

Finalmente, a classificação por fatiamento, que é uma transformação sobre histogramas que não leva em conta a forma da curva de distribuição dos níveis de cinza. Seu principal objetivo é reduzir o número de níveis de cinza através da redistribuição dos níveis existentes em um certo número especificado de faixas, para facilitar a visualização de características na imagem. Normalmente, procura-se dividir a distribuição dos níveis de cinza em até três faixas, de modo que se possa atribuir cores: azul, verde e vermelho, a cada faixa (Quintanilha, 1990).

\section{b) filtragens digitais}

Da mesma forma que na modificação de contraste, as filtragens digitais são transformações "pixel"a "pixel". Entretanto, estas não dependem apenas do valor do nível de cinza de um determinado "pixel" da imagem original, mas também da vizinhança desse "pixel". Portanto, trata-se de uma operação que depende do contexto em que se insere cada "pixel", pelo que é comumente tratada na literatura como filtragem espacial. 
As técnicas de filtragem digital podem ser implementadas de duas maneiras: operando sobre o domínio espacial da imagem, através do processo conhecido como convolução, ou operando sobre o domínio das freqüências que compõem a imagem, usando a análise de Fourier.

Curran (1988) comenta que a filtragem no domínio da freqüência, por ser tanto abstrata quanto dispendiosa, é usada com menor freqüência do que a filtragem no domínio espacial. Crósta (1992) afirma que a convolução é uma técnica mais simples e fácil de implementar, sendo a mais utilizada na maioria dos sistemas de processamento de imagens, onde tem atendido satisfatoriamente à grande maioria das necessidades em termos de imagens de sensoriamento remoto.

Para Quintanilha (1990), um conceito importante na filtragem espacial é o de freqüiencia espacial, que é dada pela relação entre um "pixel" e seus vizinhos, estabelecida na transição de uma padrão de comportamento na imagem, para outro (por exemplo, a mudança de estrutura dos elementos espaciais constituintes da imagem, quando se passa de uma área agrícola, geralmente bem organizada espacialmente, para uma área urbana, em geral desorganizada).

Com base neste conceito, definem-se áreas de altas e áreas de baixas freqüências espaciais na imagem. Uma área de altas freqüências espaciais é caracterizada pela mudança abrupta dos níveis de cinza em um número relativamente pequeno de "pixels" (por exemplo, ao cruzar rodovias ou limites de campos). Quando os níveis de cinza variam apenas gradualmente por um número relativamente grande de "pixels", tem-se a ocorrência de baixas freqüências (por exemplo, grandes campos agrícolas e corpos d'água).

Para Crósta (1992), são três os tipos de filtros de convolução: filtros passa-baixa, filtros passa-alta e direcionais. Um quarto filtro, o filtro passa banda, é geralmente menos utilizado em filtragem por convolução, por ser de difícil implementação, sendo mais nas filtragens executadas no domínio das freqüências. 
Os filtros passa-baixa ou de suavização (do termo inglês "smoothing") têm a função de eliminar as altas freqüências da imagem, deixando passar somente as baixas freqüências. Sua maior utilização é na remoção de ruídos eletrônicos, comuns em imagens de sensoriamento remoto. Um grande problema que apresenta é o efeito da desfocagem da imagem, com a conseqüente perda de informações de detalhe, embora existam alguns tipos que permitem a retenção de detalhes ou bordas. Os tipos mais comuns de filtros da família são: filtros de média, filtros de média ponderada, filtros de moda e filtros de mediana.

Os filtros passa-alta, de maneira similar, diminuem os componentes de baixa freqüência espectral e ressaltam os de alta freqüência. $O$ efeito obtido com a aplicação desse filtro é o realce das linhas de contorno ("sharpening"), algumas vezes denominado de bordas. Tem o inconveniente de realçar também, os ruídos existentes na imagem, neste caso interpretados como bordas (Quintanilha, 1990).

Os filtros direcionais são um tipo especial de filtros passa-alta, cuja função é a de realçar feições em direções pré-determinadas. Segundo Curran (1988) estes tipos de filtros tem particular importância para o realce de lineamentos geológicos, ondas oceânicas e feições transformadas pelo homem, como rodovias e limites urbanos. São exemplos de aplicação em geologia os trabalhos de Paradella \& Dutra (1980) e Burga et al. (1991).

O processo utilizado para construção e aplicação dos filtros espaciais lineares, consiste da utilização de uma matriz quadrada, de tamanho maior ou igual a $3 \times 3$ fixo (máscara ou janela), que é centrada em cada "pixel" da imagem e envolve sua vizinhança no número de pontos da matriz. O novo valor para cada "pixel" será o resultado da operação dessa máscara (média aritmética, média ponderada, moda) aplicada ao "pixel" central. Esta matriz percorre então, toda a imagem, num processo denominado de médias-móveis (Quintanilha, 1990). 
c) realce espectral

O realce espectral está relacionado a imagens multiespectrais sobre uma mesma cena, cujo objetivo é obter novas imagens que reflitam de alguma maneira, as relações existentes entre essas imagens a cada "pixel", uma vez que a posição desses nas diferentes imagens multiespectrais é a mesma.

Segundo Quintanilha (1990), entre as várias técnicas utilizadas para esse tipo de realce, as mais comuns e disponiveis nos softwares são: composições coloridas realçadas linearmente; divisão entre canais; transformação por componentes principais; transformação canônica e transformações no espaço de cores (IHS)

A composição colorida consiste da associação de uma das cores primárias do dispositivo de apresentação da imagem (azul, verde ou vermelha) ou de suas cores complementares (amarelo, magenta e cian) a cada uma das imagens relativas a um determinado intervalo do espectro eletromagnético, até o máximo de três imagens. Podem ser, por exemplo, três imagens do sensor TM, que podem ou não terem sido realçadas previamente por meio de transformações lineares com modificação de histograma.

A divisão entre canais é o tipo de realce onde se efetua a divisão de valores dos níveis de cinza de cada "pixel" de um canal pelos correspondentes de outro canal, para gerar uma terceira imagem, cujos efeitos mais importantes são:

- atenuação dos efeitos atmosféricos e da topografia, pois se supõe que ambos influenciam igualmente os dois canais;

- permite a diferenciação de alvos dentro das cenas com valores de nível de cinza não proporcionais;

- permite a redução da dimensionalidade dos dados, uma vez que as informações mais importantes de dois canais estarão representadas numa única imagem.

A transformação por componentes principais é o tipo de transformação que elimina a redundância entre as várias imagens multiespectrais de uma mesma cena (os 6 canais do TM, por exemplo), através de uma combinação linear dessas imagens, de 
modo que as novas imagens geradas (ou as imagens dos componentes principais) não são correlacionadas entre si.

Uma das vantagens dessa transformação é que as imagens associadas a cada um dos componentes principais, têm variância ordenadas, ou seja, a variância contida na imagem correspondente ao primeiro componente principal é maior que todas as demais, e a segunda é maior que as outras, e assim por diante. Este fato permite escolher um certo número de componentes principais (menor que o número inicial de imagens), de tal forma a manter o máximo de informação existente nos canais originais, o que significa reduzir a dimensionalidade dos dados, sem perda significativa (ou com perda aceitável) de informações.

As transformações no espaço de cores IHS (Intensity, Hue, Saturation) compreendem operações de uma transformação particular do sistema RGB (Red, Green, Blue), que descreve as sensações subjetivas de intensidade, cor e saturação, respectivamente para com do espaço RGB.

A implementação dessa transformação exige, além da mudança do RGB para o IHS, a transformação inversa para RGB, a fim de que se possa visualizar os resultados obtidos.

A utilização de tratamentos de realce em imagens multiespectrais é um recurso importante em sensoriamento remoto, segundo vários autores, com aplicação em áreas de interesse, como: fotointerpretação geológica (Paradella \& Dutra, 1980; Dutra \& Meneses, 1987; Paradela, 1990; Grasso, 1993), hidrografia (Godoy Júnior \& Novo, 1989; Walsh et al, 1990; Martins et al, 1993), entre outros.

Paradella \& Dutra (1980) comentam que a filtragem digital, pela possibilidade de realçar fotoestruturas nas imagens LANDSAT, segundo direções preferenciais de interesse do fotointérprete, surge como uma técnica valiosa nos campos da fotoanálise estrutural e mapeamento geológico. 
Dutra \& Meneses (1987) utilizaram um método de aumento de contraste de cores através de transformação para o espaço de cores IHS e manipulação de cada um desses elementos separadamente, para obter maior controle sobre os resultados da composição colorida gerada no monitor de vídeo. Os autores fizeram manipulação de histograma dos componentes $\mathrm{I}$, $\mathrm{H}$ e $\mathrm{S}$ em imagem TM de uma região de interesse de pesquisa geológica, onde verificaram que manipulações diferentes nos componentes como por exemplo, alterar I e $\mathrm{S}$ mantendo $\mathrm{H}$ inalterado, ou alterar também $\mathrm{H}$, promovendo uma rotação em determinados ângulos, resultaram em diferentes realces de suas litologias, anteriormente não distinguidas nas composições dos canais originais.

Paradella (1990) enfatiza o uso crescente de computadores para análise dos dados digitais, como fator importante de consolidação de um conjunto de técnicas voltadas à geologia (realce digital), cujo domínio é fundamental para os especialistas ou interessados em extrair a máxima informação disponível nos produtos de sensoriamento.

Walsh et al. (1990) trabalharam com realce de dados digitais TM-Landsat e integração de dados (GIS), para avaliação do caráter hidrológico de corpos d'água, rios e gelo glacial no Glacier National Park, Montana. Os realces utilizados foram divisão de bandas, principais componentes e filtragem espacial, sendo que cada uma das técnicas de realce forneceu uma única e proveitosa informação. Neste caso, a filtragem espacial foi útil na identificação de rios e pequenos córregos dentro da paisagem.

Segundo Grasso (1993), a transformação IHS é uma ferramenta útil e poderosa para combinar imagens de sensoriamento remoto com amplas diferenças na resolução espacial (8x), enquanto outras técnicas de fusão (substituição de bandas, por exemplo) são restritas a diferenças menores (2x a 3x). A aplicação da transformação IHS permite ainda a combinação de imagens multibanda (MSS ou TM) Landsat, facilmente disponíveis com fotografias aéreas de elevada altitude, formando um único conjunto de dados híbridos, possuindo propriedades espectral (verde ao infravermelho próximo) e espacial $(10 \mathrm{~m})$ comparáveis com imagem SPOT. O autor aplicou dois métodos alternativos, usando apenas a transformação inversa IHS para combinar dados 
espectralmente diferentes, onde foi realçada a discriminação geológica pela combinação de dados infravermelho ondas curtas com informação espacial de fotografia aérea.

Martins et al. (1993) aplicaram técnicas de realce em imagens orbitais (bandas 1,2 e 3 do sensor TM Landsat) par evidenciar as variações espectrais de massa de água superficial, utilizando os seguintes tratamentos digitais: remoção do efeito da atmosfera; realce por ampliação linear de contraste e realce por filtragem. Os autores concluíram que a banda 1 , além de sofrer maior mascaramento das respostas espectrais também foi a que passou por tratamentos digitais de maior magnitude. As bandas 2 e 3 mostraram maior correlação com os parâmetros de campo, como no caso da concentração de sais, cuja distribuição ao longo do corpo aquoso se mostrou intimamente correlacionada à distribuição dos níveis de cinza das bandas 2 e 3 .

\subsection{Classificação digital}

A classificação digital procura eliminar a subjetividade do processo de mapeamento temático e tornar possível a repetitividade do mesmo posteriormente. A maioria das técnicas disponíveis de classificação digital baseia-se apenas no agrupamento de valores de intensidade espectral (níveis de cinza), não levando em conta o arranjamento espectral dos pixels (textura e forma).

Para Crósta (1992), esta é talvez a etapa mais importante e objetiva em processamento digital. Por outro lado, Quintanilha (1990) esclarece que as técnicas de classificação dizem respeito a um campo de pesquisa que não se restringe essencialmente ao processamento digital, pois têm origens na estatística multivariada e no reconhecimento de padrões.

Normalmente o processo de classificação é dividido em duas fases: treinamento (processo de definição de critérios pelos quais os padrões são reconhecidos) e classificação propriamente dita (usando-se uma regra de decisão).

Crósta (1992) explica que a identificação dos diversos materiais na superficie terrestre é possibilitada devido ao comportamento específico que os mesmos 
possuem ao longo do espectro eletromagnético. Isto permite delineá-los, separando-os em diversos grupos que irão constituir-se em unidades de mapeamento para posterior identificação e confirmação no local, permitindo a elaboração do mapeamento da superfície terrestre com maior grau de certeza.

As técnicas de classificação ainda são divididas em: Classificação Supervisionada (há grande integração entre o analista e o sistema de análise) e Classificação Não-Supervisionada (usada quando se conhece pouco sobre os dados antes da classificação).

$\mathrm{Na}$ classificação supervisionada, são identificados alguns "pixels" das classes e informados ao computador, ao qual cabe a tarefa de localizar os demais "pixels" daquela classe, baseando-se em algumas regras estatísticas preestabelecidas. $\mathbf{O}$ usuário precisa ter um conhecimento da área através de observações diretas no terreno durante a passagem do satélite, observações estas que servem para confirmar a "verdade terrestre" (Ground Truth). Essas áreas determinadas, e que representam as classes que se desejam mapear, são chamadas de "áreas de treinamento" que, segundo Novo (1995), devem ser bastante homogêneas e representativas das classes de interesse.

Dependendo dos critérios ou regras estatísticas utilizadas no cálculo, as formas de classificação podem ser definidas como: método do paralelepipedo, método da distância mínima e o método da máxima verossimilhança ou MoxVer. Este último é o método mais utilizado, apresentando base estatística bastante complexa, para o que necessita de um tempo computacional bem maior.

Segundo Crósta (1992), esse tipo de classificação utiliza gráficos contendo frequeências de distribuição de intensidades de bandas de uma imagem multiespectral, representadas duas a duas, visto anteriormente com histograma bidimensional, definindo o chamado espaço de atributos.

A representação gráfica desse espaço de atributos é essencial para se entender como funciona a classificação de imagens multiespectrais, uma vez que mostra como espaços de atributos de materiais diferentes que se superpõem em uma 
determinada banda, podem ser inteiramente distintos em outra, conforme mostram as Figuras 4 e 5.

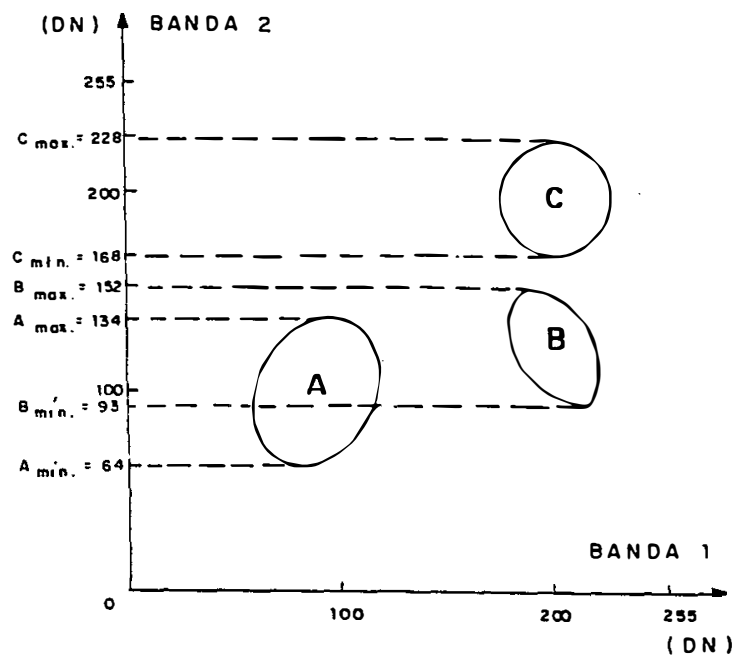

Figura 4 - Histograma bidimensional mostrando o espaço de atributos de uma imagem multiespectral, em 2 bandas, para três tipos de material ( $A, B$ e $C$ ), considerando as intensidades máxima e mínima dos DNs nas bandas 1 e 2 (adaptado de Soares, 1994).

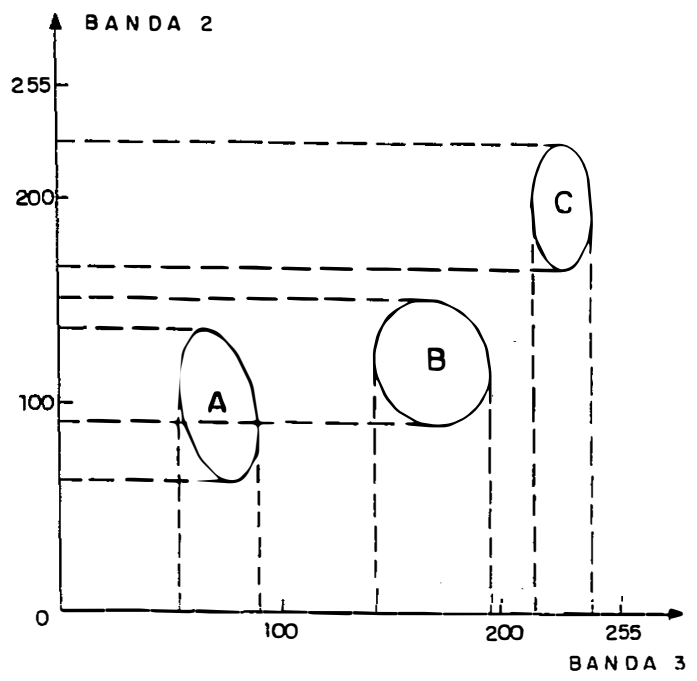

Figura 5 - Histograma bidimensional mostrando o espaço de atributos de uma imagem multiespectral, em outro par de bandas ( 2 e 3), para os mesmos tipos de material da Figura 4 (adaptado de Soares, 1994). 


\subsection{Conversão de dados e georreferenciamento de imagens}

Crósta (1992) comenta que o processo de digitalização de imagem analógica (fotografias, mapas, etc.) pode ser implementado através de um "scanner", gerando uma matriz, que é então convertida para o formato digital gráfico, podendo ser lida e manipulada por sistemas de processamento digitais.

Uma vez que as fotografias estejam no formato digital, suas feições podem ser digitalizadas diretamente em tela, de forma manual, utilizando-se o cursor do computador. Quintanilha (1996) menciona que a digitalização em tela pode ser realizada ainda de forma semi-automática ou automática, quando essas feições são traçadas com o auxílio de softwares que executam o processo de forma semi-automática ou automaticamente.

Devido às distorções geradas por alterações dinâmicas (atitude, altitude e velocidade) sofridas pelos sistemas de imageamento, as imagens de sensoriamento remoto não se ajustam diretamente a um sistema de gradeamento cartográfico. Segundo Crósta (1992), esta série de distorções a que estão sujeitas imagens de sensores remotos de qualquer tipo, ocasionam a falta de precisão cartográfica e, consequentemente, de posicionamento dos objetos. Portanto, dependendo da precisão requerida para aplicação em mapeamentos e/ou da necessidade de junção de imagens para representar uma cena completa (mosaico), essas distorções precisam ser corrigidas e um sistema de projeção cartográfica de referência precisa ser estabelecido.

Segundo Oliveira (1988), na projeção UTM não existe deformações de ângulos e em decorrência disto não deforma áreas por menores que sejam, de maneira que a escala é a mesma em qualquer ponto e as distâncias são corretamente representadas.

Para correção geométrica, Crósta (1992) cita duas formas pelas quais é calculada a relação entre os dois sistemas de coordenadas. A primeira delas é através do conhecimento exato dos parâmetros geométricos da órbita do satélite e de outras variáveis, também chamada de modelo de geometria orbital. A segunda, e mais 
comum, se faz através da definição de pontos de controle no terreno, que têm de ser reconhecíveis tanto no mapa como na imagem.

No caso de fotografias aéreas verticais, Crósta (1992) explica que a primeira condição exigida é a existência de mapa planimétrico ou planialtimétrico confiável e em escala adequada na área em questão, visto que os pontos de controle (GCPs, de "ground control points"), terão de ser identificados em ambos, imagem e mapa. Em áreas onde não existem mapas, a alternativa é medir precisamente no terreno a posição geográfica de alguns pontos identificáveis nas imagens. Para isto pode-se usar o GPS (Global Positioning Systems).

Prosseguindo, o autor esclarece que o conceito básico desse método é o de estabelecer as diferenças de posicionamento de alguns pontos na imagem e no mapa, a partir das quais pode ser estimada a natureza da distorção presente na imagem e uma transformação adequada pode ser computada, no sentido de corrigi-la.

Wolf (1983) comenta sobre a necessidade de se usar pontos de controle sobre a fotografia em combinação com coordenadas conhecidas, para se manter um nível satisfatório de exatidão.

A forma mais confiável de obtenção de pontos de controle é através de levantamento de campo, utilizando métodos geodésicos ou rastreamento de satélites de posicionamento. Porém, quando existem limitações para o uso destes métodos, a alternativa mais comum é a utilização de mapas em grande escala como fonte de dados (Delmiro, 1996).

A distribuição e quantidade desses pontos no terreno também precisam ser planejadas para que haja confiabilidade no georreferenciamento. Farret (1996) e Farret \& Gioto (1997), em estudo conduzido sobre georreferenciamento de fotografias aéreas de pequeno formato, testaram várias geometrias para quatro pontos de controle bem definidos e verificaram que o menor valor de RMS ocorreu com a distribuição dos pontos nos quatro cantos da fotografia. Além desta, a geometria que definiu os quatro pontos localizados na metade dos lados apresentou RMS próximo ao menor valor. 
Jones et al. (1993) e Montgomery \& Schuch (1993) comentam que a maioria dos programas de digitalização possui uma forma simples de controle de qualidade, apresentado na forma de uma estimativa grosseira de exatidão antes do início da digitalização e depois. Esta estimativa compreende uma análise estatística na forma de erro médio quadrático (Root Mean Square error - RMS error), que expressa o grau de variação entre as medidas de coordenadas do sistema da mesa e do sistema escolhido. Parte, portanto, da suposição de que os erros ocorrem ao acaso e, assim, serão distribuídos normalmente ao redor das coordenadas definidas como verdadeiras. Desta forma, o RMS equivale ao desvio padrão desta distribuição, sendo determinado pela seguinte expressão:

$$
\underline{R} \underline{S} S=\sqrt{\frac{\sum(x-t)^{2}}{n-1}}
$$

onde: $x$ = média da coordenada na direção de um dos eixos ( $\mathrm{x}$ ou y) do sistema da mesa; $t=$ medida da coordenada na direção do mesmo eixo acima, no, sistema escolhido; $n=$ número de pontos de controle da digitalização.

No caso da digitalização em tela, as coordenadas do sistema da mesma devem ser substituídas pelas coordenadas do sistema de "display", ou seja, as coordenadas que se lêem na tela, quando o cursor percorre a imagem.

Sobre a escolha do número de pontos de controle e um determinado RMS, em georreferenciamento de imagens, Jones et al. (1993) comentam que a decisão de aceitar um certo valor de RMS (no limite do erro aceitável) é provavelmente mais segura quando este é calculado sobre uma amostra maior de pontos (por exemplo > 30) do que sobre quatro pontos de controle.

Parise (1999), trabalhou com fotografias aéreas georreferenciadas em estudo de análise temporal de uso da terra em microbacia hidrográfica. Neste estudo, o 
autor comenta sobre a dificuldade de escolha dos pontos de controle, principalmente com relação à incerteza de que os pontos localizados na carta planialtimétrica correspondem corretamente àqueles determinados nas fotografias aéreas. Segundo o autor, na esperança de alcançar uma melhor correção das distorções e, ao mesmo tempo, garantir uma maior confiabilidade dos dados e um grau de exatidão aceitável, foi preferida uma distribuição similar à recomendada por Farret (1996) e Farret \& Giotto (1997). 


\section{MATERIAL E MÉTODOS}

\subsection{Material}

\subsubsection{Localização e caracterização da área de estudo}

\subsubsection{Localização geográfica}

A área de estudo está localizada integralmente no município de Piracicaba, Estado de São Paulo, compreendida entre os paralelos $22^{\circ} 40^{\prime} \mathrm{S}$ e $22^{\circ} 55^{\prime} \mathrm{S}$ e os meridianos $47^{\circ} 40^{\prime}$ WG e $47^{\circ} 50^{\prime}$ WG (Figura 6), com altitude média de $550 \mathrm{~m}$. Insere-se na região formada pela articulação das folhas cartográficas de Piracicaba, Capivari, Ibitiruna e São Pedro, da Fundação Instituto Brasileiro de Geografia e Estatística (1969), na escala de 1:50.000. Abrange as bacias dos Ribeirões dos Marins, Congonhal, Granal e Pau D'alhinho, todos afluentes diretos do Rio Piracicaba. Sua extensão é de aproximadamente $173 \mathrm{~km}^{2}$, estendendo-se a oeste da cidade e margem esquerda do rio Piracicaba.

\subsubsection{Geologia}

De acordo com a "Folha Geológica de Piracicaba (SF 23 - M 300)", (Governo do Estado de São Paulo) editada em 1966 na escala de 1:100.000, as unidades litoestratigráficas ocorrentes na área de estudo são as seguintes: 


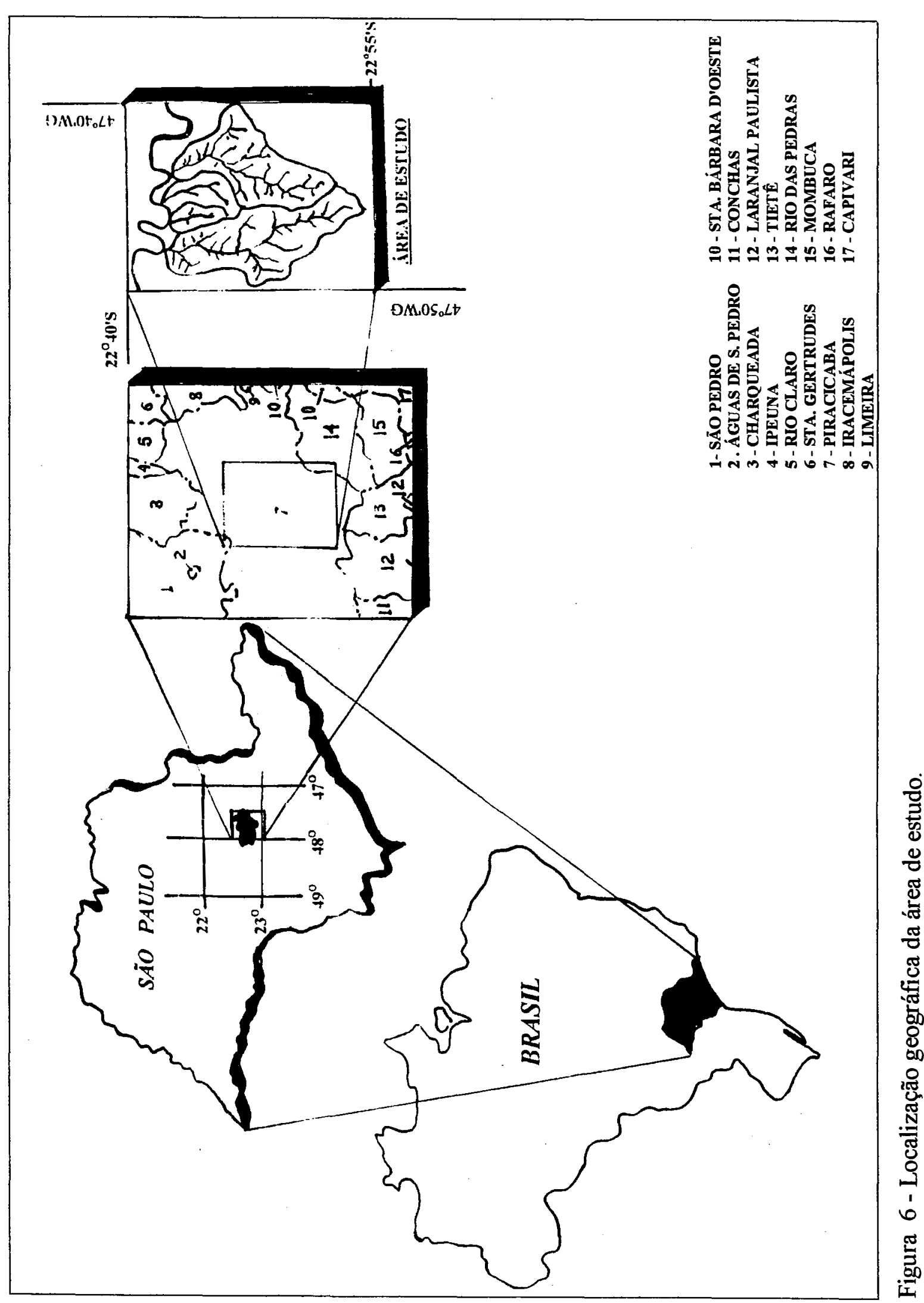


a) Holoceno $(\mathrm{H})$

- Areias, cascalho e argilas.

b) Cretáceo Inferior - Formação Serra Geral (Ksg)

- Basalto, arenito inter-trap, diabásio.

c) Jurássico - Formação Botucatu Pirambóia (Jbp)

- Arenitos, siltitos, folhelhos. Fósseis.

d) Permiano - Grupo Estrada Nova - Formação Corumbataí (Pc)

- Siltitos, folhelhos, calcários, sílex. Fósseis.

Conforme se observa na Figura 7, as unidades predominantes na área são a Formação Botucatu Pirambóia e a Formação Corumbataí do Grupo Estrada Nova. É sobre essas duas formações que estão assentadas as bacias em estudo, quase que em suas totalidades, sendo que na bacia do Ribeirão Congonhal, predomina a Formação Botucatu Pirambóia e, nas demais, a Formação Corumbataí. Em proporção bem menor, aparece a Formação Serra Geral, sobre parte do divisor da bacia do Ribeirão Congonhal e proximidades. Por último, uma pequena porção de formação geológica do Holoceno aparece na região de confluência do Ribeirão dos Marins com o Rio Piracicaba.

Pela extensão que ocupam na área e proporção que representam, será dado destaque à descrição das formações Botucatu Pirambóia e Corumbataí.

\section{- Formação Botucatu Pirambóia}

Segundo Schobbenhaus et al. (1984), a Formação Pirambóia caracterizase pela ocorrência de arenitos esbranquiçados, amarelados e avermelhados, médios a muito finos, síltico-argilosos, grãos polidos, subangulares e subarredondados com seixos de argila. Nesta formação, ocorre uma camada de 1 a $2 \mathrm{~m}$ de espessura na porção mais inferior, de cor avermelhada, areno-argilosa, com seixos de sílex; nos arenitos Pirambóia 


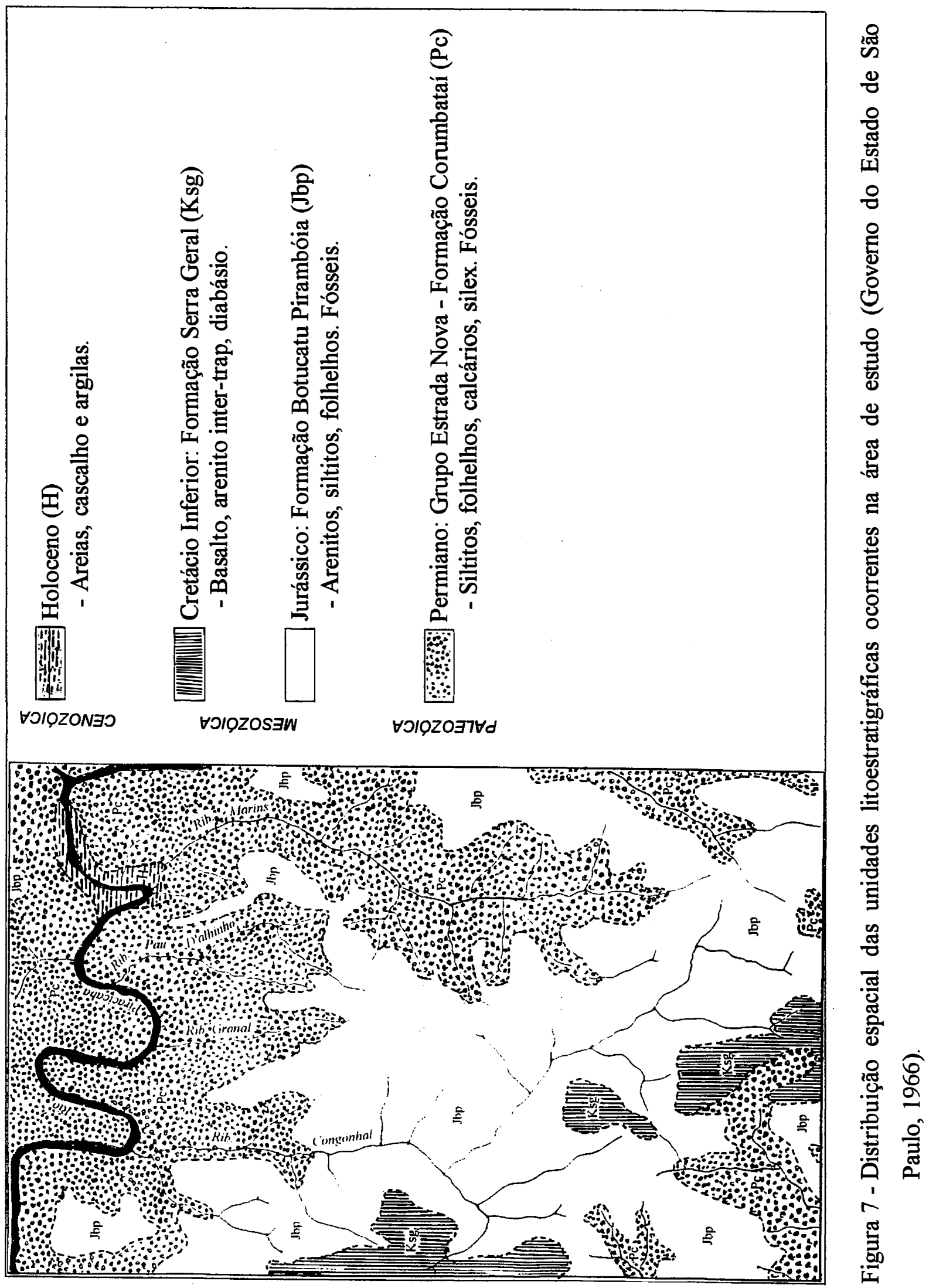


também ocorrem intercalações de siltitos e folhelhos com espessuras variando de alguns milímetros até $1 \mathrm{~m}$. A estratificação plano paralela é freqüente nestes arenitos.

Esta formação distribui-se de maneira contínua nos estados de São Paulo, Goiás, Mato Grosso e nordeste do Paraná, não tendo sido identificada nos Estados do Rio Grande do Sul e Santa Catarina.

\section{- Formação Corumbataí}

Segundo Almeida (1974), entre Piracicaba e Artemis, o rio Piracicaba apresenta nítidos meandros encaixados nos sedimentos da Formação Corumbataí. Esta designação, segundo Schobbenhaus et al. (1984), é adotada nos Estados de Goiás, Mato Grosso, São Paulo e Paraná, para indicar a seção que se estende desde o topo da Formação Irati até a base da Pirambóia. Sua espessura, em superficie, atinge valores da ordem de $250 \mathrm{~m}$.

Esta formação caracteriza-se pela ocorrência de arenitos muito finos, siltitos, lamitos e folhelhos, níveis de calcários oolíticos e coquina e cores lilás e cinza, indicando ambiente deposicional oxidante.

\subsubsection{Geomorfologia}

Para analisar o relevo do Estado de São Paulo, Almeida (1974) propôs a sua divisão em províncias geomórficas, que correspondem aproximadamente às grandes divisões de sua geologia e se estendem aos Estados vizinhos. Algumas dessas províncias são divididas em zonas, com base em feições locais do relevo, tais como: altitude, amplitude, orientação das formas topográficas, extensão de superficies de erosão antigas, processos de erosão e sedimentação, etc. Em face das diversidades estruturais ou morfológicas, algumas zonas foram ainda divididas em subzonas (Figura 8).

De acordo com esta divisão, a área de estudo situa-se na terceira província geomórfica, chamada Depressão Periférica, zona do Médio Tietê (Figura 8). 


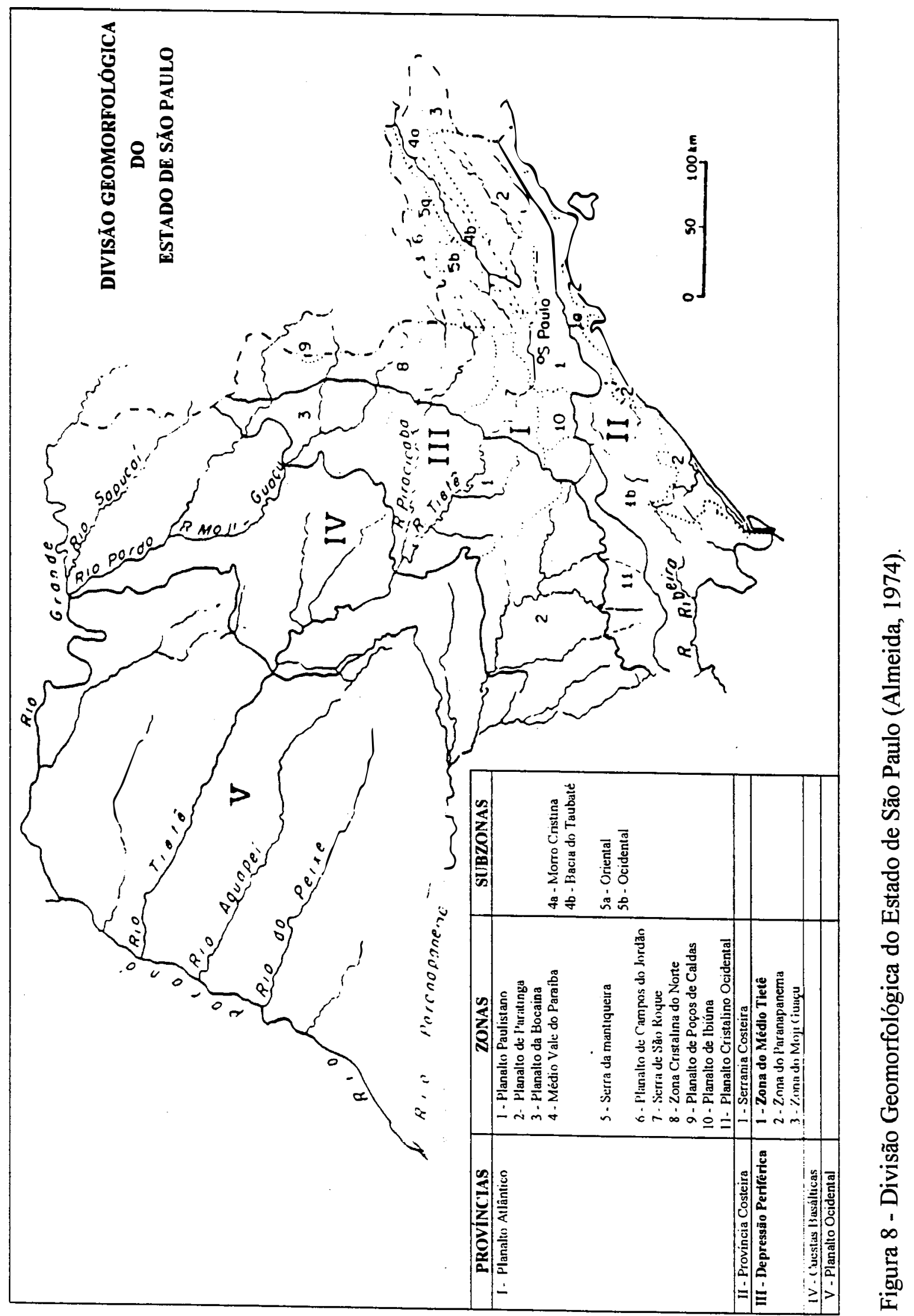


Segundo Almeida (1974), a Depressão Periférica corresponde à faixa de ocorrência das camadas carboníferas a triássicas do Estado. $\mathrm{O}$ autor ainda se refere ao termo Depressão Periférica como um qualificativo plenamente justificável, por se tratar de área sensivelmente rebaixada pela erosão, entre as terras altas do Planalto Atlântico e as cristas, igualmente elevadas, das cuestas basálticas.

Ab'Saber (1969) comenta que a Depressão Periférica Paulista tem a forma de um corredor de topografia colinosa de aproximadamente $50 \mathrm{~km}$ de largura, nitidamente embutido entre a cuesta da Borda da Mata e Monte Santo e as elevações cristalinas do acidentado Planalto Atlântico. Na altura do médio Moji Guaçu a depressão atinge de 80 a $100 \mathrm{~km}$ de largura, alcançando $120 \mathrm{~km}$ na região do médio Tietê. Na área em que a mesma se encurva de SW para W rumo ao segundo Planalto do Paraná, sua largura média continua a oscilar entre 80 e $120 \mathrm{~km}$, ao mesmo tempo em que comporta sutis modificações topográficas e morfológicas.

A divisão tríplice dessa província (Zona do Médio Tietê, Zona do Paranapanema e Zona do Mogi Guaçu) foi proposta por Defonttaines (1935) e adotada por Almeida (1974), a qual geomorfologicamente se justifica, uma vez que a área drenada para o rio Tietê mostra relevo muito mais diversificado, pois é mais fundamente erodido que o das zonas vizinhas, tendo suas estruturas resistentes postas em claros ressaltos topográficos.

Para facilidade de indicação cartográfica, Almeida (1974) propôs a delimitação da Zona do Médio Tietê segundo os divisores de água da bacia deste rio com as dos Rios Moji Guaçu e Paranapanema.

De acordo com Almeida (1974), esta zona é constituída, em grande parte, de sedimentos, aparecendo áreas importantes de derrames e intrusões de rochas basálticas, com reflexos na sua topografia. Outro fenômeno que bem se manifesta no relevo é a intrusão de eruptivas alcalinas nas camadas carboníferas de Ipanema, com o que estão relacionadas importantes perturbações devidas a falhamentos, exibidas sobre as camadas paleozóicas. 
De maneira geral, a topografia é pouco acidentada, com desníveis locais que raramente ultrapassam $200 \mathrm{~m}$, sendo que predominam, por toda a parte, colinas baixas suavizadas, separadas por vales jovens, sem planícies aluviais importantes, determinados pela interseção dos perfis das vertentes (Almeida, 1974).

Almeida (1974) comenta que toda a zona é recoberta por uma rede de drenagem bastante organizada, onde se destacam o rio Tietê e seus dois afluentes, os rios Piracicaba e Sorocaba, todos procedentes das terras elevadas do planalto cristalino. $\mathrm{O}$ padrão geral da drenagem é o dendrítico, notando-se, localmente, algum controle estrutural a partir de diáclases e da presença de corpos litológicos mais resistentes, especialmente diabásio.

\subsubsection{Clima}

O clima da região de Piracicaba é classificado, segundo o sistema de Köppen, como sendo do tipo Cwa, isto é, mesotérmico úmido, subtropical de inverno seco, em que a temperatura do mês mais frio é inferior a $18^{\circ} \mathrm{C}$ e a do mês mais quente ultrapassa os $22^{\circ} \mathrm{C}$ (Brasil, 1960). O Regime térmico dos solos é hipertérmico (Oliveira et al., 1976). O total de precipitação para os meses de inverno é de $101 \mathrm{~mm}$. Janeiro é o mês mais úmido, com uma média de $217 \mathrm{~mm}$, sendo a média geral para os meses mais úmidos (dezembro, janeiro e fevereiro) de $619 \mathrm{~mm}$. A Figura 4 mostra o balanço hídrico da região de Piracicaba.

\subsubsection{Vegetação}

Segundo Ranzani et al. (1966) tudo indica que a cobertura vegetal original das terras do Município de Piracicaba pertenceu ao subtipo floresta latifoliada tropical. Infelizmente, o efeito de acentuados desequilíbrios bióticos, introduzidos pelo uso da terra, praticamente relegou a presença de espécies arbóreas aos locais de difícil acesso, às grotas de cabeceiras de água, onde a presença dos litossolos afastam o interesse de formação dos roçados. 


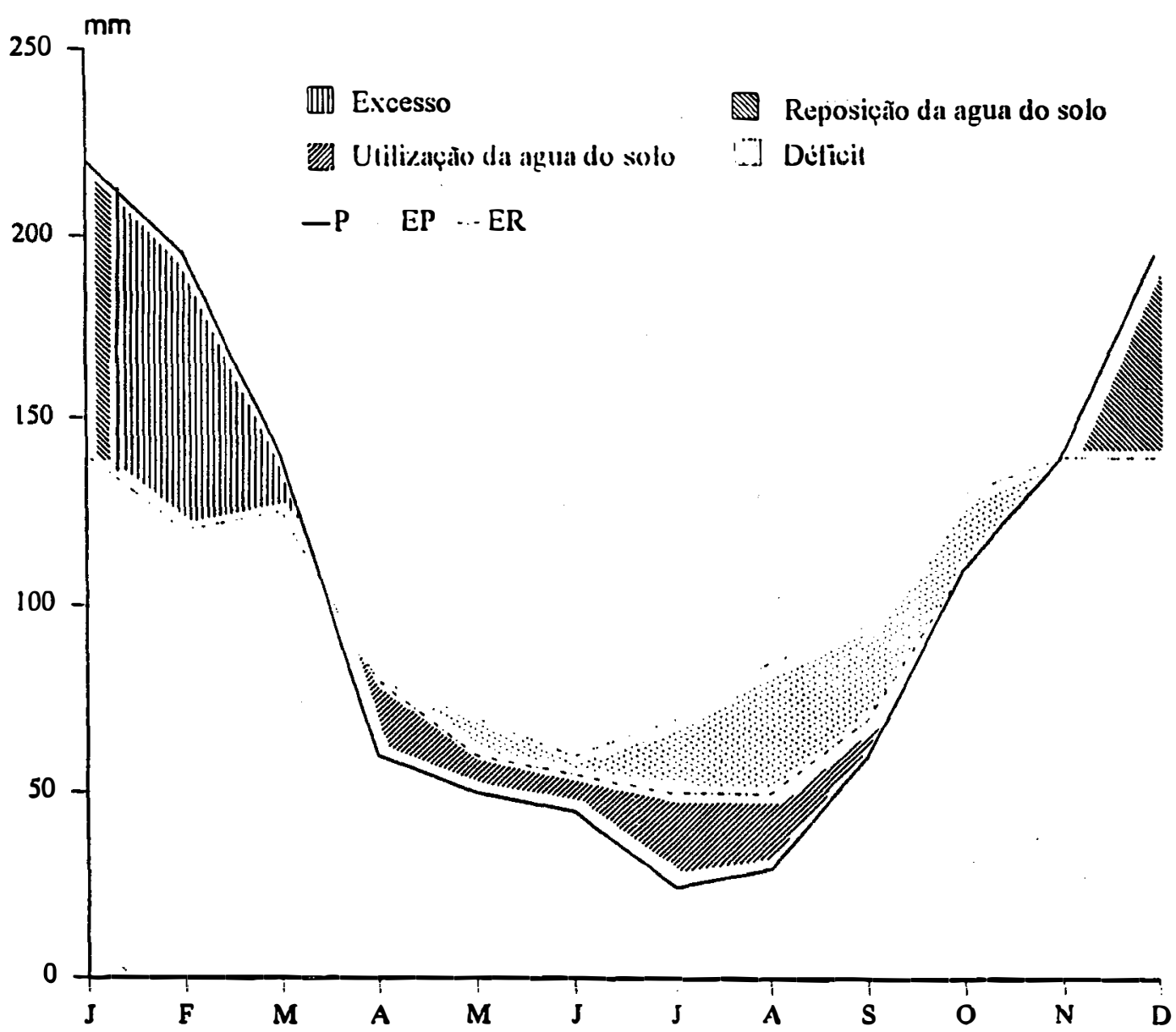

Figura 9 - Balanço hídrico da região de Piracicaba segundo Thornthwaite.

Atualmente, a presença da cana-de-açúcar, áreas de pastagem e culturas anuais é que dominam as características de cobertura e uso dessas terras. Teramoto (1995), em estudo realizado na bacia do Ribeirão dos Marins, comenta que a cana-deaçúcar é cultivada nas áreas de menor declividade, enquanto que as encostas mais íngremes são ocupadas com pastagem. Pequenas áreas de eucalipto são encontradas nas partes mais elevadas e em alguns fundos de vales, ao passo que a vegetação original quase inexiste, encontrando-se apenas alguns remanescentes em algumas grotas e nas margens do ribeirão dos Marins. Em estudo mais recente, realizado nesta mesma área, Ranieri et al. (1998) relatam que o uso dessas terras representa boa parte da produção hortícola do município de Piracicaba, além da grande pressão de ocupação com cana-deaçúcar por causa da proximidade de usinas canavieiras. 


\subsubsection{Solos}

De acordo com o mapa de solos do levantamento pedológico semidetalhado do Estado de São Paulo (Figura 10), os solos ocorrentes na área de estudo são os seguintes: Podzólico Vermelho-Amarelo, Solos Litólicos, Latossolo Roxo, Latossolo Vermelho-Escuro, Latossolo Vermelho-Amarelo, Brunizém Avermelhado, Podzólico Vermelho-Escuro, Terra Roxa Estruturada, Podzol, solos Gleizados, Areia Quartzosa, Cambissolo e Solo Aluvial.

Apesar da grande quantidade de solos ocorrentes, grupamentos e associações de Podzólico Vermelho-Amarelo e Solos Litólicos predominam em toda a extensão da área, enquanto os demais ocorrem em pequenas extensões e quase sempre acompanhando a linha dos divisores de água e beirando as margens do Rio Piracicaba. Por outro lado, as bacias selecionadas para estudo são representativas de solos Podzólicos e Litólicos, com inclusões de parte dos demais solos ocorrentes na área. Por isto, será apresentada uma descrição apenas para estes solos.

A descrição que se apresenta a seguir baseia-se na classificação geral de solos de Oliveira et al. (1992), complementada com a descrição apresentada no mapa de solos (Governo do Estado de São Paulo, 1989).

\section{- Podzólico Vermelho-Amarelo}

Segundo Oliveira et al. (1992), esta classe compreende solos minerais não hidromórficos, com horizontes $A$ ou $E$ seguidos de horizonte $B$ textural não plíntico, argila de atividade alta ou baixa, cores vermelhas a amarelas e teores de $\mathrm{Fe}_{2} \mathrm{O}_{3}<11 \%$, onde os solos mais típicos da classe apresentam distinta individualização de horizontes.

Dentre suas características principais, os Podzólicos Vermelho-Amarelos apresentam grande variação em características morfológicas e analíticas, porém com a presença distintiva do horizonte $B$ textural que diverge do $A$ ou $E$, seja pela cor (vermelha até amarela), seja pela estrutura em blocos ou pela textura argilosa ou muito 


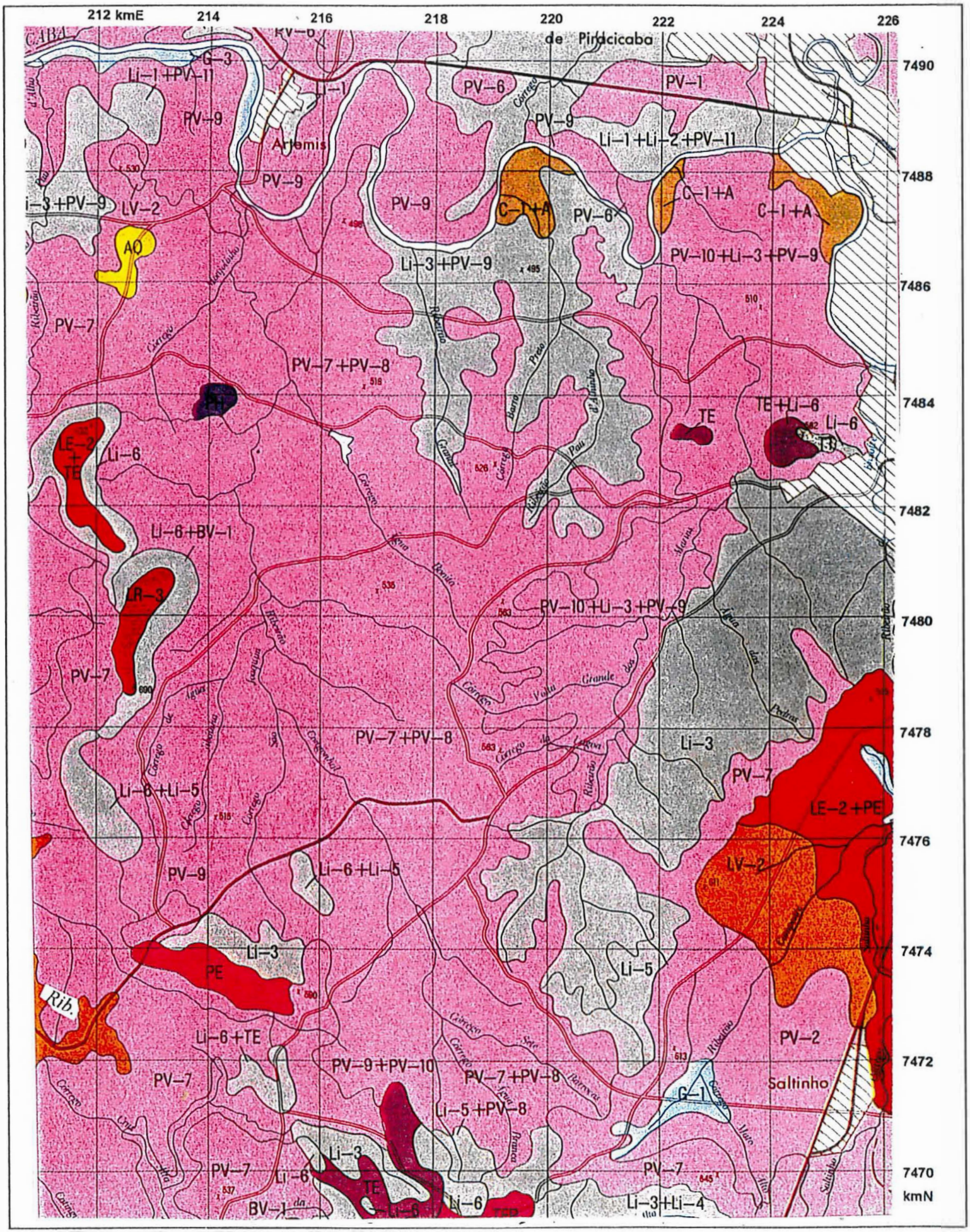

Figura 10 - Mapa de solos da área de estudo (Governo do Estado de São Paulo, 1989). 
argilosa. $\mathbf{O}$ desenvolvimento da estrutura deste horizonte está estreitamente relacionado à textura, de forma que estrutura forte do tipo prismática ou em bloco é comum nos de textura argilosa a muito argilosa, porém rara nos de textura média. Do ponto de vista analítico, podem ser tanto eutróficos como distróficos ou álicos, havendo ainda raros registros de ácricos

O horizonte $A$ mais freqüente é o moderado, ocorrendo, contudo outros tipos, exceto o turfoso.

As possibilidades de combinações, considerando-se as características morfológicas e analíticas, são grandes, permitindo ampla diversificação de modalidade de solos pertencentes a essa classe.

Devido a sua grande diversidade de atributos de interesse agronômico (profundidade, textura, eutrofismo, distrofismo, etc.), torna-se dificil a generalização de suas qualidades para a classe como um todo.

Têm as mais variadas profundidades e texturas, inclusive com presença ou não de cascalhos e calhaus. De maneira geral, essa classe ocorre em relevo ondulado ou mais acidentado, sendo que a ocorrência de pedregosidade e textura cascalhenta geralmente se dá em condições de relevo acidentado, onde os solos são mais susceptíveis à erosão. Nos abruptos, a maior susceptibilidade à erosão impõe limitações que podem ser tanto mais sérias quanto maior a declividade dos terrenos e ainda acrescidas da toxicidade pelo alumínio nos solos que, além de abruptos, são álicos.

Os Podzólicos Vermelho-Amarelos constituem, a par dos Latossolos Vermelho-Amarelos, a classe de solos mais comum no Brasil. A sua ocorrência se manifesta em todos os quadrantes brasileiros, desde o Rio Grande do Sul até o Amapá e do Acre até Pernambuco (EMBRAPA, 1981).

Os usos mais adequados são reflorestamento, pastagem ou culturas permanentes, que serão tanto mais favorecidos quanto maior o estado de fertilidade dos solos. Em regiões serranas de São Paulo e Minas Gerais, encontram-se excelentes plantações de café nesses solos. 
Oliveira et al. (1992) enfatizam que, em nível local, podem-se encontrar Podzólicos Vermelho-Amarelos de vários tipos, inclusive em apreciáveis diferenças morfológicas e analíticas. Ainda segundo o autor, isto se verifica no levantamento semidetalhado de solos da folha de Piracicaba.

Sua ocorrência na área de estudo é a seguinte (Oliveira et al., 1989):

PV-7 Grupamento indiscriminado de PODZÓLICOS VERMELHO-AMARELOS abruptos, A moderado e espesso, textura arenosa/media. Unidade Serrinha. (Arenic Abruptic Paleudalf e Arenic Abruptic Paleudult);

PV-8 Gupamento indiscriminado de PODZÓLICOS VERMELHO- AMARELOS abruptos, $A$ moderado e espesso, textura arenosa/media, pouco profundos. Unidade Serrinha fase pouco profunda. (Arenic Abruptic Paleudalf e Arenic Abruptic Paleudult);

PV-9 Gupamento indiscriminado de PODZÓLICOS VERMELHO-AMARELOS Tb abruptos, A moderado e espesso, textura arenosa/argilosa ou média/argilosa. Unidade Santa Cruz. (Abruptic Paleudalf, Abruptic Arenic Paleudalf, Abruptic Paleudult, Abruptic Arenic Paleudult);

PV-10 Grupamento indiscriminado de PODZÓLICOS VERMELHO-AMARELOS EUTRÓFICOS, A moderado, textura média/argilosa pouco profundos. Unidade Manduca. ( Abruptic Paleudalf e Typic Paleudalf).

\section{- Solos Litólicos}

Segundo Oliveira et al. (1992), são solos minerais não hidromórficos, rudimentares, pouco evoluídos, rasos ( $<50 \mathrm{~cm}$ até o substrato rochoso), com horizonte A assente diretamente sobre a rocha coerente e dura, ou cascalheira espessa, ou horizonte $\mathrm{C}$ pouco espesso ou mesmo exíguo $\mathrm{Bi}$. Usualmente contêm elevados teores em minerais primários pouco resistentes ao intemperismo e variavelmente blocos de rocha semi-intemperizada de diversos tamanhos. 
Como principais características, esses solos apresentam grande diversificação morfológica, sendo também bastante heterogêneos no que concerne aos atributos químicos, físicos e mineralógicos. Porém, a sua característica comum é a profundidade, arbitrada por muitos pedólogos em menos de $50 \mathrm{~cm}$.

A atividade da argila pode ser alta ou baixa, dependendo do material de origem, com quem tem estreita relação. Podem ainda ser eutróficos, distróficos ou álicos, com suas mais variadas texturas.

O horizonte $A$ pode variar bastante como o fraco, o moderado, 0 proeminente, o chernozêmico (exceto sobre material calcífero), ou o húmico. $\mathrm{O}$ horizonte B, quando existente, pode apresentar estádios bem variados de desenvolvimento, porém em seção de reduzida espessura, caracterizando-a como B incipiente (Bi).

Do ponto de vista agronômico, apresentam sérias limitações, mesmo que permitam que as raízes das plantas penetrem através das fendas e entre os fragmentos do substrato rochoso, indo buscar nutrientes e água a maiores profundidades do que a encontrada no solo propriamente dito.

Mesmo podendo apresentar boa disponibilidade em nutrientes para as plantas, são mais indicados para reservas naturais, reflorestamento e pastagem, com restrição das condições de umidade da região onde se encontram. Assim, na região semiárida, a falta de água impõe limitações bastante críticas para o seu uso, enquanto em outras regiões como São Paulo e Minas Gerais, constatam-se culturas de café e milho ou milho, feijão e soja nas áreas de colônias em Santa Catarina e pastagens no Rio Grande do Sul.

Sem distribuição regionalizada, sua ocorrência se dá em todo o território brasileiro, geralmente associados aos planaltos basálticos intensamente dissecados do Paraná, Santa Catarina e Rio Grande do Sul e às áreas acidentadas relacionadas principalmente com granitos, gnaisses, migmatitos, quartzitos, arenitos, xistos, filitos e ardósia (Oliveira et. al. 1992). Porém, em maior expressão geográfica, estão as áreas 
situadas nos planaltos sulinos e na região de Campanha, do Rio Grande do Sul, as do Centro-Sul do Pará, e as da zona das caatingas, do Nordeste e da chapada da Diamantina, na Bahia (EMBRAPA, 1981).

Sua ocorrência na área de estudo é a seguinte (Oliveira et al., 1989):

Li-3 SOLO LITÓLICO EUTRÓFICO OU DISTRÓFICO, A moderado, proeminente ou chernozêmico, substrato sedimentos indiscriminados do Grupo Passa Dois (Typic Udorthent);

Li-5 SOLO LITÓLICO EUTRÓFICO, A moderado ou chernozêmico, substrato arenitos das Formações Botucatu ou Pirambóia. (Typic Udorthent e Lithic Hapludoll);

Li-6 SOLO LITÓLICO EUTRÓFICO, A moderado ou chernozêmico, substrato basalto ou diabásio. (Typic Udorthent e Lithic Hapludoll).

\subsubsection{Material cartográfico}

Na execução deste trabalho foi utilizado o seguinte material cartográfico:

- Cartas planialtimétricas do IBGE, Superintendência de Cartografia, na escala 1:50.000:

\begin{tabular}{lll}
\hline FOLHA & NOMENCLATURA & ANO \\
\hline Piracicaba (SP) & (SF-23-Y-A-IV-2) & 1969 \\
Capivari (SP) & (SF-23-Y-A-IV-4) & 1969 \\
Ibitiruna (SP) & (SF-23-Y-A-IV-3) & 1969 \\
São Pedro (SP) & (SF-23-Y-A-IV-1) & 1969
\end{tabular}

- Cartas planialtimétricas do Plano Cartográfico do Estado de São Paulo, Governo do Estado de São Paulo, Secretaria de Economia e Planejamento, Coordenadoria de Ação Regional, Divisão de Geografia, $1^{\text {a }}$ edição, na escala 1:10.000: 


\begin{tabular}{lll}
\hline FOLHA & NOMENCLATURA & ANO \\
\hline Ribeirão Voçoroca & (SF-23-Y-A-IV-1-SE-C) & 1979 \\
Artemis & (SF-23-Y-A-IV-1-SE-D) & 1979 \\
Sta. Terezinha do Piracicaba & (SF-23-Y-A-IV-2-SO-C) & 1979 \\
Piracicaba V & (SF-23-Y-A-IV-2-SO-D) & 1979 \\
Ribeirão Paredão Vermelho & (SF-23-Y-A-IV-1-SE-E) & 1979 \\
Bairro Pau D'alho & (SF-23-Y-A-IV-1-SE-F) & 1979 \\
Bairro dos Marins & (SF-23-Y-A-IV-2-SO-E) & 1979 \\
Piracicaba III & (SF-23-Y-A-IV-2-SO-F) & 1979 \\
Córrego Mandacaru & (SF-23-Y-A-IV-3-NE-A) & 1978 \\
Fazenda Serra Bonita & (SF-23-Y-A-IV-3-NE-B) & 1978 \\
Bairro Volta Grande & (SF-23-Y-A-IV-4-NO-A) & 1978 \\
Piracicaba II & (SF-23-Y-A-IV-4-NO-B) & 1978 \\
Fazenda Jibóia & (SF-23-Y-A-IV-3-NE-C) & 1978 \\
Bairro Monte Branco & (SF-23-Y-A-IV-3-NE-D) & 1978 \\
Sete Barrocas & (SF-23-Y-A-IV-4-NO-C) & 1978 \\
Fazenda Pinheiros & (SF-23-Y-A-IV-4-NO-D) & 1978
\end{tabular}

- Mapa de solos do Levantamento Pedológico Semidetalhado do Estado de São Paulo, Quadrícula de Piracicaba (SF-23-Y-A-IV), Governo do Estado de São Paulo, na escala 1:100.000, edição de 1989;

- Mapa Geológico da folha de Piracicaba (SF 23 - M 300), Governo do Estado de São Paulo, na escala 1:100.000, edição de 1966.

\subsubsection{Fotografias aéreas}

Foram utilizadas fotografias aéreas verticais pancromáticas, provenientes da cobertura aerofotogramétrica do município de Piracicaba-SP, de junho de 1995, executada pela empresa BASE S.A., para o Serviço Municipal de Águas e Esgoto de 
Piracicaba (SEMAE). As fotografias foram obtidas no acervo da Prefeitura do Campus Luiz de Queiroz da USP, em Piracicaba, e apresentam as seguintes características:

a) escala aproximada: 1:25.000;

b) dimensões: $23 \mathrm{~cm} \times 23 \mathrm{~cm}$;

e) área coberta por fotografia: cerca de $33 \mathrm{~km}^{2}$;

f) recobrimento: $60 \%$ entre fotografias na faixa de vôo e $30 \%$ entre fotografias de faixas adjacentes.

\subsubsection{Equipamentos e materiais utilizados na interpretação visual}

a) estereoscópio de espelhos da marca Wild, modelo-ST-4, para obtenção da visão estereoscópica;

b) folhas transparentes de poliester estável ("ultraphan") para decalcar as informações desejadas;

c) instrumentos simples de medição e desenho: escalímetro, curvímetro, planínetro, compasso e régua.

3.1.5 Equipamentos e sistemas computacionais utilizados no processamento e análise dos dados digitas

a) Hardware

- PC 486 DX4, $32 \mathrm{Mb}, 100 \mathrm{Mhz}, 64 \mathrm{Mb}$ de RAM e PENTIUM II MMX, $400 \mathrm{Mhz}, 64$ Mb de RAM, com monitor 17" Super VGA e impressora jato de tinta colorida;

- SCANNER HP 4c de mesa para aquisição das imagens no formato digital.

b) Software

- Editor gráfico Aldus PHOTOSTYLER versão 2.0; 
- IDRISI for Windows versão 2.0 (Clark University, 1997);

- SAS - Statistical Analysis System.

O PHOTOSTYLER foi utilizado para aquisição das fotografias no formato digital, através do SCANNER, bem como para realizar transformações das imagens nos espaços de cores RGB e CYMK, para composição no IDRISI.

O IDRISI é um Sistema de Informação Geográfica e Processamento de Imagens originalmente do tipo "raster". Não se trata, no entanto, de um único programa, mas de um conjunto de mais de 100 módulos de programas que podem ser integrados por meio de um sistema de menu unificado (Eastman, 1992). Esses pequenos módulos são organizados em três grandes grupos: 1) Módulos centrais (núcleo) - composto de utilitários básicos para entrada, armazenamento e gerenciamento de dados e visualização de imagens "raster"; 2) Módulos analíticos - constituem os maiores grupos de ferramentas para a análise de dados de imagem "raster", que são: "Módulos de análise Geográfica", "Módulos de Análise Estatística" e "Módulos de Processamento de imagem"; 3) Módulos Periféricos - estão associados com utilitários de conversão de dados entre o IDRISI e outros programas e formatos para armazenamento de dados.

Câmara \& Ortiz (1998), verificaram a funcionalidade em "Processamento Digital de Imagens" e "Análise Geográfica" para diversos sistemas disponíveis, selecionando aqueles que atendem os requisitos de aplicações ambientais e cadastrais, com base em catálogos dos fabricantes, demonstrações, informações de usuários e artigos em revistas.

No caso de Processamento Digital de Imagens, os autores verificaram as funções mais importantes e apresentaram uma tabela descritiva, onde o IDRISI figura em posição de igual disponibilidade em relação a outros Softwares incluídos na pesquisa, como ENVI, EASI PACE, ERDAS, ER mapp, MGE e SPRING, nas seguintes funções: realce, mosaico de imagens, filtragem espacial, conversão matriz-vetor, componentes principais, análise de Fourier e classificação por "pixel". Neste 
aspecto, os Softwares ARC VIEW, ARC INFO e MAP INFO, também verificados, mostraram-se inadequados ao processamento digital de imagens.

\subsection{Métodos}

\subsubsection{Escolha da área de estudo}

Vários fatores foram levados em consideração no momento de se escolher a área de estudo, a começar pelo recobrimento aerofotogramétrico. Além disto, foram verificadas outras condições básicas, como a existência de mapas de solo em nível semidetalhado e informações complementares a respeito da geologia, geomorfologia, clima e vegetação natural da região. Este conjunto de informações, conforme mencionam Vettorazzi (1988) e Pfeifer (1995), proporciona segurança e minimiza o trabalho de correlação entre o produto da interpretação das imagens e a verdade terrestre.

A ocorrência de várias unidades de solo também é um aspecto importante na escolha da área de estudo, principalmente quando se trata de caracterizar a rede de drenagem ou unidades fisiográficas, para mapeamento de solos. Como no presente estudo o objetivo foi utilizar o processamento digital de fotografias aéreas para auxiliar na determinação e análise da rede de drenagem, a composição e extensão desta foram consideradas como aspectos importantes para a escolha da área de estudo, não deixando, no entanto, de abranger diferentes tipos de solos.

Foi com base nesses critérios e considerando ainda o aspecto da proximidade que se fez a escolha da área de estudo, conforme destaque na Figura 6. Considerando a sua forma retangular, a superficie total da área é de aproximadamente $290 \mathrm{~km}^{2}$, estendendo-se a oeste da cidade e margem esquerda do rio Piracicaba.

De acordo com o mapa de solos (Figura 10), existem várias unidades de mapeamento distribuídas em toda a área, com predominância de grupamentos de solos podzólicos e solos litólicos. Porém, considerando apenas as bacias selecionadas, 
distribuídas nas quatro bacias maiores que formam a área de estudo com cerca de $173 \mathrm{~km}^{2}$, além dos grupamentos de solos podzólicos e litólicos, ocorrem apenas algumas inclusões de Podzólico Vermelho-Escuro e Latossolo Vermelho-Escuro.

Segundo Ranzani (1976) a rede de drenagem do Município de Piracicaba é bastante integrada e densa.

\subsubsection{Escolha das fotografias aéreas}

As fotografias aéreas que recobrem a área de estudo foram separadas com o auxílio do fotoíndice da região, na escala aproximada de 1:100.000, seguindo o método da "pesquisa lógica" sugerido por Raben (1960). Assim, as fotografias foram examinadas tomando como referência a carta de solos disponível, separando-se aquelas que deveriam conter as informações desejadas, resultando na seguinte seleção:

\begin{tabular}{lcccc}
\hline Faixa (número) & 12 & 13 & 14 & 15 \\
Fotografia (seqüência) & 06 a 16 & 12 a 21 & 11 a 21 & 10 a 21 \\
\hline
\end{tabular}

\subsubsection{Interpretação visual}

\subsubsection{Elaboração do mapa básico de drenagem}

Para facilitar a fotointerpretação, as fotografias foram inicialmente preparadas, marcando-se seus pontos principais e transferindo-os entre fotografias adjacentes com o auxílio do estereoscópio, para então se determinar a linha de vôo pela união desses pontos. Em seguida, utilizando o método dos pares alternados, foram feitas as amarrações em papel transparente e delimitada a área útil de cada fotografia, conforme descrito por Raben (1960). 
A transferência das informações desejadas em papel transparente foi realizada com o auxílio da visão estereoscópica. Em primeiro lugar, foram decalcados todos os canais de drenagem bem definidos, quer fossem cursos d'água permanentes ou temporários, conforme sugerem Strahler (1957), Lueder (1959) e Ray (1963), e as depressões úmidas, indicadoras do grau de integração segundo Lueder (1959). Em seguida, foram delimitadas todas as bacias de $3^{\text {a }}$ ordem, traçando-se os seus divisores de água sobre o mapa da rede de drenagem, e atribuindo os números de ordem de rios de acordo com o sistema de Horton (1945), modificado por Strahler (1957).

A ordem de ramificação adotada ( $3^{a}$ ordem) seguiu observação de Parvis (1950), onde argumenta que muitos cursos d'água têm suas nascentes em substratos rochosos cobertos com solos ou mantos espessos, de forma que os padrões de rios de ordens inferiores é que fornecem indícios para identificação desses solos ou substratos por fotointerpretação, à medida que os rios de ordens mais elevadas mostram a influência de controle estrutural.

Os limites de unidades de solo foram transferidos para o mapa básico com o auxílio do mapa de solos do levantamento semidetalhado do Estado de São Paulo, Folha de Piracicaba (Governo do Estado de São Paulo, 1989), observando-se o seu nível de detalhamento e a diferença de escala, para proceder os ajustes necessários às unidades de mapeamento. Nesta etapa, recorreu-se também ao auxilio da fotointerpretação.

Para obter o mapa final, fez-se a montagem dos "templetos" individuais, utilizando-se alguns pontos previamente definidos nas margens das fotografias como pontos de ajuste, além dos pontos principais transferidos que foram usados como pontos de amarração no sentido das faixas. Em seguida, foi feita a transferência de todo o traçado para um papel transparente definitivo, cobrindo toda a área de estudo.

\subsubsection{Determinação das características dimensionais das bacias}

Após a delimitação de todas as bacias de terceira ordem, foram determinados os seguintes parâmetros dimensionais: 
- Maior comprimento (C): medido com curvímetro, é a distância que acompanha aproximadamente o vale principal, entre a foz e o ponto extremo sobre a linha do divisor de água;

- Maior largura (L): medida com escala, é a distância correspondente à maior largura que corta transversalmente ao vale principal;

- Comprimento do curso principal (Cp): medido com curvímetro, corresponde ao percurso do rio principal, da foz até a nascente, acompanhando a sua sinuosidade;

- Comprimento total da rede (Cr): medido com curvímetro, corresponde aos comprimentos do rio principal e seus tributários;

- Perímetro (P): medido com curvímetro, sendo representado pela linha do divisor de águas que circunda a bacia;

- Área: medida com planímetro, compreende a região circunscrita pelo divisor de águas.

\subsubsection{Seleção das bacias}

Inicialmente, as bacias foram organizadas em grupos mais ou menos homogêneos quanto à conformação e dimensões de área e perímetro. Ao mesmo tempo, foi observado também o aspecto da representatividade das bacia, com a finalidade de reunir grupos representativos para os dois tipos de solos predominantes da área. Desta seleção prévia resultaram dois conjuntos de bacias: um para solos litólicos e outro para solos podzólicos.

Numa segunda seleção, foram descartadas aquelas bacias que apresentavam características menos semelhantes dentro de seus respectivos grupos. $\mathrm{O}$ critério desta seleção foi baseado no método de semelhança geométrica proposto por Strahler (1957) e modificado posteriormente por França (1968), que permite comparar as bacias através de parâmetros dimensionais, para poder agrupá-las quanto as suas características geométricas e funcionais. 
Em trabalhos deste tipo, em média são selecionadas 3 bacias como amostras representativas de cada solo a ser estudado. Para o propósito deste trabalho, entretanto, decidiu-se utilizar um número maior de amostras para cada solo, visto que este aspecto seria relevante para a análise estatística. Portanto, em função do número de bacias de terceira ordem existentes em cada conjunto, a seleção resultou em 3 grupos para os solos litólicos, com três bacias cada, e 6 grupos para os podzólicos, sendo, neste caso, 3 grupos de três bacias e 3 de duas.

\subsubsection{Teste de semelhança geométrica}

O teste de semelhança geométrica foi aplicado para cada grupo de bacias selecionadas, tendo como objetivo dar maior segurança às comparações feitas $\mathrm{e}$ maior consistência aos resultados.

Empregou-se a "Razão de Equivalência" (Re), proposta por Manechini (1981) e também usada por Vettorazzi (1985), para testar a semelhança geométrica entre as bacias, comparadas duas a duas. A semelhança entre as bacias de um par comparado é tanto maior, quanto mais próximo da unidade estiver o valor de $\mathbf{R e}$.

As relações empregadas ente as bacias comparadas foram as seguintes:

$\frac{\text { Maior comprimento da bacia a }}{\text { Maior comprimento da bacia } b}=\frac{C}{C^{\prime}}$

$\frac{\text { Maior largura da bacia a }}{\text { Maior largura da bacia } \mathbf{b}}=\frac{\mathrm{L}}{\mathrm{L}^{\prime}}$

$\frac{\text { Perímetro da bacia a }}{\text { Perímetro da bacia } \mathbf{b}}=\frac{\mathrm{P}}{\mathrm{P}^{\prime}}$


$\frac{\text { Comprimento do rio principal da bacia a }}{\text { Comprimento do rio principal da bacia } \mathbf{b}}=\frac{\mathrm{Cp}}{\mathrm{Cp}^{\prime}}$

$\frac{\text { Comprimento total da rede da bacia a }}{\text { Comprimento total da rede da bacia } \mathbf{b}}=\frac{\mathrm{Cr}}{\mathrm{Cr}^{\prime}}$

$\frac{\text { Área da bacia } \mathbf{a}}{\text { Área da bacia } \mathbf{b}}=\frac{\mathrm{A}}{\mathrm{A}^{\prime}}$

$[(1)+(2)+(3)+(4)+(5)] /(5)=\mathrm{Rm} \quad$ ( razão média)

$\operatorname{Re}=(\mathrm{Rm})^{2} /(6)$

\subsubsection{Análise da rede de drenagem}

A análise aqui realizada seguiu a sistemática de Buringh (1960), do tipo analítica, ou análise de elementos. De acordo com sua natureza, os elementos foram agrupados da seguinte forma: quanto à composição das redes de drenagem e quanto às características do padrão de drenagem, conforme metodologia empregada por França (1968).

Com relação à composição da rede de drenagem, foram analisados os seguinte elementos:

- Ordem de ramificação (w): os seguimentos de rios ou canais de drenagem foram classificados, segundo o sistema de Horton (1945), ligeiramente modificado por Strahler (1957);

- Número de segmento de rios: representados pelo número de segmentos de rios em cada ordem de ramificação $(\mathrm{Nw})$ e pelo número total para cada bacia $(\mathrm{N})$, sendo obtidos através da contagem de canais; 
- Comprimentos de rios: designados por $\mathrm{Lw}$ e $\mathrm{Lt}$, representam os comprimentos dos segmentos de rios de cada ordem e o comprimento total de segmentos de rios, respectivamente, medidos em todas as bacias;

- Comprimentos médios de segmentos de rios: representados por Lm, foram calculados pela relação entre o comprimento de rios de cada ordem $(\mathrm{Lw})$ e o número de segmentos de rios da respectiva ordem. Portanto, $\mathrm{Lm}=\mathrm{Lw} / \mathrm{Nw}$.

Com relação às características do padrão de drenagem, a análise foi aplicada apenas sobre as características quantitativas, por serem mais úteis ao propósito deste trabalho, diante das comparações a serem estabelecidas para avaliação da metodologia utilizada.

Essas características referem-se a índices quantitativos do padrão de drenagem (densidade de drenagem e freqüência de rios) que, segundo Horton (1945), possibilitam a inferência sobre diversas condições do terreno, não apresentando a subjetividade das características descritivas. Além destes índices, foram determinadas a razão de textura, a razão de textura média e a classe de textura topográfica, segundo proposição de Smith (1950) modificada por França (1968), para aplicação em fotografias aéreas.

- Densidade de drenagem (Dd): calculada, segundo Horton (1945), com adaptação de Ray e Fisher (1960), pela relação entre comprimento total de rios da bacia (Lt) dado em $\mathrm{km}$, e respectiva área $\mathrm{em} \mathrm{km}^{2}$, ou seja, $\mathrm{Dd}=(\mathrm{Lt} / \mathrm{A})$.

- Frequiência de rios (Fr): corresponde à relação entre o número total de rios da bacia (N) e respectiva área (A), segundo Horton (1945), modificada por Strahler (1957). Assim, $\mathrm{Fr}=(\mathrm{N} / \mathrm{A})$.

- Razão de Textura (T): representa a relação entre o número total de segmentos de rios da bacia $(\mathrm{N})$ e respectivo perímetro $(\mathrm{P})$. Portanto, $\mathrm{T}=(\mathrm{N} / \mathrm{P})$.

- Razão de textura média (Tm): corresponde à média ponderada da razão de textura, sendo calculada pela expressão $\mathrm{Tm}=\Sigma(\mathrm{A} . \mathrm{T}) / \Sigma$. 
- Classe de textura topográfica: classificação feita com base na razão de textura média, conforme proposição de Smith (1950), adaptada por França (1968). Os parâmetros usados para esta classificação estão na Tabela1.

Tabela 1. Parâmetros para classificação da textura topográfica com base nos valores de razão de textura média (França, 1968).

\begin{tabular}{cc}
\hline $\begin{array}{c}\text { Classes de textura } \\
\text { topográfica }\end{array}$ & $\begin{array}{c}\text { Razão de textura média } \\
\text { (perímetro expresso em } \mathrm{km} \text { ) }\end{array}$ \\
\hline Grosseira & abaixo de 2,5 \\
Média & 2,5 a 6,2 \\
Fina & acima de 6,2 \\
\hline
\end{tabular}

\subsubsection{Processamento digital das fotografias}

O processamento digital é aqui entendido como o conjunto de operações realizadas no sistema de processamento de imagens, com a finalidade de prepará-las para a digitalização em tela e quantificar os elementos estudados na rede de drenagem.

\subsubsection{Aquisição dos dados digitais}

Para se dispor das fotografias aéreas no formato digital, as mesmas foram digitalizadas através de um "scanner" de mesa, utilizando-se o editor gráfico PHOTOSTYLER. Após a aquisição e processamento inicial, as imagens foram exportadas para o IDRISI, onde foi realizado o restante das operações.

Da mesma forma que na análise estereoscópica, utilizaram-se fotografias alternadas. Neste caso, porém, foram utilizadas apenas as fotografias que compõem a área onde se localizam as bacias selecionadas. 


\subsubsection{Operações de realce}

De maneira geral, as técnicas de realce podem ser reunidas em três conjuntos de operações, quais sejam: manipulação de contrastes, filtragem digital e realce espectral. Com base neste conjunto de operações, vários testes foram realizados através do sistema de processamento de imagens do IDRISI, como tentativas para se obter um produto de processamento digital, onde a rede de drenagem fosse realçada para facilitar a sua interpretação e digitalização em tela.

Com relação à manipulação de contrastes, foram utilizadas as funções de ampliação linear de contraste e equalização de histograma. São transformações que dependem apenas dos níveis de cinza dos "pixels", onde a primeira é do tipo linear e a segunda não linear.

Para filtragem digital, foram empregadas técnicas que operam sobre o domínio espacial da imagem, através do processo conhecido como convolução. São as técnicas mais simples e mais utilizadas na maioria dos sistemas de processamento de imagens (Crosta, 1992). Os filtros testados foram do tipo passa-alta não direcional para realce de bordas, utilizando matriz $3 \times 3$ (máscara), com base nos exemplos de Walsh et al. (1990), que trabalharam com dados do sensor TM/LANDSAT, para evidenciar a hidrografia da área estudada e extrair características da paisagem, como tamanho, forma, localização e orientação de rios, lagos e geleiras.

\begin{tabular}{rrrrrr}
\hline \multicolumn{3}{c}{ Filtro passa-alta } & \multicolumn{3}{c}{ Filtro Laplaciano } \\
\hline & (Walsh et al., 1990) \\
-1 & -2 & 1 & 0 & -1 & 0 \\
-2 & 5 & -2 & -1 & 5 & -1 \\
1 & -2 & 1 & 0 & -1 & 0
\end{tabular}

Como o realce espectral está relacionado com imagens multiespectrais de uma mesma cena, para usá-lo em imagens de uma só banda, como é o caso da fotografia 
pancromática, foi necessário a transformação prévia para o espaço colorido RGB, gerando as três bandas equivalentes: vermelho, verde e azul. Esta operação foi realizada no editor gráfico PHOTOSTYLER.

A partir desta operação, foram realizadas transformações HLS (hue, lightness, saturation) e CYMK (cyan, yellow, magenta, preto), para testar combinações de composição colorida, através do módulo COMPOSIT do IDRISI. A transformação HLS é uma opção do próprio sistema de processamento de imagens do IDRISI (equivalente à transformação IHS). Já a transformação CYMK foi realizada no editor gráfico PHOTOSTYLER, após a transformação para o espaço RGB. Neste caso, foram escolhidas as banda $\mathrm{K}, \mathrm{M}$ e $\mathrm{C}$, para realizar as combinações na composição colorida.

A Figura 11 mostra exemplos destes testes, em contraste com a imagem normal, sem nenhum tratamento digital.

\subsubsection{Georreferenciamento e correção geométrica das imagens}

Devido às distorções geradas por alterações dinâmicas (atitude, altitude $\mathrm{e}$ velocidade) sofridas pelos sistemas de imageamento, as imagens de sensoriamento remoto não se ajustam diretamente a um sistema de gradeamento cartográfico. Portanto, dependendo da precisão requerida para aplicação em mapeamentos e/ou da necessidade de junção de imagens para representar uma cena completa (mosaico), essas distorções precisam ser corrigidas e um sistema de projeção cartográfica de referência precisa ser estabelecido.

Com o georreferenciamento, a localização da imagem e certos atributos no espaço é definida por um sistema de coordenadas de referência conhecido, segundo um sistema de projeção que, no caso presente, é o Sistema Universal Transverso de Mercator (UTM).

Segundo Oliveira (1988), na projeção UTM não existe deformações de ângulos e, em decorrência disto, não deforma áreas por menores que sejam, de maneira 
a)
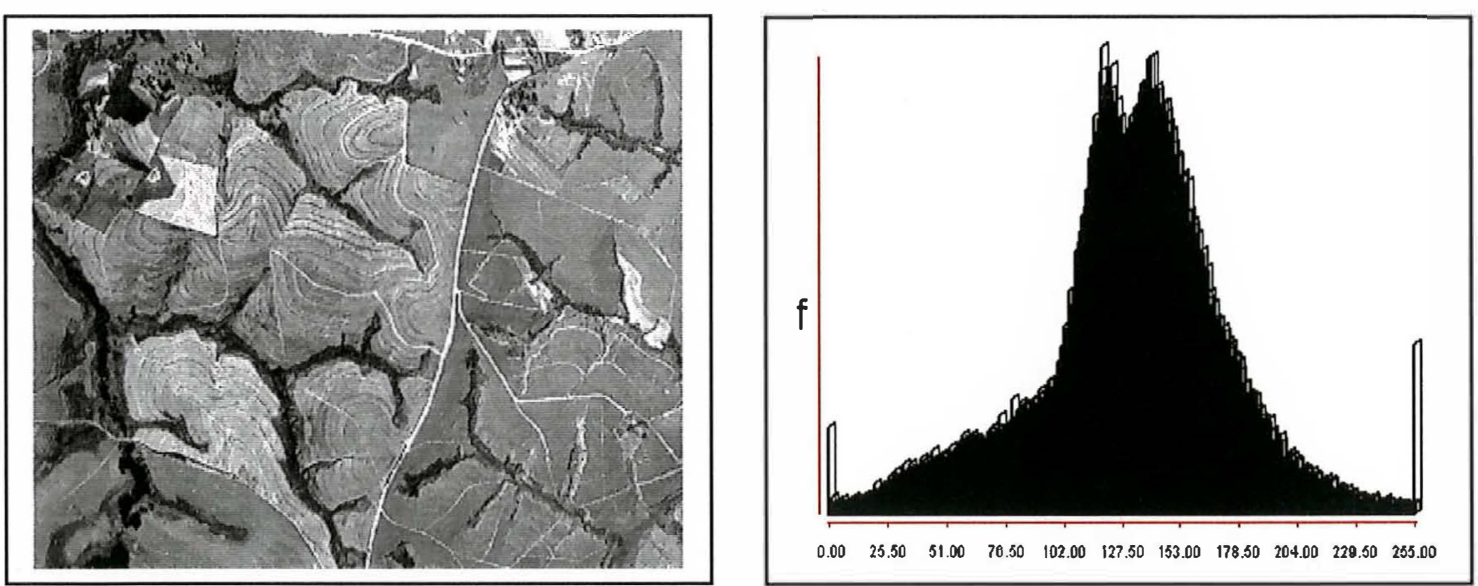

b)
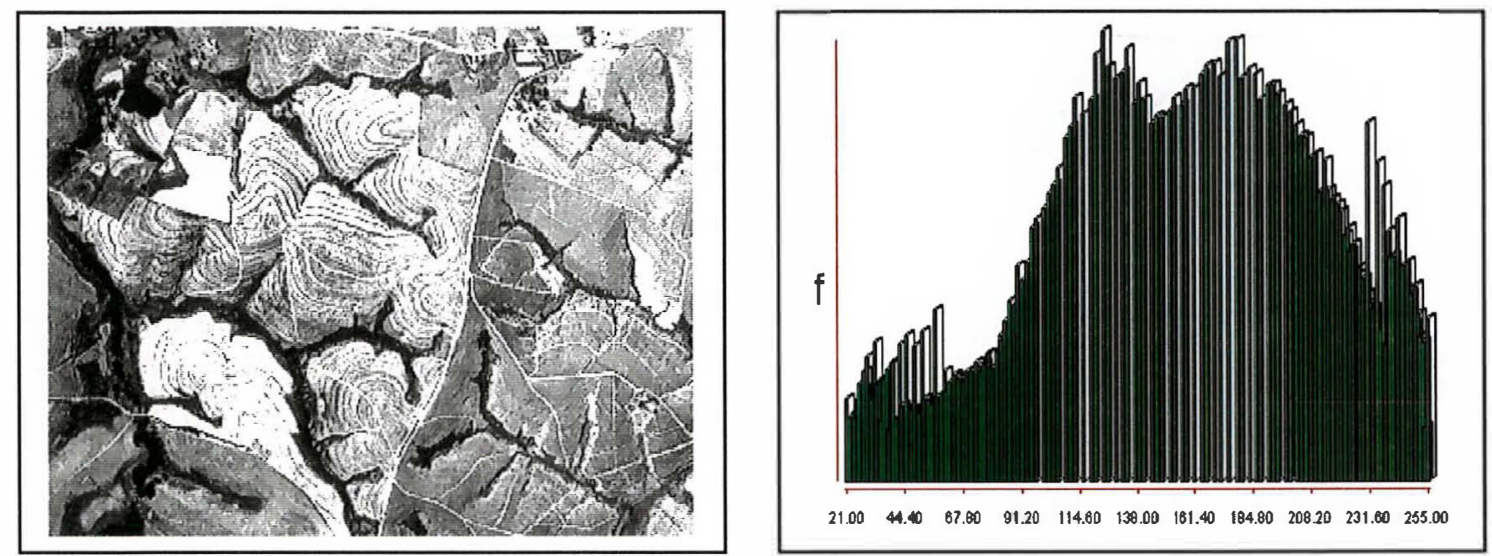

c)
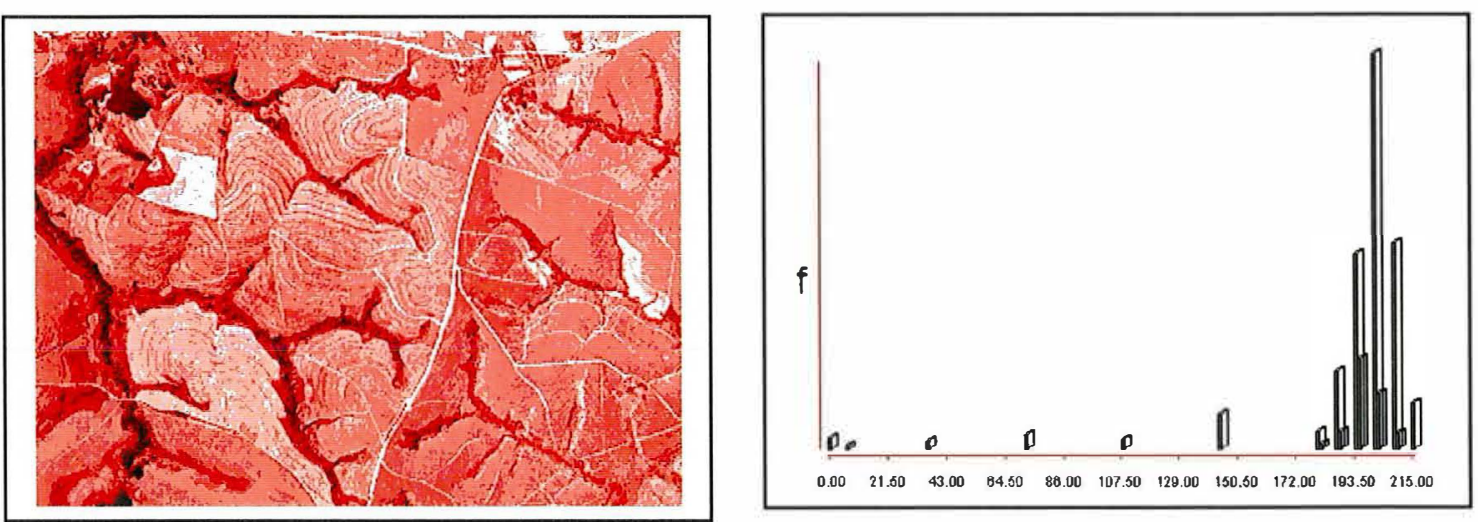

Figura 11 - Exemplos de tratamentos digitais aplicados às fotografias para realce da rede de drenagem e respectivos histogramas: a) sem tratamento de realce; b) equalização de histograma; c) composição colorida (KMC). 
que a escala é a mesma em qualquer ponto e as distâncias são corretamente representadas.

As correções geométricas e o georreferenciamento foram implementados no IDRISI através da função RESAMPLE, utilizando pontos de controle terrestres definidos sobre as fotografias aéreas, cujas coordenadas foram determinados através de medição direta com escalímetro sobre cartas planialtimétricas na escala de 1:10.000.

$\mathrm{Na}$ definição dos pontos de controle, procurou-se as confluências e cruzamentos de estradas, cruzamentos de canais de drenagem com estradas, entre outros, tentando-se, na medida do possível, localizar 1 ponto em cada canto, 2 na faixa intermediária da margem esquerda e 2 na direita, 1 na faixa intermediária da margem superior e outro na inferior e mais 2 na região central da fotografia, totalizando 12 pontos. Entretanto, nem sempre foi possível manter essa quantidade e geometria de pontos.

Farret (1996) e Farret \& Giotto (1997), em estudo conduzido sobre georreferenciamento de fotografias aéreas de pequeno formato, testaram várias geometrias para quatro pontos de controle bem definidos e verificaram que o menor valor de RMS ocorreu quando os pontos foram distribuídos nos quatro cantos da fotografia. Além desta, a geometria que definiu os quatro pontos localizados na metade dos lados apresentou RMS próximo ao menor valor.

Por outro lado, Jones et al. (1993) comentam que a decisão de aceitar um certo valor de RMS (no limite do erro aceitável) é provavelmente mais segura quando este é calculado sobre uma amostra maior de pontos (por exemplo $>30$ ) do que sobre quatro pontos de controle.

Os critérios adotados neste trabalho foram a utilização do maior número possível de pontos de controle e a base de uma geometria recomendada. Além disto, os pontos localizados nos cantos e nas margens são comuns a duas fotografias vizinhas. $\mathrm{O}$ inevitável, porém, foi o descarte de parte dos pontos no momento de ajustar o RMS para satisfazer o limite aceitável no georeferenciamento. Isto se fez, procurando manter, 
sempre que possível, os quatro pontos dos cantos e descartando os menos confiáveis entre os demais.

Segundo Jones et al. (1993), a revisão de 1947 dos Padrões Nacionais dos Estados Unidos para Exatidão de Mapas, determina que os mapas não devem ter mais de $10 \%$ dos pontos testados para verificação de erro com desvio de $1 / 30$ polegada para mapas na escala de 1:20.000 ou menores e não mais de 1/50 polegada para escalas maiores que 1:20.000. Por outro lado, a conversão dos padrões de exatidão do erro médio quadrático aceitável em análise estatística requer que $90 \%$ dos erros acidentais não sejam maiores que 1,64 vezes o RMS, ou seja, 1,64 desvios-padrão, assumindo a distribuição normal de erros. Assim,

Erro médio quadrático aceitável $=$ erro aceitável no terreno/valor $\mathbf{z}$ de probabilidade de ocorrência $=$ erro aceitável no terreno/1,64

Por sua vez,

erro aceitável no terreno = erro aceitável no mapa $\mathrm{x}$ conversão de escala $\mathrm{x}$ conversão de unidades

erro aceitável no mapa $=1 / 30$ polegada para mapas com escala $\leq 1: 20.0000$

$=1 / 50$ polegada para mapas com escala $>1: 20.0000$

conversão de unidades $=0,0254 \mathrm{~m} /$ polegada

Como a escala aproximada das fotografias utilizadas neste trabalho é 1:25.000, de acordo com esses critérios, o erro médio quadrático aceitável calculado foi de $12,91 \mathrm{~m}$.

Para facilitar a junção das fotografias num único mosaico, todas as imagens foram georreferenciadas com a mesma resolução espacial. Depois de alguns testes, foi escolhido um tamanho de pixel de $6,0 \mathrm{~m}$ como resolução, visto que esta transformação pareceu não alterar as feições da imagem original e permitiu a visualização da cena completa na tela, sem problema na operação de "display". 


\subsubsection{Formação do mosaico e delimitação de áreas de trabalho}

Após o georreferenciamento, utilizou-se a função CONCAT do IDRISI para juntar as imagens em uma única cena (mosaico). Esta função efetua a junção de duas ou mais imagens de mesma resolução, unindo os pontos de mesmas coordenadas da seqüência de imagens.

Com a montagem da cena completa, teve-se a visualização de toda a área de trabalho, onde estão distribuídas as bacias selecionadas. Por outro lado, a visualização de cada bacia individualmente e com fator de ampliação foi facilitada quando se dividiu a cena completa em áreas menores, cada uma reunindo um pequeno número de bacias. Assim, foram delimitadas 6 pequenas áreas, sendo que o número de bacias contidas em cada uma delas variou de 2 a 8 , dependo da forma como as mesmas se agnupam dentro da grande área.

\subsubsection{Digitalização sobre a tela}

Os critérios utilizados para traçar os cursos d'água sobre as imagens digitais foram os mesmos utilizados na interpretação visual com o auxílio de estereoscópio. Portanto, foram digitalizadas todas as feições interpretadas como segmentos de rio, quer fossem de $1^{\mathrm{a}}, 2^{\mathrm{a}}$ ou $3^{\mathrm{a}}$ ordem.

Como base para digitalização da área ou perímetro das bacias, procurouse definir os seus limites, adotando-se os seguintes critérios fotointerpretativos: observação de características topográficas (linhas em nível sobre áreas cultivadas); observação de estradas que normalmente acompanham os divisores; distância média entre as nascentes dos rios de $1^{\mathrm{a}}$ ordem de duas bacias vizinhas e direção mais ou menos paralela ao desenvolvimento da rede até se juntar ao canal principal na sua foz. 
O material utilizado para realizar a digitalização foi definido com o resultado dos testes de realce, tendo-se escolhido dois tratamentos para interpretação digital, conforme descrito abaixo:

- Primeiro tratamento: interpretação e digitalização da rede de drenagem a partir de fotografias visualizadas em níveis de cinza, sem realce;

- Segundo tratamento: interpretação e digitalização da rede de drenagem a partir de fotografias visualizadas com realce que, no caso, foi a composição colorida (KCM).

Em ambos os tratamentos, a digitalização sobre a tela foi realizada por três intérpretes diferentes. Este critério foi adotado para evitar o problema de dependência que é possível ocorrer quando apenas um indivíduo realiza a interpretação. Contou-se então com a colaboração de dois profissionais que já desenvolveram trabalhos de fotointerpretação e que se colocaram a par dos objetivos deste trabalho. Portanto, confiou-se a fotointerpretação ao conhecimento e experiência individual de cada um desses profissionais, sem o favorecimento de qualquer treinamento específico.

Os resultados obtidos com a aplicação desses dois tratamentos foram comparados estatisticamente entre si e com aqueles obtidos na interpretação visual, para permitir a avaliação da metodologia utilizada.

\subsubsection{Medição dos segmentos de rios, perímetro e área}

Para permitir a quantificação dos elementos da rede de drenagem através de funções do IDRISI, durante a digitalização da mesma adotou-se como identificadores de feições os respectivos números de ordem de cada segmento de rio, ou seja, o identificador 1 foi atribuído aos segmentos de $1^{\mathrm{a}}$ ordem, o 2 aos de $2^{\mathrm{a}}$ e o 3 ao de $3^{\mathrm{a}}$. Este procedimento permitiu a quantificação da rede quanto ao número e ao comprimento dos segmentos de rios.

Como o perímetro também é uma medida de comprimento, viabilizou-se a sua medição juntamente com os comprimentos de rios, atribuindo-lhe sempre um 
identificador de valor superior à maior ordem de segmentos de rios da respectiva bacia $\mathrm{e}$ digitalizando-o como uma linha que circunda a bacia sobre os seus divisores.

No caso da área da bacia, por se tratar de uma grandeza quadrática, a medição foi realizada separadamente e, por esta razão, o valor do identificador não fez diferença. Em todo caso, aceitou-se o valor inicial ou "default", que corresponde à unidade.

Todas as medições foram efetuadas através da função AREA do IDRISI, o que exigiu a transformação para o formato "raster" (representação matricial) dos arquivos vetoriais editados na fase de digitalização.

Segundo Quintanilha (1996), a representação matricial apresenta o problema de provocar erros nas estimativas das características geométricas e topológicas (áreas, perímetros etc.) por estar baseada na discretização da realidade. Neste sentido, o autor indica alguns fatores aos quais os parâmetros básicos a serem controlados na conversão vetor-matriz dizem respeito: complexidade do desenho; tamanho do elemento da imagem matricial gerada ("pixel"); método de conversão e erros advindos da conversão.

Quanto ao tamanho do "pixel", Burrough (1986) exemplifica que uma grade de $32 \times 32$ elementos ("pixels") produz a metade de erros de discordância (mismatch) de uma grade de $16 \times 16$ elementos.

Neste trabalho, utilizou-se a função EXPAND do IDRISI para reduzir o tamanho do pixel nas imagens e, assim, minimizar os erros envolvidos no cálculo devido a este fator. Este tipo de operação, porém, provoca uma expansão também de forma geométrica no tamanho do arquivo, de maneira que não é possivel reduzir infinitamente o tamanho do "pixel" e fazer o erro tender a zero. Ademais, a cada fator de expansão aplicado, a redução do erro é cada vez menor para uma expansão cada vez maior do arquivo. Este aspecto tornou inviável a redução do tamanho do "pixel" para valores abaixo de $1,0 \mathrm{~m}$. Por outro lado, o valor unitário para a dimensão do "pixel" facilitou 
bastante os cálculos, evitando a transformação de unidades de área para unidade de comprimento sobre os valores obtidos, uma vez que ambas se eqüivalem neste caso.

Na tabulação dos resultados, no IDRISI, os valores de comprimentos de segmentos de rios e perímetro da bacia foram expressos $\mathrm{em} \mathrm{m}^{2} \mathrm{e}$, os de área, em $\mathrm{km}^{2}$. Na verdade, como foi mencionado acima, os valores expressos $\mathrm{em}^{2}$ eqüivalem a metro linear neste caso, de forma que não houve necessidade de transformação de unidades.

\subsubsection{Compilação dos resultados}

Após a realização de todas as medições os dados foram organizados em tabelas semelhantes às construídas na interpretação visual, para assim permitir a comparação dos resultados.

Dispensando a análise da rede de drenagem, por se apresentar um tanto complexa e, provavelmente, pouco eficaz como instrumento de avaliação nesta situação, procedeu-se à determinação dos índices do padrão de drenagem para os dois tratamentos, calculados individualmente e em termos de média das três interpretações.

Os mesmos dados também foram organizados em planilha eletrônica para entrada no sistema de análise estatística (SAS), de acordo com a ordem requerida.

\subsubsection{Delineamento experimental e análise estatística}

Em primeiro lugar, considerou-se que a análise estatística seria realizada em separado para os dois tipos de solo. Este critério se baseia nos resultados do teste de semelhança geométrica, onde a organização dos grupos de bacias difere entre os dois solos, primeiramente com relação ao número de grupos e depois com relação ao número de bacias por grupo.

Da maneira como os grupos de bacias foram criados, foram considerados um fator de restrição (blocos), sobre o qual não se tem interesse para teste. Isto se baseia 
no fato de que as bacias que fazem parte de um mesmo grupo são ditas semelhantes quanto as suas características geométricas, com base no teste de semelhança já realizado. Colocando desta forma, entende-se que as bacias de um mesmo grupo representam as repetições, sobre as quais foram realizadas as medições.

As formas de interpretação das imagens, primeiramente com o auxílio do estereoscópio e depois com o auxílio de computador, foram definidas como métodos, recebendo as seguintes atribuições: MÉTODO 1 - Interpretação visual com auxílio de estereoscópio (Método Padrão); MÉTODO 2 - Interpretação das imagens digitais em níveis de cinza, sem tratamento de realce (convencionado como primeiro tratamento em "operações de realce"); MÉTODO 3 - Interpretação das imagens digitais na forma de composições coloridas, ou seja, com tratamento de realce (convencionado como segundo tratamento em "operações de realce").

As variáveis analisadas para cada bacia foram:

\begin{tabular}{l|l}
\hline Medições diretas & Índices calculados \\
\hline - Número de rios de primeira ordem (Nw1) & - Comprimento médio de rios de $1^{\mathrm{a}}$ \\
- Número total de rios (N) & ordem (Lm1) \\
- Comprimento de rios de $1^{\mathrm{a}}$ ordem (Lw1) & - Comprimento médio do total de rios \\
- Comprimento total de rios (Lt) & $(\mathrm{Lm})$ \\
- Área da bacia (A) & - Densidade de drenagem (Dd) \\
- Perímetro da bacia (P) & - Freqüência de rios (Fr) \\
& - Razão de textura (T) \\
& - Razão de textura média (Tm) \\
\hline
\end{tabular}

O modelo matemático para análise da variância de todas as variáveis, com exceção da variável razão de textura média $(\mathrm{Tm})$, foi o seguinte:

$$
Y_{i j k}=m+M_{i}+G_{j}+e_{i j k}
$$

onde: 
$\mathrm{Y}_{\mathrm{ijk}}=$ valor observado referente ao i-ésimo Método, no j-ésimo Grupo, na k-ésima Bacia;

$\mathrm{m}$ = fator fixo, estimado pela média geral;

$\mathbf{M}_{\mathrm{i}}=$ efeito do i-ésimo Método;

$\mathrm{G}_{\mathrm{j}}=$ efeito do j-ésimo Grupo;

$\mathrm{e}_{\mathrm{ijk}}=$ erro aleatório correspondente às parcelas (variação do acaso sobre as observações do i-ésimo Grupo e na k-ésima Bacia), supostos homocedásticos, independentes e normalmente distribuídos.

$\mathrm{O}$ quadro de análise da variância e teste $\mathrm{F}$ para Métodos nos dois solos foi o seguinte:

\begin{tabular}{|c|c|c|c|c|c|}
\hline \multirow{2}{*}{$\begin{array}{l}\text { Causa da } \\
\text { Variação }\end{array}$} & \multicolumn{2}{|c|}{ G.L. } & \multirow[t]{2}{*}{ S.Q. } & \multirow[t]{2}{*}{ Q.M. } & \multirow[t]{2}{*}{$\mathrm{F}$} \\
\hline & Solo1 & Solo2 & & & \\
\hline Métodos & 2 & 2 & SQ Métodos & QM Métodos & QM Métodos/QM Res. \\
\hline Grupos & 2 & 5 & SQ Grupos & QM Grupos & \\
\hline Resíduo & 22 & 37 & SQ Resíduo & QM Resíduos & \\
\hline Total & 26 & 44 & SQ Total & & \\
\hline
\end{tabular}

A razão QM Métodos/QM Res. testa a seguinte hipótese:

Ho: não existe diferença entre as médias de Métodos.

O nível mínimo considerado para rejeição desta hipótese foi de $5 \%$, ou seja, sempre que o valor da probabilidade do teste $F$ foi menor ou igual a 0,05 $(\alpha \leq 0,05)$, rejeitou-se a hipótese de nulidade, isto é, aceitou-se que existia diferença significativa entre pelo menos duas médias de Métodos e procedeu-se então ao detalhamento da análise.

Dado que o fator método é qualitativo, sempre que o teste $\mathrm{F}$ detectou diferença significativa entre suas médias, foi feito o detalhamento da análise através do teste de Tukey e, dado a natureza dos tratamentos (Métodos), utilizou-se também o teste F para contrastes, considerando, também, um nível mínimo de significância de $5 \%$ ( $\alpha$ $\leq 0,05)$ para os dois testes. Para o teste $\mathrm{F}$ considerou-se os seguintes contrastes ortogonais: 
Y1 = Método 1 versus Métodos 2 e 3;

Y2 = Método 2 versus Método 3.

Quanto à variável Razão de Textura Média (Tm), trata-se de uma função das variáveis Área e Razão de Textura [ $(\mathrm{A} . \mathrm{T}) / \Sigma \mathrm{A}]$, cujo resultado categoriza as bacias do grupo em grosseira, média e fina.

Para este tipo de variável Burt (1950), Anderson (1991), Greenacre (1993), entre outros, sugerem que os dados sejam tratados como dados categorizados, utilizando teste de independência ou de homogeneidade. Assim, foram feitas tabelas de contingência para cada cruzamento das variáveis estudadas (Métodos) nos dois tipos de solos e utilizado o Teste Exato de Fisher (Pimentel Gomes, 1985; Campos, 1983) para inferência, devido ao pequeno número de observações.

Embora o teste de $\chi^{2}$ (qui-quadrado) seja o mais usual dos testes nãoparamétricos aplicáveis ao caso de duas amostras independentes, ele não é apropriado para o caso de pequenas amostras.

As tabelas de contingência tomaram a seguinte forma:

\begin{tabular}{|c|c|c|c|c|c|}
\hline \multirow{2}{*}{$\begin{array}{c}\text { VARIÁVEL } \\
\mathbf{x}_{\mathbf{i}}\end{array}$} & \multicolumn{4}{|c|}{ VARIÁVEL $\mathbf{Z}_{\mathbf{j}}$} & \multirow{2}{*}{$\begin{array}{c}\text { TOTAL DE } \\
\mathbf{X}\end{array}$} \\
\hline & $\mathrm{z}_{1}$ & $\mathrm{z}_{2}$ & $\ldots$ & $\mathrm{z}$ & \\
\hline $\mathrm{x}_{1}$ & $\mathbf{y}_{11}$ & $\mathrm{y}_{12}$ & $\cdots$ & $\overline{Y_{1 j}}$ & $y_{1 \bullet}$ \\
\hline$x_{2}$ & $\mathbf{y}_{21}$ & $\mathrm{y}_{22}$ & $\ldots$ & $Y_{2 j}$ & $\mathrm{y}_{2}$ \\
\hline$\cdots$ & $\cdots$ & $\cdots$ & $\cdots$ & $\cdots$ & $\cdots$ \\
\hline $\mathbf{x}_{\mathrm{i}}$ & $y_{i l}$ & $\mathrm{y}_{\mathrm{i} 2}$ & $\cdots$ & $Y_{i j}$ & $\mathrm{y}_{\mathrm{i} \bullet}$ \\
\hline TOTAL DE Z & $y_{01}$ & $\mathrm{y}_{\bullet 2}$ & $\cdots$ & $Y_{\circ j}$ & n \\
\hline
\end{tabular}

Onde: $\mathrm{y}_{\mathrm{ij}}=$ freqüência observada de ocorrência do i-ésimo nível da variável $\mathrm{X}$ com o j-ésimo nível da variável $Z$ (por exemplo, MÉTODO com Categorias de TEXTURA GROSSEIRA no solo 1);

$\mathrm{y}_{\mathrm{i} \text { }}=$ total de ocorrência do i-ésimo nível de X (por exemplo, MÉTODO 1), ou marginal de $\mathrm{X}$; 
$\mathrm{y}_{\bullet_{\mathrm{j}}}=$ total de ocorrência do j-ésimo nível de $\mathrm{Z}$ (por exemplo, TEXTURA GROSSEIRA), ou marginal de Z;

$\mathrm{n}=$ total de observações da amostra, das quais foram obtidas informações das duas variáveis que estão sendo cruzadas.

Obs.: Todos os elementos dessa tabela devem ser não negativos e a soma de cada linha ou coluna deve ser não nula.

O Teste Exato de Fisher calcula a probabilidade (p), sob hipótese de independência, de que as freqüências da tabela de contingência ocorrem por acaso, e não devido a dependência entre as variáveis. Portanto, a hipótese de independência será rejeitada sempre que o valor da probabilidade (p) for menor ou igual a 0,05 , e isto implica em aceitar que existe dependência entre as variáveis estudadas.

Para o caso de tabelas de dimensões maiores que $2 \times 2$ o cálculo da probabilidade torna-se complicado para ser realizado manualmente, e portanto exige 0 emprego de softwares estatísticos. Neste caso, foi utilizado o SAS - Statistical Analysis System.

Para que os modelos de análise de variância tenham validade e os testes tenham poder, as seguintes pressuposições precisam ser satisfeitas:

- homogeneidade de variâncias, ou seja, só podem ser comparados tratamentos com variâncias homogêneas entre si;

- independência dos erros;

- erros com distribuição normal (ou aproximadamente normal).

Para testar essas pressuposições, procedeu-se à análise exploratória dos dados, auravés de:

- Análise gráfica dos resíduos: consiste em plotar num diagrama de dispersão dos valores estimados pelo modelo da análise da variância versus os resíduos padronizados (erro referente a cada observação dividido pelo desvio padrão amostral). A forma desse gráfico permite a detecção de falta de independência e existência de heterogeneidade regular (que pode ser eliminada através do uso de uma 
transformação adequada) ou irregular (que não permite transformação). $\mathrm{O}$ intervalo dos resíduos padronizados detecta se há algum(uns) valor(es) desviando-se da normalidade. Consideram-se normalmente distribuídos os resíduos que estiverem no intervalo de -3 a 3 .

- Diagrama de "ramos e folhas": ordenação dos dados de forma programada para mostrar sua distribuição aproximada, dispersão, assimetria, curtose, agrupamento de valores e, principalmente, detecção de "outliers" (dados discrepantes) e sua localização espacial, alertando para possíveis problemas não notados durante o experimento. 


\section{RESULTADOS E DISCUSSÃO}

Os resultados obtidos neste trabalho estão organizados em figuras, tabelas e gráficos, onde apresentam-se as bacias selecionadas, os dados de medições e análises da rede de drenagem, e os resultados da análise estatística.

Primeiramente são apresentados e discutidos os resultados da interpretação visual e, em seguida, os resultados referentes ao processamento digital.

\subsection{Interpretação visual}

Como o objetivo do presente trabalho foi avaliar o emprego de processamento digital como técnica auxiliar na fotointerpretação de bacias hidrográficas, a interpretação visual foi utilizada como referência (padrão). Portanto, as análises realizadas não foram utilizadas para o fim específico de inferir sobre possíveis diferenças de solos, mas, principalmente, par validar os dados obtidos e permitir comparações entre o método de interpretação visual, com auxílio de estereoscópio, e o proposto, com auxílio de processamento digital.

Seguindo os critérios básicos normalmente recomendados neste tipo de interpretação, foram selecionadas bacias de mesma ordem como amostras, para validar a comparação dos resultados obtidos. Também observou-se o critério de homogeneidade das amostras quanto à geologia e edafologia, para assegurar a condição de semelhança de solos, e realizou-se teste de semelhança geométrica entre as bacias, para assegurar que todas as medições nelas realizadas guardassem razões de escala aproximadamente constantes, conforme se apresentou na metodologia. 


\subsubsection{Características das bacias}

a) Localização

Como pode ser observado na representação gráfica (Figuras 12 a 16), as amostras selecionas estão distribuídas nas bacias dos Ribeirões dos Marins (RM), Congonhal (RC), Pau D'alhinho (PD) e Granal (RG), sendo que a maioria se localiza nas bacias dos Ribeirões Congonhal e dos Marins.

b) Representatividade

De acordo com o mapa de solos (Figura 10) é dominante a ocorrência de solos litólicos e podzólicos na área de estudo, sendo que várias unidades de mapeamento figuram a nível de grupamentos. Este aspecto prevaleceu na seleção das amostras, tendendo ainda a ocorrerem inclusões de um podzólico em bacias selecionadas como representativas de litólicos e vice-versa, ou mesmo de outros solos, como LE-2 e PE. No caso destes últimos, as inclusões foram mínimas.

c) Seleção das bacias

Em trabalhos deste tipo, normalmente são selecionadas em média 3 bacias como amostragem representativa de cada solo a ser estudado, de maneira que sejam satisfeitos os critérios acima mencionados e atendidas as exigências do modelo estatístico, quando utilizado. Neste trabalho, entretanto, foi selecionado um número maior de amostras para cada solo, com a finalidade de permitir a aplicação do modelo estatístico proposto. Portanto, feita a seleção, resultaram 3 grupos como representativos de solos litólicos, com três bacias cada, e 6 grupos representativos de solos podzólicos, sendo, neste caso, 3 grupos de três bacias e 3 de duas. 


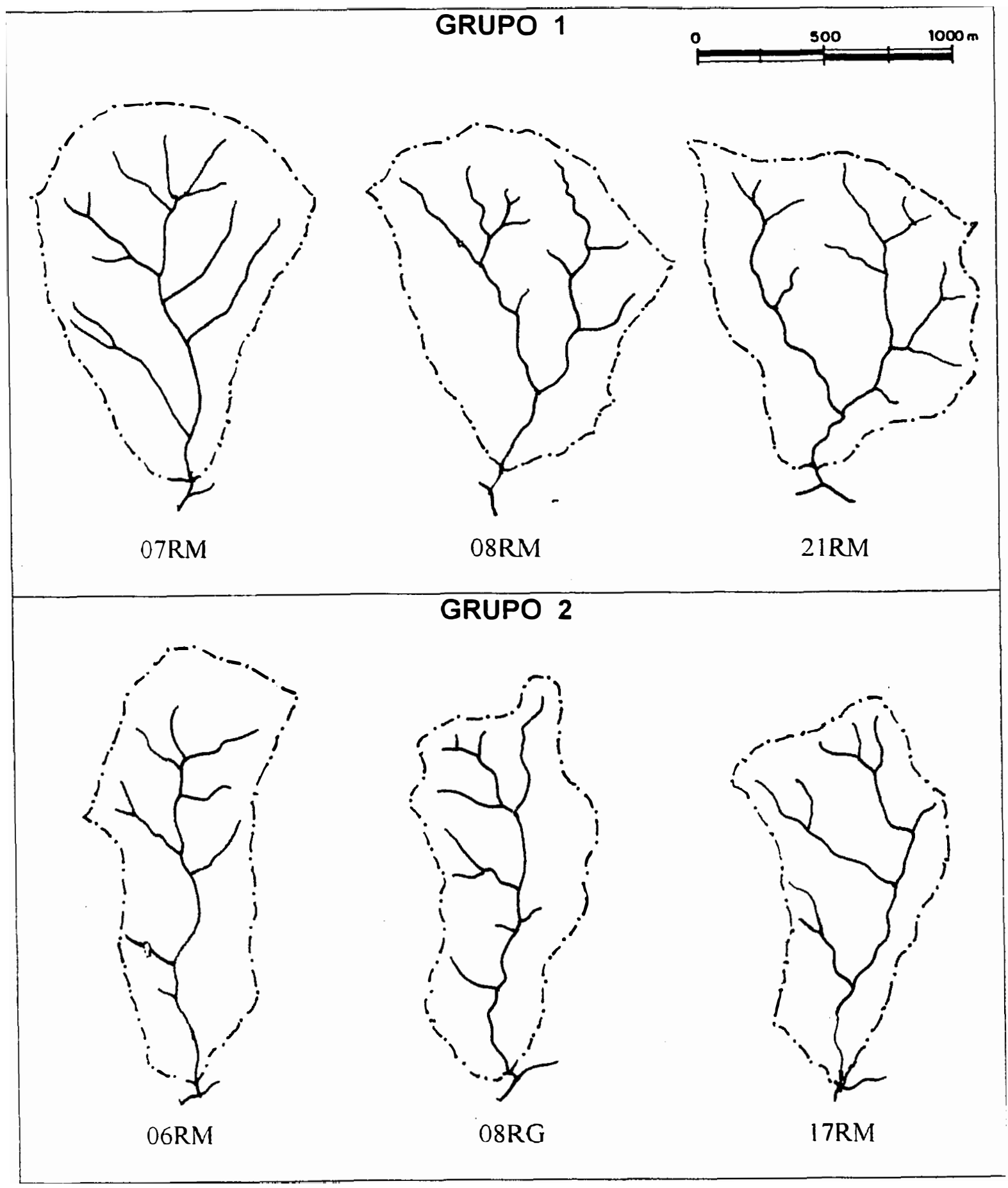

Figura 12 - Bacias hidrográficas dos grupos 1 e 2 , representativas de solos litólicos, distribuídas nas bacias do Ribeirão dos Marins e do Ribeirão Granal. 

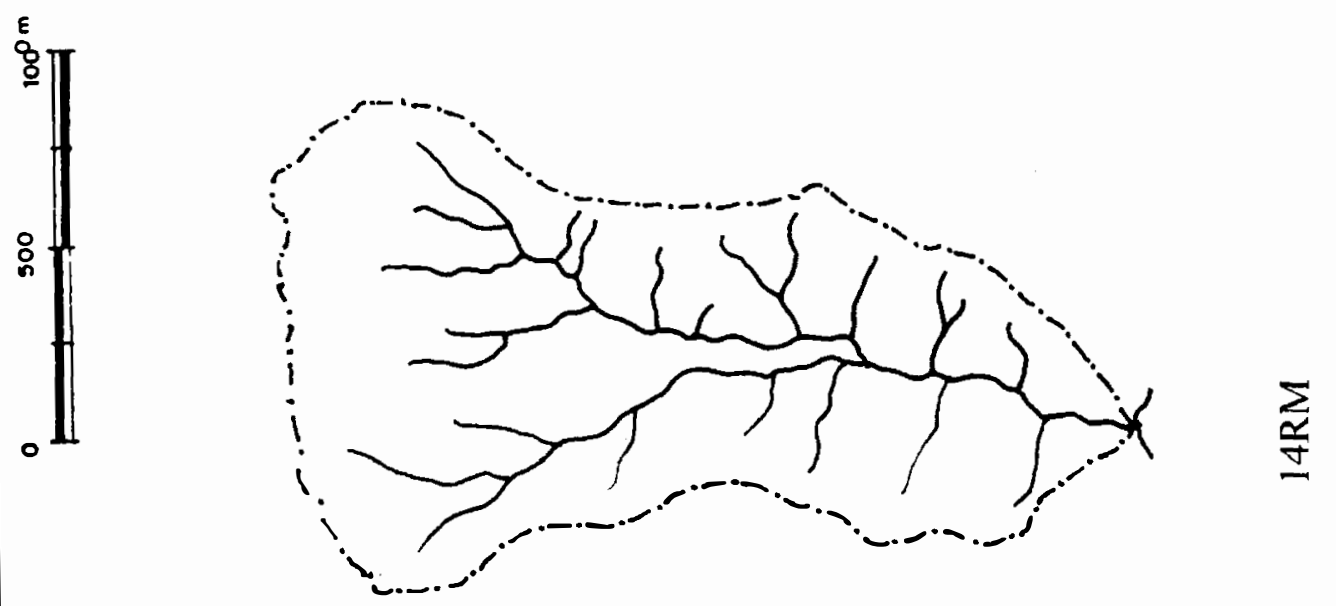

$m$

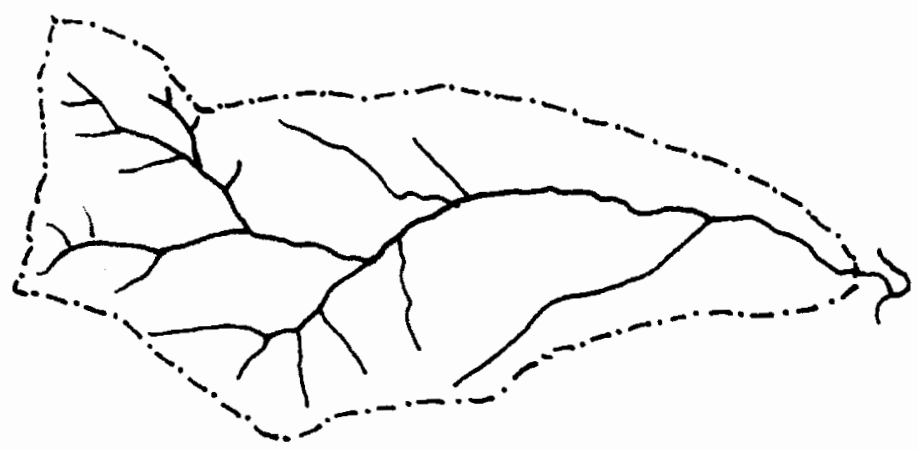

$\frac{\sum}{N}$

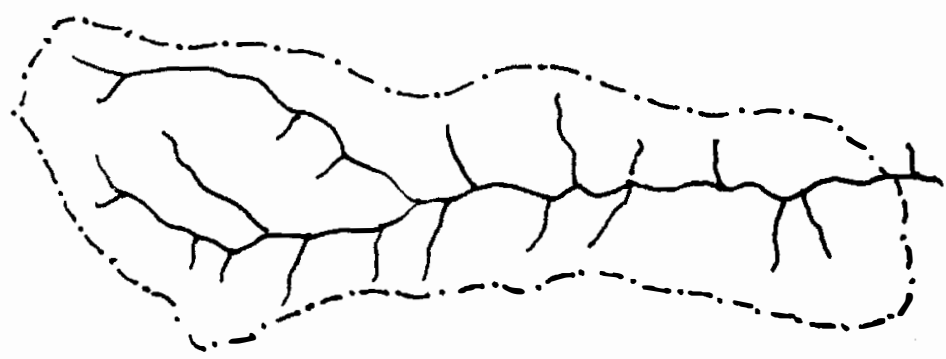

$\frac{\sum}{8}$

Figura 13 - Bacias hidrográficas do grupo 3, representativas de solos litólicos, todas localizadas na bacia do Ribeirão dos Marins. 


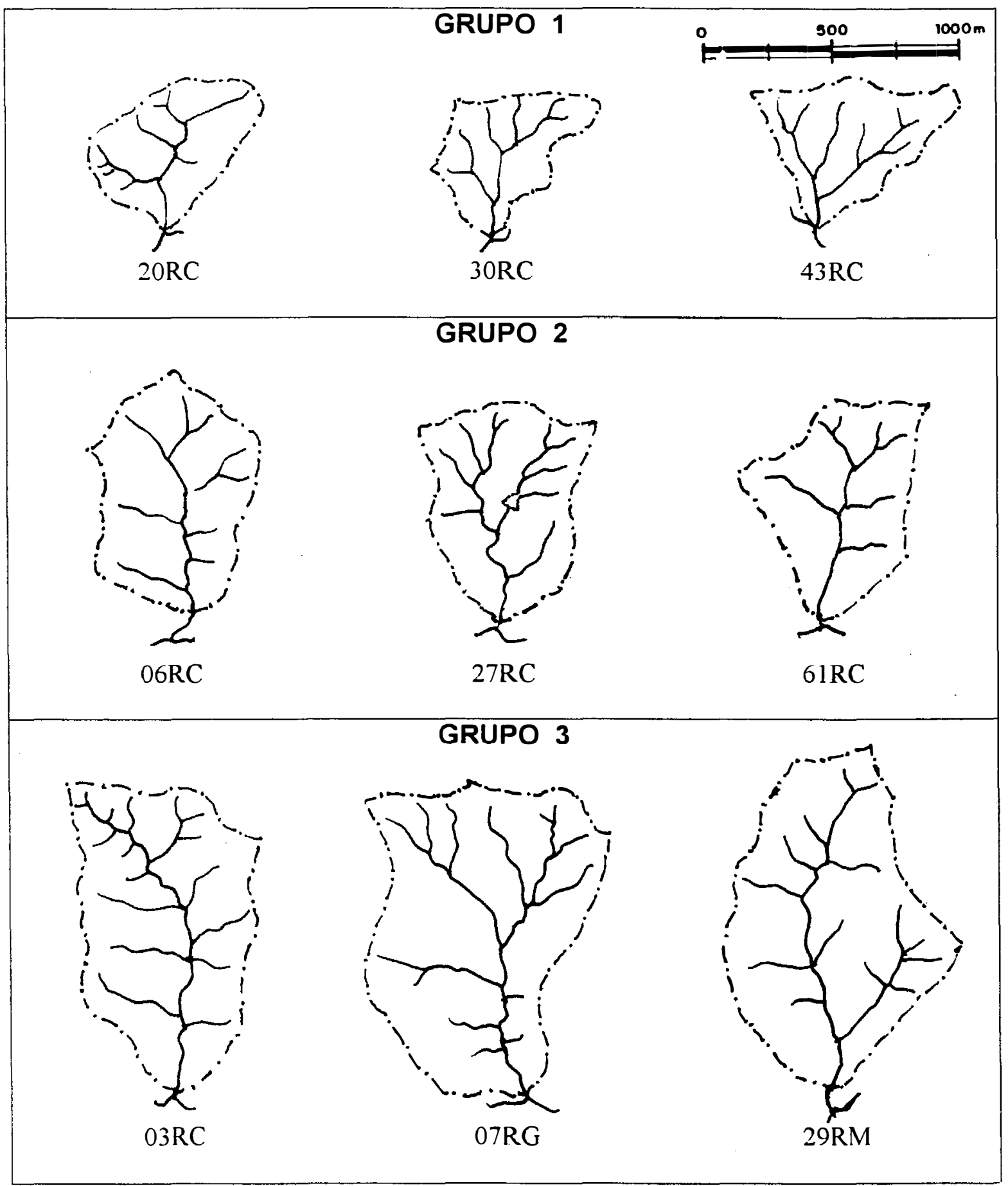

Figura 14 - Bacias hidrográficas dos grupos 1, 2 e 3, representativas de solos podzólicos, distribuídas nas bacias dos Ribeirões Congonhal, Granal e Marins. 


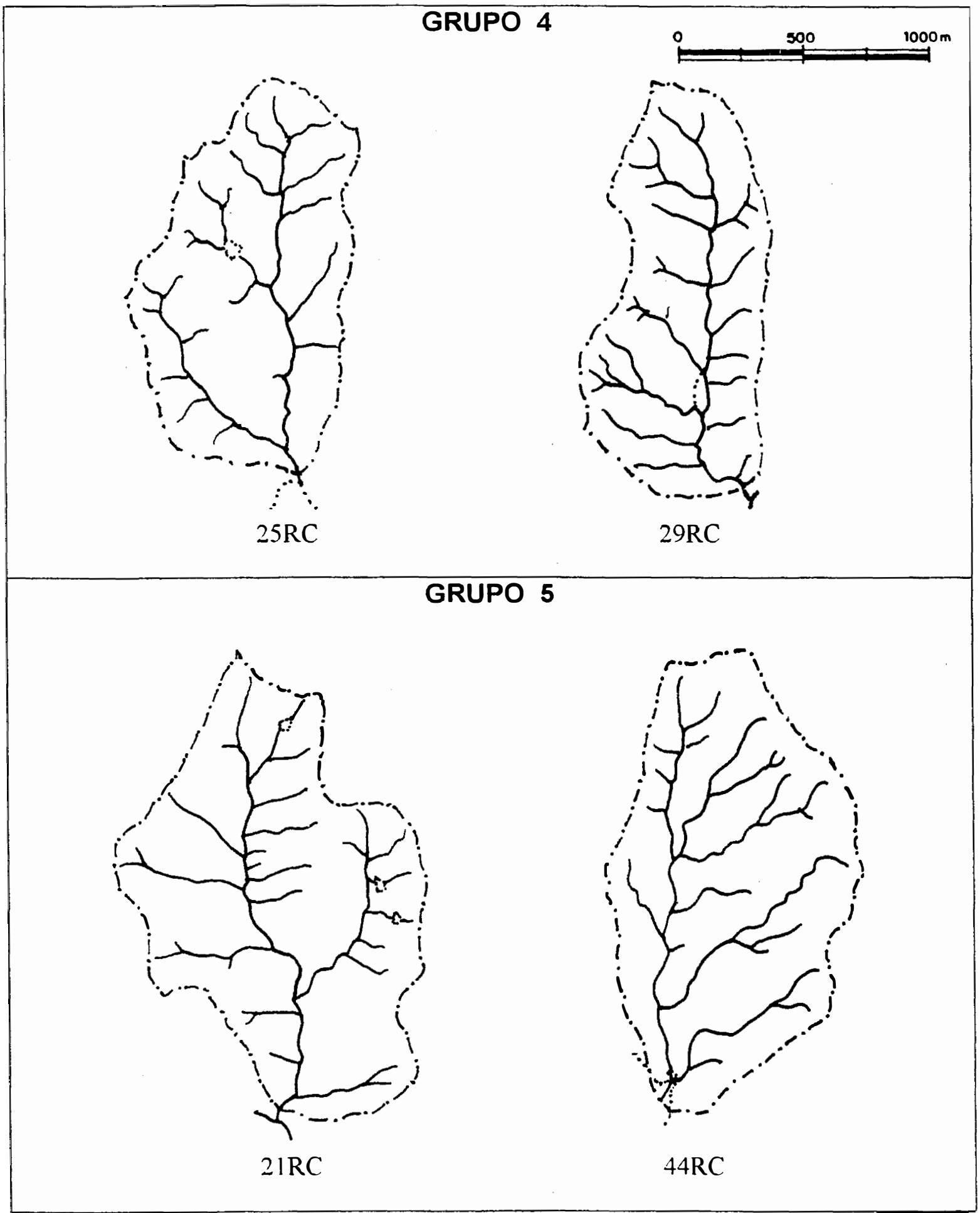

Figura 15 - Bacias hidrográficas dos gnupos 4 e 5 , representativas de solos podzólicos, todas localizadas na bacia do Ribeirão Congonhal. 


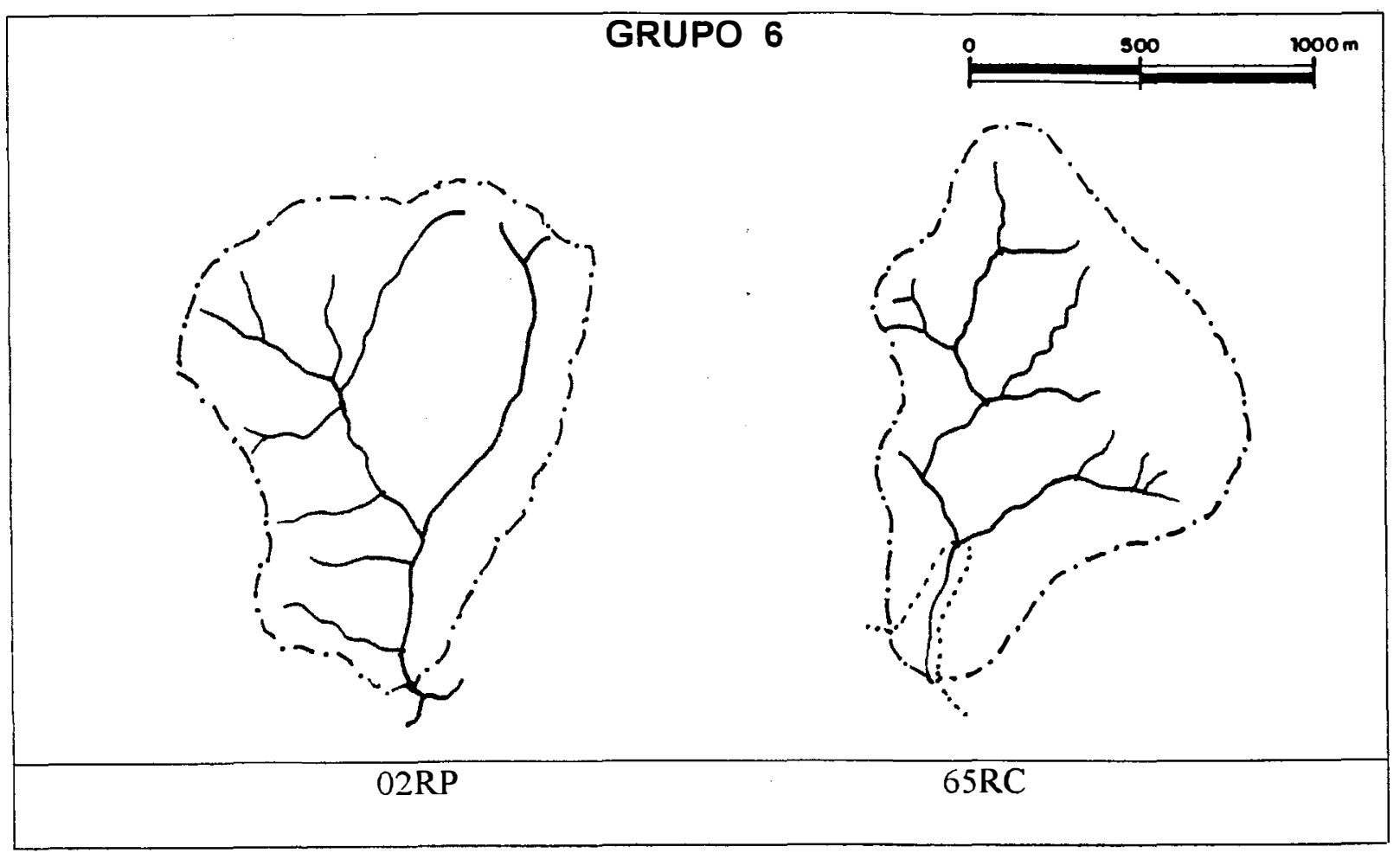

Figura 16 - Bacias hidrográficas do grupo 6, representativas de solos podzólicos, a primeira localizada na bacia do Ribeirão Pau D'alhinho e, a segunda, na bacia do Ribeirão Congonhal.

d) Propriedades dimensionais e semelhança geométrica

Os dados referentes às propriedades dimensionais utilizadas na seleção das bacias encontram-se na Tabela 2. Nesta mesma tabela estão relacionados os tipos ou grupamentos de solos ocorrentes em cada bacia, iniciando com (Li-3) ou (Li-5) para solos litólicos e, (PV-7), (PV-7+PV-8) ou (PV-10 + Li-3+PV-9) para solos podzólicos.

Observando os dados da Tabela 2, percebe-se diferenças de tamanho e conformação das bacias entre os três grupos dos solos litólicos. Por outro lado, notam-se semelhanças entre as bacias de cada grupo, refletidas através dos valores de maior comprimento, maior largura, perímetro e área. 
Tabela 2. Propriedades dimensionais de bacias hidrográficas representativas de solos litólicos e podzólicos, e discriminação das unidades de mapeamento.

\begin{tabular}{|c|c|c|c|c|c|c|c|}
\hline \multirow{2}{*}{$\begin{array}{l}\text { Bacia } \\
\text { Hidro- } \\
\text { gráfica }\end{array}$} & \multirow{2}{*}{$\begin{array}{c}\text { Maior } \\
\text { Compri } \\
\text {-mento } \\
\text { (C) }\end{array}$} & \multirow{2}{*}{$\begin{array}{l}\text { Maior } \\
\text { Largura } \\
\text { (L) }\end{array}$} & \multicolumn{2}{|c|}{ Comprimento de rios } & \multirow{2}{*}{$\begin{array}{c}\text { Perímetro } \\
\text { (P) }\end{array}$} & \multirow{2}{*}{$\begin{array}{l}\text { Área } \\
\\
(A) \\
-\mathrm{km}^{2}-\end{array}$} & \multirow{2}{*}{$\begin{array}{c}\text { Tipo ou grupamento de solos } \\
\text { ocorrentes }\end{array}$} \\
\hline & & & $\begin{array}{c}\text { Principal } \\
(\mathrm{Cp}) \\
\ldots . .-\mathrm{km}-.\end{array}$ & $\begin{array}{l}\text { Rede } \\
\text { (Cr) }\end{array}$ & & & \\
\hline \multicolumn{8}{|c|}{ Solos litólicos } \\
\hline \multicolumn{8}{|l|}{ GRUPO 1} \\
\hline $07 \mathrm{RM}$ & 1,51 & 1,10 & 1,42 & 4,77 & 3,93 & 1,09 & $(\mathrm{Li}-3)+(\mathrm{PV}-\mathrm{T})+(\mathrm{LE}-2+\mathrm{PE})$ \\
\hline $08 \mathrm{RM}$ & 1,37 & 1,02 & 1,29 & 3,75 & 3,75 & 1,00 & $(\mathrm{Li}-3)+(\mathrm{PV}-7)$ \\
\hline $21 \mathrm{RM}$ & 1,51 & 1,06 & 1,30 & 4,19 & 3,83 & 1,00 & $(\mathrm{Li}-3)+(\mathrm{Li}-5)+(\mathrm{PV}-7+\mathrm{PV}-8)$ \\
\hline \multicolumn{8}{|l|}{ GRUPO 2} \\
\hline $06 \mathrm{RM}$ & 1,79 & 0,66 & 1,46 & 3,17 & 4,08 & 0,87 & $(\mathrm{Li}-3)+(\mathrm{PV}-7)+(\mathrm{LE}-2+\mathrm{PE})$ \\
\hline $08 \mathrm{RG}$ & 1,60 & 0,64 & 1,50 & 3,09 & 3,75 & 0,73 & $(\mathrm{Li}-3+\mathrm{PV}-9)+(\mathrm{PV}-7+\mathrm{PV}-8)$ \\
\hline $17 \mathrm{RM}$ & 1,58 & 0,68 & 1,58 & 3,52 & 3,65 & 0,74 & $(\mathrm{Li}-5)+(\mathrm{PV}-\mathrm{T})+(\mathrm{Li}-3)$ \\
\hline \multicolumn{8}{|l|}{ GRUPO 3} \\
\hline $09 \mathrm{RM}$ & 2,22 & 0,77 & 2,12 & 5,68 & 5,17 & 1,17 & $(\mathrm{Li}-3)$ \\
\hline $12 \mathrm{RM}$ & 2,30 & 0,84 & 2,08 & 6,33 & 4,75 & 1,26 & $(\mathrm{Li}-3)+(\mathrm{PV}-7)+(\mathrm{PV}-10+\mathrm{Li}-3+\mathrm{PV}-9)$ \\
\hline $14 \mathrm{RM}$ & 2,12 & 1,22 & 2,01 & 8,25 & 5,29 & 1,71 & $(\mathrm{Li}-3)+(\mathrm{PV}-7)$ \\
\hline \multicolumn{8}{|c|}{ Solos podzólicos } \\
\hline \multicolumn{8}{|l|}{ GRUPO 1} \\
\hline $20 \mathrm{RC}$ & 0,75 & 0,47 & 0,65 & 1,65 & 1,90 & 0,25 & (PV-7+PV-8) \\
\hline $30 \mathrm{RC}$ & 0,63 & 0,46 & 0,68 & 1,50 & 1,93 & 0,21 & (PV-7+PV-8) \\
\hline $43 \mathrm{RC}$ & 0,77 & 0,61 & 0,54 & 1,71 & 2,17 & 0,26 & $(\mathrm{PV}-7+\mathrm{PV}-8)+(\mathrm{PV}-9+\mathrm{PV}-10)$ \\
\hline \multicolumn{8}{|l|}{ GRUPO 2} \\
\hline $06 \mathrm{RC}$ & 0,99 & 0,65 & 0,85 & 2,46 & 2,50 & 0,44 & (PV-7+PV-8) \\
\hline $27 \mathrm{RC}$ & 0,91 & 0,67 & 0,88 & 2,60 & 2,50 & 0,40 & (PV-7+PV-8) \\
\hline $61 \mathrm{RC}$ & 0,97 & 0,66 & 0,85 & 1,97 & 2,50 & 0,38 & $(\mathrm{PV}-7)$ \\
\hline \multicolumn{8}{|l|}{ GRUPO 3} \\
\hline $03 \mathrm{RC}$ & 1,40 & 0,74 & 1,30 & 4,25 & 3,25 & 0,67 & (PV-7+PV-8) \\
\hline 07 RG & 1,39 & 0,85 & 1,25 & 4,25 & 3,25 & 0,84 & $(\mathrm{PV}-7+\mathrm{PV}-8)+(\mathrm{Li}-3+\mathrm{PV}-9)$ \\
\hline 29 RM & 1,36 & 0,93 & 1,25 & 3,52 & 3,33 & 0,77 & $(\mathrm{PV}-10+\mathrm{Li}-3+\mathrm{PV}-9)+(\mathrm{PV}-7+\mathrm{PV}-8)$ \\
\hline \multicolumn{8}{|l|}{ GRUPO 4} \\
\hline $25 \mathrm{RC}$ & 1,59 & 0,85 & 1,50 & 5,83 & 4,08 & 1,01 & (PV-7+PV-8) \\
\hline $29 \mathrm{RC}$ & 1,79 & 0,70 & 1,78 & 6,65 & 4,10 & 0,93 & (PV-7+PV-8) \\
\hline \multicolumn{8}{|l|}{ GRUPO 5} \\
\hline $21 \mathrm{RC}$ & 1,91 & 1,20 & 1,83 & 8,00 & 5,03 & 1,42 & $($ PV-7+PV-8) \\
\hline $44 \mathrm{RC}$ & 1,76 & 0,99 & 1,71 & 7,71 & 4,57 & 1,31 & $(\mathrm{PV}-7+\mathrm{PV}-8)+(\mathrm{Li}-3)+(\mathrm{PE})$ \\
\hline \multicolumn{8}{|l|}{ GRUPO 6} \\
\hline $02 \mathrm{RP}$ & 1,59 & 1,12 & 1,46 & 4,75 & 4,00 & 1,19 & $(\mathrm{PV}-7+\mathrm{PV}-8)+(\mathrm{Li}-3+\mathrm{PV}-9)$ \\
\hline $65 \cdot \mathrm{RC}$ & 1,66 & 1,00 & 1,63 & 4,25 & 4,17 & 1,13 & $(\mathrm{PV}-7+\mathrm{PV}-8)+(\mathrm{Li}-6+\mathrm{Li}-5)$ \\
\hline
\end{tabular}

Analisando o grupo 1 dos solos litólicos, percebe-se pouca diferença entre valores de maior comprimento e maior largura, comparado com os outros dois. Isto confere às bacias deste grupo, conformação mais arredondada e, consequentemente, menor variação de perímetro e área. Já as bacias do grupo 2 apresentam um formato alongado, com redução da maior largura, em relação ao grupo 1, porém apresentam as menores áreas (média de $0,78 \mathrm{~km}^{2}$, contra $1,03 \mathrm{~km}^{2}$ no grupo 1 e $1,38 \mathrm{~km}^{2}$ no grupo 3 ). 
No que concerne ao grupo 3, a principal diferença em relação aos dois primeiros está nos maiores valores apresentados para maior comprimento, perímetro e área, o que o caracteriza como o grupo de bacias maiores e mais alongadas dentre do conjunto.

Ainda na Tabela 2, observam-se grandes diferenças de tamanho de bacias entre os seis grupos representativos dos solos podzólicos, bem como semelhanças dentro de cada grupo. Para este conjunto de bacias, nota-se um aumento gradual nos valores dos parâmetros dimensionais (considerando valores médios) do primeiro ao terceiro grupo, enquanto entre os três últimos, destaca-se o grupo 5, por apresentar valores mais elevados para todas as propriedades. Neste caso, sobressaiu-se o comprimento da rede $(\mathrm{Cr})$, com uma média de $7,86 \mathrm{~km}$, contra $6,24 \mathrm{~km}$ no grupo $4 \mathrm{e}$ 4,5 km no grupo 6. A maior variação, entretanto, ocorreu entre os grupos 1 e 5, onde a diferença do grupo 5 para o grupo 1 variou de cerca de 2 vezes para maior comprimento e maior largura, a 5 vezes e meia, para a área.

De acordo com a Tabela 2 e as Figuras 15 e 16, verifica-se que os três últimos grupos dos solos podzólicos possuem apenas 2 bacias cada, diferentemente dos demais, inclusive dos solos litólicos. Este fato se deu diante da difículdade de se reunir maior número de bacias geometricamente semelhantes dentro desses grupos.

Essas observações revelam que a análise de semelhança geométrica foi útil para separar grupos quanto às propriedades dimensionais de bacias. Por outro lado, essas propriedades seriam insuficientes para mostrar diferenças entre solos, dada a grande variação dimensional observada, principalmente entre as bacias dos grupos representativos de solos podzólicos. Neste aspecto, estudos de França (1968), Marchetti (1969), Fadel (1972) e Vasques Filho (1972), mostraram que os dados referentes a forma e tamanho de bacias são pouco consistentes para estabelecer diferenciação entre solos.

A Tabela 3 mostra os resultados da aplicação dos princípios de análise dimensional e de semelhança geométrica $\mathrm{p}$ ara as bacias representativas dos solos litólicos e podzólicos. Nesta tabela, observam-se pequenas variações para os valores da Razão de Equivalência ( $\mathrm{Re}$ ), aproximando-se da unidade, conforme proposto por 
Manechini (1981), indicando semelhança geométrica entre as bacias comparadas, o que já ficou evidente na discussão anterior.

Tabela 3. Análise dimensional e de semelhança geométrica aplicada a bacias hidrográficas representativa de solos litólicos e podzólicos.

\begin{tabular}{|c|c|c|c|c|c|c|c|c|c|}
\hline \multirow{2}{*}{$\begin{array}{c}\text { Bacia } \\
\text { Hidrográfica } \\
\text { Comparada }\end{array}$} & \multicolumn{5}{|c|}{ Razão de escala linear $(\mathrm{R})$} & \multirow{2}{*}{$\begin{array}{c}\text { Razão } \\
\text { Média }(\mathrm{Rm})\end{array}$} & \multirow{2}{*}{\multicolumn{2}{|c|}{$\begin{array}{l}\text { Razão de escala } \\
\text { Quadrática }\left(\mathrm{R}^{2}\right)\end{array}$}} & \multirow{2}{*}{$\begin{array}{c}\text { Razão de } \\
\text { Equivalência } \\
\operatorname{Re}\end{array}$} \\
\hline & $\mathrm{C} / \mathrm{C}^{\prime}$ & $\mathrm{L} / \mathrm{L}^{\prime}$ & $\mathrm{Cp} / \mathrm{Cp}$ & $\mathrm{Cr} / \mathrm{Cr}^{\mathrm{r}}$ & $\mathrm{P} / \mathrm{P}^{\prime}$ & & & & \\
\hline \multicolumn{10}{|c|}{ Solos litólicos } \\
\hline GRUPO 1 & & & & & & & & & \\
\hline 07RM/08RM & 1,10 & 1,08 & 1,10 & 1,27 & $1,0.5$ & 1,12 & 1,09 & 1,26 & 1,16 \\
\hline 07RM/21RM & 1,00 & 1,04 & 1,09 & 1,14 & 1,03 & 1,06 & 1,09 & 1,12 & 1,03 \\
\hline $08 \mathrm{RM} / 21 \mathrm{RM}$ & 0,91 & 0,96 & 0,99 & 0,89 & 0,98 & 0,95 & 1,00 & 0,90 & 0,90 \\
\hline \multicolumn{10}{|l|}{ GRUPO 2} \\
\hline 06RM/08RG & 1,12 & 1,03 & 0,97 & 1,03 & 1,09 & 1,05 & 1,19 & 1,10 & 0,92 \\
\hline 06RM/17RM & 1,13 & 0,97 & 0,92 & 0,90 & 1,12 & 1,01 & 1,18 & 1,02 & 0,86 \\
\hline 08RG/17RM & 1,01 & 0,94 & 0,95 & 0,88 & 1,03 & 0,96 & 0,99 & 0,92 & 0,93 \\
\hline \multicolumn{10}{|l|}{ GRUPO 3} \\
\hline 09RM/12RM & 0,97 & 0,92 & 1,02 & 0,90 & 1,09 & 0,98 & 0,93 & 0,96 & 1,03 \\
\hline 09RM/14RM & 1,05 & 0,63 & 1,05 & 0,69 & 0,98 & 0,88 & 0,68 & 0,77 & 1,13 \\
\hline $12 \mathrm{RM} / 14 \mathrm{RM}$ & 1,08 & 0,69 & 1,03 & 0,77 & 0,90 & 0,89 & 0,74 & 0,80 & 1,08 \\
\hline \multicolumn{10}{|c|}{ Solos podzólicos } \\
\hline GRUPO 1 & & & & & & & & & \\
\hline $20 \mathrm{RC} / 30 \mathrm{RC}$ & 1,19 & 1,02 & 0,96 & 1,10 & 0,98 & 1,05 & 1,19 & 1,10 & 0,92 \\
\hline $20 \mathrm{RC} / 43 \mathrm{RC}$ & 0,97 & 0,77 & 1,20 & 0,96 & 0,88 & 0,96 & 0,96 & 0,92 & 0,96 \\
\hline 30RC/43RC & 0,82 & 0,75 & 1,26 & 0,88 & 0,89 & 0,92 & 0,81 & 0,85 & 1,05 \\
\hline \multicolumn{10}{|l|}{ GRUPO 2} \\
\hline 06RC/27RC & 1,09 & 0,97 & 0,97 & 0,95 & 1,00 & 0,99 & 1,10 & 0,99 & 0,90 \\
\hline 06RC/61RC & 1,02 & 0,98 & 1,00 & 1,25 & 1,00 & 1,05 & 1,16 & 1,10 & 0,95 \\
\hline $27 \mathrm{RC} / 61 \mathrm{RC}$ & 0,94 & 1,02 & 1,04 & 1,32 & 1,00 & 1,06 & 1,05 & 1,13 & 1,08 \\
\hline \multicolumn{10}{|l|}{ GRUPO 3} \\
\hline 03RC/07RM & 1,01 & 0,87 & 1,04 & 1,00 & 1,00 & 0,98 & 0,80 & 0,97 & 1,21 \\
\hline 03RC/29RM & 1,03 & 0,80 & 1,04 & 1,21 & 0,98 & 1,01 & 0,87 & 1,02 & 1,17 \\
\hline 07RG/29RM & 1,02 & 0,91 & 1,00 & 1,21 & 0,98 & 1,02 & 1,09 & 1,05 & 0,96 \\
\hline \multicolumn{10}{|l|}{ GRUPO 4} \\
\hline $25 \mathrm{RC} / 29 \mathrm{RC}$ & 0,89 & 1,21 & 0,84 & 0,88 & 1,00 & 0,96 & 1,09 & 0,93 & 0,85 \\
\hline \multicolumn{10}{|l|}{ GRUPO 5} \\
\hline 21RC/44RC & 1,09 & 1,21 & 1,07 & 1,04 & 1,10 & 1,10 & 1,08 & 1,21 & 1,12 \\
\hline \multicolumn{10}{|l|}{ GRUPO 6} \\
\hline 02RP/65RC & 0,96 & 1,12 & 0,90 & 1,12 & 0,96 & 1,01 & 1,05 & 1,02 & 0,97 \\
\hline
\end{tabular}




\subsubsection{Características da rede de drenagem}

\subsubsection{Análise do número de segmentos de rios}

De acordo com a Lei de Horton (1945), existe uma relação entre os números de segmentos de rios de cada ordem e a ordem de ramificação, em termos de uma série geométrica inversa que tem como base a razão de ramificação. Vários autores, entre eles França (1968), Marchetti (1969), Fadel (1972), Leão (1973) e Carvalho (1977), constataram a Lei de Horton em estudos de solos. Estes autores atribuíram grande utilidade do número de rios para expressar a composição da rede de drenagem e a sua importância como parâmetro para diferenciar unidades de solos.

O número de segmentos de rios observados em cada ordem de ramificação e o número total para cada bacia, em ambos os solos, são apresentados na Tabela 4.

As equações que relacionam os números de rios às ordens de ramificação, ajustadas pela função logarítmica (logNw = loga - logb.w) de Maxwell (1955), com os respectivos coeficientes de determinação $\left(\mathrm{R}^{2}\right)$, para os dois solos, são apresentadas na Tabela 5.

Pela Tabela 5, observa-se que, no caso dos solos litólicos, as equações se ajustam bem à distribuição dos dados, apresentando alta correlação entre número e ordem de rios, o que significa pouca dispersão dos dados em torno da curva ajustada. A qualidade dẹsse ajuste é notada pelos altos coeficientes de determinação.

Nos solos podzólicos, os ajustes para os grupos 1, 2 e 3 apresentam coeficientes de determinação que indicam pouca dispersão dos dados em torno da curva ajustada. Observando os grupos 4, 5 e 6, percebe-se que estes apresentam dados ainda melhor correlacionados do que os 3 primeiros grupos, principalmente no caso do grupo 4, onde os dados são totalmente correlacionados, ajustando-se perfeitamente à função logarítmica de Maxwell (1955). 
Tabela 4. Número de segmentos de rios observados em cada ordem de ramificação e respectiva média ponderada, para bacias representativas de solos litólicos e podzólicos.

\begin{tabular}{|c|c|c|c|c|c|}
\hline $\begin{array}{l}\text { Bacia } \\
\text { Hidro- } \\
\text { gráfica }\end{array}$ & $\begin{array}{l}\text { Area } \\
\left(\mathrm{km}^{2}\right)\end{array}$ & Número de s & s de rios & $\operatorname{dem}(\mathrm{Nw})$ & $\begin{array}{c}\text { Total de cada } \\
\text { Bacia } \\
(\mathrm{N})\end{array}$ \\
\hline \multicolumn{6}{|c|}{ Solos litólicos } \\
\hline GRUPO 1 & & & & & \\
\hline $07 \mathrm{RM}$ & 1,09 & 11 & 3 & 1 & 15 \\
\hline $08 \mathrm{RM}$ & 1,00 & 10 & 2 & 1 & 13 \\
\hline $21 \mathrm{RM}$ & 1,00 & 12 & 3 & 1 & 16 \\
\hline Média ponderada & & 11,00 & 2,68 & $1, \mathbf{0 0}$ & 14,68 \\
\hline \multicolumn{6}{|l|}{ GRUPO 2} \\
\hline $06 \mathrm{RM}$ & 0,87 & 09 & 2 & 1 & 12 \\
\hline $08 \mathrm{RG}$ & 0,73 & 10 & 2 & 1 & 13 \\
\hline $17 \mathrm{RM}$ & & 08 & 3 & 1 & 12 \\
\hline Média ponderada & & 9,00 & 2,32 & 1,00 & 12,32 \\
\hline \multicolumn{6}{|l|}{ GRUPO 3} \\
\hline $09 \mathrm{RM}$ & 1,17 & 20 & 2 & 1 & 23 \\
\hline $12 \mathrm{RM}$ & 1,26 & 20 & 4 & 1 & 25 \\
\hline $14 \mathrm{RM}$ & 1,71 & 23 & 5 & 1 & 29 \\
\hline Média ponderada & & 21,24 & $\mathbf{3 , 8 5}$ & 1,00 & 26,09 \\
\hline \multicolumn{6}{|c|}{ Solos podzólicos } \\
\hline GRUPO 1 & & & & & \\
\hline $20 \mathrm{RC}$ & 0,25 & 09 & 2 & 1 & 12 \\
\hline $30 \mathrm{RC}$ & 0,21 & 06 & 2 & 1 & 09 \\
\hline $43 \mathrm{RC}$ & 0,26 & 07 & 2 & 1 & 10 \\
\hline Média ponderada & & $\mathbf{7 , 4 0}$ & 2,00 & $1, \mathbf{0 0}$ & 10,40 \\
\hline \multicolumn{6}{|l|}{ GRUPO 2} \\
\hline $06 \mathrm{RC}$ & 0,44 & 09 & 2 & 1 & 12 \\
\hline $27 \mathrm{RC}$ & 0,40 & 10 & 2 & 1 & 13 \\
\hline $61 \mathrm{RC}$ & 0,38 & 07 & 2 & 1 & 10 \\
\hline Média ponderada & & 8,70 & 2,00 & $\mathbf{1 , 0 0}$ & 11,70 \\
\hline \multicolumn{6}{|l|}{ GRUPO 3} \\
\hline $03 \mathrm{RC}$ & 0,67 & 17 & 2 & 1 & 20 \\
\hline 07 RG & 0,84 & 14 & 3 & 1 & 18 \\
\hline $29 \mathrm{RM}$ & 0,77 & 14 & 2 & 1 & 17 \\
\hline Média ponderada & & 14,88 & 2,37 & $\mathbf{1 , 0 0}$ & 18,25 \\
\hline \multicolumn{6}{|l|}{ GRUPO 4} \\
\hline $25 \mathrm{RC}$ & 1,01 & 21 & 4 & 1 & 26 \\
\hline $29 \mathrm{RC}$ & 0,93 & 27 & 6 & 1 & 34 \\
\hline Média ponderada & & $\mathbf{2 3 , 8 8}$ & 4,96 & $\mathbf{1 , 0 0}$ & 29,84 \\
\hline \multicolumn{6}{|l|}{ GRUPO 5} \\
\hline $21 \mathrm{RC}$ & 1,42 & 28 & 7 & 1 & 36 \\
\hline $44 \mathrm{RC}$ & 1,31 & 21 & 5 & 1 & 27 \\
\hline Média ponderada & & 24,64 & 6,04 & $\mathbf{1 , 0 0}$ & 31,68 \\
\hline \multicolumn{6}{|l|}{ GRUPO 6} \\
\hline $02 \mathrm{RP}$ & 1,19 & 11 & 3 & 1 & 15 \\
\hline $65 \mathrm{RC}$ & 1,13 & 12 & 4 & 1 & 17 \\
\hline Média ponderada & & 11,49 & 3,49 & 1,00 & 15,98 \\
\hline
\end{tabular}


Tabela 5. Equações ajustadas segundo Maxwell (1955) (logNw = loga - logb.w) para números de segmentos de rios, com os respectivos coeficientes de determinação $\left(\mathrm{R}^{2}\right)$, para bacias representativas de solos litólicos e podzólicos.

\begin{tabular}{|c|c|c|}
\hline Grupo & Equação & $\left(\mathbf{R}^{2}\right)$ \\
\hline \multicolumn{3}{|c|}{ Solos litólicos } \\
\hline G1 & $\log N w=1,5320-0,5270 w$ & 0,9896 \\
\hline G2 & $\log N w=1,3942-0,4771 w$ & 0,9821 \\
\hline G3 & $\log N w=1,9647-0,6636 w$ & 0,9954 \\
\hline \multicolumn{3}{|c|}{ Solos podzólicos } \\
\hline G1 & $\log N w=1,2593-0,4346 w$ & 0,9695 \\
\hline G2 & $\log N w=1,3530-0,4698 w$ & 0,9588 \\
\hline G3 & $\log N w=1,6864-0,5863 w$ & 0,9584 \\
\hline G4 & $\log \mathrm{Nw}=2,0692-0,6890 \mathrm{w}$ & 1,0000 \\
\hline G5 & $\log \mathrm{Nw}=2,1159-0,6950 \mathrm{w}$ & 0,9950 \\
\hline G6 & $\log \mathrm{Nw}=1,5947-0,5302 \mathrm{w}$ & 0,9998 \\
\hline
\end{tabular}

Na Tabela 6, encontram-se valores para a razão de ramificação $(\mathrm{Rb})$ das redes de drenagem, para os dois solos, calculados sobre os dados observados e representados em termos de média aritmética, média ponderada e antilog $b$.

Observando os dados dos solos litólocos na Tabela 6, pode-se verificar que a razão de ramificação média calculada pelas três formas resultou em valores bem próximos, quando se passa de uma ordem para outra mais baixa dentro de cada grupo, principalmente para os dois primeiros. No terceiro grupo, a variação é um pouco maior e, a exemplo do número de rios (Tabela 4), apresenta valores mais elevados em relação aos dois primeiros, sugerindo comportamento hidrológico diferenciado entre os mesmos.

Observando os dados dos solos podzólicos, verifica-se que a mesma tendência de proximidade de valores ocorre no caso dos grupos 1,4 e 6 . Nos demais grupos, percebe-se maior variação entre esses valores, sendo os grupos 3 e 5 os mais divergentes. Esta variação, a exemplo do que ocorreu com o número de rios (Tabela 4), sugere comportamento hidrológico diferenciado entre esses grupos de bacias.

Da mesma forma que o número de rios, a razão de ramificação mostrou tendência de formar uma seqüência crescente, onde os valores dos grupos 4 e 5 são 
superiores aos demais, principalmente em relação aos grupos 1 e 2, com incremento de mais de uma vez e meia em média.

Tabela 6. Valores observados e calculados da Razão de Ramificação (Rb) de redes de drenagem para bacias representativas de solos litólicos e podzólicos.

\begin{tabular}{|c|c|c|c|c|c|c|c|}
\hline \multirow{4}{*}{$\begin{array}{l}\text { Bacia } \\
\text { Hidro- } \\
\text { gráfica }\end{array}$} & \multicolumn{7}{|c|}{ Razão de ramificação } \\
\hline & \multicolumn{4}{|c|}{ Ordens relacionadas } & \multirow{3}{*}{$\begin{array}{l}\text { Média } \\
\text { aritmética }\end{array}$} & \multirow{3}{*}{$\begin{array}{c}\text { Média } \\
\text { ponderada }\end{array}$} & \multirow{3}{*}{$\begin{array}{l}\text { Maxwell } \\
\text { (antilog b) }\end{array}$} \\
\hline & \multicolumn{2}{|c|}{ Para cada bacia } & \multicolumn{2}{|c|}{ Média ponderada } & & & \\
\hline & $\mathrm{W} 1 / \mathrm{w} 2$ & w2/w3 & $w 1 p / w 2 p$ & $w 2 p / w 3 p$ & & & \\
\hline \multicolumn{8}{|c|}{ Solos litólicos } \\
\hline $07 \mathrm{RM}$ & 3,67 & 3 & & & & & GRUPO 1 \\
\hline $08 \mathrm{RM}$ & 5,00 & 2 & 4,10 & 2,68 & 3,45 & 3,39 & 3,32 \\
\hline $21 \mathrm{RM}$ & 4,00 & 3 & & & & & \\
\hline \multicolumn{8}{|l|}{ GRUPO 2} \\
\hline $06 \mathrm{RM}$ & 4,50 & 2 & & & & & \\
\hline $08 \mathrm{RG}$ & 5,00 & 2 & 3,88 & 2,32 & 3,20 & 3,10 & 3,00 \\
\hline $17 \mathrm{RM}$ & 2,67 & 3 & & & & & \\
\hline \multicolumn{8}{|l|}{ GRUPO 3} \\
\hline $09 \mathrm{RM}$ & 10,00 & 2 & & & & & \\
\hline $12 \mathrm{RM}$ & 5,00 & 4 & 5,52 & 3,85 & 5,10 & 4,69 & 4,61 \\
\hline $14 \mathrm{RM}$ & 4,60 & 5 & & & & & \\
\hline \multicolumn{8}{|c|}{ Solos podzólicos } \\
\hline GRUPO 1 & & & & & & & \\
\hline $20 \mathrm{RC}$ & 4,50 & 2 & 3,70 & 2,00 & 2,83 & 2,85 & 2,72 \\
\hline $30 \mathrm{RC}$ & 3,00 & 2 & & & & & \\
\hline $43 \mathrm{RC}$ & 3,50 & 2 & & & & & \\
\hline \multicolumn{8}{|l|}{ GRUPO 2} \\
\hline $06 \mathrm{RC}$ & 4,50 & 2 & 4,35 & 2,00 & 3,17 & 3,18 & 2,95 \\
\hline $27 \mathrm{RC}$ & 5,00 & 2 & & & & & \\
\hline $61 \mathrm{RC}$ & 3,50 & 2 & & & & & \\
\hline \multicolumn{8}{|l|}{ GRUPO 3} \\
\hline $03 \mathrm{RC}$ & 8,50 & 2 & 6,28 & 2,37 & 4,53 & 4,33 & 3,86 \\
\hline 07 RG & 4,67 & 3 & & & & & \\
\hline $29 \mathrm{RM}$ & 7,00 & 2 & & & & & \\
\hline \multicolumn{8}{|l|}{ GRUPO 4} \\
\hline $25 \mathrm{RC}$ & 5,25 & 4 & 4,81 & 4,96 & 4,94 & 4,89 & 4,89 \\
\hline $29 \mathrm{RC}$ & 4,50 & 6 & & & & & \\
\hline \multicolumn{8}{|l|}{ GRUPO 5} \\
\hline $\begin{array}{l}21 \mathrm{RC} \\
44 \mathrm{RC}\end{array}$ & $\begin{array}{l}4,00 \\
4,0\end{array}$ & $\begin{array}{l}7 \\
5\end{array}$ & 4,08 & 6,04 & 4,30 & 5,06 & 4,95 \\
\hline $44 \mathrm{KC}$ & 4,20 & 3 & & & & & \\
\hline \multicolumn{8}{|l|}{ GRUPO 6} \\
\hline $\begin{array}{l}02 \mathrm{RP} \\
65 \mathrm{RC}\end{array}$ & $\begin{array}{l}3,67 \\
3,00\end{array}$ & 3 & 3,29 & 3,49 & 3,42 & 3,39 & 3,39 \\
\hline . & 0,00 & 4 & & & & & \\
\hline
\end{tabular}




\subsubsection{Análise dos comprimentos dos rios}

Os comprimentos totais de segmentos de rios observados em cada ordem, juntamente com os comprimentos totais de cada bacia, e respectivas médias ponderadas, para os solos litólicos e podzólicos, são apresentados na Tabela 7.

A análise desses dados deve ser complementada com a observação das Figuras 12 a 16, onde são apresentadas as bacias e, ainda, observando a análise do número de rios, realizada anteriormente.

Pela Tabela 7, observa-se que nos solos litólicos, as bacias do grupo 2 apresentaram a menor variação para comprimentos de rios de primeira ordem e comprimento total, enquanto a maior variação ocorreu no grupo 3. Visto que a mesma tendência ocorre com os números de rios, pode-se inferir que as bacias do grupo 2 apresentam grande semelhança de comportamento hidrológico.

No caso dos solos podzólicos, a Tabela 7 mostra que a média ponderada do comprimento total de rios foi incrementada do grupo 1 ao 5 , na razão de aproximadamente uma vez e meia, de um grupo para outro. No grupo 6 , a média apresentou um valor intermediário aos dos grupos 4 e 5 .

Esta tendência de variação revela a heterogeneidade desta característica entre os grupos. Nestas condições, é impossível fazer qualquer comparação com as bacias dos solos litólicos, em termos de inferência sobre o tipo de solo que representam. Talvez a seleção de apenas um grupo mais representativo, em cada solo, proporcione indícios para inferir sobre esta questão, o que não é de maior importância neste caso.

Pelos valores da média ponderada na Tabela 7, verifica-se que nos grupos 2 e 3 dos solos litólicos, a lei dos comprimentos de rios de Horton não é obedecida com a mesma proximidade que a lei dos números de rios. Isto vem confirmar observações de Horton (1945), Schumm (1956), França (1068), Carvalho (1977) e outros. Na opinião de Carvalho (1977), esta observação indica que o comprimento total de rios é um parâmetro que, por si, não reflete as condições hidrológicas das unidades de solo. 
Tabela 7. Comprimento total de segmentos de rios observados em cada ordem de ramificação e o total em cada bacia, para solos litólicos e podzólicos.

\begin{tabular}{|c|c|c|c|c|c|}
\hline \multirow{2}{*}{$\begin{array}{l}\text { Bacia } \\
\text { Hidro- } \\
\text { gráfica }\end{array}$} & \multirow{2}{*}{$\begin{array}{l}\text { Área } \\
\left(\mathrm{km}^{2}\right)\end{array}$} & \multicolumn{3}{|c|}{ Comprimentos de rios em cada ordem - $\mathrm{Lw}(\mathrm{km})$} & \multirow{2}{*}{$\begin{array}{l}\text { Total } \\
\text { (Lt) }\end{array}$} \\
\hline & & $1^{\mathrm{a}}$ & $2^{\mathrm{a}}$ & $3^{\mathrm{a}}$ & \\
\hline & \multicolumn{4}{|c|}{ Solos litólicos } & \\
\hline GRUPO 1 & & & & & \\
\hline $07 \mathrm{RM}$ & 1,09 & 3,22 & 0,80 & 0,75 & 4,77 \\
\hline $08 \mathrm{RM}$ & 1,00 & 2,07 & 1,38 & 0,30 & 3,75 \\
\hline $21 \mathrm{RM}$ & 1,00 & 1,90 & 1,71 & 0,58 & 4,19 \\
\hline Média ponderada & & 2,42 & 1,28 & $\mathbf{0 , 5 5}$ & 4,25 \\
\hline \multicolumn{6}{|l|}{ GRUPO 2} \\
\hline $06 \mathrm{RM}$ & 0,87 & 1,67 & 0,58 & 0,92 & 3,17 \\
\hline $08 \mathrm{RG}$ & 0,73 & 1,62 & 0,75 & 0,72 & 3,09 \\
\hline $17 \mathrm{RM}$ & 0,74 & 1,63 & 1,08 & 0,81 & 3,52 \\
\hline Média ponderada & & 1,64 & $\mathbf{0 , 7 9}$ & $\mathbf{0 , 8 2}$ & 3,26 \\
\hline \multicolumn{6}{|l|}{ GRUPO 3} \\
\hline $09 \mathrm{RM}$ & 1,17 & 3,05 & 1,55 & 1,08 & 5,68 \\
\hline $12 \mathrm{RM}$ & 1,26 & 3,33 & 1,25 & 1,75 & 6,33 \\
\hline $14 \mathrm{RM}$ & 1,71 & 5,12 & 1,71 & 1,42 & 8,25 \\
\hline Média ponderada & & 3,99 & 1,52 & 1,42 & 6,94 \\
\hline \multicolumn{6}{|c|}{ Solos podzólicos } \\
\hline \multicolumn{6}{|l|}{ GRUPO 1} \\
\hline $20 \mathrm{RC}$ & 0,25 & 0,85 & 0,63 & 0,17 & 1,65 \\
\hline $30 \mathrm{RC}$ & 0,21 & 0,87 & 0,55 & 0,08 & 1,50 \\
\hline $43 \mathrm{RC}$ & 0,26 & 0,85 & 0,75 & 0,11 & 1,71 \\
\hline Média ponderada & & $\mathbf{0 , 8 6}$ & 0,65 & $\mathbf{0 , 1 2}$ & 1,63 \\
\hline \multicolumn{6}{|l|}{ GRUPO 2} \\
\hline $06 \mathrm{RC}$ & 0,44 & 1,58 & 0,38 & 0,50 & 2,46 \\
\hline $27 \mathrm{RC}$ & 0,40 & 1,42 & 0,83 & 0,35 & 2,60 \\
\hline $61 \mathrm{RC}$ & 0,38 & 1,19 & 0,28 & 0,50 & 1,97 \\
\hline Média ponderada & & 1,41 & $\mathbf{0 , 5 0}$ & $\mathbf{0 , 4 5}$ & 2,35 \\
\hline \multicolumn{6}{|l|}{ GRUPO 3} \\
\hline $03 \mathrm{RC}$ & 0,67 & 2,75 & 0,58 & 0,92 & 4,25 \\
\hline 07 RG & 0,84 & 2,45 & 1,25 & 0,55 & 4,25 \\
\hline $29 \mathrm{RM}$ & 0,77 & 2,07 & 1,28 & 0,17 & 3,52 \\
\hline Média ponderada & & 2,41 & 1,06 & $\mathbf{0 , 5 3}$ & $\mathbf{4 , 0 0}$ \\
\hline \multicolumn{6}{|l|}{ GRUPO 4} \\
\hline $25 \mathrm{RC}$ & 1,01 & 3,16 & 1,75 & 0,92 & 5,83 \\
\hline $29 \mathrm{RC}$ & 0,93 & 3,73 & 1,67 & 1,25 & 6,65 \\
\hline Média ponderada & & $3, \mathbf{4 3}$ & 1,71 & 1,08 & 6,22 \\
\hline \multicolumn{6}{|l|}{ GRUPO 5} \\
\hline $21 \mathrm{RC}$ & 1,42 & 4,42 & 2,23 & 1,35 & 8,00 \\
\hline $44 \mathrm{RC}$ & 1,31 & 3,96 & 2,75 & 1,00 & 7,71 \\
\hline Média ponderada & & 4,20 & 2,48 & 1,18 & 7,86 \\
\hline \multicolumn{6}{|l|}{ GRUPO 6} \\
\hline $02 \mathrm{RP}$ & 1,19 & 2,58 & 1,42 & 0,75 & 4,75 \\
\hline $65 \mathrm{RC}$ & 1,13 & 1,95 & 1,25 & 1,05 & 4,25 \\
\hline Média ponderada & & 2,27 & 1,34 & 0,90 & $\mathbf{4 , 5 1}$ \\
\hline
\end{tabular}


Para reforçar esta discussão, as equações ajustadas segundo França (1968) na Tabela 8, mostram que, para os grupos 2 e 3, o ajuste não foi tão bom quanto no caso do número de rios, uma vez que seus coeficientes de determinação $\left(\mathrm{R}^{2}\right)$ são bem inferiores $(0,7098$ e 0,7992 , respectivamente).

Observando os valores da média ponderada para os solo podzólicos Tabela 7, verifica-se que para os grupo 1 e 2 , a lei dos comprimentos de rios de Horton não se ajusta bem, a exemplo dos grupos 2 e 3 dos solos litólicos. Esta constatação pode ser confirmada pelos dados da Tabela 8 , em função dos respectivos coeficientes de determinação. Como se observa, estes coeficientes são mais baixos nos grupos 1 e 2 . Já nos demais grupos, comprimento e ordem de rios são altamente correlacionados.

O comprimento médio de rios observados para os dois solos, em cada ordem de ramificação e total nas bacias, são apresentados na Tabela 9. Estes valores foram obtidos dividindo-se a soma dos comprimentos de rios de cada ordem pelos respectivos números de segmentos e a soma do total de rios de cada bacia pelo respectivo número de rios.

Tabela 8. Equações ajustadas segundo França (1968) (logLw = loga - logb.w) para comprimentos totais de segmentos de rios, com os respectivos coeficientes de determinação $\left(\mathrm{R}^{2}\right)$, para bacias representativas de solos litólicos e podzólicos.

\begin{tabular}{|c|c|c|}
\hline Grupo & Equação & $\left(\mathbf{R}^{2}\right)$ \\
\hline \multicolumn{3}{|c|}{ Solos litólicos } \\
\hline G1 & $\log L w=0,7206-0,3217 w$ & 0,9935 \\
\hline G2 & $\log L w=0,3098-0,1505 w$ & 0,7098 \\
\hline G3 & $\log L w=0,7604-0,2243 w$ & 0,7992 \\
\hline \multicolumn{3}{|c|}{ Solos podzólicos } \\
\hline G1 & $\log L w=0,4642-0,4277 w$ & 0,8542 \\
\hline G2 & $\log L w=0,3298-0,2480 w$ & 0,8185 \\
\hline G3 & $\log L w=0,7016-0,3289 w$ & 0,9976 \\
\hline G4 & $\log L w=0,7691-0,2509 w$ & 0,9862 \\
\hline G5 & $\log L w=0,9146-0,2757 w$ & 0,9905 \\
\hline G6 & $\log L w=0,5476-0,2009 w$ & 0,9936 \\
\hline
\end{tabular}


Tabela 9. Comprimento médio de rios observados em cada ordem de ramificação e o total, para bacias representativa de solos litólicos e podzólicos.

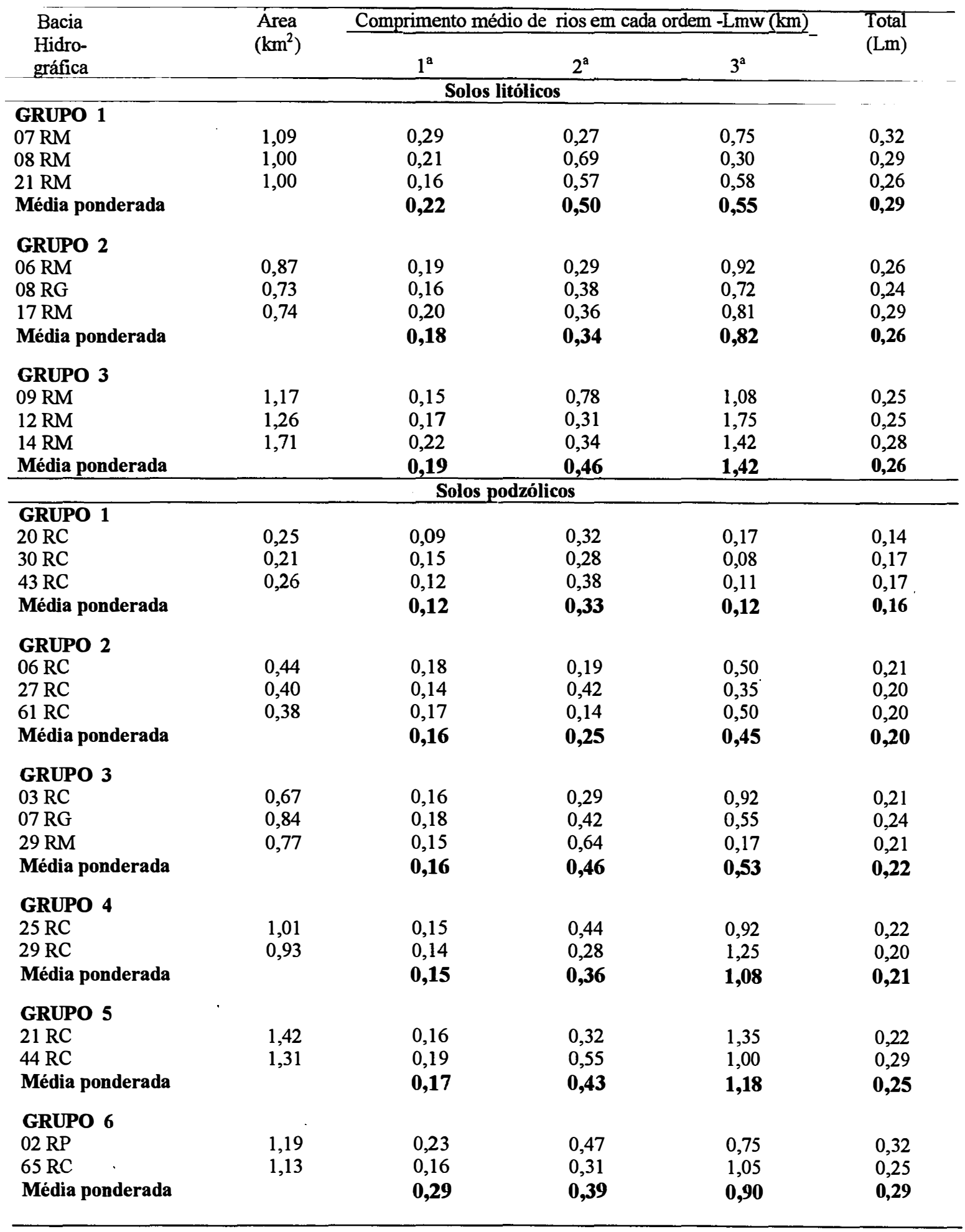


Para os solos litólicos, a análise destes dados mostra que houve um aumento do comprimento médio dos rios de $3^{\mathrm{a}}$ ordem do grupo 1 para o grupo 3 . Este comportamento está de acordo com os dados da Tabela 7, para os comprimentos de rios. Como o divisor nesta média é a unidade, comprimento total e comprimento médio são equivalentes neste caso. Já pelas Figuras 12 e 13, percebe-se o alongamento das bacias no mesmo sentido, correspondendo, igualmente, ao aumento de comprimento dos rios de $3^{\mathrm{a}}$ ordem.

Para os solos podzólicos, os dados da Tabela 9 mostram que houve um aumento do comprimento médio dos rios de $3^{\mathrm{a}}$ ordem do grupo 1 ao grupo 5. Da mesma forma que se analisou o caso dos solos litólicos, isto pode ser comprovado pela observação da Tabela 7. Observando ainda as Figuras 14 e 15, constata-se o aumento no tamanho das bacias neste mesmo sentido, o que deve corresponder, igualmente, ao aumento de comprimento dos rios de $3^{\mathrm{a}}$ ordem.

No caso do grupo 6 , o comprimento médio dos rios de $3^{\text {a }}$ ordem é ligeiramente inferior em relação aos grupos 4 e 5 . Pela Figura 16, percebe-se que as bacias deste grupo são menores do que as dos grupo 4 e 5 , além de apresentarem comportamento hidrológico diferente.

Em termos de valores médios dos grupos, para o comprimento médio do total de rios, pode-se afirmar que quase não houve diferença entre os grupos 2,3 e 4, os quais apresentam valores intermediários aos dos grupos 1 e 5 . Por outro lado, este valor se eleva no grupo seis, refletindo, portanto, comportamento hidrológico diferente em relação aos demais.

Com relação à média ponderada, os dados mostram valores iguais de segmentos de rios de $1^{\mathrm{a}}$ e $3^{\mathrm{a}}$ ordem no grupo 1 do solos podzólicos.

As equações que relacionam os comprimentos médios de rios às ordens de ramificação (logLm = loga - blog.w), segundo Vasques Filho (1972), e respectivos coeficientes de determinação, para os dois solos, estão representadas na Tabela 10. 
Tabela 10. Equações ajustadas segundo Vasques Filho (1972) (logLm = loga blog.w) para comprimentos médios de rios, com os respectivos coeficientes de determinação $\left(\mathrm{R}^{2}\right)$, para bacias representativas de solos litólicos e podzólicos.

\begin{tabular}{|c|c|c|}
\hline Grupo & Equação & $\left(\mathbf{R}^{2}\right)$ \\
\hline \multicolumn{3}{|c|}{ Solos litólicos } \\
\hline G1 & $\log \mathrm{Lm}=-0,8040+0,1990 w$ & 0,8271 \\
\hline G2 & $\log L m=-1,0917+0,3293 w$ & 0,9914 \\
\hline G3 & $\log \mathrm{Lm}=-1,1756+0,4368 w$ & 0,9952 \\
\hline \multicolumn{3}{|c|}{ Solos podzólicos } \\
\hline G1 & $\log L m=-0,7875+0,0068 w$ & 0,0007 \\
\hline G2 & $\log L m=-1,0178+0,2199 w$ & 0,9909 \\
\hline G3 & $\log \mathrm{Lm}=-0,9770+0,2549 w$ & 0,8446 \\
\hline G4 & $\log L m=-1,2857+0,4354 w$ & 0,9976 \\
\hline G5 & $\log L m=-1,1818+0,4156 w$ & 0,9990 \\
\hline G6 & $\log L m=-1,0477+0,3302 w$ & 0,9975 \\
\hline
\end{tabular}

Comparando os coeficientes de determinação das equações entre comprimentos totais e comprimentos médios, pode-se dizer que estes últimos apresentaram melhores resultados para os solos litólicos, tendo em vista manter correlações mais altas dentro dos grupos 2 e 3 , enquanto o comprimento total apresenta valores mais baixos nos mesmos grupos (Tabela 8).

Para os solos podzólicos, a Tabela 10 mostra que os coeficientes de determinação dos grupos 2, 4, 5 e 6 indicam correlação muito alta entre comprimentos médios e ordens de rios. No grupo 1, entretanto, comprimentos médios e ordens de rios não se correlacionam $\left(R^{2}=0,0007\right)$. Excluindo-se este grupo, pode-se considerar que os demais mostraram boa correlação e, como um todo, apresentando consistência semelhante ao comprimento total.

De maneira geral, pode-se aceitar que estes resultados mostraram-se mais consistente para o comprimento médio do que para o total, concordando com Horton (1945), França (1969), Fadel (1972), Vasques Filho (1972), Gevaerd (1974), Carvalho (1977) e outros. 


\subsubsection{Características do padrão de drenagem}

No caso do presente trabalho, os solos apresentam características do padrão de drenagem muito similares, de maneira que as características descritivas não se mostraram úteis para indicar diferenças entre solos. Talvez o fato das unidades serem definidas a nível de grupamentos, tenha contribuído para equiparar as características que refletem o desenvolvimento do padrão de drenagem, ao ponto de não mostrar diferenças por conta do tipo de solo onde o mesmo se desenvolveu.

Na opinião de França (1968), a descrição de características do padrão, por mais detalhada que seja, sempre permanecerá um tanto vaga para permitir a identificação e delimitação de solos por fotointerpretação, a menos que se trate de trabalhos conduzidos a um nível de generalização muito grande.

Diante destas limitações, realizou-se a análise da rede de drenagem apenas sob o aspecto das características quantitativas.

A importância dessas características, com base em amostragem representativa e medições simples, deve-se ao fato de permitir uma descrição do padrão de drenagem em termos mais objetivos, ao contrário das características descritivas, que apresentam o aspecto da subjetividade como principal limitação.

Vários autores, dentre eles França (1968), Marchetti (1969), Fadel (1972), Vasques Filho (1972), Souza (1975) e Carvalho (1977), para dar exemplo, trabalhando com solos a nível de séries e com bacias hidrográficas pequenas, demonstraram que nessas condições os índices apresentam consistência e refletem a influência do fator solo sobre o desenvolvimento das redes de drenagem.

$\mathrm{Na}$ Tabela 11 estão reunidas as características quantitativas dos padrões de drenagem e a classificação da textura topográfica com base na razão de textura média para todas as bacias e grupos dos dois solos. 
Tabela 11. Características quantitativas do padrão de drenagem e classes de textura topográfica de bacias representativas de solos litólicos e podzólicos.

\begin{tabular}{|c|c|c|c|c|c|c|}
\hline $\begin{array}{c}\text { Bacia } \\
\text { Hidro- } \\
\text { gráfica } \\
\text { Referência }\end{array}$ & $\left(\mathrm{km}^{2}\right)$ & $\begin{array}{c}\begin{array}{c}\text { Densidade de } \\
\text { drenagem }\end{array} \\
\left(\mathrm{km} / \mathrm{km}^{2}\right) \\
\end{array}$ & $\begin{array}{c}\text { Frequência de } \\
\text { Rios } \\
\left(\mathrm{N} / \mathrm{km}^{2}\right) \\
\end{array}$ & $\begin{array}{c}\text { Textura } \\
\text { De drenagem } \\
(\mathrm{N} / \mathrm{km})\end{array}$ & $\begin{array}{l}\text { Razão } \\
\text { de textura média }\end{array}$ & $\begin{array}{c}\text { Classe } \\
\text { de textura } \\
\text { topográfica }\end{array}$ \\
\hline & & \multicolumn{3}{|c|}{ Solos Litólicos } & \multirow{6}{*}{3,82} & \multirow{6}{*}{ Média } \\
\hline GRUPO 1 & & & & & & \\
\hline $07 \mathrm{RM}$ & 1,09 & 4,38 & 13,76 & 3,82 & & \\
\hline $08 \mathrm{RM}$ & 1,00 & 3,75 & 13,00 & 3,47 & & \\
\hline $21 \mathrm{RM}$ & 1,00 & 4,19 & 16,00 & 4,18 & & \\
\hline Média & 1,03 & 4,11 & 14,25 & 3,82 & & \\
\hline \multicolumn{7}{|l|}{ GRUPO 2} \\
\hline $06 \mathrm{RM}$ & 0,87 & 3,64 & 13,79 & 2,94 & \multirow[t]{3}{*}{3,21} & \multirow[t]{4}{*}{ Média } \\
\hline 08 RG & 0,73 & 4,23 & 17,81 & 3,47 & & \\
\hline $17 \mathrm{RM}$ & 0,74 & 4,76 & 16,22 & 3,29 & & \\
\hline Média & 0,78 & 4,21 & 15,94 & 3,23 & & \\
\hline \multicolumn{7}{|l|}{ GRUPO 3} \\
\hline $09 \mathrm{RM}$ & 1,17 & 4,85 & 19,66 & 4,45 & \multirow[t]{4}{*}{5,12} & \multirow[t]{4}{*}{ Média } \\
\hline $12 \mathrm{RM}$ & 1,26 & 5,02 & 19,84 & 5,26 & & \\
\hline $14 \mathrm{RM}$ & 1,71 & 4,82 & 16,96 & 5,48 & & \\
\hline Média & 1,38 & 4,90 & 18,82 & 5,06 & & \\
\hline Média geral & & 4,41 & 16,34 & 4,04 & 4,05 & \\
\hline \multicolumn{7}{|c|}{ Solos Podzólicos } \\
\hline \multicolumn{7}{|l|}{ GRUPO 1} \\
\hline $20 \mathrm{RC}$ & 0,25 & 6,60 & 48,00 & 6,32 & \multirow[t]{4}{*}{5,22} & \multirow{4}{*}{ Média } \\
\hline $30 \mathrm{RC}$ & 0,21 & 7,14 & 42,86 & 4,66 & & \\
\hline $43 \mathrm{RC}$ & 0,26 & 6,58 & 38,46 & 4,61 & & \\
\hline $\begin{array}{r}\text { Média } \\
\text { GRUPO } 2\end{array}$ & 0,24 & 6,77 & 43,11 & 5,20 & & \\
\hline $06 \mathrm{RC}$ & 0,44 & 5,59 & 27,27 & 4,80 & \multirow[t]{4}{*}{4,68} & \multirow[t]{4}{*}{ Média } \\
\hline $27 \mathrm{RC}$ & 0,40 & 6,50 & 32,50 & 5,20 & & \\
\hline $61 \mathrm{RC}$ & 0,38 & 5,18 & 26,32 & 4,00 & & \\
\hline Média & $\mathbf{0 , 4 1}$ & 5,76 & 28,70 & 4,67 & & \\
\hline \multicolumn{7}{|l|}{ GRUPO 3} \\
\hline $03 \mathrm{RC}$ & 0,67 & 6,34 & 29,85 & 6,15 & \multirow[t]{4}{*}{5,57} & \multirow[t]{4}{*}{ Média } \\
\hline 07 RG & 0,84 & 5,06 & 21,43 & 5,54 & & \\
\hline $29 \mathrm{RM}$ & 0,77 & 4,57 & 22,08 & 5,11 & & \\
\hline Média & 0,76 & 5,32 & 24,45 & 5,60 & & \\
\hline \multicolumn{7}{|l|}{ GRUPO 4} \\
\hline $25 \mathrm{RC}$ & 1,01 & 5,77 & 25,74 & 6,37 & \multirow[t]{4}{*}{7,29} & \multirow[t]{4}{*}{ Fina } \\
\hline $29 \mathrm{RC}$ & 0,93 & 7,15 & 36,56 & 8,29 & & \\
\hline Média & 0,97 & 6,46 & 31,15 & 7,33 & & \\
\hline \multicolumn{5}{|l|}{ GRUPO 5} & & \\
\hline $21 \mathrm{RC}$ & 1,42 & 5,63 & 25,35 & 3,75 & \multirow[t]{3}{*}{3,91} & Média \\
\hline $44 \mathrm{RC}$ & 1,31 & 5,89 & 20,61 & 4,08 & & \\
\hline Média & 1,37 & 5,76 & 22,98 & 3,92 & & \\
\hline GRUPO 6 & & & & & & \\
\hline $02 \mathrm{RP}$ & 1,19 & 3,99 & 12,61 & 7,16 & 6,56 & Fina \\
\hline $65 \mathrm{RC}$ & 1,13 & 3,76 & 15,04 & 5,91 & & \\
\hline Média & 1,16 & 3,88 & 13,83 & 6,54 & & \\
\hline Média geral & & 5,66 & 27,37 & 5,54 & 5,54 & \\
\hline
\end{tabular}


Observando a Tabela 11, pode-se dizer que, de modo geral, os valores encontrados para esses índices nos solos podzólicos foram superiores aos dos solos litólicos. Também percebe-se que, no caso dos solos lítólicos, o grupo 3 apresenta valores ligeiramente superiores aos dois primeiros. Já nos solos podzólicos, a divergência é bem aparente na freqüência de rios, onde o grupo 1 apresenta valor bem superior e o grupo 6 bem inferior aos demais. Com relação à densidade de drenagem, a diferença mais acentuada mostrou-se no grupo 6 em relação aos demais. A razão de textura média foi classificada como fina nos grupos 4 e 6 , enquanto os demais foram classificados como média, embora o grupo 5 apresente um valor um pouco inferior aos 3 primeiros.

Apesar de a frequência de rios ter sido o índice mais sensível para indicar distinção no comportamento hidrológico da rede de drenagem dos dois solos, ela vem reforçar a pequena diferença mostrada pela densidade de drenagem que, isoladamente, parece ser um fraco indicador desta diferença. Portanto, considerou-se que ambos os índices, freqüência de rios e densidade de drenagem, são importantes neste caso, para serem utilizados com a finalidade de caracterizar quantitativamente as redes de drenagem de bacias hidrográficas, conforme sugerido por Horton (1945).

França (1968), verificou que o melhor índice para diferenciar solos de séries diferentes foi a frequência de rios, numa situação, e a densidade de drenagem, em outra. Para o autor, a importância de considerar as duas características está no fato de ambas relacionarem à composição da rede (comprimento total e número de segmentos de rios) à área, que é uma variável muito mais importante do que o perímetro. 


\subsection{Análise digital}

\subsubsection{Processamento digital das imagens}

\subsubsection{Digitalização das fotografias}

Após a digitalização, as imagens (fotografias aéreas digitalizadas) ficaram com uma estrutura de aproximadamente 640 colunas por 680 linhas (435.200 "pixels") e quantização em 256 níveis de cinza. Em sensoriamento remoto, freqüentemente uma imagem consiste de $512 \times 512$ ou 1024x 1024 "pixels", cada um quantizado com 6 "bits" (64 níveis) a 10 "bits" (1024 níveis) (Mascarenhas, 1987).

A visualização em tela das fotografias digitalizadas mostrou que suas características foram mantidas, apresentando definição visual similar às originais no formato analógico. Neste aspecto, foi satisfeita uma das exigências básicas dos procedimentos de processamento de imagem, que é a capacidade de transformação da imagem entre os estados contínuo e discreto, conforme se refere Curran (1988).

Transformados para o formato digital, os dados ficaram prontos para serem manipulados posteriormente com a aplicação de técnicas de realce. No momento da digitalização, apenas pequenos ajustes tonais foram implementados, na tentativa de minimizar diferenças tonais, de uma ou outra fotografia que se apresentava com tonalidade mais clara ou mais escura dentro do conjunto

\subsubsection{Realce de imagens}

Seguindo a forma de apresentação na metodologia, os resultados serão discutidos na seguinte ordem: manipulação de contrastes, filtragem digital e realce espectral 
A Figura 17, apresenta resultados da aplicação de aumento linear de contraste e equalização de histograma, juntamente com a imagem sem tratamento de realce.

Segundo Quintanilha (1990), a técnica de modificação de histograma é a primeira atividade ou manipulação a ser conduzida sobre a imagem, cujo objetivo é modificar os níveis de cinza de tal modo que se obtenha um histograma com a forma desejada pelo usuário. A idéia é redistribuir os valores de níveis de cinza na imagem de modo a melhorar a qualidade da visualização da informação nela contida.

Observando a imagem da Figura 17b, resultado da aplicação do aumento linear de contraste, não se percebe nenhuma diferença em relação à imagem sem realce (Figura 17a). A forma do histograma, em ambos os casos, é a mesma. Como a fotografia apresentou distribuição de níveis de cinza em todo o intervalo de 0 a 255 (Figura 17a), o resultado do aumento linear de contraste foi nulo (Figura 17b).

Segundo Crósta (1992), uma das aplicações mais comuns do aumento linear de contraste é na preparação de composições coloridas usando três bandas de um sensor, permitindo uma maior variação de matizes nas três cores básicas (vermelho, azul e verde) às quais são atribuídas as três bandas, proporcionando boa distribuição de cores na composição resultante.

Ao contrário do aumento linear de contraste, a equalização de histograma destacou-se um pouco na formação de contraste (Figura 17c), cuja diferença é perceptível em relação à imagem sem realce (Figura 17a). Segundo Crósta (1992), a equalização de histograma (ou achatamento) parte do princípio que o contraste de uma imagem seria otimizado se todos os 256 níveis de intensidade fossem igualmente utilizados, o que na verdade não é possível, devido à natureza discreta dos dados digitais da imagem. Pela Figura 17b, verifica-se que uma aproximação foi conseguida, havendo um espalhamento do pico do histograma. 
a)
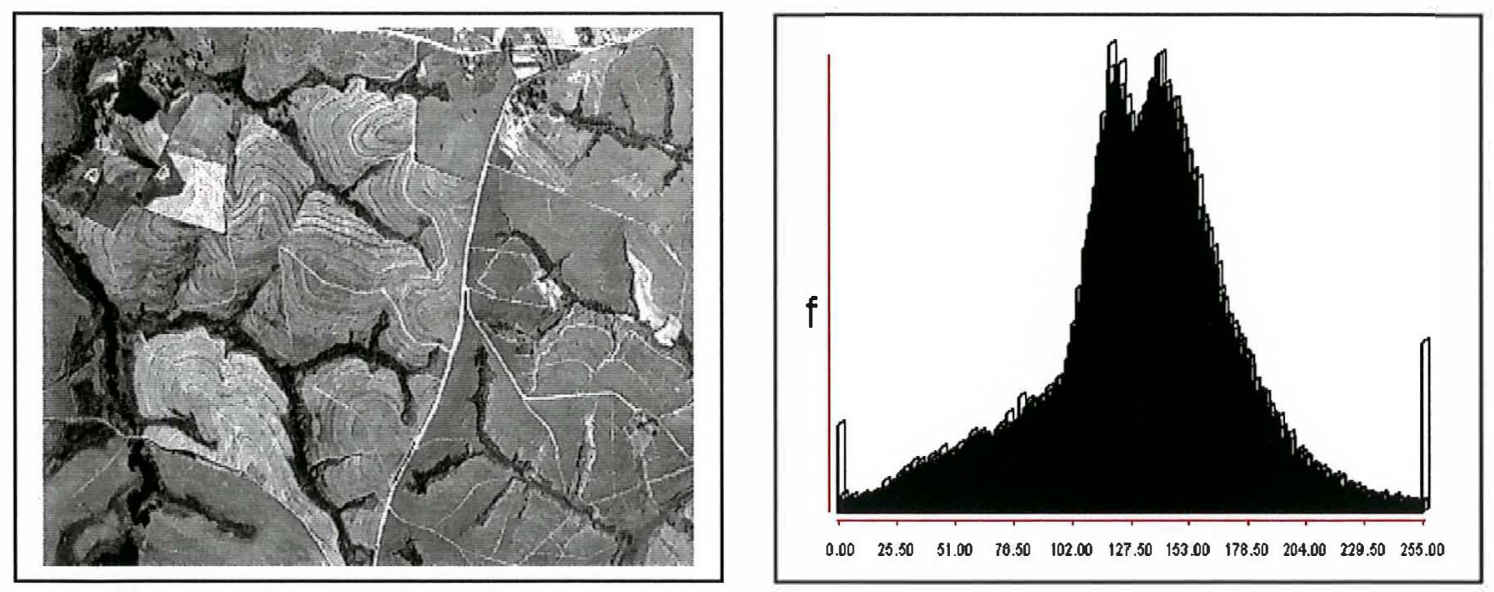

b)
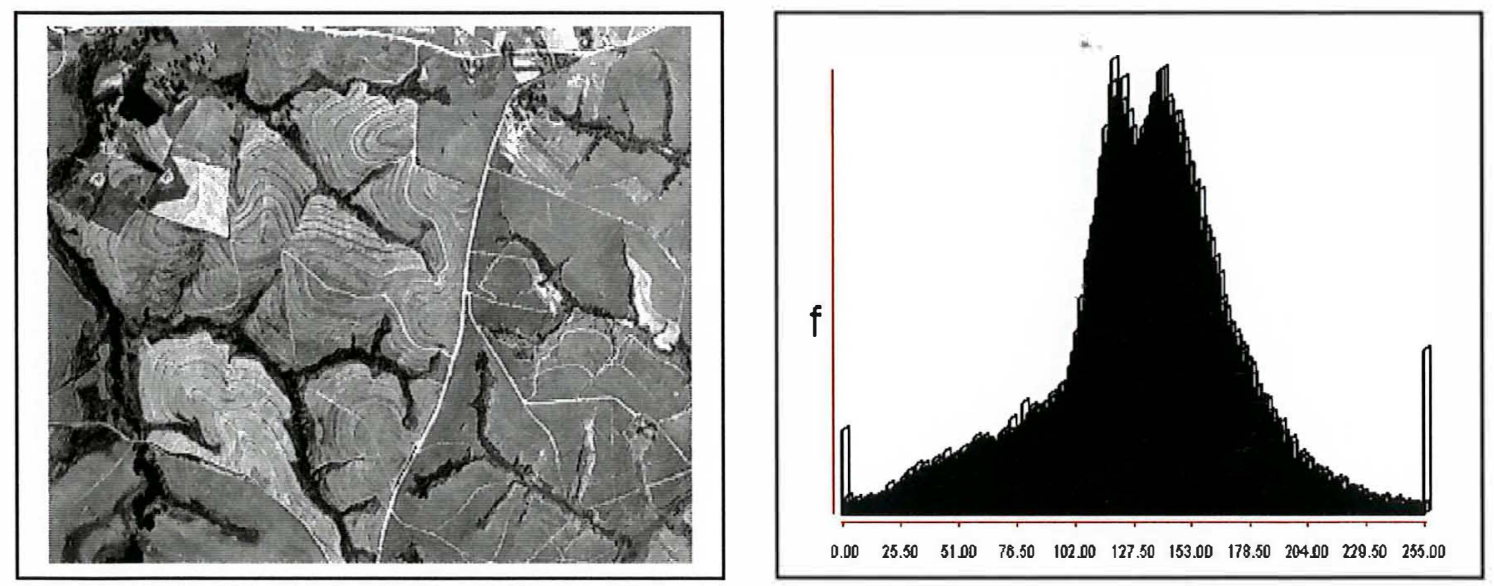

c)
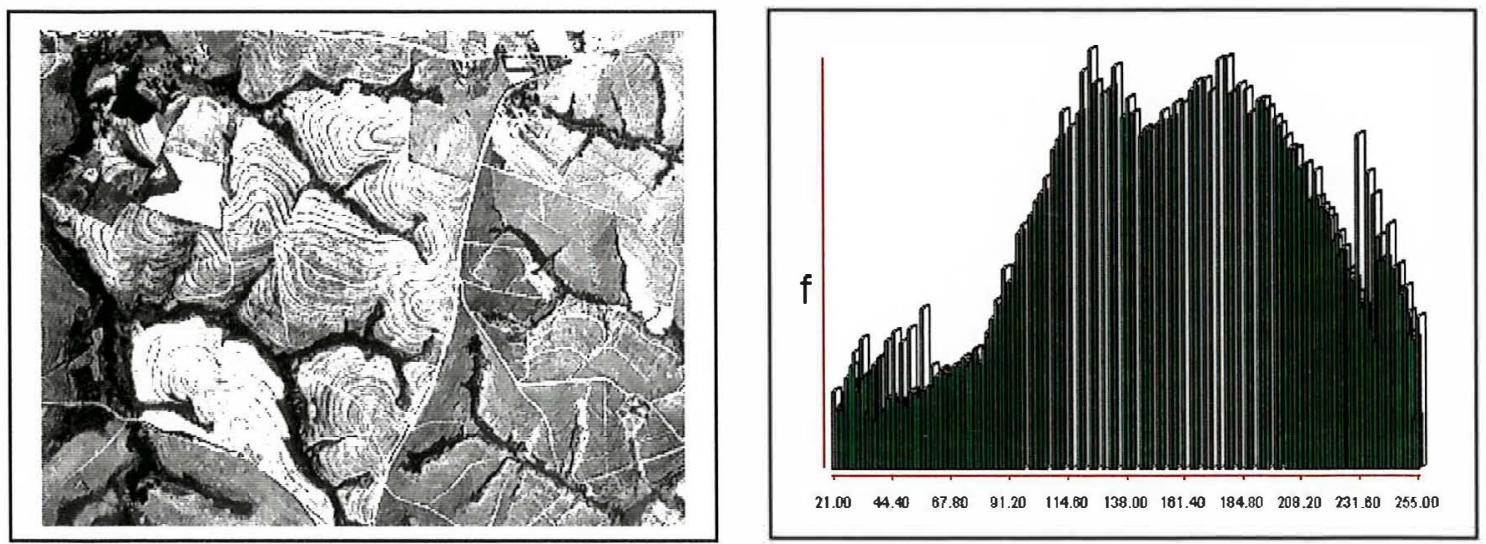

Figura 17 - Realce de fotografias aéreas digitalizadas por modificação de histogramas: a) fotografia sem realce; b) aumento linear de contraste; c) equalização de histograma. 
A filtragem espectral, consistiu da aplicação de filtros do tipo passa-alta, não direcional, para realce de bordas, utilizando matriz $3 \times 3$ como máscara. Neste caso, utilizaram-se como base o filtro passa-alta e o filtro loplaciano reaplicado à imagem original, empregados por Walsh et al. (1990), em dados de TM, para evidenciar a hidrografia da área estudada e extrair características da paisagem, como tamanho, forma, localização e orientação de rios, lagos e geleiras.

Vários testes foram realizados, fazendo-se algumas modificações a partir do modelo de Walsh et al. (1990). Os resultados que mostraram o melhor contraste estão apresentados na Figura $18 \mathrm{e}$, as máscaras, mostradas a seguir.

Filtro passa-alta

\begin{tabular}{rrrrrrr} 
Base (Walsh et al., 1990) & \multicolumn{3}{c}{ Modificado } \\
-1 & -2 & 1 & -1 & -2 & 1 \\
-2 & 5 & -2 & -2 & -5 & -2 \\
1 & -2 & 1 & 1 & -2 & 1
\end{tabular}

Filtro Laplaciano

\begin{tabular}{ccccccc} 
Base (Walsh et al,1990) & \multicolumn{3}{c}{ Modificado } \\
0 & -1 & 0 & 0 & -1 & 0 \\
-1 & 5 & -1 & -1 & -5 & -1 \\
0 & -1 & 0 & 0 & -1 & 0
\end{tabular}

Segundo Walsh et al. (1990), os filtros passa-alta utilizados acentuaram os detalhes em geral, enquanto filtros laplacianos não direcionais de realce de bordas reduziram a zero todos os valores de "pixel" exceto aqueles associados com bordas. No caso presente, o resultado não foi semelhante, o que levou a introduzir modificações, chegando-se aos resultados apresentados na Figura 18.

Pela Figura 18, observa-se que os filtros, em ambos os casos, correspondem ao negativo da fotografia original, ou seja, alvos que apareciam em tons escuros na imagem original aparecem em tons claros na imagem filtrada e vice-versa.

Neste aspecto, observa-se que feições de tonalidades claras, como estradas, caminhos, curvas de nível etc., aparecem em tons bem escuros como se fosse um mapa básico sobreposto sobre a imagem. Além disto, a noção de relevo também se manifesta de forma inversa à imagem original, como uma visão pseudoestereoscópica. 
a)

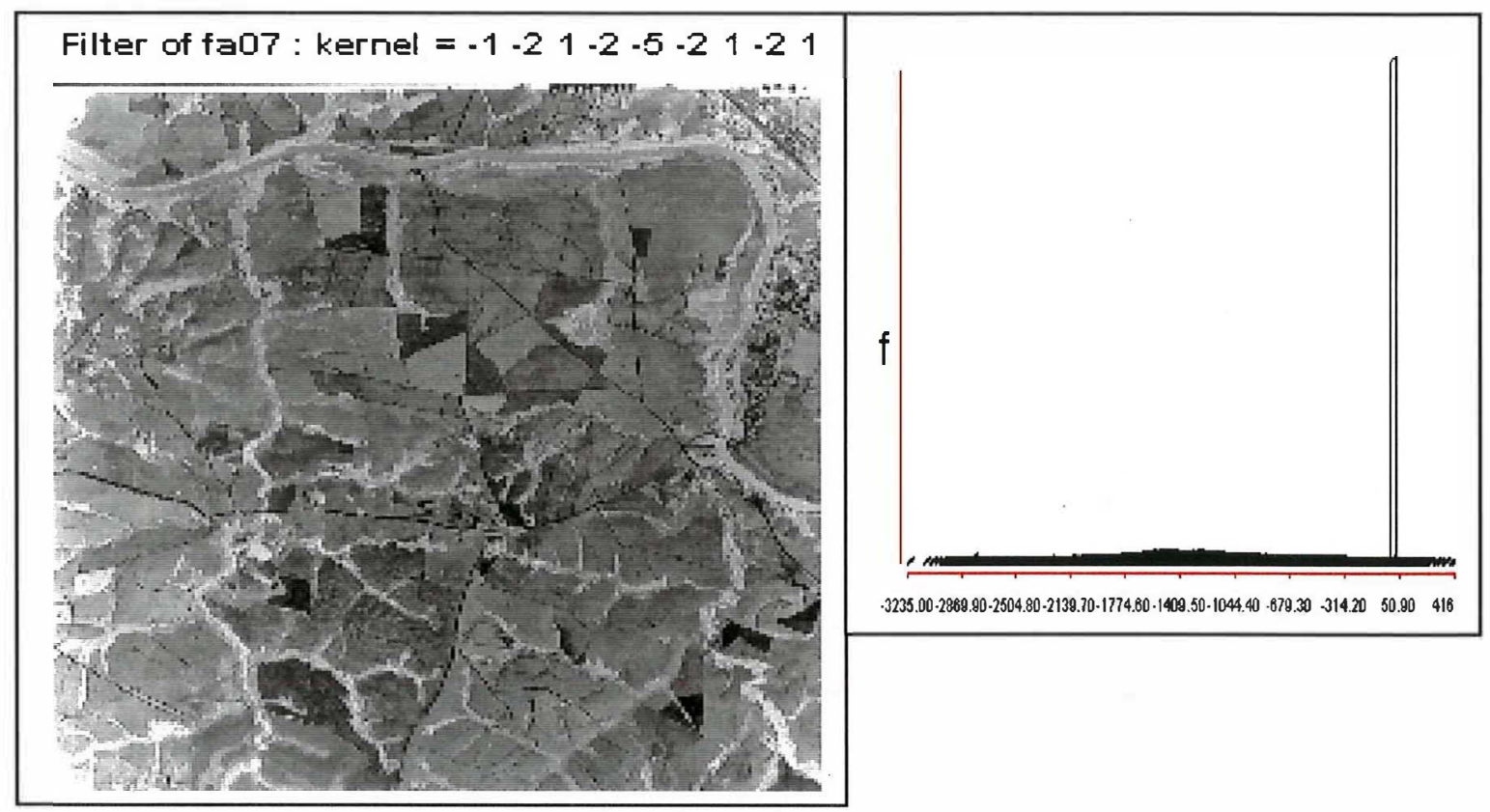

b)

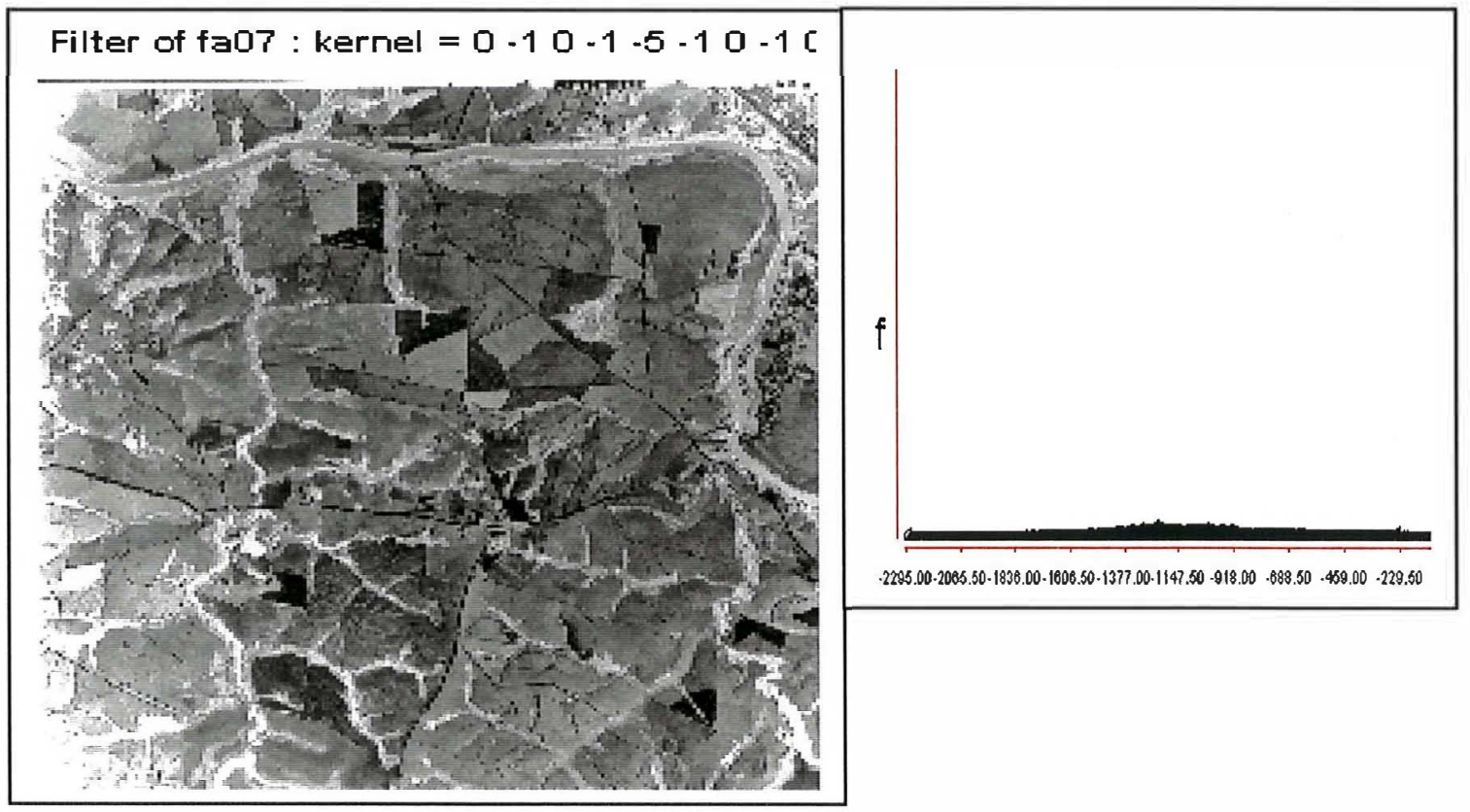

Figura 18 - Realce de fotografias aéreas digitalizadas por filtragem digital: a) filtro passa-alta; b) filtro laplaciano (modificados de Walsh et al., 1990). 
A Figura 19 mostra realces espectrais em composições coloridas, resultantes de transformações no espaço de cores. A Figura 19a mostra o efeito da componente $L$ da transformação HLS, com atribuição das cores verde, vermelha e azul, respectivamente, para realizar a composição colorida. A segunda composição (Figura 19b), mostra o efeito da componente K resultante da transformação KMC, pela atribuição das cores vermelho, verde e azul, respectivamente, para realizar a composição colorida.

A primeira composição, além do aspecto colorido em vermelho, não produziu realce quanto às feições da rede de drenagem. Já a segunda composição, que produziu um colorido de aspecto magenta, possui variação de tons mais escuros a mais claros, que caracterizam feições entre os extremos de cobertura vegetal completa e solo totalmente descoberto.

Como se percebe pelas Figuras 17, 18 e 19, todos os tratamentos aplicados, com exceção do aumento linear de contraste, resultaram em realces mais ou menos acentuados das características da imagem, mas os contrastes não evidenciaram detalhes importantes nas feições de interesse, no caso, a rede de drenagem. Possivelmente, isto se deve ao fato de as fotografias aéreas serem produtos de um sistema sensor de resolução espectral limitada (pouco além do visível) comparado aos sensores multiespectrais, para os quais as técnicas foram especificamente desenvolvidas.

A utilização de tratamentos de realce em imagens multiespectrais é um recurso importante em sensoriamento remoto, para vários autores, com aplicação em áreas de interesse, como: fotointerpretação geológica (Paradella \& Dutra, 1980; Dutra \& Meneses, 1987; Paradela 1990; Grasso, 1993), hidrografia (Godoy Júnior \& Novo, 1989; Walsh et al., 1990; Martins et al., 1993), entre outros. É oportuno observar que, muitas vezes os resultados obtidos nessas condições, normalmente evidenciam características de interesse, como padrão, forma, tamanho, posição, orientação, extensão etc., de feições que não estavam bem definidas na fase anterior ao tratamento aplicado. 
a)

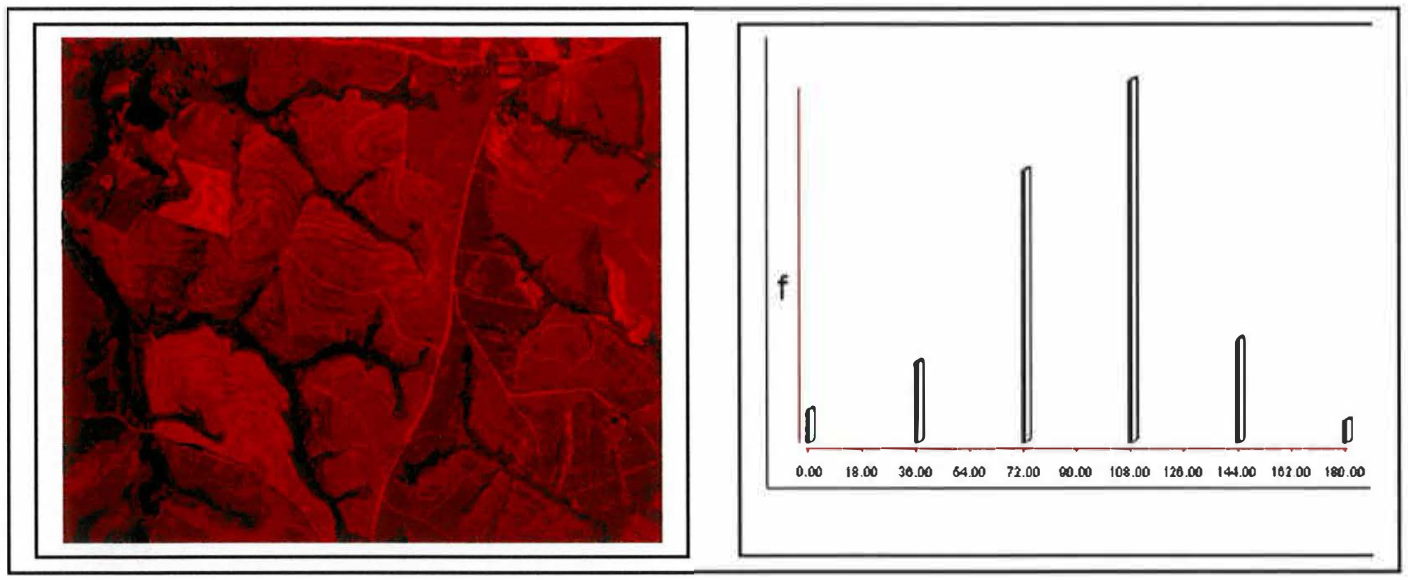

b)

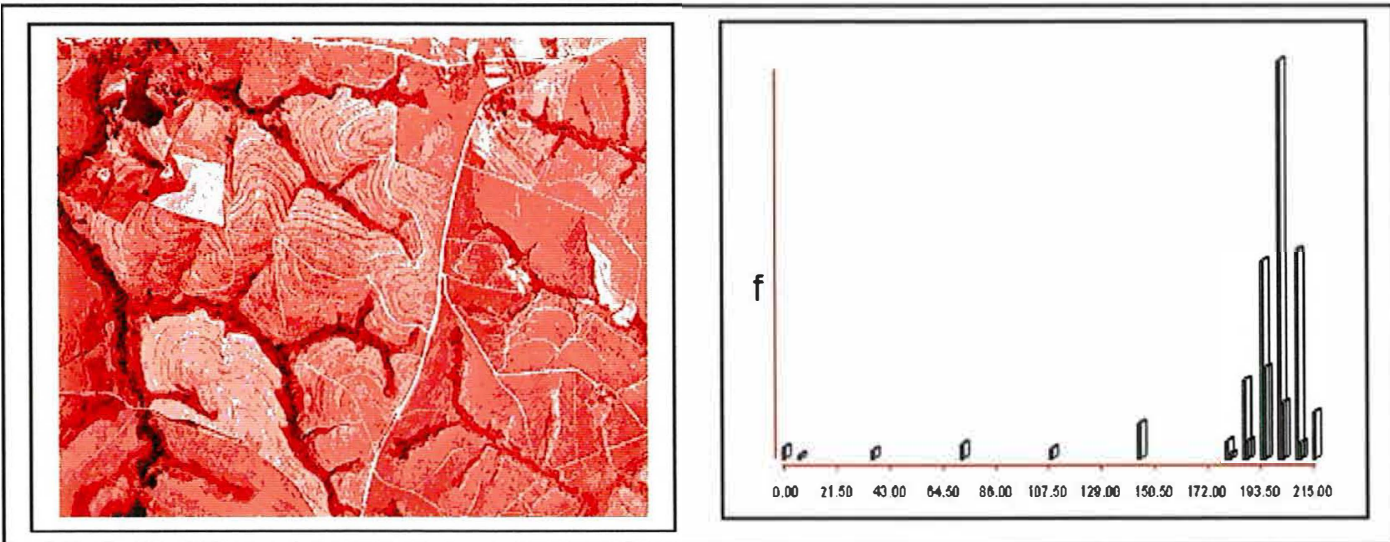

Figura 19 - Composições coloridas a partir de transformações no espaço de cores: a) transformação (HLS); b) transformação (KMC). 
No presente caso, a rede de drenagem já aparece como uma feição definida, com exceção de alguns trechos, os quais se pretendia realçar, de maneira que pudesse ser digitalizada integralmente e sua composição quantificada com exatidão comparável ao método tradicional da estereoscopia. Entretanto, pelos resultados apresentados, os tratamentos aplicados não evidenciaram suficientemente a rede de drenagem para facilitar as sua digitalização.

Entre os resultados apresentados da Figura 17 à Figura 19, a composição colorida obtida com a transformação (KMC) foi escolhida para se realizar a digitalização e comparar os resultados aos do tratamento sem realce e da interpretação com auxílio de estereoscópio. Este tipo de realce pareceu o mais interessante pelo aspecto colorido que apresenta, e que se julgou mais agradável para o trabalho de digitalização, quando comparado à visualização da mesma cena em níveis de cinza. Além disto, o realce manteve evidente a rede de drenagem onde os canais eram acompanhados de vegetação, conforme aparece no tratamento sem realce.

\subsubsection{Seleção de pontos de controle e georreferenciamento}

Os números de pontos de controle demarcados, descartados $\mathrm{e}$ selecionados em cada fotografia e os respectivos erros médios quadráticos (RMS) de georreferenciamento estão relacionados na Tabela 12 .

Conforme mostra a tabela, na maioria das fotografias foram demarcados 12 pontos de controle, sendo que apenas uma ficou com 10 pontos. Isto ocorreu pelo fato de alguns pontos selecionados nas fotografias não terem sido igualmente identificados na carta topográfica. Além disto, nem sempre é possível identificar, sobre a fotografia, grande quantidade de pontos com a distribuição que se deseja. Esta dificuldade de escolha dos pontos de controle foi mencionada por Parise (1999), em estudo de análise temporal de uso da terra em microbacia hidrográfica, onde o autor comenta sobre a incerteza de que os pontos localizadas na carta planialtimétrica correspondam corretamente àqueles determinados nas fotografias aéreas. 
Tabela 12. Números de pontos de controle demarcados, descartados e selecionados para cada fotografia e respectivos erros médios quadráticos.

\begin{tabular}{|c|c|c|c|c|c|}
\hline $\mathrm{n}^{\circ}$ da faixa & $\begin{array}{c}\mathrm{n}^{\mathrm{o}} \mathrm{da} \\
\text { fotografia }\end{array}$ & $\begin{array}{l}\mathrm{n}^{\mathbf{o}} \text { de pontos } \\
\text { demarcados }\end{array}$ & $\begin{array}{l}\mathrm{n}^{\mathrm{o}} \text { de pontos } \\
\text { descartados }\end{array}$ & $\begin{array}{l}\mathrm{n}^{\mathrm{o}} \text { de pontos } \\
\text { selecionados }\end{array}$ & $\begin{array}{l}\text { RMS } \\
\text { (m) }\end{array}$ \\
\hline \multirow{4}{*}{12} & 7 & 12 & 3 & 9 & 9,55 \\
\hline & 9 & 12 & 3 & 9 & 8,86 \\
\hline & 11 & 11 & 3 & 8 & 8,97 \\
\hline & 13 & 12 & 3 & 9 & 8,40 \\
\hline \multirow{4}{*}{13} & 14 & 12 & 3 & 9 & 8,53 \\
\hline & 15 & 12 & 3 & 9 & 8,80 \\
\hline & 17 & 12 & 4 & 8 & 9,89 \\
\hline & 19 & 11 & 3 & 8 & 8,54 \\
\hline \multirow[t]{5}{*}{14} & 13 & 11 & 3 & 8 & 10,30 \\
\hline & 15 & 11 & 4 & 7 & 8,57 \\
\hline & 17 & 12 & 3 & 9 & 7,82 \\
\hline & 18 & 12 & 4 & 8 & 9,47 \\
\hline & 12 & 12 & 4 & 8 & 8,93 \\
\hline \multirow[t]{2}{*}{15} & 14 & 12 & 4 & 8 & 9,93 \\
\hline & 15 & 10 & 3 & 7 & 7,82 \\
\hline
\end{tabular}

Quanto ao número e distribuição dos pontos de controle, Farret (1996) e Farret \& Giotto (1997), indicaram, para fotografias de pequeno formato, quatro pontos distribuídos nos quatro cantos da fotografia. Por outro lado, Jones et al. (1993) comentam que a decisão de aceitar um certo valor de RMS (no limite do erro aceitável) é provavelmente mais segura quando este é calculado sobre uma amostra maior de pontos (por exemplo > 30) do que sobre quatro pontos de controle.

Neste trabalho, procurou-se dar mais importância ao limite permitido, mantendo um maior número de pontos, ao invés de diminui-los através do descarte para reduzir o valor do RMS. Com esta escolha, pensou-se em contribuir para a melhor correção das distorções, confiabilidade dos dados e grau de exatidão aceitável. Após os ajustes de georreferenciamento, os valores de RMS (Tabela 12) ficaram abaixo do permitido para mapas na escala de 1:25.000, segundo critérios apresentados por Jones et al. (1993), que é de $12,91 \mathrm{~m}$.

Parise (1999) procurou seguir a geometria indicada por Farret (1996) e Farret \& Giotto (1997), mantendo, em parte de suas fotografia (ou decalques) o mínimo 
de quatro pontos, distribuídos um em cada canto. No georreferenciamento, o RMS variou de $5,62 \mathrm{~m}$ a $10,01 \mathrm{~m}$.

\subsubsection{Mosaicagem}

Após a montagem do mosaico, observou-se que tanto no sentido das linhas de vôo quanto entre as mesmas, nem sempre ocorreu um bom ajuste entre as fotografias. Em alguns pontos das linhas de contato, observou-se pequenas discordâncias na imagem. A principal fonte de erro para que ocorram estas discordâncias deve ser o efeito do deslocamento de imagens devido ao relevo, visto que a correção geométrica é apenas do tipo planimétrica e não uma ortorretificação.

Wolf (1983), comenta que a fotografia aérea não pode ser considerada um mapa, já que possui variações de escala e deslocamentos devido ao relevo, porém, se as variações do terreno forem moderadas e não houver inclinação exagerada da câmara, resultados exatos poderão ser alcançados.

A Figura 20 exemplifica dois casos onde se pode observar diferentes graus de ajuste das imagens nessas linhas. A Figura 20a, onde não há muita variação no relevo, praticamente não se percebe a linha de contato entre as duas faixas, a não ser pelo detalhe sobre o rio, onde a diferença de tonalidade no espelho d'água está evidente. Já na Figura 20b, percebe-se a linha de contato entre fotografias diferentes, com deslocamentos da imagem em alguns trecho sobre essa linha.

\subsubsection{Digitalização da rede de drenagem e das bacia}

$\mathrm{Na}$ digitalização dos canais de drenagem e perímetros das respectivas bacias, a utilização de pequenas áreas, ao invés da cena completa, permitiu que a imagem fosse exibida com fator de ampliação, proporcionando uma melhor visualização da cena desejada. 
a)

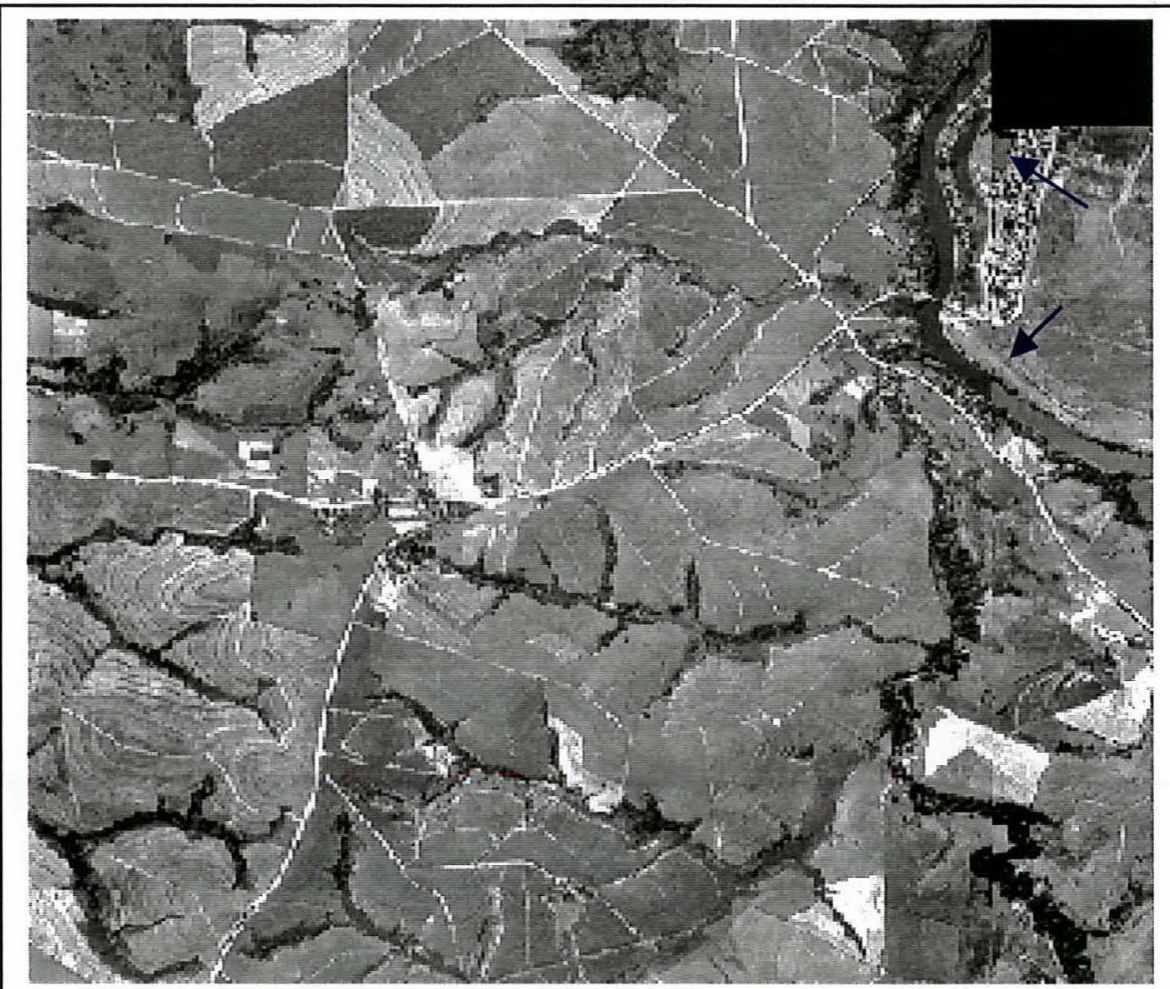

b

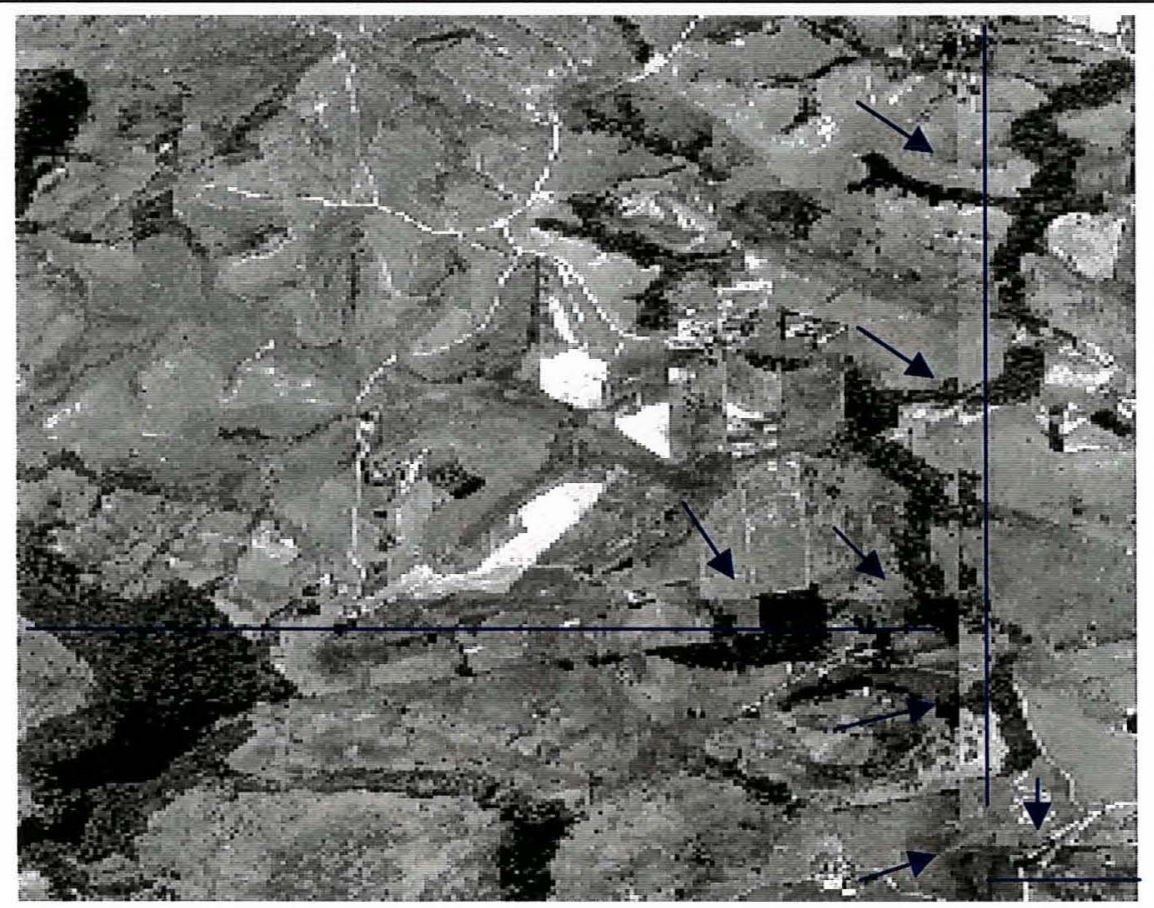

Figura 20 - Amostras do mosaico, evidenciando linhas de contato entre fotografias no sentido da linha de vôo e entre faicas: a) área de pouca variação do relevo; b) área com maior variação do relevo. 
As pequenas distorções apresentadas nas linhas de contato, como se verificou na Figura 20, não dificultaram o traçado da rede de drenagem, quando ocorreu de uma bacia situar-se nessa região.

Nas bacias em que havia presença de vegetação ao longo dos canais de drenagem, não houve dificuldade de identificação e digitalização da rede de drenagem, o que ocorreu mais frequentemente nas bacias dos solos litólicos. Entretanto, quando a área se apresentava com solo erodido e canais desprovidos de vegetação (Figura 21), houve certa dificuldade em identificação dos canais em ambos os tratamentos (com e sem realce), sendo estas áreas mais comuns aos solos litólicos.

Com relação às bacias, a análise estereoscópica permite a identificação dos seus limites, pela noção exata do relevo. No caso da análise digital, entretanto, os elementos de interpretação utilizados foram aspectos associados para reunir indícios sobre o provável local dos seus limites, como presença de estradas sobre as partes mais elevadas das bacias (Figura 21), presença de curvas de nível etc.

a)

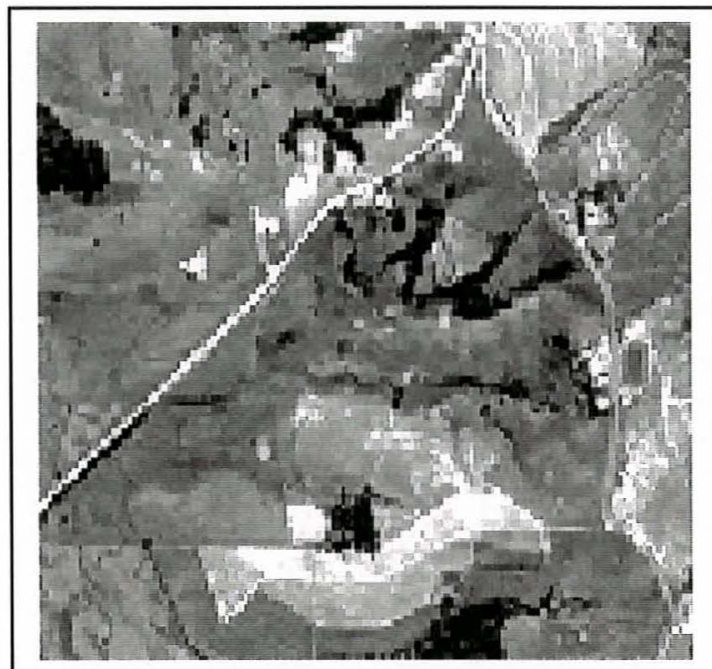

b)

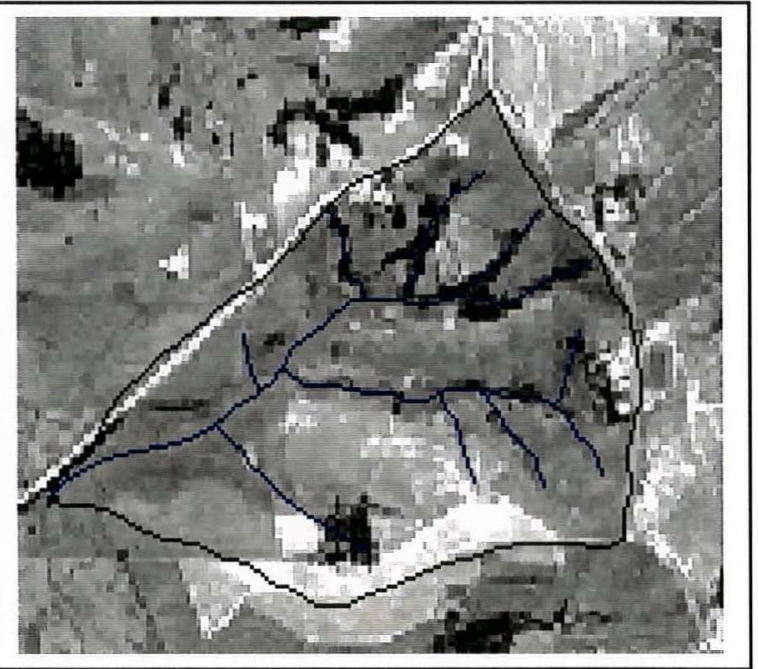

Figura 21 - Detalhe da bacia hidrográfica 27RC na fotografia aérea georreferenciada: a) antes da digitalização da rede de drenagem e dos limites da bacia; b) após a digitalização. 
No traçado da rede de drenagem, a visualização na tela também foi dificultada pela ausência da noção de relevo, presente na estereoscopia, de forma que o tamanho e a quantidade dos canais podem não corresponder aos que realmente são determinados na estereoscopia.

Segundo Mello \& Cintra (1993), na aquisição de dados georreferenciados surgem erros de todos os tipos, que são introduzidos nas diversas etapas do processo. Vários fatores podem interferir na qualidade da digitalização, seja em mesa ou diretamente sobre a tela. Com relação à digitalização em mesa, Thapa \& Bossler, (1992) apontam os seguintes fatores: espessura da linha; habilidade do operador, complexidade da feição a ser digitalizada, resolução do cursor e densidade das feições.

Dentre esses fatores, pode-se afirmar que a habilidade do operador e a complexidade das feições a serem digitalizadas, influíram no resultado final da digitalização, neste caso. Somem-se a estes, o cansaço visual e mental do operador diante do tedioso trabalho que é a tarefa de digitalização, e o tempo disponível para revisões e correções.

A utilização de três intérpretes na digitalização sobre a tela permitiu observar a influência desses fatores, que refletiu na tendência dos dados resultantes.

Diferenças no resultado da digitalização entre os três intérpretes e os dois tratamentos digitais podem ser constatadas na Figura 22, em uma bacia hidrográfica localizada em área de solos litólicos. Estes resultados ainda podem ser comparados com a mesma bacia decalcada com auxílio de estereoscópio (Figura 14 - GRUPO 2- 27RC).

Pela Figura 22, percebe-se que o traçado dos limites da bacia são bem parecidos entre o primeiro e o terceiro intérpretes, para os MÉTODOS 2 E 3, aproximado-se ainda do traçado obtido através do MÉTODO 1 (Figura 14). A diferença de área também foi mínima $\left(0,01 \mathrm{~km}^{2}\right.$ entre métodos e intérpretes). Entretanto, comparado com o MÉTODO 1, as variação são maiores (entre 0,05 e $0,07 \mathrm{~km}^{2}$ ). 
a)

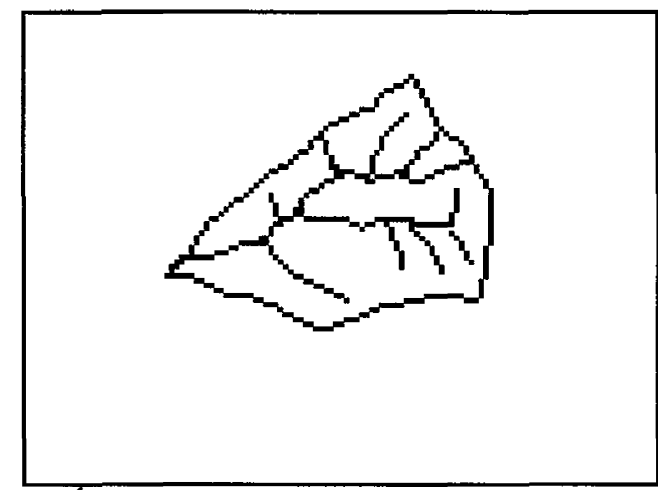

MÉTODO 1

$\mathrm{N}=10$

área $=0,45 \mathrm{~km}^{2}$

b)

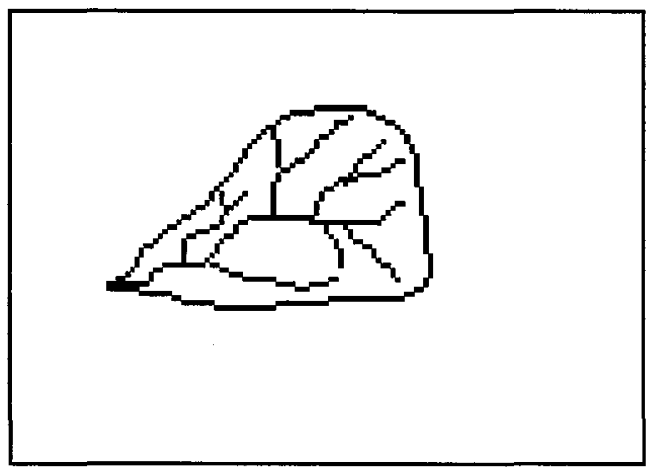

MÉTODO 1

$\mathrm{N}=10$

área $=0,43 \mathrm{~km}^{2}$

c)

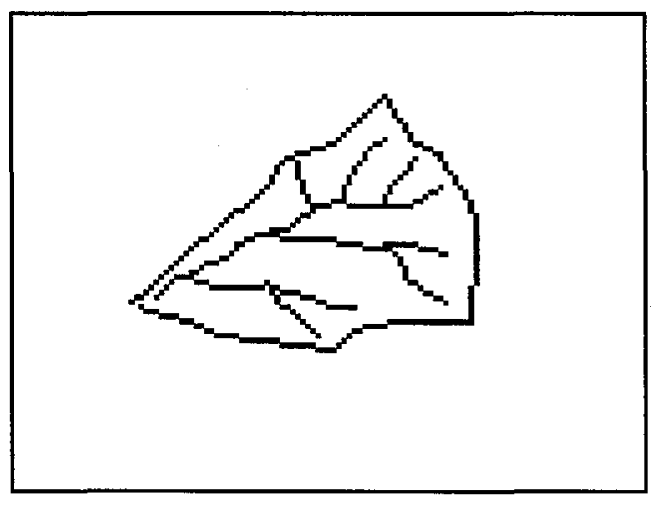

MÉTODO 1

$\mathrm{N}=08$

$$
\text { área }=0,46 \mathrm{~km}^{2}
$$

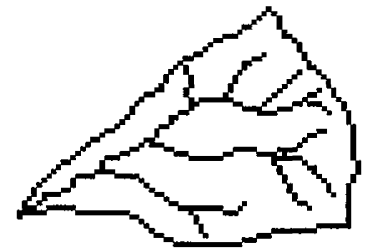

MÉTODO 2

$\mathrm{N}=10 \quad$ área $=0,46 \mathrm{~km}^{2}$

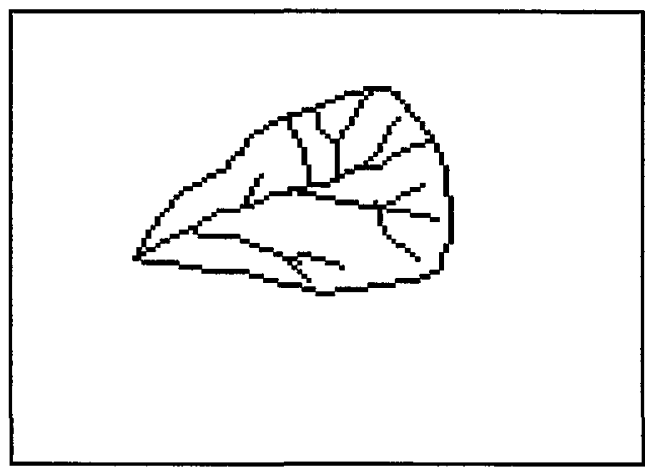

MÉTODO 2

$\mathrm{N}=11 \quad$ área $=0,47 \mathrm{~km}^{2}$

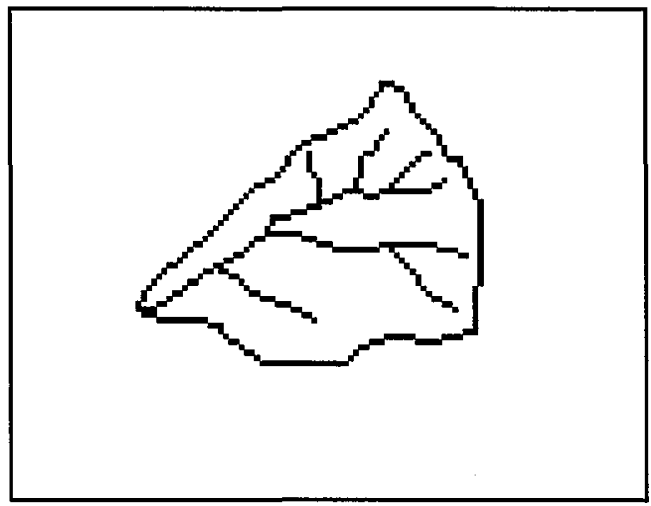

MÉTODO 2

$\mathrm{N}=07$

Figura 22 - Representação da bacia hidrográfica 27RC digitalizada pelos três intérpretes, para os MÉTODOS 2 e 3: a) primeiro intérprete; b) segundo intérprete; c) terceiro intérprete. 
No caso do segundo intérprete, a diferença ocorreu tanto entre os métodos, como em relação aos intérpretes 1 e 3 . É importante observar ainda que a forma da bacia, definida pelo traçado dos seus limites, também diferiu neste caso.

O nível de conhecimento e a familiaridade do intérprete com a área de estudo foi uma condição importante para a identificação e digitalização das feições mais complexas. Neste sentido, pode-se afirmar que a interpretação sempre esteve associada à digitalização, sendo uma combinação indispensável ao processo. Consequentemente, em áreas de difícil interpretação das feições, como no caso de áreas totalmente descobertas ou pulverizadas com fragmentos de vegetação, os elementos do sistema de drenagem digitalizados mostraram diferenças significativas em relação a interpretação visual.

Numa comparação subjetiva entre as imagens em nível de cinza e a composição com realce, esta última apresentou aparência mais agradável na tela $\mathrm{e}$ melhor visibilidade da linha digitalizada pelo cursor. Por outro lado, apresentou limitação nas regiões de solos descobertos, onde quase não produziu contraste, dificultando a identificação dos canais de drenagem.

A falta de contraste nestas condições também é comum às fotografias em nível de cinza, devendo-se ao fato de os solos descobertos refletirem igualmente, produzindo uma textura fina de dificil interpretação, no que se refere a pequenos canais de drenagem e limites de bacias, para determinação de área e perímetro.

Com relação ao aspecto visual do relevo, que auxiliou na interpretação dos limites das bacias, a composição colorida perdeu definição em relação à fotografia original em níveis de cinza, especialmente nas condições referidas acima.

\subsubsection{Composição da rede de drenagem}

Os dados referentes à composição da rede de drenagem, estão apresentados no ANEXO (A1 e A2). Em A1 estão apresentados os dados das bacias dos solos litólicos e, em A2, os dados das bacias dos solos podzólicos. 
A análise da rede de drenagem, da forma como foi realizada sobre os dados da interpretação não seria relevante na análise digital, uma vez que a análise estatística será mais segura para aferir qualquer semelhança ou diferença entre os métodos empregados. Portanto, discussões desta ordem serão apresentadas com base na análise estatística.

\subsubsection{Características do padrão de drenagem}

Os dados referentes às características do padrão de drenagem estão apresentados no ANEXO (A3 e A4), apresentados da mesma forma que nos anteriores.

Na Tabela 13, encontra-se um resumo dessas características em termos de valores médios para os tratamentos da análise digital nos dois solos, bem como um resumo geral com os dados dos tratamentos digitais e da análise visual.

Uma análise geral da Tabela 13 mostra que houve variação dos valores obtidos entre intérpretes, independentemente do tipo de solo ou tratamento. Essas variações mostram tendências e confirmaram a expectativa apresentada na metodologia, no sentido de se usar mais de um intérprete para a digitalização. A magnitude e tendência dessa variação, entretanto, devem estar associadas a condições específicas de cada intérprete e complexidade das feições digitalizadas.

Observando os valores obtidos pelo $3^{0}$ intérprete, verifica-se que os mesmos são inferiores aos dos dois primeiros, em termos de média, para todos os dados. Vários fatores podem ter influenciado estes resultados, entre os quais parecem ser mais importantes, os seguintes: falta de conhecimento do intérprete sobre as características da área estudada (praticamente nenhum contato prévio com o material fotográfico no seu formato original) e condições de visualização ("display") inferiores do equipamento utilizado. 
Tabela 13. Resumo das características quantitativas dos padrões de drenagem e classe de textura topográfica obtidas na interpretação digital das bacias dos dois solos, e resumo geral, incluindo a interpretação visual.

\begin{tabular}{|c|c|c|c|c|c|c|c|c|c|c|c|c|c|c|c|}
\hline \multirow[t]{2}{*}{ Grupo } & \multicolumn{3}{|c|}{ Dd (média) } & \multicolumn{3}{|c|}{ Fr (média) } & \multicolumn{3}{|c|}{ T (média) } & \multicolumn{3}{|c|}{ Tm (média) } & \multicolumn{3}{|c|}{ Classe } \\
\hline & 1 & 2 & 3 & 1 & 2 & 3 & 1 & 2 & 3 & 1 & 2 & 3 & 1 & 2 & 3 \\
\hline \multicolumn{16}{|c|}{$\begin{array}{c}\text { Solos litólicos } \\
\text { Tratamento } 1\end{array}$} \\
\hline 1 & 4,05 & 4,27 & 3,64 & 13,22 & 15,37 & 11,45 & 3,88 & 4,36 & 3,28 & 3,88 & 4,35 & 3,25 & M & M & M \\
\hline 2 & 4,25 & 3,98 & 3,95 & 16,35 & 16,52 & 13,99 & 3,59 & 3,83 & 3,13 & 3,59 & 3,82 & 3,13 & M & M & M \\
\hline 3 & 4,37 & 4,33 & 3,53 & 15,54 & 18,63 & 13,13 & 4,62 & 5,92 & 3,87 & 4,69 & 5,91 & 3,92 & M & M & M \\
\hline $\begin{array}{l}\text { Média } \\
\text { M. Geral }\end{array}$ & 4,22 & $\begin{array}{l}4,19 \\
4,04\end{array}$ & 3,71 & 15,04 & $\begin{array}{l}16,84 \\
14,91\end{array}$ & 12,86 & 4,03 & $\begin{array}{l}4,70 \\
4,05\end{array}$ & 3,43 & 4,05 & $\begin{array}{l}4,69 \\
4,06\end{array}$ & 3,43 & \multicolumn{3}{|c|}{ MÉDIA } \\
\hline & \multicolumn{15}{|c|}{ Tratamento 2} \\
\hline 1 & 4,12 & 3,98 & 3,21 & 14,05 & 13,44 & 8,91 & 4,21 & 3,95 & 2,69 & 4,22 & 3,88 & 2,71 & M & M & M \\
\hline 2 & 4,40 & 4,67 & 3,67 & 16,59 & 19,73 & 12,87 & 3,53 & 4,01 & 2,92 & 3,54 & 4,00 & 2,92 & M & M & M \\
\hline 3 & 4,34 & 4,33 & 3,53 & 15,41 & 18,63 & 13,13 & 4,52 & 5,92 & 3,87 & 4,52 & 5,11 & 2,34 & M & $\mathbf{M}$ & G \\
\hline $\begin{array}{l}\text { Média } \\
\text { M. Geral }\end{array}$ & 4,29 & $\begin{array}{l}4,33 \\
4,03\end{array}$ & 3,47 & 15,35 & $\begin{array}{l}17,27 \\
14,75\end{array}$ & 11,64 & 4,09 & $\begin{array}{l}4,63 \\
3,96\end{array}$ & 3,16 & 4,09 & $\begin{array}{l}4,33 \\
3,69\end{array}$ & 2,66 & \multicolumn{3}{|c|}{ MÉDIA } \\
\hline \multicolumn{16}{|c|}{ Solos podzólicos } \\
\hline \multicolumn{16}{|c|}{ Tratamento 1} \\
\hline 1 & 5,86 & 6,91 & 5,62 & 29,10 & 43,48 & 28,67 & 4,02 & 6,57 & 4,39 & 4,02 & 6,57 & 4,42 & M & M & M \\
\hline 2 & 5,22 & 5,11 & 4,49 & 26,46 & 26,71 & 24,29 & 4,62 & 4,84 & 4,51 & 4,64 & 4,89 & 4,53 & $\mathbf{M}$ & M & $\mathbf{M}$ \\
\hline 3 & 4,86 & 4,62 & 4,35 & 20,30 & 22,74 & 17,94 & 4,82 & 5,55 & 4,37 & 4,76 & 5,41 & 4,28 & M & M & $\mathbf{M}$ \\
\hline 4 & 5,51 & 5,57 & 4,86 & 24,72 & 27,37 & 19,37 & 6,64 & 7,22 & 5,66 & 6,57 & 7,17 & 5,66 & $\mathrm{~F}$ & $\mathrm{~F}$ & $\mathbf{M}$ \\
\hline 5 & 4,94 & 4,85 & 4,32 & 17,26 & 22,52 & 16,92 & 3,06 & 4,05 & 3,00 & 3,04 & 4,06 & 3,07 & $\mathbf{M}$ & M & M \\
\hline 6 & 3,57 & 3,58 & 3,44 & 9,78 & 12,26 & 10,02 & 5,57 & 7,27 & 5,40 & 5,57 & 7,36 & 5,40 & M & $\mathrm{F}$ & M \\
\hline $\begin{array}{l}\text { Média } \\
\text { M. Geral }\end{array}$ & 4,99 & $\begin{array}{l}4,67 \\
4,62\end{array}$ & 4,21 & 17,25 & $\begin{array}{l}20,72 \\
17,81\end{array}$ & 15,44 & 5,09 & $\begin{array}{c}6,18 \\
5,32\end{array}$ & 4,69 & 5,06 & $\begin{array}{l}6,20 \\
5,34\end{array}$ & 4,71 & & MÉDIA & \\
\hline \multicolumn{16}{|c|}{ Tratamento 2} \\
\hline 1 & 6,44 & 6,83 & 4,81 & 32,58 & 39,17 & 26,85 & 4,36 & 6,00 & 4,20 & 4,36 & 6,08 & 4,26 & M & M & M \\
\hline 2 & 5,00 & 5,72 & 5,85 & 24,78 & 29,99 & 22,28 & 4,45 & 5,28 & 4,25 & 4,50 & 5,32 & 4,31 & M & $\mathrm{M}$ & M \\
\hline 3 & 4,59 & 4,97 & 3,89 & 18,50 & 22,94 & 15,99 & 4,43 & 5,60 & 3,96 & 4,38 & 5,60 & 3,91 & M & M & M \\
\hline 4 & 4,96 & 5,68 & 4,00 & 21,08 & 24,82 & 16,68 & 5,88 & 5,87 & 4,63 & 5,83 & 6,07 & 4,59 & M & M & $\mathbf{M}$ \\
\hline 5 & 4,76 & 4,77 & 4,12 & 17,39 & 18,36 & 15,91 & 3,42 & 3,16 & 2,06 & 3,42 & 3,25 & 2,06 & M & M & G \\
\hline 6 & 3,32 & 3,16 & 2,64 & 10,7 & 10,05 & 7,06 & 5,68 & 6,12 & 5,07 & 5,70 & 6,14 & 5,06 & $\mathrm{M}$ & $\mathrm{M}$ & $\mathbf{M}$ \\
\hline $\begin{array}{l}\text { Média } \\
\text { M. Geral }\end{array}$ & 4,85 & $\begin{array}{l}4,54 \\
4,33\end{array}$ & 3,59 & 16,39 & $\begin{array}{l}17,74 \\
15,78\end{array}$ & 13,22 & 4,99 & $\begin{array}{l}5,05 \\
4,65\end{array}$ & 3,92 & 4,98 & $\begin{array}{l}5,15 \\
4,68\end{array}$ & 3,90 & & MÉDIA & \\
\hline
\end{tabular}

Resumo dos dados

\begin{tabular}{lccccc}
\hline & Dd (média) & Fr (média) & T (média) & Tm (média) & Classe \\
\hline & & & Solos litólicos & & \\
\hline Ester. & 4,41 & $\mathbf{1 6 , 3 4}$ & $\mathbf{4 , 0 4}$ & $\mathbf{4 , 0 5}$ & MÉDIA \\
Trat. 1 & $\mathbf{4 , 0 4}$ & $\mathbf{1 4 , 9 1}$ & $\mathbf{4 , 0 5}$ & $\mathbf{4 , 0 6}$ & MÉDIA \\
Trat. 2 & $\mathbf{4 , 0 3}$ & $\mathbf{1 4 , 7 5}$ & $\mathbf{3 , 9 6}$ & $\mathbf{3 , 6 9}$ & MÉDIA \\
& & & & & \\
\hline & & & Solos podzólicos & & \\
\hline Ester. & $\mathbf{5 , 6 6}$ & $\mathbf{2 7 , 3 7}$ & $\mathbf{5 , 5 4}$ & $\mathbf{5 , 5 4}$ & MÉDIA \\
Trat. 1 & $\mathbf{4 , 6 2}$ & $\mathbf{1 7 , 8 1}$ & $\mathbf{5 , 3 2}$ & $\mathbf{5 , 3 4}$ & MÉDIA \\
Trat. 2 & $\mathbf{4 , 3 3}$ & $\mathbf{1 5 , 7 8}$ & $\mathbf{4 , 6 5}$ & $\mathbf{4 , 6 8}$ & MÉDIA \\
& & & & \\
\hline
\end{tabular}


Os dados do $2^{\circ}$ intérprete, ao contrário do $3^{\circ}$, mostraram tendência de superioridade nos índices "freqüência de rios", "razão de textura" e "razão de textura média". Essas diferenças, para mais, podem estar associadas a uma combinação de aumento no número de canais e redução nos valores de área e perímetro em alguns casos, conforme pode-se verificar na Tabela A3 do ANEXO .

No caso do $1^{\mathrm{o}}$ intérprete, os dados se mostram bem próximos entre os dois tratamentos, sendo os dados do segundo tratamento pouco superiores nas bacias dos solos litólicos e pouco inferiores nos podzólicos, para todos os índices. No caso das bacias dos solos litólicos, os dados ainda são semelhantes aos da análise estereoscópica, principalmente nos índices razão de textura e razão de textura média.

A média geral dos três intérpretes mostra resultados bastante próximos entre os dois tratamentos nas bacias dos solos litólicos, à exceção da "razão de textura média", que resultou num valor de 4,06 no primeiro tratamento, contra 3,69 no segundo.

No caso das bacias dos solos podzólicos, os dados mais próximos entre os dois tratamentos são os de "densidade de drenagem" (4,62 no primeiro, contra 4,33 no segundo) e "freqüência de rios (17,81 no primeiro, contra 15,78 no segundo), entretanto divergem dos resultados da análise estereoscópica ("densidade de drenagem" de 5,66 e "frequência de rios" de 27,37).

Os valores de "frequência de rios" mostraram-se mais inconsistentes no caso dos solos podzólicos, não permitindo a mesma inferência que se fez no caso da interpretação visual, onde esta foi bastante diferente para os dois solos $(16,34$ nos litólicos e 27,37 nos podzólicos).

A maior variação dos dados no caso das bacias dos solos podzólicos refle a maior complexidade das feições a serem digitalizadas, variando com o tamanho das bacias e a escassez de vegetação arbórea nos canais. Esta dificuldade na digitalização levou ainda à composição de redes de ordem diferentes, como o caso de $4^{\mathrm{a}}$ ordem nas bacias 3 de G3 nos solos litólicos, 1 de G5 e 2 de G6, nos solos podzólicos (pelo $2^{\text {o }}$ intérprete) e de $2^{\underline{a}}$ para as bacias 1 de $\mathrm{G} 1$ nos solos litólicos (pelos $1^{\circ}$ e $3^{\circ}$ intérpretes). 


\subsection{Análise estatística dos dados}

\subsubsection{Análise exploratória dos dados}

$\mathrm{Na}$ interpretação gráfica dos resíduos para todas as variáveis estudadas através da análise da variância nas bacias dos dois solos, foram detectadas heterogeneidades de variância para grande parte das variáveis. Portanto, foram utilizadas as seguintes transformações de dados:

\begin{tabular}{|c|c|c|}
\hline Solo & Transformação & Variável \\
\hline \multirow[t]{2}{*}{ Litólico } & Inversa & $\begin{array}{l}\text { Número de rios de } 1^{\mathrm{a}} \text { ordem }(\mathrm{Nw}) \text {; número total de rios }(\mathrm{N}) \text {; } \\
\text { comprimento de rios de } 1^{\mathrm{a}} \text { ordem }(\mathrm{Lwl}) \text {; comprimento total de } \\
\text { rios }(\mathrm{Lt}) \text {; comprimento médio de rios de primeira ordem }(\mathrm{Lml}) \mathrm{e} \\
\text { Área da bacia (A) }\end{array}$ \\
\hline & Logarítmica & Razão de textura (T) \\
\hline \multirow[t]{3}{*}{ Podzólico } & Logarítmica & $\begin{array}{l}\text { Número de rios de } 1^{\mathrm{a}} \text { ordem }(\mathrm{Nwl}) \text {; número total de rios }(\mathrm{N}) \text {; } \\
\text { frequência de rios }(\mathrm{Fr}) \text { e razão de textura }(\mathrm{T})\end{array}$ \\
\hline & Raiz quadrada & Área da bacia (A) \\
\hline & Raiz inversa & Perímetro da bacia (P) \\
\hline
\end{tabular}

A análise gráfica dos resíduos permitiu afirmar que as pressuposições de independência (através da forma do gráfico), de normalidade (através dos intervalos dos resíduos padronizados) e também de homogeneidade de variâncias não foram violadas para as variáveis que não foram transformadas, e que para variáveis acima essas pressuposições foram restabelecidas com as transformações utilizadas.

A observação dos diagramas de ramos e folhas para as bacias dos dois solos, permitiu a visualização de uma simetria razoável para os resíduos padronizados do modelo adotado, o que é de interesse.

A Tabela 14 mostra a localização espacial dos "outliers" para as variáveis originais (sem transformação). 
Pela tabela, verifica-se que nas bacias dos solos litólicos houve uma certa sistematização dos "outliers", localizados na sua maioria no Método 1, Grupo 3, Bacia 3. Já nas bacias dos solos podzólicos, a sistematização é evidenciada pela maioria dos "outliers" associados ao Grupo 5. Esses "outliers" já eram esperados, dado que a formação de grupos foi elaborada exatamente para extrair da variação do acaso essa heterogeneidade. Apesar da existência desses "outliers", as pressuposições para que os testes de inferência tenham poder na realização da análise não foram violadas, ou foram restabelecidas quando da aplicação da transformação adequada.

Tabela 14 - Localização espacial de "outliers".

\begin{tabular}{|c|c|c|}
\hline Variáveis & Solos litólicos & Solo podzólicos \\
\hline 1) Número de rios de $1^{2}$ ordem (Nwl) & $\begin{array}{l}\text { Para maior: } \\
\text { - Método 1, Grupo 3, Bacia } 3\end{array}$ & \\
\hline 2) Número total de rios (N) & $\begin{array}{l}\text { Para maior: } \\
\text { - Método 1, Grupo 3, Bacia } 3 \\
\text { - Método 2, Grupo 3, Bacia } 3\end{array}$ & $\begin{array}{l}\text { Para maior: } \\
\text { - Método 2, Grupo 6, Bacia } 1 \\
\text { - Método 1, Grupo 4, Bacia } 2 \\
\text { - Método 1, Grupo 6, Bacia } 1\end{array}$ \\
\hline $\begin{array}{l}\text { 3) Comprimento dos rios de } 1^{2} \text { ordem } \\
\text { (Lw1) }\end{array}$ & $\begin{array}{l}\text { Para maior: } \\
\text { - Método 1, Grupo 3, Bacia } 3\end{array}$ & \\
\hline $\begin{array}{l}\text { 4) Comprimento médio dos rios de } 1^{\mathrm{a}} \\
\text { ordem (Lm1) }\end{array}$ & $\begin{array}{l}\text { Para maior: } \\
\text { - Método 3, Grupo 1, Bacia } 2 \\
\end{array}$ & $\begin{array}{l}\text { Para menor: } \\
\text { - Método 1, Grupo 1, Bacia } 1 \\
\end{array}$ \\
\hline $\begin{array}{l}\text { 5) Comprimento médio de todos os rios } \\
\text { (Lm) }\end{array}$ & & $\begin{array}{l}\text { Para maior: } \\
\text { - Método 1, Grupo 5, Bacia } 1 \\
\text { - Método 2, Grupo 5, Bacia } 1 \\
\text { - Método 3, Grupo 5, Bacia } 2 \\
\text { - Método 3, Grupo 5, Bacia } 1\end{array}$ \\
\hline 6) Freqüência de rios (Fr) & $\begin{array}{l}\text { Para maior: } \\
\text { - Método 2, Grupo 3, Bacia } 3 \\
\end{array}$ & $\begin{array}{l}\text { Para maior: } \\
\text { - Método 1, Grupo 1, Bacia } 1\end{array}$ \\
\hline 7) Textura (T) & $\begin{array}{l}\text { Para maior: } \\
\text { - Método 1, Grupo 3, Bacia } 2 \\
\text { - Método 1, Grupo 3, Bacia } 3 \\
\text { - Método 2, Grupo 3, Bacia } 3\end{array}$ & \\
\hline
\end{tabular}

\subsubsection{Análise de variância e comparação de médias através do teste de Tukey e do teste F para contrastes}

A análise da variância ${ }^{1}$ para as bacias dos dois tipos de solo, para as variáveis analisadas pelo modelo proposto, encontra-se nas Tabela 15 e 16.

\footnotetext{
${ }^{1}$ Somente serão apresentados aqui os Quadrados Médios de cada causa de variação e os G.L. respectivos, já que as Somas de Quadrados podem ser obtidas pela multiplicação de Q.M. pelo G.L. respectivo, e o valor do teste F pelo quociente Q.M. de Causa de Variação / Q.M. Resíduo respectivo
} 
Tabela 15 - Análise da variância e teste $\mathrm{F}$ para as variáveis Nw1, N, Lw1, Lt, Lm1 e Lm.

\begin{tabular}{|c|c|c|c|c|}
\hline \multicolumn{5}{|c|}{ Número de rios de $1^{2}$ ordem (Nw1) } \\
\hline Causas de Variação & G.L. & Solos litólicos (Q.M.) ${ }^{m}$ & G.L. & Solos podzólicos (Q.M.) ${ }^{12}$ \\
\hline Grupos & 2 & 0,0072 & 5 & 0,3046 \\
\hline Métodos & 2 & $0,0003^{\text {ng }}$ & 2 & $0,0173 *$ \\
\hline Resíduo & 22 & 0,0002 & 37 & 0,0052 \\
\hline Total & 26 & & 44 & \\
\hline C.V. (\%) & - & $13,94 \%$ & - & $6,77 \%$ \\
\hline \multicolumn{5}{|c|}{ Número total de rios $(\mathrm{N})$} \\
\hline Causas de Variação & G.L. & Solos litólicos (Q.M.) ${ }^{\mathrm{TT}}$ & G.L. & Solos podzólicos (Q.M.) $)^{\mathrm{T} 2}$ \\
\hline Grupos & 2 & 0,0029 & 5 & 8,5548 \\
\hline Métodos & 2 & $0,00005^{\mathrm{ns}}$ & 2 & $0,1399^{\text {ns }}$ \\
\hline Resíduo & 22 & 0,00006 & 37 & 0,0045 \\
\hline Total & 26 & & 44 & \\
\hline C.V. $(\%)$ & - & 12,09 & - & $5,60 \%$ \\
\hline \multicolumn{5}{|c|}{ Comprimento de rios de $1^{2}$ ordem (Lw1) } \\
\hline Causas de Variação & G.L. & Solos litólicos (Q.M.) ${ }^{n}$ & G.L. & Solos podzólicos (Q.M.) \\
\hline Grupos & 2 & 0,2769 & 5 & 8,5777 \\
\hline Métodos & 2 & $0,0050^{\text {ns }}$ & 2 & $0,1412^{\text {ns }}$ \\
\hline Resíduo & 22 & 0,0055 & 37 & 0,1234 \\
\hline Total & 26 & & 44 & \\
\hline C.V. $(\%)$ & - & $15,81 \%$ & - & $16,36 \%$ \\
\hline \multicolumn{5}{|c|}{ Comprimento total dos rios (Lt) } \\
\hline Causas de Variação & G.L. & Solos litólicos $\left(\mathbf{Q} \cdot \mathrm{M}_{.}\right)^{\mathrm{T}}$ & G.L. & Solos podzólicos (Q.M.) \\
\hline Grupos & 2 & 0,0436 & 5 & 32,0231 \\
\hline Métodos & 2 & $0,00009^{\text {ns }}$ & 2 & $0,1495^{\text {ns }}$ \\
\hline Resíduo & 22 & 0,0006 & 37 & 0,1948 \\
\hline Total & 26 & & 44 & \\
\hline C.V. $(\%)$ & - & $10,86 \%$ & - & $11,08 \%$ \\
\hline \multicolumn{5}{|c|}{ Comprimento médio dos rios de $1^{2}$ ordem (Lm1) } \\
\hline Causas de Variação & G.L. & Solos litólicos (Q.M.) ${ }^{\mathrm{TI}}$ & G.L. & Solos podzólicos (Q.M.) \\
\hline Grupos & 2 & 4,0521 & 5 & 0,0050 \\
\hline Métodos & 2 & $0,4007^{\text {ns }}$ & 2 & $0,0010^{\mathrm{ns}}$ \\
\hline Resíduo & 22 & 0,8041 & 37 & 0,0007 \\
\hline Total & 26 & & 44 & \\
\hline C.V. (\%) & - & $17,12 \%$ & - & $16,48 \%$ \\
\hline \multicolumn{5}{|c|}{ Comprimento médio de todos os rios (Lm) } \\
\hline Causas de Variação & G.L. & Solos litólicos (Q.M.) & G.L. & Solos podzólicos (Q.M.) \\
\hline Grupos & 2 & 0,0040 & 5 & 0,0149 \\
\hline Métodos & 2 & $0,0014^{\mathrm{ns}}$ & 2 & $0,0020 *$ \\
\hline Resíduo & 22 & 0,0008 & 37 & 0,0006 \\
\hline Total & 26 & & 44 & \\
\hline C.V. (\%) & - & $10,14 \%$ & - & $10,67 \%$ \\
\hline
\end{tabular}

$\bar{*}^{*}=$ Significativo, pelo teste $\mathrm{F}$, ao nível de $5 \%(\alpha \leq 0,05)$.

ns $=$ Não significativo, pelo teste F, considerando-se um n.m.s. de $5 \%(\alpha>0,05)$.

$\mathrm{T} 1=$ Observações transformadas em $1 / x$.

$\mathrm{T} 2$ = Observações transformadas em $\log (x)$. 
Tabela 16 Análise da variância e teste $\mathrm{F}$ para as variáveis A, P, Dd, Fr e T.

\begin{tabular}{|c|c|c|c|c|}
\hline \multicolumn{5}{|c|}{ Area da bacia (A) } \\
\hline Causas de Variação & G.L. & Solos litólicos (Q.M.) ${ }^{\mathrm{II}}$ & G.L. & Solos podzólicos (Q.M.) \\
\hline Grupos & 2 & 0,7221 & 5 & 0,5563 \\
\hline Métodos & 2 & $0,0166^{\text {ns }}$ & 2 & $0,0205^{* *}$ \\
\hline Resíduo & 22 & 0,1123 & 37 & 0,0011 \\
\hline Total & 26 & & 44 & \\
\hline C.V. (\%) & - & $7,49 \%$ & - & $3,81 \%$ \\
\hline \multicolumn{5}{|c|}{ Perímetro da bacia (P) } \\
\hline Causas de Varią̣ão & G.L. & Solos litólicos (Q.M.) & G.L. & Solos podnólicos (Q.M.) ${ }^{\mathrm{T} 4}$ \\
\hline Grupos & 2 & 4,9272 & 5 & 0,0704 \\
\hline Métodos & 2 & $0,0062^{\mathrm{ns}}$ & 2 & $0,0005^{\mathrm{ns}}$ \\
\hline Resíduo & 22 & 0,0190 & 37 & 0,0001 \\
\hline Total & 26 & & 44 & \\
\hline C.V. (\%) & - & $3,27 \%$ & - & $2,14 \%$ \\
\hline \multicolumn{5}{|c|}{ Densidade de drenagem (Dd) } \\
\hline Causas de Variação & G.L. & Solos litólicos (Q.M.) & G.L. & Solos podzólicos(Q.M.) \\
\hline Grupos & 2 & 0,2487 & 5 & 6,3126 \\
\hline Métodos & 2 & $0,4950^{\text {ns }}$ & 2 & $3,3203 * *$ \\
\hline Resíduo & 22 & 0,1852 & 37 & 0,5434 \\
\hline Total & 26 & & 44 & \\
\hline C.V. (\%) & - & $10,40 \%$ & - & $14,24 \%$ \\
\hline \multicolumn{5}{|c|}{ Freqüência de rios (Fr) } \\
\hline Causas de Variação & G.L. & Solos litólicos (Q.M.) & G.L. & Solos podzólicos (Q.M.) ${ }^{\mathrm{r}}$ \\
\hline Grupos & 2 & 22,7909 & 5 & 0,1994 \\
\hline Métodos & 2 & $12,5166^{\mathrm{ns}}$ & 2 & $0,1118^{* *}$ \\
\hline Residuo & 22 & 5,2579 & 37 & 0,0047 \\
\hline Total & 26 & & 44 & \\
\hline C.V. $(\%)$ & - & $15,20 \%$ & - & $5,06 \%$ \\
\hline \multicolumn{5}{|c|}{ Textura (T) } \\
\hline Causas de Variação & G.L. & Solos litólicos (Q.M.) ${ }^{2 t}$ & G.L. & Solos modzólicos (Q.M.) ${ }^{\mathrm{T} 2}$ \\
\hline Grupos & 2 & 0,0676 & 5 & 0,0759 \\
\hline Métodos & 2 & $0,0054^{\text {ns }}$ & 2 & $0,0269 *$ \\
\hline Resíduo & 22 & 0,0052 & 37 & 0,0053 \\
\hline Total & 26 & & 44 & \\
\hline C.V. $(\%)$ & - & $15,81 \%$ & - & $12,86 \%$ \\
\hline
\end{tabular}

* = Significativo, pelo teste $\mathrm{F}$, ao nível de $5 \%(\alpha \leq 0,05)$.

** = Significativo, pelo teste F, ao nível de $1 \%(\alpha \leq 0,01)$.

ns = Não significativo, pelo teste F, considerando-se um n.m.s. de $5 \%(\alpha>0,05)$.

$\mathrm{T} 1$ = Observações ransformadas em $1 / x$.

T2 = Observações transformadas em $\log (x)$.

$\mathrm{T} 3=$ Observações transformadas em $\sqrt{\mathrm{x}}$.

T4 = Observações transformadas em $1 / \sqrt{\mathrm{x}}$.

Observa-se pelas Tabelas 15 e 16 que o teste $\mathrm{F}$ para Métodos não foi significativo (considerando-se um n.m.s. de 5\%) para nenhuma das variáveis nas bacias dos solos litólicos, enquanto nas bacias dos podzólicos o teste $\mathrm{F}$ para Métodos foi significativo apenas para as variáveis Nwl, Lm e T (ao nível de 5\%) e para A, Dd e Fr (ao nível de 1\%).

A Tabela 17 mostra o detalhamento da análise pelo teste de Tukey para todas as variáveis nos dois tipos de solo. 
Tabela 17 Médias de métodos de medição e teste de Tukey para todas as variáveis analisadas nas bacias dos dois solos.

\begin{tabular}{|c|c|c|c|c|c|c|}
\hline \multirow{2}{*}{ Métodos } & \multicolumn{2}{|c|}{ Nw1 } & \multicolumn{2}{|c|}{$\mathbf{N}$} & \multicolumn{2}{|c|}{$\mathbf{L 1}$} \\
\hline & Litólicos & Podzólicos & Litólicos & Podzólicos & Litólicos & Podzólicos \\
\hline 1 & $13,667 \mathrm{a}$ & $14,200 \mathrm{a}$ & $17,556 a$ & $18,400 \mathrm{a}$ & $2,623 \mathrm{a}$ & $2,255 \mathrm{a}$ \\
\hline 2 & $12,630 \mathrm{a}$ & $12,978 \mathrm{ab}$ & $17,259 \mathrm{a}$ & 17,311 a & $2,350 \mathrm{a}$ & $2,118 \mathrm{a}$ \\
\hline 3 & $11,667 \mathrm{a}$ & $11,889 \mathrm{~b}$ & $15,556 \mathrm{a}$ & $16,000 \mathrm{a}$ & $2,350 \mathrm{a}$ & $2,068 \mathrm{a}$ \\
\hline \multirow{2}{*}{ Métodos } & \multicolumn{2}{|c|}{$\mathbf{L t}$} & \multicolumn{2}{|c|}{ Lm1 } & \multicolumn{2}{|c|}{$\mathbf{L m}$} \\
\hline & Litólicos & Podzólicos & Litólicos & Podzólicos & Litólicos & Podzólicos \\
\hline 1 & $4,750 \mathrm{a}$ & $4,073 \mathrm{a}$ & $0,194 \mathrm{a}$ & $0,158 \mathrm{a}$ & $0,271 \mathrm{a}$ & $0,217 \mathrm{~b}$ \\
\hline 2 & $4,664 a$ & $3,997 \mathrm{a}$ & $0,192 \mathrm{a}$ & $0,165 \mathrm{a}$ & $0,280 \mathrm{a}$ & $0,230 \mathrm{ab}$ \\
\hline 3 & $4,471 \mathrm{a}$ & $3,875 \mathrm{a}$ & $0,210 \mathrm{a}$ & $0,174 \mathrm{a}$ & $0,296 \mathrm{a}$ & $0,240 \mathrm{a}$ \\
\hline \multirow{2}{*}{ Métodos } & \multicolumn{2}{|c|}{$\mathbf{A}$} & \multicolumn{2}{|c|}{$\mathbf{P}$} & \multicolumn{2}{|c|}{ Dd } \\
\hline & Litólicos & Podzólicos & Litólicos & Podzólicos & Litólicos & Podzólicos \\
\hline 1 & $1,063 \mathrm{a}$ & $0,747 \mathrm{~b}$ & $4,244 \mathrm{a}$ & $3,285 \mathrm{a}$ & $4,404 \mathrm{a}$ & $5,717 \mathrm{a}$ \\
\hline 2 & $1,156 \mathrm{a}$ & $0,860 \mathrm{a}$ & $4,196 \mathrm{a}$ & $3,370 \mathrm{a}$ & $4,040 \mathrm{a}$ & $4,941 \mathrm{~b}$ \\
\hline 3 & $1,143 \mathrm{a}$ & $0,869 \mathrm{a}$ & $4,203 \mathrm{a}$ & $3,427 \mathrm{a}$ & $3,966 \mathrm{a}$ & $4,868 \mathrm{~b}$ \\
\hline \multirow{2}{*}{ Métodos } & \multicolumn{4}{|c|}{$\mathbf{F r}$} & \\
\hline & & Litólicos & Podzólicos & Litólicos & Podzólicos & \\
\hline 1 & & $16,338 \mathrm{a}$ & $28,312 \mathrm{a}$ & $3,122 \mathrm{a}$ & $4,184 \mathrm{a}$ & \\
\hline 2 & & $14,912 \mathrm{a}$ & $23,192 \mathrm{~b}$ & $2,955 \mathrm{a}$ & $3,770 \mathrm{ab}$ & \\
\hline 3 & & $13,998 \mathrm{a}$ & $21,851 \mathrm{~b}$ & $2,740 \mathrm{a}$ & $3,435 \mathrm{~b}$ & \\
\hline
\end{tabular}

Médias seguidas de letras diferentes, nas colunas para cada variável, diferem entre si pelo teste de Tukey ao nivel de $5 \%$ ( $\alpha \leq 0,05)$.

Pela observação da Tabela 17 pode-se fazer as seguintes inferências:

- nas bacias dos solos litólicos não se observaram diferenças significativas pelo teste de Tukey entre os Métodos de medição para nenhuma das variáveis analisadas, resultados concordantes com os evidenciados na análise da variância. Esses resultados também concordam com a análise feita sobre a tabela 13;

- nas bacias dos solos podzólicos, no entanto, observaram-se diferenças significativas entre os Métodos de medição para as variáveis Nw1, Lm, A, Dd, Fr e T, e não para as demais. Note-se que para as variáveis Nw1, Lm e T, o Método da análise estereoscópica diferiu do Método de interpretação digital com realce, mas ambos não diferiram do Método de interpretação digital sem realce, sendo que para as variáveis Nwl e T, o método da análise estereoscópica apresentou a maior média e, para a variável $\mathrm{Lm}$, a menor média. Para as variáveis $\mathrm{A}$, Dd e Fr o Método da análise estereoscópica diferiu dos dois métodos de interpretação digital, tendo apresentado a maior média para as variáveis Dd e Fr e a menor média para a variável A. 
O comportamento das 11 variáveis em função dos métodos pode ser melhor visualizado através das Figuras 23, 24 e 25

Nw 1: Solos litólicos

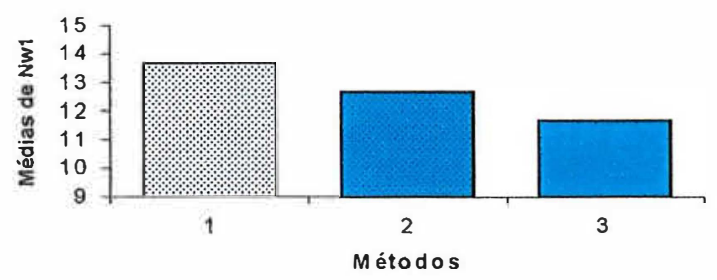

$N$ : Solos litólicos

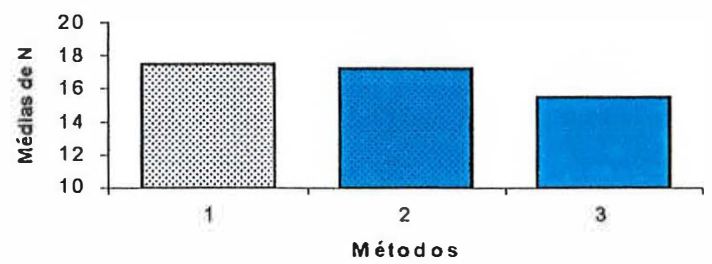

Lw 1: Solos litólicos

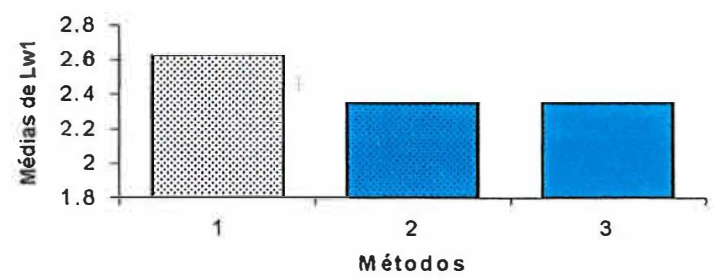

Lt: Solos litólicos

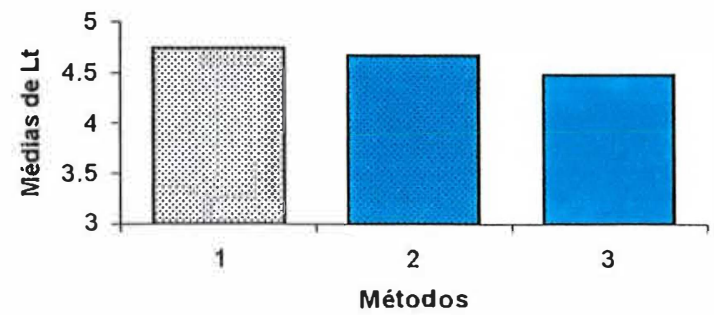

Nw1: Solos podzólicos

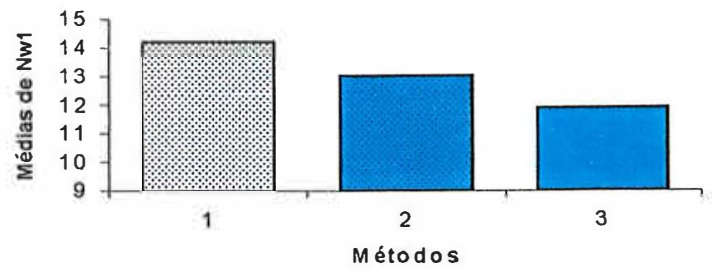

N: Solos podzólicos

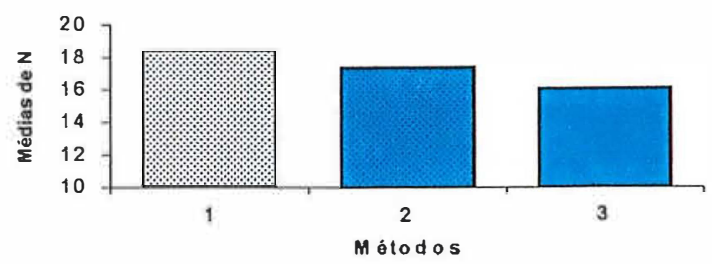

Lw 1: Solos podzólicos

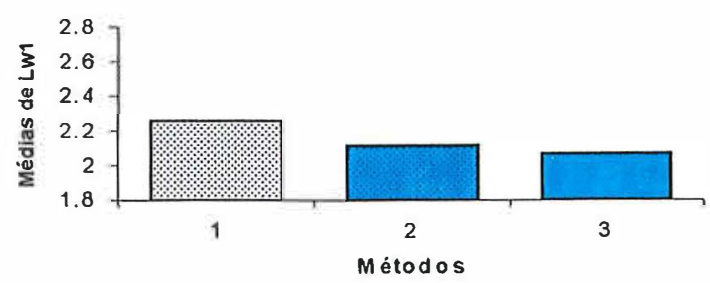

Lt: Solos podzólicos

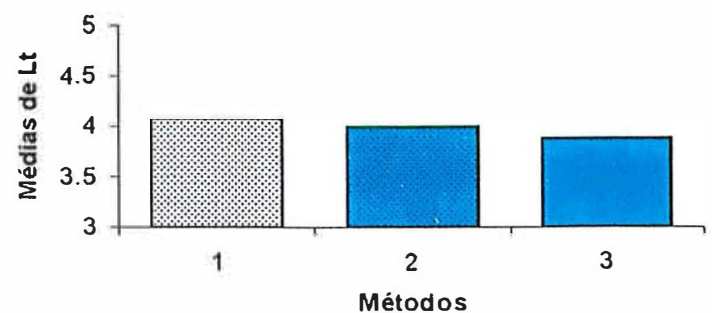

Figura 23 - Médias em função dos Métodos de medição para as variáveis Nw1, N, Lw1 e Lt, nas bacias dos dois solos. 
Lm1: Solos litólicos

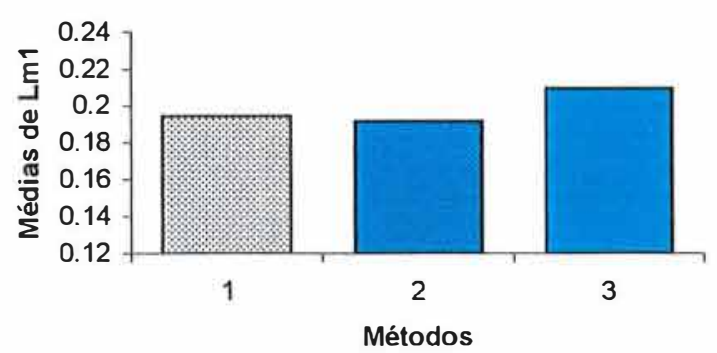

Lm: Solos litólicos

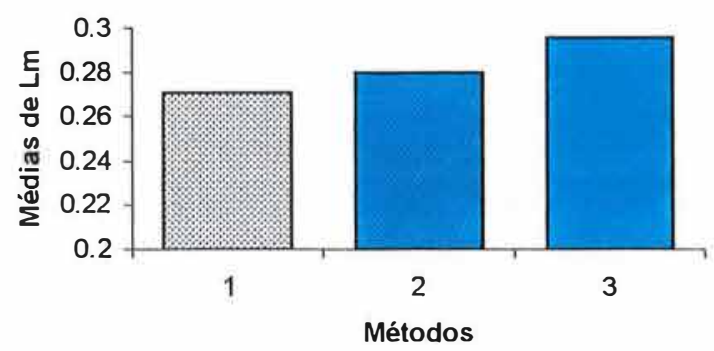

A: Solos litólicos

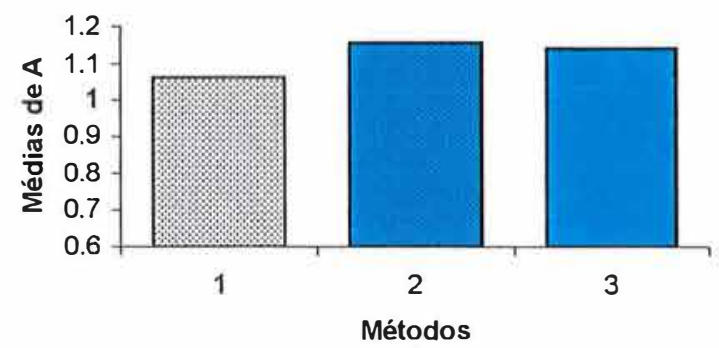

P: Solos litólicos

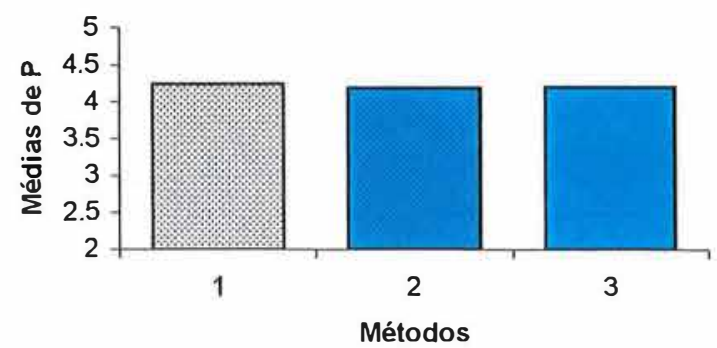

Lm1: Solos podzólicos

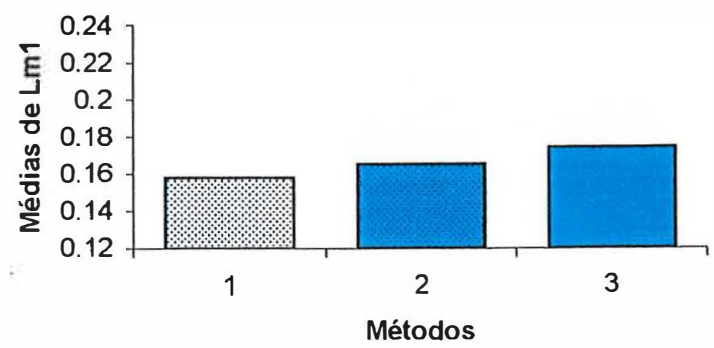

Lm: Solos podzólicos

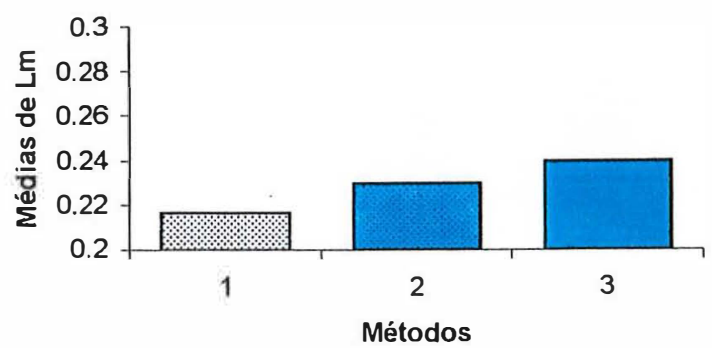

A: Solos podzólicos

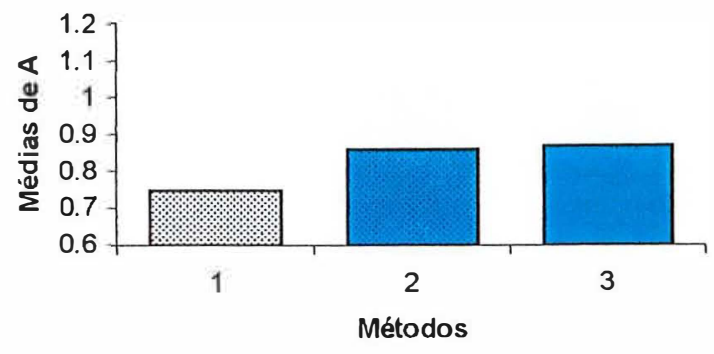

P: Solos podzólicos

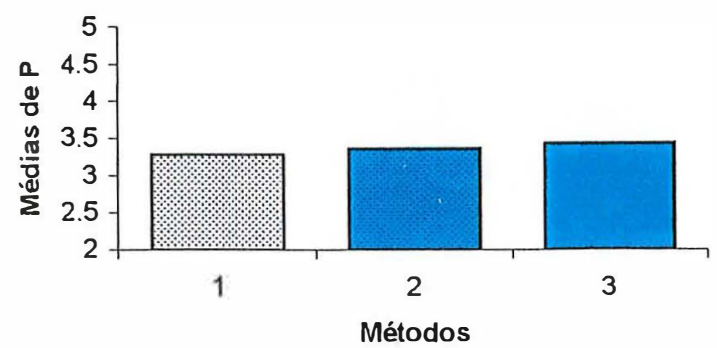

Figura 24 - Médias em função dos Métodos de medição para as variáveis Lm1, Lm, A e $\mathrm{P}$, nas bacias dos dois solos. 
Dd: Solos litólicos

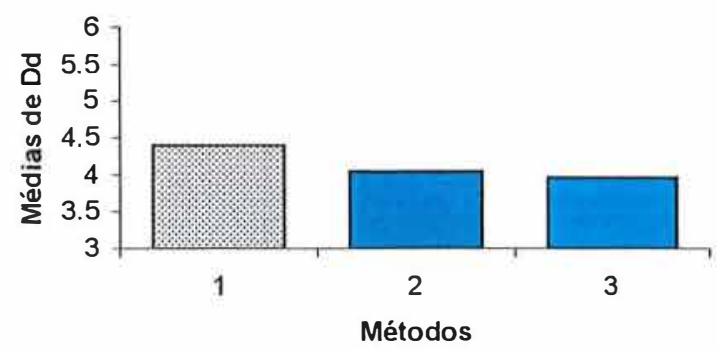

Fr: Solos litólicos

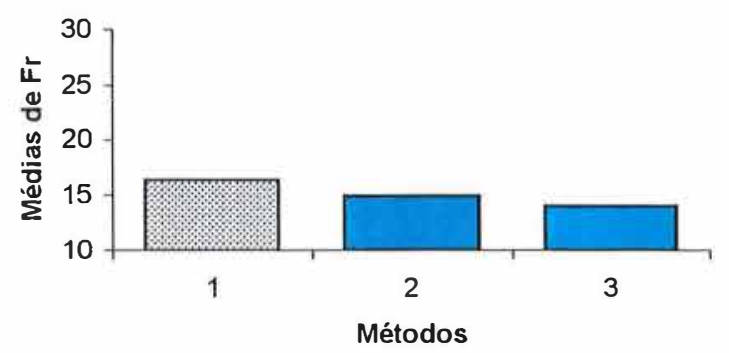

T: Solos litólicos

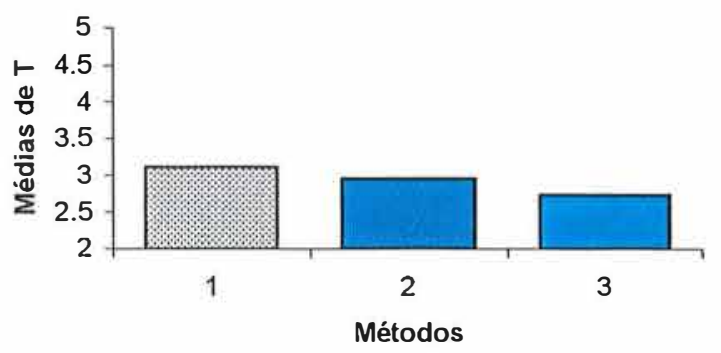

Dd: Solos podzólicos

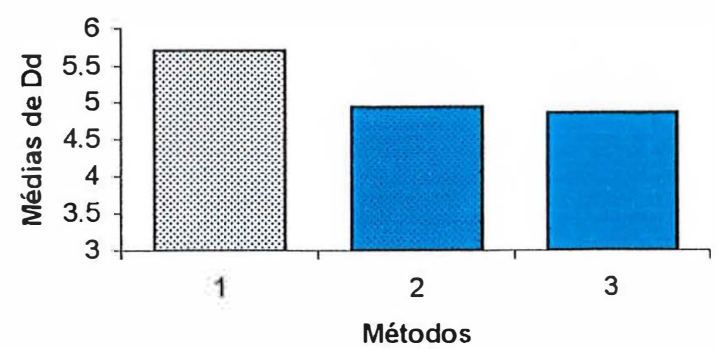

Fr: Solos podzólicos

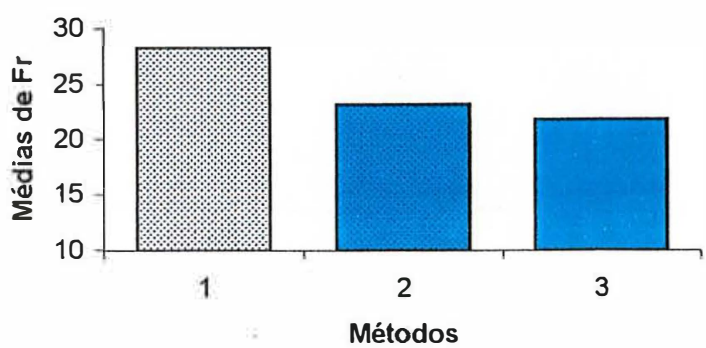

T: Solos podzólicos

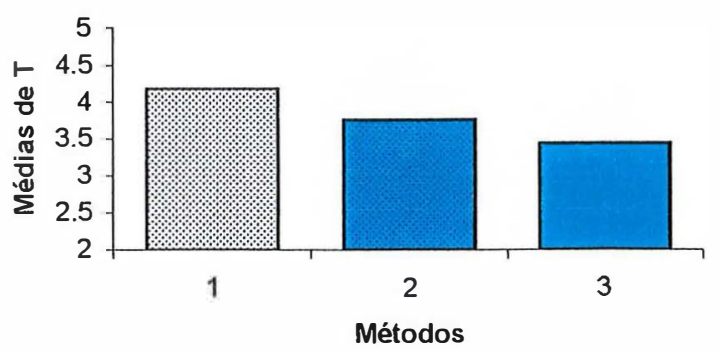

Figura 25 - Médias em função dos Métodos de medição para as variáveis Dd, Fr e T, nas bacias dos dois solos.

Visto que o teste $\mathrm{F}$ foi significativo somente para 6 variáveis nas bacias dos solos podzólicos, procedeu-se ao detalhamento da análise para estas variáveis utilizando-se o teste F para os contrastes descritos anteriormente. Esse detalhamento é ilustrado na Tabela 18. 
Tabela 18 - Teste F para contrastes para as variáveis N1, Lm, A, Dd, Fr e T nas bacias dos solos podzólicos.

\begin{tabular}{|c|c|c|c|c|}
\hline \multirow{2}{*}{ Causas de Variação } & \multirow{2}{*}{ G.L. } & \multicolumn{3}{|c|}{ Quadrados Médios } \\
\hline & & Nw1 & $\mathrm{Lm}$ & A \\
\hline Método 1 vs Métodos 2 e 3 & 1 & $0,0253^{*}$ & $0,0033^{*}$ & $0,0409 * *$ \\
\hline Método 2 vs Método 3 & 1 & $0,0094^{\mathrm{ns}}$ & $0,0007^{\mathrm{ns}}$ & $0,0001^{\text {ns }}$ \\
\hline Resíduo & 37 & 0,0052 & 0,0006 & 0,0011 \\
\hline \multirow{2}{*}{ Causas de Variação } & \multirow{2}{*}{ G.L. } & \multicolumn{3}{|c|}{ Quadrados Médios } \\
\hline & & $\overline{D d}$ & $\mathrm{Fr}$ & $\mathrm{T}$ \\
\hline Método 1 vs Métodos 2 e 3 & 1 & $6,6007 * *$ & $0,1050 * *$ & $0,0415^{* *}$ \\
\hline Método 2 vs Método 3 & 1 & $0,0398^{\text {ns }}$ & $0,0068^{\text {ns }}$ & $0,0124^{\text {ns }}$ \\
\hline Resíduo & 37 & 0,5434 & 0,0047 & 0,0053 \\
\hline
\end{tabular}

* = Significativo, pelo teste $\mathrm{F}$, ao nivel de $5 \%(\alpha \leq 0,05)$.

$* *$ = Significativo, pelo teste $\mathrm{F}$, ao nivel de $1 \%(\alpha \leq 0,01)$.

ns = Não significativo, pelo teste $F$, considerando-se um n.m.s. de $5 \%(\alpha>0,05)$.

Pela Tabela 18 verifica-se que para as variáveis Nw1, Lm, A, Dd, Fr e T nas bacias dos solos podzólicos, o teste $\mathrm{F}$ para contrastes foi significativo aos níveis de $5 \%(\mathrm{Nw} 1$ e $\mathrm{Lm})$ e $1 \%\left(\mathrm{~A}, \mathrm{Dd}, \mathrm{Fr}\right.$ e $\mathrm{T}$ ) para o $1^{\circ}$ contraste (Método da análise estereoscópica vs Métodos computacionais) e não significativo para o $2^{\circ}$ (entre os Métodos Computacionais), isto é, existe diferença entre o Método da análise estereoscópica e os métodos de digitalização em tela para as bacias destes solos, mas não existe diferença entre os dois métodos de digitalização em tela. A Tabela 19 mostra as estimativas dos contrastes significativos.

Tabela 19 - Estimativas dos contrastes significativos.

\begin{tabular}{ccccccc}
\hline \multirow{2}{*}{ Contraste } & \multicolumn{6}{c}{ Estimativas } \\
\cline { 2 - 7 } & Nw1 & Lm & A & Dd & Fr & T \\
\hline Método 1 vs Métodos 2 e 3 & 3,533 & $-0,036$ & $-0,234$ & 1,623 & 11,581 & 1,163 \\
\hline
\end{tabular}

Observa-se que para as variáveis Nwl, Dd, Fr e T o Método de análise estereoscópica apresentou médias significativamente maiores que as dos métodos computacionais, enquanto para as variáveis Lm e A ocorreu o inverso. 
Esses resultados foram concordantes com os obtidos pelo teste de Tukey, podendo ser considerados complementares.

Complementando as análises anteriores, estudaram-se as correlações parciais entre as variáveis estudadas (através dos valores dos resíduos, isentos dos efeitos de métodos e grupos). As Tabelas 20 e 21 mostram os valores desses coeficientes para as bacias dos solos litólicos e podzólicos, respectivamente.

Tabela 20 - Coeficientes de correlação parcial e teste $t$, para o cruzamento das variáveis duas a duas nas bacias dos solos litóliocs.

\begin{tabular}{|c|c|c|c|c|c|c|c|c|c|c|}
\hline & $\mathbf{N}$ & Lwl & $\overline{\mathrm{Lt}}$ & Lml & $\mathrm{Lm}$ & $A$ & $\mathrm{P}$ & $\overline{\mathrm{Dd}}$ & Fr & $\mathrm{T}$ \\
\hline N1 & $0,981^{* *}$ & $0,595 * *$ & $0,749 * *$ & $-0,292^{\mathrm{ns}}$ & $-0,499 * *$ & $0,339^{\text {ns }}$ & $-0,012^{\text {ns }}$ & $0,586^{* *}$ & $0,816 * *$ & $0,973 * *$ \\
\hline $\mathbf{N}$ & & $0,626 * *$ & $0,789^{* *}$ & $-0,241^{\mathrm{ns}}$ & $-0,467 *$ & $0,398 *$ & $-0,026^{n s}$ & $0,588 * *$ & $0,788^{* *}$ & $0,950 * *$ \\
\hline L1 & & & $0,924^{* *}$ & $0,517 * *$ & $0,277^{\mathrm{ns}}$ & $0,752 * *$ & $0,200^{\mathrm{ns}}$ & $0,499 * *$ & $0,182^{\mathrm{ns}}$ & $0,529 * *$ \\
\hline $\mathrm{Lt}$ & & & & $0,253^{\mathrm{ns}}$ & $0,101^{\text {ns }}$ & $0,663^{* *}$ & $0,047^{\mathrm{ns}}$ & $0,674^{* *}$ & $0,408^{*}$ & $0,709 * *$ \\
\hline $\mathrm{Lml}$ & & & & & $0,875^{* *}$ & $0,481^{*}$ & $0,267^{\mathrm{ns}}$ & $-0,050^{\mathrm{ns}}$ & $-0,585^{* *}$ & $-0,366^{\mathrm{ns}}$ \\
\hline $\mathrm{Lm}$ & & & & & & $0,291^{\text {ns }}$ & $0,152^{n s}$ & $-0,035^{n s}$ & $-0,698^{* *}$ & $-0,542 * *$ \\
\hline A & & & & & & & $0,474^{*}$ & $-0,080^{\mathrm{ns}}$ & $-0,223^{\mathrm{ng}}$ & $0,225^{\mathrm{ns}}$ \\
\hline $\mathrm{P}$ & & & & & & & & $-0,443 *$ & $-0,373^{\text {ns }}$ & $-0,213^{n s}$ \\
\hline Dd & & & . & & & & & & $0,694^{* *}$ & $0,656^{* *}$ \\
\hline $\mathrm{Fr}$ & & & & & & & & & & $0,877^{* *}$ \\
\hline
\end{tabular}

ns = Não significativo, pelo teste " $t$ ", considerando-se um n.m.s. de $5 \%(\alpha>0,05)$.

* = Significativo, pelo teste " $t$ ", considerando-se um n.m.s de $5 \%(\alpha \leq 0,05)$.

$* *$ = Significativo, pelo teste " $t$ ", considerando-se um n.m.s de $1 \%(\alpha \leq 0,01)$.

Tabela 21 - Coeficientes de correlação parcial e teste $t$, para o cruzamento das variáveis duas a duas nas bacias dos solos podzólicos.

\begin{tabular}{|c|c|c|c|c|c|c|c|c|c|c|}
\hline & $\mathrm{N}$ & Lwl & $\mathrm{Lt}$ & Lm1 & $\mathrm{Lm}$ & $\mathrm{A}$ & $\mathrm{P}$ & $\mathrm{Dd}$ & Fr & $\mathrm{T}$ \\
\hline N1 & $0,977^{* *}$ & $0,683^{* *}$ & $0,638^{* *}$ & $-0,161^{\text {ns }}$ & $-0,499 * *$ & $-0,080^{\mathrm{ns}}$ & $0,111^{\text {ns }}$ & $0,559 * *$ & $0,714^{* *}$ & $0,923 * *$ \\
\hline $\mathrm{N}$ & & $0,682 * *$ & $0,672 * *$ & $-0,129^{n s}$ & $-0,506 * *$ & $-0,082^{n s}$ & $0,116^{\text {ns }}$ & $0,587^{* *}$ & $0,732 * *$ & $0,890 * *$ \\
\hline L1 & & & $0,908^{* *}$ & $0,564 * *$ & $0,171^{n s}$ & $0,014^{n s}$ & $0,073^{\mathrm{ns}}$ & $0,747^{* *}$ & $0,473 * *$ & $0,671^{* *}$ \\
\hline $\mathrm{Lt}$ & & & & $0,452^{* *}$ & $0,216^{\mathrm{ns}}$ & $-0,009^{n s}$ & $0,075^{\mathrm{ms}}$ & $0,821^{* *}$ & $0,507 * *$ & $0,655^{* *}$ \\
\hline Lm1 & & & & & $0,790 * *$ & $0,212^{\mathrm{ns}}$ & $0,082^{\text {ns }}$ & $0,332 *$ & $-0,194^{\mathrm{ns}}$ & $-0,147^{\mathrm{ns}}$ \\
\hline $\mathrm{Lm}$ & & & & & & $0,197^{\text {ns }}$ & $0,027^{n s}$ & $0,107^{n s}$ & $-0,448^{* *}$ & $-0,426^{* *}$ \\
\hline A & & & & & & & $0,648 * *$ & $-0,290^{\mathrm{ns}}$ & $-0,260^{\mathrm{ns}}$ & $-0,167^{\mathrm{ns}}$ \\
\hline $\mathrm{P}$ & & & & & & & & $-0,146^{\mathrm{ns}}$ & $-0,105^{\mathrm{ns}}$ & $-0,118^{n s}$ \\
\hline Dd & & & & & & & & & $0,756 * *$ & $0,680^{* *}$ \\
\hline $\mathrm{Fr}$ & & & & & & & & & & $0,825 * *$ \\
\hline
\end{tabular}

ns = Não significativo, pelo teste 't", considerando-se um n.m.s. de $5 \%(\alpha>0,05)$.

* = Significativo, pelo teste " 4 ", considerando-se um n.m.s de $5 \%(\alpha \leq 0,05)$.

** = Significativo, pelo teste " $t$ ", considerando-se um n.m.s de $1 \%(\alpha \leq 0,01)$. 
Observa-se que $o$ teste " $t$ " detectou correlação significativa entre a maioria das variáveis, e que estes coeficientes foram semelhantes nas bacias dos dois solos para a maioria das variáveis.

Pode-se observar também, nas Tabelas 20 e 21 que algumas das variáveis apresentaram correlação alta e positiva entre si (acima de 0,6), enquanto outras apresentaram correlação moderada e baixa, positiva ou negativa. Houve apenas uma correlação alta negativa ( $\mathrm{Lm} v s$. Fr). Há, portanto, uma indicação de que, nem todas as variáveis são necessárias no estudo. Existem algumas que explicam o comportamento de muitas das demais.

\subsubsection{Teste exato de Fisher para a variável Razão textura de média das bacias}

A tabela 22 ilustra os resultados para a classificação de textura topográfica em função da variável "razão de textura média" e de cada tratamento nas bacias dos dois tipos de solo.

Tabela 22 - Freqüência observada e porcentagem (\%) por total de linha de "razão de textura média" das bacias (Tm) em função dos Métodos estudados.

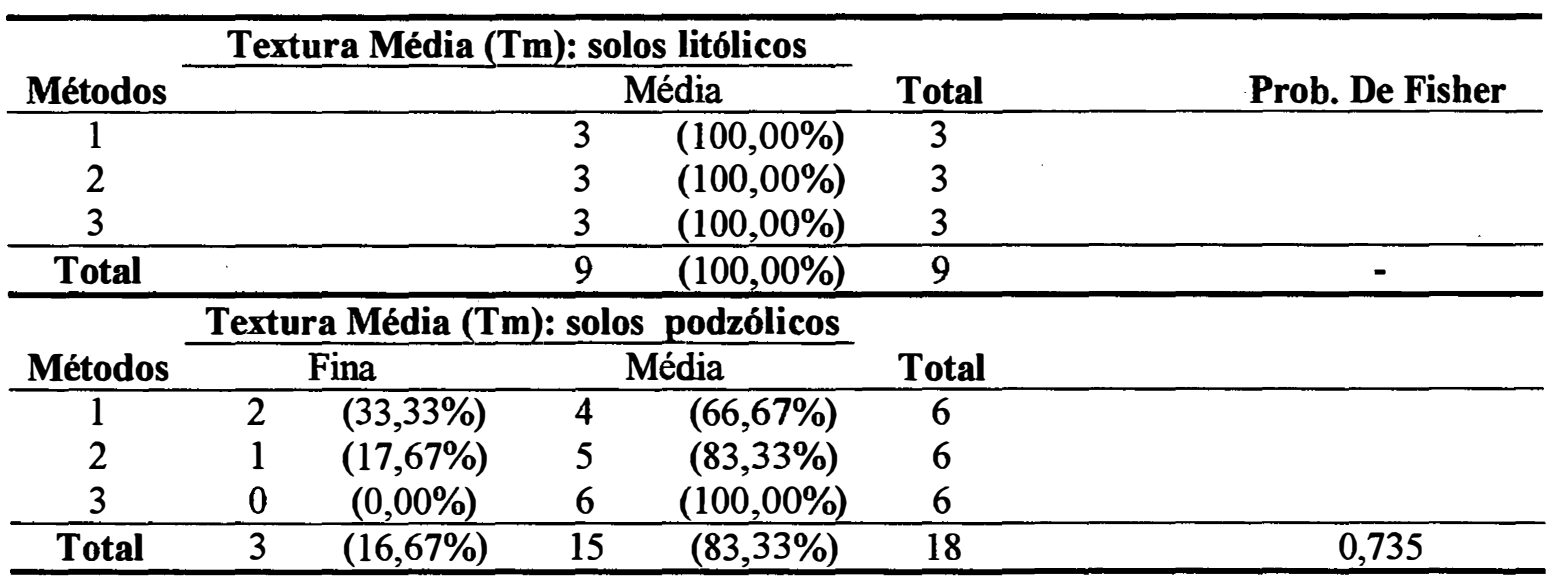

Observa-se que para as bacias dos solos litólicos não foi possível realizar o Teste Exato de Fisher, pois os métodos classificaram todas as bacias como de "textura média", implicando que essa classificação, dessa forma independe do Método de 
medição utilizado. Para as bacias dos solos podzólicos, o Teste Exato de Fisher também não foi significativo, isto é, a classificação da textura topográfica com base na variável Tm dessa forma independe do método de medição utilizado. Esses resultados são concordantes, em parte, com os obtidos até aqui para as demais variáveis, já que naquelas alguma significância foi obtida entre os métodos nas bacias dos solos podzólicos. A Figura 26 ilustra esse comportamento.

Textura Média: Solos litólicos

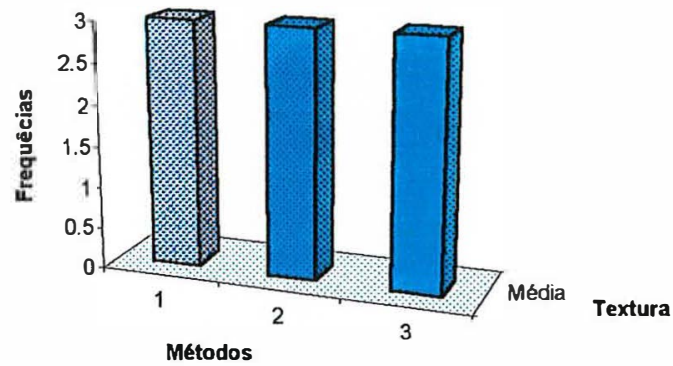

Textura Média: Solos podzólicos

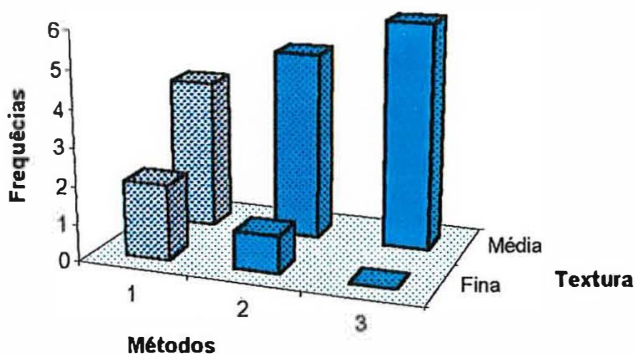

Figura 26 - Freqüências observadas para Textura média em função dos Métodos de medição. 


\section{CONCLUSÕES}

Considerando os objetivos deste trabalho, as condições específicas sob as quais foi desenvolvido e a metodologia utilizada, os resultados obtidos permitem as seguintes conclusões:

- os tratamentos digitais aplicados aos dados, de maneira geral, não produziram o efeito esperado em termos de realce das feições de interesse. $O$ realce por meio da composição colorida, embora tenha proporcionado um aspecto visual, aparentemente, melhor que o da fotografia sem realce, isto não se traduziu em resultados significativos na comparação entre os métodos;

- a melhor condição para uso da metodologia como alternativa à análise estereoscópica, foi em bacias com rede de drenagem bem definida, geralmente identificada pela presença de vegetação arbórea, neste caso, mais frequentes nos solos litólicos;

- o método da estereoscopia foi imprescindível para a interpretação de bacias hidrográficas situadas em áreas de solos descobertos ou com gramíneas, a exemplo dos solos podzólicos, para permitir a diferenciação entre solos;

- a forma de aquisição dos dados digitais via "scanner" foi satisfatória para o desenvolvimento do trabalho, pois as fotografias mantiveram suas características após a digitalização, apresentando definição visual similar às imagens no formato analógico; 
- no georreferenciamento, as geometrias de pontos de controle selecionados apresentaram, em todos os casos, valores de erro abaixo do limite aceitável. Assim, na elaboração do mosaico, foram obtidos bons ajustes na linha de contato entre fotografias, tanto no sentido da linha de vôo como entre faixas. Contudo, nas regiões de relevo mais acidentado ocorreram algumas discordâncias de imagem nessa linha de contato, uma vez que não se trata de um produto ortorretificado, mas apenas corrigido planimetricamente. Este fato, no entanto, não prejudicou significativamente a digitalização da rede de drenagem e os limites das bacias nessas regiões. 


\section{ANEXO}

CARACTERÍSTICAS DA REDE E DO PADRÃO DE DRENAGEM DAS BACIAS ESTUDADAS, DETERMINADAS PELOS TRÊS INTÉRPRETES, PARA OS MÉTODOS 2 E 3. 
A1 - Número, comprimentos total e médio de canais observados em cada ordem de ramificação para as bacias dos solos litólicos.

\begin{tabular}{|c|c|c|c|c|c|c|c|c|c|c|c|c|c|c|c|c|}
\hline \multirow[t]{2}{*}{ Bacias } & \multicolumn{5}{|c|}{$\begin{array}{c}\text { Número de canais por } \\
\text { ordem }\end{array}$} & \multicolumn{5}{|c|}{$\begin{array}{l}\text { Comprimento total de } \\
\text { canais por ordem }\end{array}$} & \multicolumn{5}{|c|}{$\begin{array}{l}\text { Comprimento médio de canais } \\
\text { por ordem }\end{array}$} & \multirow[b]{2}{*}{$\begin{array}{l}\text { Área } \\
\left(\mathbf{l m}^{2}\right)\end{array}$} \\
\hline & $1^{\mathrm{a}}$ & $2^{a}$ & $3^{\mathrm{a}}$ & $4^{a}$ & $\mathrm{~N}$ & $1^{\mathrm{a}}$ & $2^{\mathrm{a}}$ & $3^{\mathrm{a}}$ & $4^{\mathrm{a}}$ & Lt & $1^{\mathrm{a}}$ & $2^{a}$ & $3^{\mathrm{a}}$ & $4^{a}$ & $\mathrm{Lm}$ & \\
\hline \multicolumn{9}{|c|}{ Primeiro intérprete } & \multicolumn{7}{|c|}{ Método 2 (cinza) } & \\
\hline \multicolumn{9}{|c|}{ G 1} & & & & & & & & \\
\hline $07 \mathrm{RM}$ & 13 & 3 & \multirow{2}{*}{\multicolumn{2}{|c|}{$\begin{array}{l}1 \\
1\end{array}$}} & 17 & 3,03 & 1,61 & 0,87 & & 5,51 & 0,23 & 0,54 & 0,87 & & 0,32 & 1,15 \\
\hline $08 \mathrm{RM}$ & 7 & 3 & & & 11 & 1,72 & 1,23 & 0,71 & & 3,66 & 0,25 & 0,41 & 0,71 & & 0,33 & 1,14 \\
\hline $21 \mathrm{RM}$ & 11 & 4 & \multicolumn{2}{|l|}{1} & 16 & 2,15 & 1,17 & 1,03 & & 4,35 & 0,20 & 0,29 & 1,03 & & 0,27 & 1,05 \\
\hline \multicolumn{17}{|l|}{ G2 } \\
\hline $06 \mathrm{RM}$ & 8 & 2 & 1 & & 11 & 1,68 & 0,60 & 1,06 & & 3,34 & 0,21 & 0,30 & 1,06 & & 0,30 & 0,81 \\
\hline 08 RG & 12 & 3 & 1 & & 16 & 1,53 & 0,86 & 1,01 & & 3,40 & 0,13 & 0,29 & 1,01 & & 0,21 & 0,80 \\
\hline $17 \mathrm{RM}$ & 9 & 3 & 1 & & 13 & 1,52 & 1,27 & 0,90 & & 3,69 & 0,17 & 0,42 & 0,90 & & 0,28 & 0,84 \\
\hline \multicolumn{17}{|l|}{ G3 } \\
\hline $09 \mathrm{RM}$ & 18 & 2 & 1 & & 21 & 3,69 & 0,71 & 1,41 & & 5,81 & 0,21 & 0,36 & 1,41 & & 0,28 & 1,36 \\
\hline $12 \mathrm{RM}$ & 15 & 4 & 1 & & 20 & 4,03 & 0,97 & 1,55 & & 6,55 & 0,27 & 0,24 & 1,55 & & 0,33 & 1,49 \\
\hline $14 \mathrm{RM}$ & 24 & 5 & 1 & & 30 & 4,43 & 1,66 & 1,41 & & 7,50 & 0,18 & 0,33 & 1,41 & & 0,25 & 1,69 \\
\hline \multicolumn{9}{|c|}{ Primeiro intérprete } & \multicolumn{8}{|c|}{ Método 3 (colorido) } \\
\hline \multicolumn{17}{|l|}{ G 1} \\
\hline $07 \mathrm{RM}$ & 12 & 4 & 1 & & 17 & 2,92 & 1,68 & 0,86 & & 5,46 & 0,24 & 0,42 & 0,86 & & 0,32 & 1,18 \\
\hline $08 \mathrm{RM}$ & 11 & 3 & 1 & & 15 & 2,31 & 0,97 & 0,93 & & 4,21 & 0,21 & 0,32 & 0,93 & & 0,28 & 1,15 \\
\hline $21 \mathrm{RM}$ & 11 & 3 & 1 & & 15 & 1,95 & 1,59 & 0,62 & & 4,16 & 0,18 & 0,53 & 0,62 & & 0,28 & 1,02 \\
\hline \multicolumn{17}{|l|}{ G2 } \\
\hline $06 \mathrm{RM}$ & 10 & 2 & 1 & & 13 & 1,76 & 0,75 & 0,97 & & 3,48 & 0,18 & 0,38 & 0,97 & & 0,27 & 0,77 \\
\hline $08 \mathrm{RG}$ & 12 & 2 & 1 & & 15 & 1,93 & 0,73 & 1,01 & & 3,67 & 0,16 & 0,37 & 1,01 & & 0,24 & 0,83 \\
\hline $17 \mathrm{RM}$ & 8 & 3 & 1 & & 12 & 1,49 & 1,14 & 0,82 & & 3,45 & 0,19 & 0,38 & 0,82 & & 0,29 & 0,81 \\
\hline \multicolumn{17}{|l|}{ G3 } \\
\hline $09 \mathrm{RM}$ & 19 & 3 & 1 & & 23 & 3,69 & 1,55 & 1,22 & & 6,46 & 0,19 & 0,52 & 1,22 & & 0,28 & 1,49 \\
\hline $12 \mathrm{RM}$ & 19 & 3 & 1 & & 23 & 3,53 & 1,33 & 1,55 & & 6,41 & 0,19 & 0,44 & 1,55 & & 0,28 & 1,41 \\
\hline $14 \mathrm{RM}$ & 20 & 2 & 1 & & 23 & 4,00 & 1,58 & 0,98 & & 6,56 & 0,20 & 0,79 & 0,98 & & 0,29 & 1,59 \\
\hline \multicolumn{9}{|c|}{ Segundo intérprete } & \multicolumn{8}{|c|}{ Método 2 (cinza) } \\
\hline \multicolumn{17}{|l|}{ G 1} \\
\hline $07 \mathrm{RM}$ & 11 & 3 & 1 & & 15 & 3,11 & 1,27 & 0,84 & & 5,22 & 0,28 & 0,42 & 0,84 & & 0,35 & 1,13 \\
\hline $08 \mathrm{RM}$ & 13 & 3 & 1 & & 17 & 2,13 & 1,42 & 0,94 & & 4,49 & 0,16 & 0,47 & 0,94 & & 0,26 & 1,03 \\
\hline $21 \mathrm{RM}$ & 11 & 4 & 1 & & 16 & 1,32 & 1,41 & 1,01 & & 3,74 & 0,12 & 0,35 & 1,01 & & 0,23 & 0,98 \\
\hline G2 & & & & & & & & & & & & & & & & \\
\hline $06 \mathrm{RM}$ & 10 & 4 & 1 & & 15 & 1,36 & 0,61 & 1,30 & & 3,27 & 0,14 & 0,15 & 1,30 & & 0,22 & 0,77 \\
\hline $08 \mathrm{RG}$ & 10 & 3 & 1 & & 14 & 1,29 & 1,12 & 0,76 & & 3,17 & 0,13 & 0,37 & 0,76 & & 0,23 & 0,97 \\
\hline $17 \mathrm{RM}$ & 9 & 3 & 1 & & 13 & 1,57 & 1,27 & 0,82 & & 3,66 & 0,17 & 0,42 & 0,82 & & 0,28 & 0,83 \\
\hline $\mathbf{G 3}$ & & & & & & & & & & & & & & & & \\
\hline $09 \mathrm{RM}$ & 13 & 5 & 1 & & 19 & 2,59 & 1,41 & 1,50 & & 5,50 & 0,20 & 0,28 & 1,50 & & 0,29 & 1,77 \\
\hline $12 \mathrm{RM}$ & 15 & 4 & 1 & & 20 & 3,58 & 0,62 & 1,76 & & 5,96 & 0,24 & 0,16 & 1,76 & & 0,30 & 1,37 \\
\hline $14 \mathrm{RM}$ & 35 & 10 & 2 & 1 & 48 & 4,47 & 1,68 & 1,50 & 1,02 & 8,67 & 0,13 & 0,17 & 0,75 & & 0,18 & 1,57 \\
\hline
\end{tabular}




\begin{tabular}{|c|c|c|c|c|c|c|c|c|c|c|c|c|c|c|c|c|}
\hline \multirow[t]{2}{*}{ Bacias } & \multicolumn{5}{|c|}{$\begin{array}{c}\text { Número de canais por } \\
\text { ordem }\end{array}$} & \multicolumn{5}{|c|}{$\begin{array}{l}\text { Comprimento total de } \\
\text { canais por ordem }\end{array}$} & \multicolumn{5}{|c|}{$\begin{array}{l}\text { Comprimento médio de canais } \\
\text { por ordem }\end{array}$} & \multirow[b]{2}{*}{$\begin{array}{l}\text { Area } \\
\left(\mathrm{km}^{2}\right)\end{array}$} \\
\hline & $1^{\mathrm{a}}$ & $2^{a}$ & $3^{a}$ & $4^{a}$ & $\mathrm{~N}$ & $1^{\mathrm{a}}$ & $2^{a}$ & $3^{a}$ & $4^{a}$ & $\mathrm{Lt}$ & $1^{\mathrm{a}}$ & $2^{\mathrm{a}}$ & $3^{\mathrm{a}}$ & $4^{a}$ & $\mathrm{Lm}$ & \\
\hline \multicolumn{9}{|c|}{ Segundo intérprete } & \multicolumn{8}{|c|}{ Método 3 (colorido) } \\
\hline \multicolumn{17}{|l|}{ G 1} \\
\hline $07 \mathrm{RM}$ & 12 & 3 & 1 & & 16 & 3,10 & 1,29 & 0,85 & & 5,24 & 0,26 & 0,43 & 0,85 & & 0,33 & 1,18 \\
\hline $08 \mathrm{RM}$ & 9 & 2 & 1 & & 12 & 3,08 & 0,32 & 0,98 & & 4,38 & 0,34 & 0,16 & 0,98 & & 0,37 & $\begin{array}{l}1,25 \\
099\end{array}$ \\
\hline $21 \mathrm{RM}$ & 12 & 4 & 1 & & 17 & 1,93 & 1,05 & 0,99 & & 3,97 & 0,16 & 0,26 & 0,99 & & 0,23 & 0,99 \\
\hline \multicolumn{17}{|l|}{ G2 } \\
\hline $06 \mathrm{RM}$ & 11 & 3 & 1 & & 15 & 1,67 & 0,31 & 1,35 & & 3,33 & 0,15 & 0,10 & 1,35 & & 0,22 & 0,78 \\
\hline $08 \mathrm{RG}$ & 12 & 3 & 1 & & 16 & 1,60 & 1,01 & 1,00 & & 3,61 & 0,13 & 0,34 & 1,00 & & 0,23 & 0,70 \\
\hline $17 \mathrm{RM}$ & 9 & 3 & 1 & & 13 & 1,63 & 1,14 & 0,70 & & 3,47 & 0,18 & 0,38 & 0,70 & & 0,27 & 0,76 \\
\hline \multicolumn{17}{|l|}{ G3 } \\
\hline $09 \mathrm{RM}$ & 18 & 3 & 1 & & 22 & 3,23 & 0,98 & 1,32 & & 5,53 & 0,18 & 0,33 & 1,32 & & 0,25 & 1,44 \\
\hline $12 \mathrm{RM}$ & 17 & 4 & 1 & & 22 & 2,98 & 1,75 & 1,50 & & 6,23 & 0,18 & 0,44 & 1,50 & & 0,28 & 1,38 \\
\hline $14 \mathrm{RM}$ & 25 & 6 & 1 & & 32 & 4,27 & 1,99 & 1,67 & & 7,93 & 0,17 & 0,33 & 1,67 & & 0,25 & 1,60 \\
\hline \multicolumn{9}{|c|}{ Terceiro intérprete } & \multicolumn{8}{|c|}{ Método 2 (cinza) } \\
\hline \multicolumn{17}{|l|}{ G 1} \\
\hline $07 \mathrm{RM}$ & 11 & 3 & 1 & & 15 & 2,55 & 1,44 & 0,85 & & 4,84 & 0,23 & 0,48 & 0,85 & & 0,32 & 1,13 \\
\hline $08 \mathrm{RM}$ & 7 & 2 & 1 & & 10 & 1,84 & 1,33 & 0,43 & & $.3,60$ & 0,26 & 0,67 & 0,43 & & 0,36 & 1,23 \\
\hline $21 \mathrm{RM}$ & 10 & 3 & 1 & & 14 & 1,85 & 1,53 & 0,64 & & 4,02 & 0,19 & 0,51 & 0,64 & & 0,29 & 1,08 \\
\hline \multicolumn{17}{|l|}{ G2 } \\
\hline $06 \mathrm{RM}$ & 6 & 2 & 1 & & 9 & 1,23 & 0,54 & 1,03 & & 2,80 & 0,21 & 0,27 & 1,03 & & 0,31 & 0,83 \\
\hline $08 \mathrm{RG}$ & 10 & 3 & 1 & & 14 & 1,38 & 0,83 & 1,06 & & 3,27 & 0,14 & 0,28 & 1,06 & & 0,23 & 0,84 \\
\hline $17 \mathrm{RM}$ & 8 & 3 & 1 & & 12 & 1,69 & 1,30 & 0,81 & & 3,80 & 0,21 & 0,43 & 0,81 & & 0,32 & 0,83 \\
\hline \multicolumn{17}{|l|}{ G3 } \\
\hline $09 \mathrm{RM}$ & 12 & 3 & 1 & & 16 & 2,12 & 1,07 & 1,30 & & 4,49 & 0,18 & 0,36 & 1,30 & & 0,28 & 1,42 \\
\hline $12 \mathrm{RM}$ & 13 & 4 & 1 & & 18 & 2,05 & 1,37 & 1,56 & & 4,98 & 0,16 & 0,34 & 1,56 & & 0,28 & 1,48 \\
\hline $14 \mathrm{RM}$ & 20 & 5 & 1 & & 26 & 3,53 & 1,60 & 1,52 & & 6,65 & 0,18 & 0,32 & 1,52 & & 0,26 & 1,63 \\
\hline \multicolumn{9}{|c|}{ Terceiro intérprete } & \multicolumn{8}{|c|}{ Método 3 (colorido) } \\
\hline \multicolumn{17}{|l|}{ G 1} \\
\hline 07 RM & 10 & 3 & 1 & & 14 & 3,03 & 1,12 & 0,81 & & 4,96 & 0,30 & 0,37 & 0,81 & & 0,35 & 1,28 \\
\hline $08 \mathrm{RM}$ & 5 & 2 & 1 & & 8 & 2,04 & 1,05 & 0,34 & & 3,43 & 0,41 & 0,53 & 0,34 & & 0,43 & 1,21 \\
\hline $21 \mathrm{RM}$ & 6 & 3 & 1 & & 10 & 1,47 & 1,03 & 0,67 & & 3,17 & 0,25 & 0,34 & 0,67 & & 0,32 & 1,09 \\
\hline \multicolumn{17}{|l|}{ G2 } \\
\hline $06 \mathrm{RM}$ & 6 & 2 & 1 & & 9 & 0,84 & 0,72 & 1,04 & & 2,60 & 0,14 & 0,36 & 1,04 & & 0,29 & 0,81 \\
\hline 08 RG & 8 & 2 & 1 & & 11 & 1,71 & 0,70 & 0,76 & & 3,17 & 0,21 & 0,35 & 0,76 & & 0,29 & 0,80 \\
\hline $17 \mathrm{RM}$ & 7 & 3 & 1 & & 11 & 1,15 & 1,14 & 0,77 & & 3,06 & 0,16 & 0,38 & 0,77 & & 0,28 & 0,80 \\
\hline \multicolumn{17}{|l|}{ G3 } \\
\hline $09 \mathrm{RM}$ & 9 & 3 & 1 & & 13 & 1,87 & 0,73 & 1,35 & & 3,95 & 0,21 & 0,24 & 1,35 & & 0,30 & 1,39 \\
\hline $12 \mathrm{RM}$ & 9 & 2 & 1 & & 12 & 2,55 & 1,06 & 1,16 & & 4,77 & 0,28 & 0,53 & 1,16 & & 0,40 & 1,58 \\
\hline $14 \mathrm{RM}$ & 8 & 2 & 1 & & 11 & 1,71 & 1,30 & 1,05 & & 4,06 & 0,21 & 0,65 & 1,05 & & 0,37 & 1,56 \\
\hline
\end{tabular}


A2 - Número, comprimentos total e médio de canais observados em cada ordem de ramificação para as bacias dos solos podzólicos.

\begin{tabular}{|c|c|c|c|c|c|c|c|c|c|c|c|c|c|}
\hline \multirow[t]{2}{*}{ Bacias } & \multicolumn{4}{|c|}{$\begin{array}{c}\text { Número de canais por } \\
\text { ordem }\end{array}$} & \multicolumn{4}{|c|}{$\begin{array}{l}\text { Comprimento total de canais } \\
\text { por ordem }\end{array}$} & \multicolumn{4}{|c|}{$\begin{array}{c}\text { Comprimento médio de canais } \\
\text { por ordem }\end{array}$} & \multirow[b]{2}{*}{$\begin{array}{l}\text { Area } \\
\left(\mathrm{km}^{2}\right)\end{array}$} \\
\hline & $1^{\mathrm{a}}$ & $2^{a}$ & $3^{\mathrm{a}} 4^{\mathrm{a}}$ & $\mathrm{N}$ & $1^{\mathrm{a}}$ & $2^{\mathrm{a}}$ & $3^{\mathrm{a}}$ & $4^{\mathrm{a}} \quad$ Lt & $1^{\mathrm{a}}$ & $2^{\mathrm{a}}$ & $3^{a} \quad 4^{a}$ & $\mathrm{Lm}$ & \\
\hline \multicolumn{8}{|c|}{ Primeiro intérprete } & \multicolumn{5}{|c|}{ Método 2 (cinza) } & \\
\hline \multicolumn{14}{|l|}{ G1 } \\
\hline $20 \mathrm{RC}$ & 5 & 1 & - & 6 & 0,97 & 0,55 & - & 1,52 & 0,19 & 0,55 & & 0,25 & 0,29 \\
\hline $30 \mathrm{RC}$ & 6 & 3 & 1 & 10 & 0,92 & 0,57 & 0,34 & 1,83 & 0,15 & 0,19 & 0,34 & 0,18 & 0,29 \\
\hline $43 \mathrm{RC}$ & 6 & 2 & 1 & 9 & 0,90 & 0,63 & 0,16 & 1,69 & 0,15 & 0,32 & 0,16 & 0,19 & 0,28 \\
\hline \multicolumn{14}{|l|}{ G2 } \\
\hline $06 \mathrm{RC}$ & 9 & 2 & 1 & 12 & 1,25 & 0,41 & 0,53 & 2,19 & 0,14 & 0,21 & 0,53 & 0,18 & 0,46 \\
\hline $27 \mathrm{RC}$ & 10 & 2 & 1 & 13 & 1,66 & 0,84 & 0,42 & 2,92 & 0,17 & 0,42 & 0,42 & 0,22 & 0,45 \\
\hline $61 \mathrm{RC}$ & 7 & 2 & 1 & 10 & 0,93 & 0,26 & 0,62 & 1,81 & 0,13 & 0,13 & 0,62 & 0,18 & 0,41 \\
\hline \multicolumn{14}{|l|}{ G3 } \\
\hline $03 \mathrm{RC}$ & 16 & 2 & 1 & 19 & 2,76 & 0,42 & 0,94 & 4,12 & 0,17 & 0,21 & 0,94 & 0,22 & 0,75 \\
\hline 07 RG & 11 & 2 & 1 . & 14 & 2,22 & 0,76 & 0,78 & 3,76 & 0,20 & 0,38 & 0,78 & 0,27 & 0,90 \\
\hline $29 \mathrm{RM}$ & 14 & 2 & 1 & 17 & 2,37 & 1,50 & 0,30 & 4,17 & 0,17 & 0,75 & 0,30 & 0,25 & 0,85 \\
\hline \multicolumn{14}{|l|}{ G4 } \\
\hline $25 \mathrm{RC}$ & 21 & 4 & 1 & 26 & 3,30 & 1,80 & 1,21 & 6,31 & 0,16 & 0,45 & 1,21 & 0,24 & 1,28 \\
\hline $29 \mathrm{RC}$ & 24 & 5 & 1 & 30 & 3,49 & 1,57 & 1,20 & 6,26 & 0,15 & 0,31 & 1,20 & 0,21 & 1,03 \\
\hline \multicolumn{14}{|l|}{ G5 } \\
\hline $21 \mathrm{RC}$ & 22 & 5 & 1 & 28 & 4,34 & 1,65 & 1,35 & 7,34 & 0,20 & 0,33 & 1,35 & 0,26 & 1,56 \\
\hline $44 \mathrm{RC}$ & 19 & 5 & 1 & 25 & 3,95 & 2,61 & 1,25 & 7,81 & 0,21 & 0,52 & 1,25 & 0,31 & 1,51 \\
\hline \multicolumn{14}{|l|}{ G6 } \\
\hline $02 \mathrm{RP}$ & 10 & 3 & 1 & 14 & 2,32 & 1,47 & 0,94 & 4,73 & 0,23 & 0,49 & 0,94 & 0,34 & 1,33 \\
\hline $65 \mathrm{RC}$ & 14 & 4 & 1 & 13 & 2,70 & 1,22 & 1,24 & 5,16 & 0,19 & 0,31 & 1,24 & 0,40 & 1,44 \\
\hline \multicolumn{8}{|c|}{ Primeiro intérprete } & \multicolumn{6}{|c|}{ Método 3 (colorido) } \\
\hline \multicolumn{14}{|l|}{ G1 } \\
\hline $20 \mathrm{RC}$ & 5 & 1 & - & 6 & 0,95 & 0,55 & - & 1,50 & 0,19 & 0,55 & & 0,25 & 0,29 \\
\hline $30 \mathrm{RC}$ & 8 & 3 & 1 & 12 & 1,16 & 0,69 & 0,33 & 2,18 & 0,15 & 0,23 & 0,33 & 0,18 & 0,30 \\
\hline $43 \mathrm{RC}$ & 6 & 3 & 1 & 10 & 0,99 & 0,57 & 0,30 & 1,86 & 0,17 & 0,19 & 0,30 & 0,19 & 0,27 \\
\hline \multicolumn{14}{|l|}{ G2 } \\
\hline $06 \mathrm{RC}$ & 8 & 2 & 1 & 11 & 1,38 & 0,26 & 0,58 & 2,22 & 0,17 & 0,13 & 0,58 & 0,20 & 0,46 \\
\hline $27 \mathrm{RC}$ & 10 & 3 & 1 & 14 & 1,41 & 1,21 & 0,42 & 3,04 & 0,14 & 0,40 & 0,42 & 0,22 & 0,46 \\
\hline $61 \mathrm{RC}$ & 5 & 2 & 1 & 8 & 0,53 & 0,29 & 0,60 & 1,42 & 0,11 & 0,15 & 0,60 & 0,18 & 0,40 \\
\hline \multicolumn{14}{|l|}{ G3 } \\
\hline $03 \mathrm{RC}$ & 14 & 2 & 1 & 17 & 2,59 & 0,53 & 0,92 & 4,04 & 0,19 & 0,27 & 0,92 & 0,24 & 0,74 \\
\hline $07 \mathrm{RG}$ & 11 & 2 & 1 & 14 & 2,49 & 0,63 & 0,77 & 3,89 & 0,23 & 0,32 & 0,77 & 0,28 & 0,94 \\
\hline $29 \mathrm{RM}$ & 12 & 2 & 1 & 15 & 1,85 & 1,28 & 0,41 & 3,54 & 0,15 & 0,64 & 0,41 & 0,24 & 0,85 \\
\hline \multicolumn{14}{|l|}{ G4 } \\
\hline $25 \mathrm{RC}$ & 19 & 3 & 1 & 23 & 2,90 & 2,07 & 0,86 & 5,83 & 0,15 & 0,69 & 0,86 & 0,25 & 1,29 \\
\hline $29 \mathrm{RC}$ & 20 & 6 & 1 & 27 & 3,31 & 1,41 & 1,26 & 5,98 & 0,17 & 0,24 & 1,26 & 0,22 & 1,11 \\
\hline G5 & & & & & & & & & & & & & \\
\hline $21 \mathrm{RC}$ & 26 & 5 & 1 & 32 & 4,51 & 1,84 & 1,44 & 7,79 & 0,17 & 0,37 & 1,44 & 0,24 & 1,62 \\
\hline $44 \mathrm{RC}$ & 17 & 5 & 1 & 23 & 3,73 & 2,21 & 1,26 & 7,20 & 0,22 & 0,44 & 1,26 & 0,31 & 1,53 \\
\hline G6 & & & & & & & & & & & & & \\
\hline $02 \mathrm{RP}$ & 10 & 3 & 1 & 14 & 2,26 & 1,46 & 0,97 & 4,69 & 0,23 & 0,49 & 0,97 & 0,34 & 1,36 \\
\hline $65 \mathrm{RC}$ & 13 & 2 & 1 & 16 & 2,53 & 1,43 & 0,63 & 4,59 & 0,19 & 0,72 & 0,63 & 0,29 & 1,44 \\
\hline
\end{tabular}




\begin{tabular}{|c|c|c|c|c|c|c|c|c|c|c|c|c|c|c|c|c|}
\hline \multirow[t]{2}{*}{ Bacias } & \multicolumn{5}{|c|}{$\begin{array}{l}\text { Número de canais por } \\
\text { ordem }\end{array}$} & \multicolumn{5}{|c|}{$\begin{array}{c}\text { Comprimento total de canais } \\
\text { por ordem }\end{array}$} & \multicolumn{5}{|c|}{$\begin{array}{c}\text { Comprimento médio de canais } \\
\text { por ordem }\end{array}$} & \multirow[b]{2}{*}{$\begin{array}{l}\text { Area } \\
\left(\mathrm{km}^{2}\right)\end{array}$} \\
\hline & $1^{a}$ & $2^{\mathrm{a}}$ & $3^{\mathrm{a}}$ & $4^{\mathrm{a}}$ & $\mathbf{N}$ & $1^{8}$ & $2^{\mathrm{a}}$ & $3^{a}$ & $4^{\mathrm{a}}$ & $\mathrm{Lt}$ & $1^{\mathrm{a}}$ & $2^{\mathrm{a}}$ & $3^{\mathrm{a}}$ & $4^{\mathrm{a}}$ & $\mathrm{Lm}$ & \\
\hline \multicolumn{9}{|c|}{ Segundo intérprete } & \multicolumn{7}{|c|}{ Método 2 (cinza) } & \\
\hline \multicolumn{17}{|l|}{ G1 } \\
\hline $20 \mathrm{RC}$ & 9 & 3 & 1 & & 13 & 0,65 & 0,57 & 0,43 & & 1,65 & 0,07 & 0,19 & & & 0,13 & 0,30 \\
\hline $30 \mathrm{RC}$ & 10 & 3 & 1 & & 14 & 1,29 & 0,76 & 0,34 & & 2,39 & 0,13 & 0,25 & 0,34 & & 0,17 & 0,31 \\
\hline $43 \mathrm{RC}$ & 9 & 3 & 1 & & 13 & 1,47 & 0,53 & 0,33 & & 2,33 & 0,16 & 0,18 & 0,33 & & 0,18 & 0,31 \\
\hline \multicolumn{17}{|l|}{ G2 } \\
\hline $06 \mathrm{RC}$ & 10 & 3 & 1 & & 14 & 1,10 & 0,60 & 0,56 & & 2,26 & 0,11 & 0,20 & 0,56 & & 0,16 & 0,49 \\
\hline $27 \mathrm{RC}$ & 10 & 4 & 1 & & 15 & 1,80 & 0,68 & 0,68 & & 3,16 & 0,18 & 0,17 & 0,68 & & 0,21 & 0,43 \\
\hline $61 \mathrm{RC}$ & 6 & 1 & & & 7 & 0,73 & 0,68 & & & 1,41 & 0,12 & 0,68 & & & 0,20 & 0,42 \\
\hline \multicolumn{17}{|l|}{ G3 } \\
\hline $03 \mathrm{RC}$ & 18 & 5. & 1 & & 24 & 1,84 & 1,27 & 0,93 & & 4,04 & 0,10 & 0,25 & 0,93 & & 0,17 & 0,72 \\
\hline 07 RG & 11 & 3 & 1 & & 15 & 1,89 & 0,70 & 0,83 & & 3,42 & 0,17 & 0,23 & 0,83 & & 0,23 & 0,95 \\
\hline $29 \mathrm{RM}$ & 13 & 3 & 1 & & 17 & 2,38 & 0,77 & 0,98 & & 4,13 & 0,18 & 0,26 & 0,98 & & 0,24 & 0,89 \\
\hline \multicolumn{17}{|l|}{ G4 } \\
\hline $25 \mathrm{RC}$ & 20 & 5 & 1 & & 26 & 2,42 & 1,81 & 1,25 & & 5,48 & 0,12 & 0,36 & 1,25 & & 0,21 & 1,13 \\
\hline $29 \mathrm{RC}$ & 25 & 7 & 1 & & 33 & 2,77 & 2,52 & 1,24 & & 6,53 & 0,11 & 0,36 & 1,24 & & 0,20 & 1,04 \\
\hline \multicolumn{17}{|l|}{ G5 } \\
\hline $21 \mathrm{RC}$ & 34 & 8 & 2 & 1 & 45 & 3,81 & 1,98 & 0,65 & 0,98 & 7,42 & 0,11 & 0,25 & 0,33 & 0,98 & 0,16 & 1,58 \\
\hline $44 \mathrm{RC}$ & 18 & 5 & 1 & & 24 & 3,78 & 2,17 & 1,28 & & 7,23 & 0,21 & 0,43 & 1,28 & & 0,30 & 1,45 \\
\hline \multicolumn{17}{|l|}{ G6 } \\
\hline $02 \mathrm{RP}$ & 12 & 3 & 1 & & 16 & 2,54 & 1,54 & 0,89 & & 4,97 & 0,21 & 0,51 & 0,89 & & 0,31 & 1,37 \\
\hline $65 \mathrm{RC}$ & 11 & 5 & 2 & 1 & 19 & 2,45 & 0,89 & 1,23 & 0,65 & 5,22 & 0,22 & 0,18 & 0,62 & 0,65 & 0,27 & 1,48 \\
\hline \multicolumn{9}{|c|}{ Segundo intérprete } & \multicolumn{8}{|c|}{ Método 3 (colorido) } \\
\hline \multicolumn{17}{|l|}{ G1 } \\
\hline $20 \mathrm{RC}$ & 6 & 2 & 1 & & 9 & 0,88 & 0,41 & 0,33 & & 1,62 & 0,15 & 0,21 & 0,33 & & 0,18 & 0,28 \\
\hline $30 \mathrm{RC}$ & 11 & 3 & 1 & & 15 & 1,39 & 0,95 & 0,30 & & 2,64 & 0,13 & 0,32 & 0,30 & & 0,18 & 0,37 \\
\hline $43 \mathrm{RC}$ & 9 & 3 & 1 & & 13 & 1,24 & 0,50 & 0,45 & & 2,19 & 0,14 & 0,17 & 0,45 & & 0,17 & 0,29 \\
\hline \multicolumn{17}{|l|}{ G2 } \\
\hline $06 \mathrm{RC}$ & 9 & 2 & 1 & & 12 & 1,44 & 0,39 & 0,54 & & 2,37 & 0,16 & 0,20 & 0,54 & & 0,20 & 0,49 \\
\hline $27 \mathrm{RC}$ & 11 & 4 & 1 & & 16 & 1,85 & 0,81 & 0,67 & & 3,33 & 0,17 & 0,20 & 0,67 & & 0,21 & 0,47 \\
\hline $61 \mathrm{RC}$ & 7 & 3 & 1 & & 11 & 0,63 & 0,58 & 0,62 & & 1,83 & 0,09 & 0,19 & 0,62 & & 0,17 & 0,35 \\
\hline \multicolumn{17}{|l|}{ G3 } \\
\hline $03 \mathrm{RC}$ & 16 & 3 & 1 & & 20 & 2,44 & 0,64 & 0,96 & & 4,04 & 0,15 & 0,21 & 0,96 & & 0,20 & 0,75 \\
\hline 07 RG & 12 & 4 & 1 & & 17 & 2,13 & 0,86 & 0,84 & & 3,83 & 0,18 & 0,22 & 0,84 & & 0,23 & 0,84 \\
\hline $29 \mathrm{RM}$ & 19 & 3 & 1 & & 23 & 2,95 & 1,30 & 0,96 & & 5,21 & 0,16 & 0,43 & 0,96 & & 0,23 & 1,05 \\
\hline G4 & & & & & & & & & & & & & & & & \\
\hline $25 \mathrm{RC}$ & 15 & 3 & 1 & & 19 & 2,32 & 0,75 & 1,34 & & 4,41 & 0,15 & 0,25 & 1,34 & & 0,23 & 0,80 \\
\hline $29 \mathrm{RC}$ & 21 & 7 & 1 & & 29 & 3,31 & 1,92 & 1,32 & & 6,55 & 0,16 & 0,27 & 1,32 & & 0,23 & 1,12 \\
\hline G5 & & & & & & & & & & & & & & & & \\
\hline $21 \mathrm{RC}$ & 25 & 5 & 1 & & 31 & 4,34 & 2,07 & 1,00 & & 7,41 & 0,17 & 0,41 & 1,00 & & 0,24 & 1,60 \\
\hline $44 \mathrm{RC}$ & 20 & 5 & 1 & & 26 & 3,93 & 2,16 & 1,26 & & 7,35 & 0,20 & 0,43 & 1,26 & & 0,28 & 1,50 \\
\hline G6 & & & & & & & & & & & & & & & & \\
\hline $02 \mathrm{RP}$ & 8 & 2 & 1 & & 11 & 1,65 & 1,63 & 0,46 & & 3,74 & 0,21 & 0,82 & 0,46 & & 0,34 & 1,12 \\
\hline $65 \mathrm{RC}$ & 14 & 4 & 1 & & 19 & 2,81 & 1,28 & 1,43 & & 5,52 & 0,20 & 0,32 & 1,43 & & 0,29 & 1,85 \\
\hline
\end{tabular}




\begin{tabular}{|c|c|c|c|c|c|c|c|c|c|c|c|c|c|}
\hline \multirow[t]{2}{*}{ Bacias } & \multicolumn{4}{|c|}{$\begin{array}{l}\text { Número de canais por } \\
\text { ordem }\end{array}$} & \multicolumn{4}{|c|}{$\begin{array}{l}\text { Comprimento total de canais } \\
\text { por ordem }\end{array}$} & \multicolumn{4}{|c|}{$\begin{array}{l}\text { Comprimento médio de canais } \\
\text { por ordem }\end{array}$} & \multirow[b]{2}{*}{$\begin{array}{l}\text { Area } \\
\left(\mathbf{m}^{2}\right)\end{array}$} \\
\hline & $1^{\mathrm{a}}$ & $2^{\mathrm{a}}$ & $3^{a} \quad 4^{a}$ & $\mathrm{~N}$ & $1^{\mathrm{a}}$ & $2^{\mathrm{a}}$ & $3^{\mathrm{a}} 4$ & $\begin{array}{ll}4^{\mathrm{a}} & \mathrm{Lt}\end{array}$ & $1^{\mathrm{a}}$ & $2^{\mathrm{a}}$ & $3^{\mathrm{a}} \quad 4^{\mathrm{a}}$ & $\mathrm{Lm}$ & \\
\hline \multicolumn{8}{|c|}{ Terceiro intérprete } & \multicolumn{5}{|c|}{ Método 2 (cinza) } & \\
\hline \multicolumn{14}{|l|}{ G1 } \\
\hline $20 \mathrm{RC}$ & 5 & 1 & - & 6 & 0,93 & 0,54 & & 1,47 & 0,19 & 0,54 & & 0,25 & 0,32 \\
\hline $30 \mathrm{RC}$ & 9 & 3 & 1 & 13 & 1,04 & 0,86 & 0,42 & 2,32 & 0,12 & 0,29 & 0,42 & 0,18 & 0,34 \\
\hline $43 \mathrm{RC}$ & 6 & 2 & 1 & 9 & 1.04 & 0,49 & 0,16 & 1,69 & 0,17 & 0,25 & 0,16 & 0,19 & 0,31 \\
\hline \multicolumn{14}{|l|}{ G2 } \\
\hline $06 \mathrm{RC}$ & 9 & 2 & 1 & 12 & 1,20 & 0,40 & 0,54 & 2,14 & 0,13 & 0,20 & 0,54 & 0,18 & 0,51 \\
\hline $27 \mathrm{RC}$ & 8 & 3 & 1 & 12 & 1,32 & 0.93 & 0,40 & 2,65 & 0,17 & 0,31 & 0,40 & 0,22 & 0,47 \\
\hline $61 \mathrm{RC}$ & 7 & 2 & 1 & 10 & 0,65 & 0,28 & 0,59 & 1,52 & 0,09 & 0,14 & 0,59 & 0,15 & 0,42 \\
\hline \multicolumn{14}{|l|}{ G3 } \\
\hline $03 \mathrm{RC}$ & 15 & 2 & 1 & 18 & 2,53 & 0,42 & 0,99 & 3,94 & 0,17 & 0,21 & 0,99 & 0,22 & 0,72 \\
\hline 07 RG & 8 & 2 & 1 & 11 & 2,27 & 0,48 & 0,72 & 3,47 & 0,28 & 0,24 & 0,72 & 0,32 & 0,92 \\
\hline $29 \mathrm{RM}$ & 11 & 3 & 1 & 15 & 1,37 & 1,41 & 0,61 & 3,39 & 0,12 & 0,47 & 0,61 & 0,23 & 0,89 \\
\hline \multicolumn{14}{|l|}{ G4 } \\
\hline $25 \mathrm{RC}$ & 19 & 4 & 1 & 24 & 2,75 & 1,71 & 1,25 & 5,71 & 0,14 & 0,43 & 1,25 & 0,24 & 1,33 \\
\hline $29 \mathrm{RC}$ & 19 & 4 & 1 & 24 & 3,83 & 1,52 & 0,95 & 6,30 & 0,20 & 0,38 & 0,95 & 0,26 & 1,16 \\
\hline \multicolumn{14}{|l|}{ G5 } \\
\hline $21 \mathrm{RC}$ & 21 & 6 & 1 & 28 & 3,49 & 1,67 & 1,37 & 6,53 & 0,17 & 0,28 & 1,37 & 0,23 & 1,59 \\
\hline $44 \mathrm{RC}$ & 19 & 5 & 1 & 25 & 3,43 & 2,25 & 1,28 & 6,96 & 0,18 & 0,45 & 1,28 & 0,28 & 1,54 \\
\hline \multicolumn{14}{|l|}{ G6 } \\
\hline $02 \mathrm{RP}$ & 11 & 3 & 1 & 15 & 2,63 & 1,17 & 0,96 & 4,76 & 0,24 & 0,39 & 0,96 & 0,32 & 1,37 \\
\hline $65 \mathrm{RC}$ & 7 & 2 & 1 & 10 & 1,82 & 1,26 & 0,66 & 3,74 & 0,26 & 0,63 & 0,66 & 0,37 & 1,10 \\
\hline \multicolumn{8}{|c|}{ Terceiro intérprete } & \multicolumn{6}{|c|}{ Método 3 (colorido) } \\
\hline \multicolumn{14}{|l|}{ G1 } \\
\hline $20 \mathrm{RC}$ & 5 & 2 & 1 & 8 & 0,47 & 0,38 & 0,43 & 1,28 & 0,09 & 0,19 & 0,43 & 0,16 & 0,32 \\
\hline $30 \mathrm{RC}$ & 7 & 3 & 1 & 11 & 1,09 & 0,65 & 0,33 & 2,07 & 0,16 & 0,22 & 0,33 & 0,19 & 0,36 \\
\hline $43 \mathrm{RC}$ & 4 & 2 & 1 & 7 & 0,83 & 0,32 & 0,16 & 1,31 & 0,21 & 0,16 & 0,16 & 0,19 & 0,28 \\
\hline \multicolumn{14}{|l|}{ G2 } \\
\hline $06 \mathrm{RC}$ & 10 & 3 & 1 & 14 & 3,57 & 0,40 & 0,66 & 4,63 & 0,36 & 0,13 & 0,66 & 0,33 & 0,52 \\
\hline $27 \mathrm{RC}$ & 7 & 2 & 1 & 10 & 1,45 & 0,69 & 0,41 & 2,55 & 0,21 & 0,35 & 0,41 & 0,26 & 0,46 \\
\hline $61 \mathrm{RC}$ & 5 & 2 & 1 & 8 & 0,50 & 0,27 & 0,60 & 1,37 & 0,10 & 0,14 & 0,60 & 0,17 & 0,44 \\
\hline \multicolumn{14}{|l|}{ G3 } \\
\hline $03 \mathrm{RC}$ & 14 & 2 & 1 & 17 & 2,54 & 0,40 & 0,91 & 3,85 & 0,18 & 0,20 & 0,91 & 0,23 & 0,82 \\
\hline 07 RG & 9 & 2 & 1 & 12 & 2,04 & 0,47 & 0,73 & 3,24 & 0,23 & 0,24 & 0,73 & 0,27 & 0,95 \\
\hline $29 \mathrm{RM}$ & 9 & 3 & 1 & 13 & 1,52 & 0,66 & 0,98 & 3,16 & 0,17 & 0,22 & 0,98 & 0,24 & 0,89 \\
\hline \multicolumn{14}{|l|}{ G4 } \\
\hline $25 \mathrm{RC}$ & 12 & 4 & 1 & 17 & 0,99 & 1,78 & 1,21 & 3,98 & 0,08 & 0,45 & 1,21 & 0,23 & 1,24 \\
\hline $29 \mathrm{RC}$ & 16 & 5 & 1 & 22 & 2,44 & 2,08 & 0,85 & 5,37 & 0,15 & 0,42 & 0,85 & 0,24 & 1,12 \\
\hline G5 & & & & & & & & & & & & & \\
\hline $21 \mathrm{RC}$ & 18 & 5 & 1 & 24 & 2,73 & 1,85 & 0,97 & 5,55 & 0,15 & 0,37 & 0,97 & 0,23 & 1,51 \\
\hline $44 \mathrm{RC}$ & 19 & 5 & 1 & 25 & 3,76 & 2,13 & 1,26 & 7,15 & 0,20 & 0,43 & 1,26 & 0,29 & 1,57 \\
\hline G6 & & & & & & & & & & & & & \\
\hline $02 \mathrm{RP}$ & 7 & 2 & 1 & 10 & 1,46 & 1,54 & 0,50 & 3,50 & 0,21 & 0,77 & 0,50 & 0,35 & 1,38 \\
\hline $65 \mathrm{RC}$ & 6 & 2 & 1 & 9 & 1,77 & 1,16 & 0,64 & 3,57 & 0,30 & 0,58 & 0,64 & 0,40 & 1,31 \\
\hline
\end{tabular}


A3 - Índices do padrão de drenagem calculados para as bacias dos solos litólicos.

\begin{tabular}{|c|c|c|c|c|c|c|c|c|c|c|}
\hline Bacias & Lt & $\mathbf{N}$ & Nw1a & $\mathbf{A}$ & $\mathbf{P}$ & Dd & $\mathbf{F r}$ & $\mathbf{T}$ & $\mathbf{T m}$ & Classe \\
\hline \multicolumn{6}{|c|}{ Primeiro intérprete } & \multicolumn{5}{|c|}{ Método 2 (cinza) } \\
\hline \multicolumn{11}{|l|}{ G1 } \\
\hline 07 RM & 5,51 & 17 & 13 & 1,15 & 3,49 & 4,79 & 14,78 & 4,87 & 3,88 & Média \\
\hline $08 \mathrm{RM}$ & 3,66 & 11 & 7 & 1,14 & 4,08 & 3,21 & 9,65 & 2,70 & & \\
\hline $21 \mathrm{RM}$ & 4,35 & 16 & 11 & 1,05 & 3,93 & 4,14 & 15,24 & 4,07 & & \\
\hline \multicolumn{11}{|l|}{ G2. } \\
\hline $06 \mathrm{RM}$ & 3,34 & 11 & 8 & 0,81 & 3,71 & 4,12 & 13,58 & 2,96 & 3,59 & Média \\
\hline $08 \mathrm{RG}$ & 3,40 & 16 & 12 & 0,80 & 3,65 & 4,25 & 20,00 & 4,38 & & \\
\hline $17 \mathrm{RM}$ & 3,69 & 13 & 9 & 0,84 & 3,78 & 4,39 & 15,48 & 3,44 & & \\
\hline \multicolumn{11}{|l|}{ G3 } \\
\hline $09 \mathrm{RM}$ & 5,81 & 21 & 18 & 1,36 & 4,99 & 4,27 & 15,44 & 4,21 & 4,69 & Média \\
\hline $12 \mathrm{RM}$ & 6,55 & 20 & 15 & 1,49 & 5,14 & 4,40 & 13,42 & 3,89 & & \\
\hline 14 RM & 7,50 & 30 & 24 & 1,69 & 5,20 & 4,44 & 17,75 & 5,77 & & \\
\hline \multicolumn{6}{|c|}{ Primeiro intérprete } & \multicolumn{5}{|c|}{ Método 3 (colorido) } \\
\hline \multicolumn{11}{|l|}{ G1 } \\
\hline $07 \mathrm{RM}$ & 5,46 & 17 & 12 & 1,18 & 3,49 & 4,63 & 14,41 & 4,87 & 4,22 & Média \\
\hline $08 \mathrm{RM}$ & 4,21 & 15 & 11 & 1,15 & 4,07 & 3,66 & 13,04 & 3,69 & & \\
\hline $21 \mathrm{RM}$ & 4,16 & 15 & 11 & 1,02 & 3,69 & 4,08 & 14,71 & 4,07 & & \\
\hline \multicolumn{11}{|l|}{ G2 } \\
\hline $06 \mathrm{RM}$ & 3,48 & 13 & 10 & 0,77 & 3,77 & 4,52 & 16,88 & 3,45 & 3,54 & Média \\
\hline $08 \mathrm{RG}$ & 3,67 & 15 & 12 & 0,83 & 3,83 & 4,42 & 18,07 & 3,92 & & \\
\hline $17 \mathrm{RM}$ & 3,45 & 12 & 8 & 0,81 & 3,71 & 4,26 & 14,81 & 3,23 & & \\
\hline \multicolumn{11}{|l|}{ G3 } \\
\hline $09 \mathrm{RM}$ & 6,46 & 23 & 19 & 1,49 & 5,26 & 4,34 & 15,44 & 4,37 & 4,52 & Média \\
\hline $12 \mathrm{RM}$ & 6,41 & 23 & 19 & 1,41 & 5,03 & 4,55 & 16,31 & 4,57 & & \\
\hline $14 \mathrm{RM}$ & 6,56 & 23 & 20 & 1,59 & 4,99 & 4,13 & 14,47 & 4,61 & & \\
\hline \multicolumn{6}{|c|}{ Segundo intérprete } & \multicolumn{5}{|c|}{ Método 2 (cinza) } \\
\hline \multicolumn{11}{|l|}{ G1 } \\
\hline $07 \mathrm{RM}$ & 5,22 & 15 & 11 & 1,13 & 3,68 & 4,62 & 13,27 & 4,08 & 4,35 & Média \\
\hline $08 \mathrm{RM}$ & 4,49 & 17 & 13 & 1,03 & 3,82 & 4,36 & 16,50 & 4,45 & & \\
\hline $21 \mathrm{RM}$ & 3,74 & 16 & 11 & 0,98 & 3,51 & 3,82 & 16,33 & 4,56 & & \\
\hline \multicolumn{11}{|l|}{ G2 } \\
\hline $06 \mathrm{RM}$ & 3,27 & 15 & 10 & 0,77 & 3,66 & 4,25 & 19,48 & 4,10 & 3,82 & Média \\
\hline $08 \mathrm{RG}$ & 3,17 & 14 & 10 & 0,97 & 3,76 & 3,27 & 14,43 & 3,72 & & \\
\hline 17 RM & 3,66 & 13 & 9 & 0,83 & 3,53 & 4,41 & 15,66 & 3,68 & & \\
\hline \multicolumn{11}{|l|}{ G3 } \\
\hline $09 \mathrm{RM}$ & 5,50 & 19 & 13 & 1,77 & 5,01 & 3,11 & 10,73 & 3,79 & 5,91 & Média \\
\hline $12 \mathrm{RM}$ & 5,96 & 20 & 15 & 1,37 & 4,83 & 4,35 & 14,60 & 4,14 & & \\
\hline $14 \mathrm{RM}$ & 8,67 & 48 & 35 & 1,57 & 4,88 & 5,52 & 30,57 & 9,84 & & \\
\hline \multicolumn{6}{|c|}{ Segundo intérprete } & \multicolumn{5}{|c|}{ Método 3 (colorido) } \\
\hline \multicolumn{11}{|l|}{ G1 } \\
\hline $07 \mathrm{RM}$ & 5,24 & 16 & 12 & 1,18 & 3,85 & 4,44 & 13,56 & 4,16 & 3,88 & Média \\
\hline $08 \mathrm{RM}$ & 4,38 & 12 & 9 & 1,25 & 4,02 & 3,50 & 9,60 & 2,99 & & \\
\hline $21 \mathrm{RM}$ & 3,97 & 17 & 12 & 0,99 & 3,62 & 4,01 & 17,17 & 4,70 & & \\
\hline \multicolumn{11}{|l|}{ G2 } \\
\hline $06 \mathrm{RM}$ & 3,33 & 15 & 11 & 0,78 & 3,85 & 4,27 & 19,23 & 3,90 & 4,00 & Média \\
\hline $08 \mathrm{RG}$ & 3,61 & 16 & 12 & 0,70 & 3,55 & 5,16 & 22,86 & 4,51 & & \\
\hline $17 \mathrm{RM}$ & 3,47 & 13 & 9 & 0,76 & 3,58 & 4,57 & 17,11 & 3,63 & & \\
\hline
\end{tabular}




\begin{tabular}{|c|c|c|c|c|c|c|c|c|c|c|}
\hline Bacias & Lt & $\mathbf{N}$ & Nw1a & $\mathbf{A}$ & $\mathbf{P}$ & Dd & $\mathbf{F r}$ & $\mathbf{T}$ & Tm & Classe \\
\hline \multicolumn{6}{|c|}{ Segundo intérprete } & \multicolumn{5}{|c|}{ Método 3 (colorido) } \\
\hline \multicolumn{11}{|l|}{ G3 } \\
\hline $09 \mathrm{RM}$ & 5,53 & 22 & 18 & 1,44 & 5,22 & 3,84 & 15,28 & 4,21 & 5,11 & Média \\
\hline $12 \mathrm{RM}$ & 6,23 & 22 & 17 & 1,38 & 4,85 & 4,51 & 15,94 & 4,54 & & \\
\hline 14 RM & 7,93 & 32 & 25 & 1,60 & 4,99 & 4,96 & 20,00 & 6,41 & & \\
\hline \multicolumn{6}{|c|}{ Terceiro intérprete } & \multicolumn{5}{|c|}{ Método 2 (cinza) } \\
\hline \multicolumn{11}{|l|}{ G1 } \\
\hline 07 RM & 4,84 & 15 & 11 & 1,13 & 3,81 & 4,28 & 13,27 & 3,94 & 3,25 & Média \\
\hline $08 \mathrm{RM}$ & 3,60 & 10 & 7 & 1,23 & 4,23 & 2,93 & 8,13 & 2,36 & & \\
\hline $21 \mathrm{RM}$ & 4,02 & 14 & 10 & 1,08 & 3,95 & 3,72 & 12,96 & 3,54 & & \\
\hline \multicolumn{11}{|l|}{ G2 } \\
\hline $06 \mathrm{RM}$ & 2,80 & 9 & 6 & 0,83 & 3,66 & 3,37 & 10,84 & 2,46 & 3,13 & Média \\
\hline 08 RG & 3,27 & 14 & 10 & 0,84 & 3,69 & 3,89 & 16,67 & 3,79 & & \\
\hline $17 \mathrm{RM}$ & 3,80 & 12 & 8 & 0,83 & 3,83 & 4,58 & 14,46 & 3,13 & & \\
\hline \multicolumn{11}{|l|}{ G3 } \\
\hline $09 \mathrm{RM}$ & 4,49 & 16 & 12 & 1,42 & 5,03 & 3,16 & 11,27 & 3,18 & 3,92 & Média \\
\hline $12 \mathrm{RM}$ & 4,98 & 18 & 13 & 1,48 & 5,25 & 3,36 & 12,16 & 3,43 & & \\
\hline $14 \mathrm{RM}$ & 6,65 & 26 & 20 & 1,63 & 5,20 & 4,08 & 15,95 & 5,00 & & \\
\hline \multicolumn{6}{|c|}{ Terceiro intérprete } & \multicolumn{5}{|c|}{ Método 3 (colorido) } \\
\hline \multicolumn{11}{|l|}{ G1 } \\
\hline $07 \mathrm{RM}$ & 4,96 & 14 & 10 . & 1,28 & 4,11 & 3,88 & 10,94 & 3,41 & 2,71 & Média \\
\hline $08 \mathrm{RM}$ & 3,43 & 8 & 5 & 1,21 & 3,74 & 2,83 & 6,61 & 2,14 & & \\
\hline $21 \mathrm{RM}$ & 3,17 & 10 & 6 & 1,09 & 3,95 & 2,91 & 9,17 & 2,53 & & \\
\hline \multicolumn{11}{|l|}{ G2 } \\
\hline $06 \mathrm{RM}$ & 2,60 & 9 & 6 & 0,81 & 3,65 & 3,21 & 11,11 & 2,47 & 2,92 & Média \\
\hline $08 \mathrm{RG}$ & 3,17 & 12 & 8 & 0,80 & 3,56 & 3,96 & 13,75 & 3,37 & & \\
\hline $17 \mathrm{RM}$ & 3,06 & 11 & 7 & 0,80 & 3,77 & 3,83 & 13,75 & 2,92 & & \\
\hline \multicolumn{11}{|l|}{ G3 } \\
\hline $09 \mathrm{RM}$ & 3,95 & 13 & 9 & 1,39 & 5,01 & 2,84 & 9,35 & 2,59 & 2,34 & Gross. \\
\hline $12 \mathrm{RM}$ & 4,77 & 12 & 9 & 1,58 & 5,27 & 3,02 & 7,59 & 2,28 & & \\
\hline $14 \mathrm{RM}$ & 4,06 & 11 & 8 & 1,56 & 5,03 & 2,60 & 7,05 & 2,19 & & \\
\hline
\end{tabular}


A4 - Índices do padrão de drenagem calculados para as bacias dos solo podzólicos

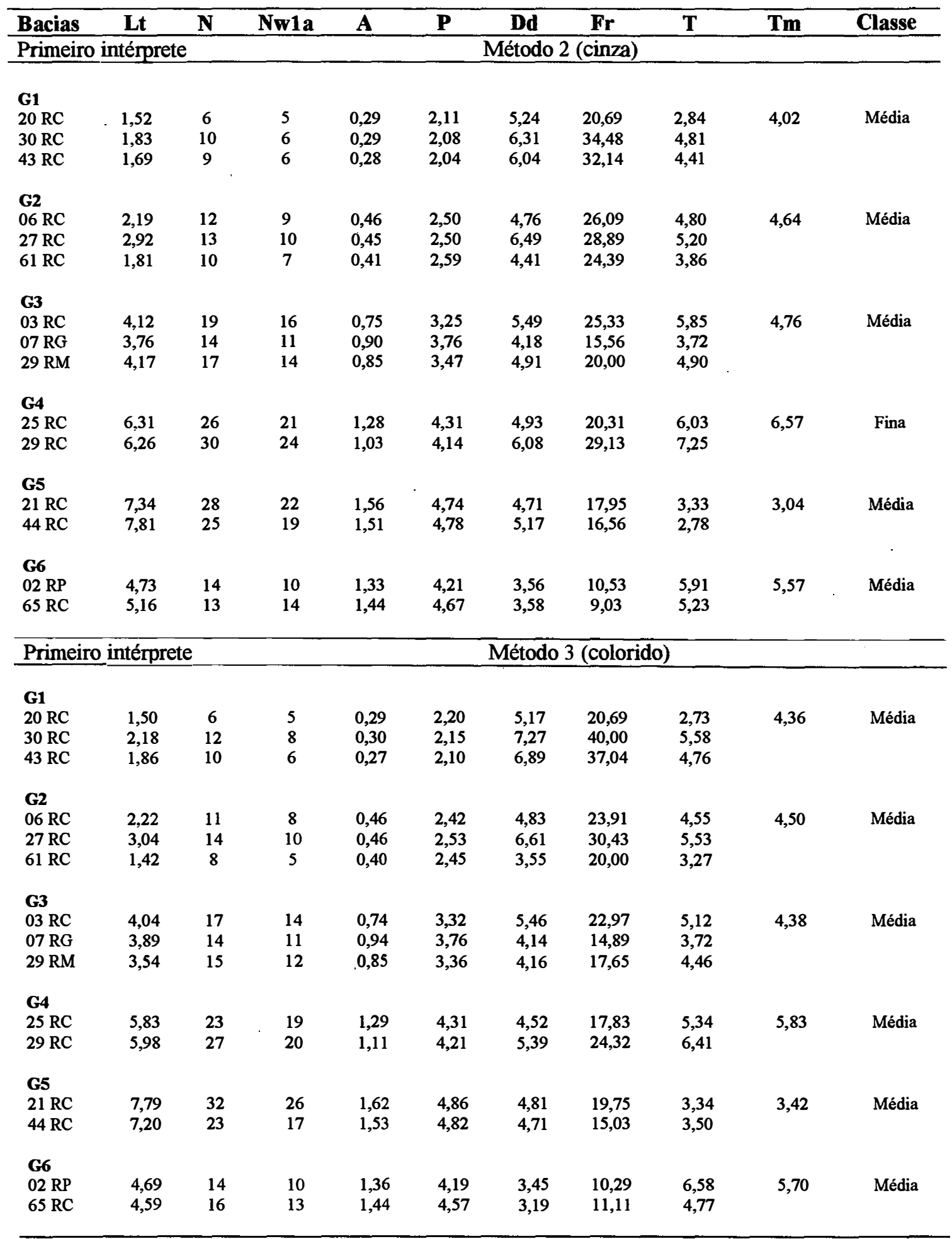




\begin{tabular}{|c|c|c|c|c|c|c|c|c|c|c|}
\hline Bacias & Lt & $\mathbf{N}$ & Nw1a & A & $\mathbf{P}$ & Dd & $\mathbf{F r}$ & $\mathbf{T}$ & Tm & Classe \\
\hline \multicolumn{6}{|c|}{ Segundo intérprete } & \multicolumn{5}{|c|}{ Método 2 (cinza) } \\
\hline \multicolumn{11}{|l|}{ G1 } \\
\hline $20 \mathrm{RC}$ & 1,65 & 13 & 9 & 0,30 & 2,06 & 5,50 & 43,33 & 6,31 & 6,57 & Fina \\
\hline $30 \mathrm{RC}$ & 2,39 & 14 & 10 & 0,31 & 2,15 & 7,71 & 45,16 & 6,51 & & \\
\hline $43 \mathrm{RC}$ & 2,33 & 13 & 9 & 0,31 & 1,89 & 7,52 & 41,94 & 6,88 & & \\
\hline \multicolumn{11}{|l|}{ G2 } \\
\hline $06 \mathrm{RC}$ & 2,26 & 14 & 10 & 0,49 & 2,48 & 4,61 & 28,57 & 5,65 & 4,89 & Média \\
\hline $27 \mathrm{RC}$ & 3,16 & 15 & 10 & 0,43 & 2,50 & 7,35 & 34,88 & 6,00 & & \\
\hline $61 \mathrm{RC}$ & 1,41 & 7 & 6 & 0,42 & 2,43 & 3,36 & 16,67 & 2,88 & & \\
\hline \multicolumn{11}{|l|}{ G3 } \\
\hline $03 \mathrm{RC}$ & 4,04 & 24 & 18 & 0,72 & 3,32 & 5,61 & 33,33 & 7,23 & 5,41 & Média \\
\hline 07 RG & 3,42 & 15 & 11 & 0,95 & 3,41 & 3,60 & 15,79 & 4,40 & & \\
\hline $29 \mathrm{RM}$ & 4,13 & 17 & 13 & 0,89 & 3,38 & 4,64 & 19,10 & 5,03 & & \\
\hline \multicolumn{11}{|l|}{ G4 } \\
\hline $25 \mathrm{RC}$ & 5,48 & 26 & 20 & 1,13 & 4,13 & 4,85 & 23,01 & 6,30 & 7,17 & Fina \\
\hline $29 \mathrm{RC}$ & 6,53 & 33 & 25 & 1,04 & 4,06 & 6,28 & 31,73 & 8,13 & & \\
\hline \multicolumn{11}{|l|}{ G5 } \\
\hline $21 \mathrm{RC}$ & 7,42 & 45 & 34 & 1,58 & 4,80 & 4,70 & 28,48 & 3,90 & 4,06 & Média \\
\hline $44 \mathrm{RC}$ & 7,23 & 24 & 18 & 1,45 & 4,65 & 4,99 & 16,55 & 4,20 & & \\
\hline \multicolumn{11}{|l|}{ G6 } \\
\hline $02 \mathrm{RP}$ & 4,97 & 16 & 12 & 1,37 & 4,10 & 3,63 & 11,68 & 9,38 & 7,36 & Fina \\
\hline $65 \mathrm{RC}$ & 5,22 & 19 & 11 & 1,48 & 4,52 & 3,53 & 12,84 & 5,16 & & \\
\hline \multicolumn{6}{|c|}{ Segundo intérprete } & \multicolumn{5}{|c|}{ Método 3 (colorido) } \\
\hline \multicolumn{11}{|l|}{ G1 } \\
\hline $20 \mathrm{RC}$ & 1,62 & 9 & 6 & 0,28 & 2,04 & 5,79 & 32,14 & 4,41 & 6,08 & Média \\
\hline $30 \mathrm{RC}$ & 2,64 & 15 & 11 & 0,37 & 2,22 & 7,14 & 40,54 & 6,76 & & \\
\hline $43 \mathrm{RC}$ & 2,19 & 13 & 9 & 0,29 & 1,90 & 7,55 & 44,83 & 6,84 & & \\
\hline \multicolumn{11}{|l|}{ G2 } \\
\hline $06 \mathrm{RC}$ & 2,37 & 12 & 9 & 0,49 & 2,47 & 4,84 & 24,49 & 4,86 & 5,32 & Média \\
\hline $27 \mathrm{RC}$ & 3,33 & 16 & 11 & 0,47 & 2,55 & 7,09 & 34,04 & 6,27 & & \\
\hline $61 \mathrm{RC}$ & 1,83 & 11 & 7 & 0,35 & 2,34 & 5,23 & 31,43 & 4,70 & & \\
\hline \multicolumn{11}{|l|}{ G3 } \\
\hline $03 \mathrm{RC}$ & 4,04 & 20 & 16 & 0,75 & 3,32 & 5,39 & 26,67 & 6,02 & 5,60 & Média \\
\hline 07 RG & 3,83 & 17 & 12 & 0,84 & 3,39 & 4,56 & 20,24 & 5,01 & & \\
\hline $29 \mathrm{RM}$ & 5,21 & 23 & 19 & 1,05 & 3,99 & 4,96 & 21,90 & 5,76 & & \\
\hline \multicolumn{11}{|l|}{ G4 } \\
\hline $25 \mathrm{RC}$ & 4,41 & 19 & 15 & 0,80 & 4,06 & 5,51 & 23,75 & 4,68 & 6,07 & Média \\
\hline $29 \mathrm{RC}$ & 6,55 & 29 & 21 & 1,12 & 4,11 & 5,85 & 25,89 & 7,06 & & \\
\hline \multicolumn{11}{|l|}{ G5 } \\
\hline $21 \mathrm{RC}$ & 7,41 & 31 & 25 & 1,60 & 4,56 & 4,63 & 19,38 & 2,78 & 3,25 & Média \\
\hline $44 \mathrm{RC}$ & 7,35 & 26 & 20 & 1,50 & 4,78 & 4,90 & 17,33 & 3,53 & & \\
\hline \multicolumn{11}{|l|}{ G6 } \\
\hline $02 \mathrm{RP}$ & $\begin{array}{l}3,74 \\
55 ?\end{array}$ & 11 & 8 & 1,12 & $\begin{array}{l}3,95 \\
5,20\end{array}$ & 3,34 & $\begin{array}{c}9,82 \\
\end{array}$ & 6,80 & 6,14 & Média \\
\hline $65 \mathrm{RC}$ & 5,52 & 19 & 14 & 1,85 & 5,39 & 2,98 & 10,27 & 5,44 & & \\
\hline
\end{tabular}




\begin{tabular}{|c|c|c|c|c|c|c|c|c|c|c|}
\hline Bacias & $\mathbf{L t}$ & $\mathbf{N}$ & Nw1a & $\mathbf{A}$ & $\mathbf{P}$ & Dd & $\mathbf{F r}$ & $\mathbf{T}$ & Tm & Classe \\
\hline Terceiro & térprete & \multicolumn{9}{|c|}{ Método 2 (cinza) } \\
\hline \multicolumn{11}{|l|}{ G1 } \\
\hline $20 \mathrm{RC}$ & 1,47 & 6 & 5 & 0,32 & 2,09 & 4,59 & 18,75 & 2,87 & 4,42 & Média \\
\hline $30 \mathrm{RC}$ & 2,32 & 13 & 9 & 0,34 & 2,19 & 6,82 & 38,24 & 5,94 & & \\
\hline $43 \mathrm{RC}$ & 1,69 & 9 & 6 & 0,31 & 2,07 & 5,45 & 29,03 & 4,35 & & \\
\hline \multicolumn{11}{|l|}{ G2 } \\
\hline $06 \mathrm{RC}$ & 2,14 & 12 & 9 & 0,51 & 2,55 & 4,20 & 23,53 & 4,71 & 4,53 & Média \\
\hline $27 \mathrm{RC}$ & 2,65 & 12 & 8 & 0,47 & 2,53 & 5,64 & 25,53 & 4,74 & & \\
\hline $61 \mathrm{RC}$ & 1,52 & 10 & 7 & 0,42 & 2,45 & 3,62 & 23,81 & 4,08 & & \\
\hline \multicolumn{11}{|l|}{$\mathbf{G 3}$} \\
\hline $03 \mathrm{RC}$ & 3,94 & 18 & 15 & 0,72 & 3,27 & 5,47 & 25,00 & 5,50 & 4,28 & Média \\
\hline 07 RG & 3,47 & 11 & 8 & 0,92 & 3,59 & 3,77 & 11,96 & 3,06 & & \\
\hline $29 \mathrm{RM}$ & 3,39 & 15 & 11 & 0,89 & 3,29 & 3,81 & 16,85 & 4,56 & & \\
\hline \multicolumn{11}{|l|}{ G4 } \\
\hline $25 \mathrm{RC}$ & 5,71 & 24 & 19 & 1,33 & 4,24 & 4,29 & 18,05 & 5,66 & 5,66 & Média \\
\hline $29 \mathrm{RC}$ & 6,30 & 24 & 19 & 1,16 & 4,24 & 5,43 & 20,69 & 5,66 & & \\
\hline \multicolumn{11}{|l|}{ G5 } \\
\hline $21 \mathrm{RC}$ & 6,53 & 28 & 21 & 1,59 & 4,93 & 4,11 & 17,61 & 3,56 & 3,07 & Média \\
\hline $44 \mathrm{RC}$ & 6,96 & 25 & 19 & 1,54 & 4,89 & 4,52 & 16,23 & 2,44 & & \\
\hline \multicolumn{11}{|l|}{ G6 } \\
\hline $02 \mathrm{RP}$ & 4,76 & 15 & 11 & 1,37 & 4,21 & 3,47 & 10,95 & 5,68 & 5,40 & Média \\
\hline $65 \mathrm{RC}$ & 3,74 & 10 & 7 & 1,10 & 4,09 & 3,40 & 9,09 & 5,11 & & \\
\hline \multicolumn{6}{|c|}{ Terceiro intérprete } & \multicolumn{5}{|c|}{ Método 3 (colorido) } \\
\hline \multicolumn{11}{|l|}{ G1 } \\
\hline $20 \mathrm{RC}$ & 1,28 & 8 & 5 & 0,32 & 2,01 & 4,00 & 25,00 & 3,98 & 4,26 & Média \\
\hline $30 \mathrm{RC}$ & 2,07 & 11 & 7 & 0,36 & 2,21 & 5,75 & 30,56 & 4,98 & & \\
\hline $43 \mathrm{RC}$ & 1,31 & 7 & 4 & 0,28 & 1,92 & 4,68 & 25,00 & 3,65 & & \\
\hline \multicolumn{11}{|l|}{ G2 } \\
\hline $06 \mathrm{RC}$ & 4,63 & 14 & 10 & 0,52 & 2,52 & 8,90 & 26,92 & 5,56 & 4,31 & Média \\
\hline $27 \mathrm{RC}$ & 2,55 & 10 & 7 & 0,46 & 2,56 & 5,54 & 21,74 & 3,91 & & \\
\hline $61 \mathrm{RC}$ & 1,37 & 8 & 5 & 0,44 & 2,45 & 3,11 & 18,18 & 3,27 & & \\
\hline \multicolumn{11}{|l|}{$\mathbf{G 3}$} \\
\hline $03 \mathrm{RC}$ & 3,85 & 17 & 14 & 0,82 & 3,41 & 4,70 & 20,73 & 4,99 & 3,91 & Média \\
\hline $07 \mathrm{RG}$ & 3,24 & 12 & 9 & 0,95 & 3,87 & 3,41 & 12,63 & 3,10 & & \\
\hline $29 \mathrm{RM}$ & 3,16 & 13 & 9 & 0,89 & 3,44 & 3,55 & 14,61 & 3,78 & & \\
\hline \multicolumn{11}{|l|}{ G4 } \\
\hline $25 \mathrm{RC}$ & 3,98 & 17 & 12 & 1,24 & 4,39 & 3,21 & 13,71 & 3,87 & 4,59 & Média \\
\hline $29 \mathrm{RC}$ & 5,37 & 22 & 16 & 1,12 & 4,08 & 4,79 & 19,64 & 5,39 & & \\
\hline \multicolumn{11}{|l|}{ G5 } \\
\hline $21 \mathrm{RC}$ & 5,55 & 24 & 18 & 1,51 & 4,84 & 3,68 & 15,89 & 2,34 & 2,06 & Gross. \\
\hline $44 \mathrm{RC}$ & 7,15 & 25 & 19 & 1,57 & 4,84 & 4,55 & - 15,92 & 1,77 & & \\
\hline \multicolumn{11}{|l|}{ G6 } \\
\hline $02 \mathrm{RP}$ & 3,50 & 10 & 7 & 1,38 & 4,28 & 2,54 & 7,25 & 4,96 & 5,06 & Média \\
\hline $65 \mathrm{RC}$ & 3,57 & 9 & 6 & 1,31 & 5,09 & 2,73 & 6,87 & 5,17 & & \\
\hline
\end{tabular}




\section{REFERÊNCIAS BIBLIOGRÁFICAS}

AB'SABER, A.N. A depressão periférica paulista: um setor das áreas de circundesnudação pós-cretácea na Bacia do Paraná. São Paulo: USP/IGEOG, 1969. 11p. (Geomorfologia, 15).

ALMEIDA, F.F.M. de. Fundamentos geológicos do relevo paulista. São Paulo: USP/IGEOG, 1974. 111p. (Série Teses e Monografias, 14).

AMARAL, A.Z.; AUDI, R. Fotopedologia. In: MONIZ, A.C. (Coord). Elementos de pedologia. São Paulo: EDUSP/Polígono, 1972. p. 429-442.

ANDERSON, E.B. The statistical analysis of categorical data. 2.ed. Copenhagem, 1991. 532p.

ANGULO FILHO, R. Variações de características de redes drenagem em função das fotografias aéreas verticais obtidas em épocas diferentes. Piracicaba, 1981. 128p. Dissertação (Mestrado) - Escola Superior de Agronomia "Luiz de Queiroz", Universidade de São Paulo.

ANGULO FILHO, R. Caracterização da drenagem e do relvo de três solos do Estado de São Paulo, através de fotografias aéreas e cartas planialtimétricas. Piracicaba, 1986. 132p. Tese (Doutorado) - Escola Superior de Agronomia "Luiz de Queiroz", Universidade de São Paulo. 
BASTOS, S.A. Soils mapping and aerial photography on soils conservation. In: CONGRESSO PANAMERICANO DE CONSERVAÇÃO DO SOLO, 1, São Paulo, Atas. São Paulo, Secretaria da Agricultura, 1966, p.383-388.

BOMBERGER, E.H.; DILL, H.W. Photo interpretation in agriculture. In: AMERICAN SOCIETY OF PHOTOGRAMMETRY. Manual of Photographic Interpretation. Washington: Falls Church, 1960. cap. 10, p. 561-632.

BRASIL. Ministério da Agricultura. Centro Nacional de Ensino e Pesquisas Agronômicas. Serviço Nacional de Pesquisas Agronômicas. Levantamento de Reconhecimento dos Solos do Estado de São Paulo. Rio de Janeiro, 1960. 634p. (Boletim, 12).

BURGA, J.D.; MATTOS, J.T. de; OHARA, T. Mapeo geológico de depositos volcanicos terciatio-cuaternatios, utilizando imagens Landst, MSS y TM. In: SIMPOSIO LATINOAMERICANO DE PERCEPTION REMOTA, 5. Cuzco, 1991. Anais. Cuzco, 1991. v.1, p.30-42.

BURINGH, P. The applications of aerial photographs in soil survey. In: AMERICAN SOCIETY OF PHOTOGRAMMETRY. Manual of Photographic Interpretation. Washington: Falls Church, 1960. Cap. 11, p. 633-66.

BURROUGH, P.A. Principles of geographical information system for land resources assessment. Oxford: Clarendon Press, 1986. 193p.

BURT, C. The Factorial Analysis of Qualitative Data. British Journal of Psychology, Leicester, England, p.166-85. 1950. 
CÂMARA, G.; ORTIZ, M.J. Sistemas de informação geográfica para aplicações ambientais e cadastrais: uma visão geral. In: CONGRESSO BRASILEIRO DE ENGENHARIA AGRÍCOLA, 27. Cartografia, Sensoriamento e Geoprocessamento (Simpósio)-Cap. 2, Coord. Silva, M.S., 1998. p.59-88.

CAMPOS, H. Estatística Experimental Não-Paramétrica. 3.ed. Piracicaba: Departamento de Matemática e Estatística, 1979. 343p.

CARVALHO, W.A. Fotointerpretação de bacias hidrográficas e amostras circulares de redes de drenagem de solos com horizonte B textural. Piracicaba, 1977. 126p. Tese (Doutorado) - Escola Superior de Agronomia "Luiz de Queiroz", Universidade de São Paulo.

CARVALHO, W.A.; PIEDADE, G.C.R.; FRANÇA, G.V. Redes de drenagem em duas áreas diferentes. Revista Brasileira de Ciência do Solo, v.2, p.204-209, 1978.

CLARK UNIVERSITY. Graduate School of Geography. IDRISI. version 2.0 for Windows. Worcester: Graduate School of Geography/Clark University, 1997.

COLWELL, R.N. Photographic interpretation for civil purposes. In: AMERICAN SOCIETY OF PHOTOGRAMMETRY. Manual of Photographic Interpretation. 2.ed. Washington, 1952. p. 535-602.

CRESWICK, W.J.; ROCKWELL, W.H. Applications of aerial photographic techniques to agricultural surviveys. In: Aerial Photographic Interpretation: principle and applications. New York, 1959, p.373-385.

CRÓSTA, A.P. Processamento digital de imagens de sensoriamento remoto. Campinas: GI/UNICAMP, 1992. 170p. 
CURRAN, P. J. Principles of remote sensing. London: Longman, 1988.

DEFFONTAINES, P. Regiões e paisagens do Estado de São Paulo: primeiro esboço de divisão regional. Geografia, v.1, n.2, p.117-169, 1935.

DELMIRO, M.A.T. Mosaico de imagens para sistemas de informações geográficas. IN; SEMANA ESTADUAL DE GEOPROCESSAMENTO. Rio de Janeiro. "Geoprocessamento: Mito \& Realidade". 1996.

DEMATÊ, J.A.M. Utilização de parâmetros de drenagem com o auxílio de fotografias aéreas, na caracterização de solos desenvolvidos de rochas eruptivas, no Estado do Paraná. Piracicaba, 1992. 141p. Dissertação (Mestrado) - Escola Superior de Agronomia "Luiz de Queiroz", Universidade de São Paulo.

DIAS, L.A.V. Correção radiométrica de imagens de satélite. São José dos Campos: INPE, 1982. (INPE-2406-PRE/116).

DUTRA, L.V.; MENESES, P.R. Realce de cores em imagens de sensoriamento remoto utilizando rotação de matiz no espaço IHS. São José dos Campos: INPE, 1987. 13p. (INPE-4207-PRE/1088).

EASTMAN, J.R. IDRISI: version 4.0, User's Guide. Clark University, Graduate School of Geography: Worcester, Massachusetts, 1992. 178p.

EMPRESA BRASILEIRA DE PESQUISA AGROPECUÁRIA. Serviço Nacional de Levantamento e Conservação de Solos. Mapa de Solos do Brasil, coordenado e planejado por M.N. Camargo. Rio de Janeiro, 1981. Escala 1:5.000.000. 
FADEL, H. Fotointerpretação de bacias e de redes de drenagem de três séries de solos da Fazenda Ipanema, município de Araçoiaba da Serra (SP). Piracicaba, 1972. 92p. Dissertação (Mestrado) - Escola Superior de Agricultura "Luiz de Queiroz", Universidade de São Paulo.

FARRET, J.C. Aplicabilidade do georeferenciamento de aerofotos de pequeno formato na formação de bancos de dados espaciais - uma alternativa para o cadastro técnico rural municipal. Santa Maria, 1996. 111p. Dissertação (Mestrado) - Universidade Federal de Santa Maria.

FARRET, J.C.; GIOTTO, E. Aplicabilidade do georeferenciamento de aerofotos de pequeno formato na formação de bancos de dados espaciais - uma alternativa para o cadastro técnico rural municipal. Ciência Rural, v.27, n.4, p.577-581, abr. 1997.

FRANÇA, G.V. de. Interpretação fotográfica de bacias e redes de drenagem aplicada a solos da região de Piracicaba. Piracicaba, 1968. 151p. Tese (Doutorado) - Escola Superior de Agricultura "Luiz de Queiroz", Universidade de São Paulo.

FRANÇA, G.V. de; DEMATTÊ, J.A.M. Levantamento de solos e interpretação fotográfica dos padrões de solos originados do arenito de Bauru. Scientia Agricola, v.50, n.1, p.77-86, 1993.

FREIRE, J.C. Fotointerpretação de redes de drenagem de três solos da Região de Alpinópolis, Mina Gerais. Piracicaba, 1977. 136p. Tese (Doutorado) - Escola Superior de Agricultura "Luiz de Queiroz", Universidade de São Paulo.

FROST, R.R. Photointerpretation of soil. In: AMERICAN SOCIETY OF PHOTOGRAMMETRY. Manual of Photographic Interpretation. Falls Church, 1960. Cap. 5, p. 343-402. 
FUNDAÇÃO INSTITUTO BRASILEIRO DE GEOGRAFIA E ESTATÍSITCA. Folhas Topográficas de Piracicaba, Capivarí, Ibitiruna e São Pedro. Rio de Janeiro, Diretoria de Geodésica e Cartografia. Escala 1:50.000. 1969.

GEVAERD, I. Parâmetros Fotoanalíticos de três unidades de solo da região Nordeste Paranaense. Piracicaba, 1974. 110p. Dissertação (Mestrado) - Escola Superior de Agricultura "Luiz de Queiroz", Universidade de São Paulo.

GODOY JÚNIOR, M.; NOVO, E.M.L.M. Processamento digital de dados TM/Landsat no monitoramento de águas interiores. São José dos Campos: INPE, 1989. 266p. (INPE-4956-PRE/1533).

GOOSEN, D. Interpretacion de fotos areas y su inportancia en levantamiento de suelos. Roma, Organizacion de las Naciones Unidas para la Agricultura y la Alimentacion, 1968. 58p. (Boletin sobre suelos, 6)

GOVERNO DO ESTADO DE SÃo PAULO. Mapa Geológico do Estado de São Paulo: Folha de Piracicaba. São Paulo: Secretaria de Obras e do Meio Ambiente. Escala 1:100.000. 1966.

Governo do eStado de SÃo PAUlo. Mapa Pedológico do Estado de São Paulo: Folha de Piracicaba. São Paulo: Secretaria de Agricultura e Abastecimento. Secretaria de Economia e Planejamento. Escala 1:50.000. 1989.

GRAÇA, L.M.A. O uso de "scanners" para a digitalização de cartas topográficas e para a implantação de um sistema de geo-informações urbanas. In: SIMPÓSIO BRASILEIRO DE GEOPROCESAMENTO. Escola Politécnica da Universidade de São Paulo. 1990. p219-224. 
GRASSO, D.N. Aplications of the IHS Color Transformation for 1:24,000-Scale Geológic Mapping: A Low Cost SPOT Alternative. Photogrammetric Engineering and Remote Sensing, v.59, n.1, p.73-80, jan. 1993.

GREENACRE, M.J. Correspondence Analysis in Practice. London: Academic Press, 1993. 193p.

HENDERSON, F.M.; RHOADES, D.A.; KNAPP, V.J. Digital image processing with a microcomputer: a philosophy and approach for classroom instruction. Technical Paper of $49^{\text {th }}$ Annual Meeting of American Society or Photogrammetry. Washington D.C. p410-419. 1983.

HORTON, R.E. Erosional development of steams and their drainage basins: hydrophysical approach to quantitative morphology. Bul. Geol. Soc. Amer., v.56, n. 1, p.275-370, 1945.

JONES, J.R.; LANEY, R.; FULK, M.; AUBLE, J. TOSCA. Reference guide. version 2.0. Worcester: Graduate School of Geography/Clark University, 1993. 86p.

KOFFLER, N.F. Utilização de imagens aerofotogramétricas e orbitais no estudo do padrão de drenagem em solos originados do arenito bauru. São José dos Campos, 1976. 150p. Dissertação (Mestrado) - Instituto de Pesquisas Espaciais.

LEÃO, S.T.F. Interpretação fotográfica dos padrões de drenagem desenvolvidos em dois solos do Distrito Federal. Piracicaba, 1973. 110p. Dissertação (Mestrado) Escola Superior de Agricultura "Luiz de Queiroz", Universidade de São Paulo.

LILLESAND, T.M.; KIEFER, R.W. Remote sensing and image interpretation. 3.ed. John Wiley \& Sons, 1994. 750p. 
LUEDER, D.R. Aerial Photographic Interpretation: Principles and Applications. New York, Mc Graw-Hill, 1959. 462p.

MANECHINI, C. Utilização de fotografias aéreas na comparação de sistemas de amostragem e estudos da rede de drenagem de três solos da região de Tambaú (SP). Piracicaba, 1981. 133p. Dissertação (Mestrado) - Escola Superior de Agricultura "Luiz de Queiroz", Universidade de São Paulo.

MARCHETTI, D.A.B. Fotointerpretação de atributos do relevo aplicados a solos da região de Piracicaba. Piracicaba, 1969. 58p. Tese (Doutorado) - Escola Superior de Agricultura “Luiz de Queiroz”, Universidade de São Paulo.

MARTINS, M.R.; MATTOS, J.T.; BRANDINI, F.P. Tecnicas de realce de imagens orbitais, evidenciando as variações espectrais da massa de água superficial das baías de Paranaguá e Antonina - PR. In: SIMPOSIO BRASILEIRO DE SENSORIAMENTO REMOTO, 7., 1993. resumos. p.181-189.

MASCARENHAS, N.D.A. Processamento digital de imagens: um resumo das principais técnicas. São José dos Campos: INPE, 1987. 10p. (INPE-4404-PRE/1220).

MASCARENHAS, N.D.A. Introdução ao processamento digital de imagens. São José dos Campos: INPE, 1990. 35p. (INPE-5212-MD/46).

MAXWELL, J.C. The bifucation ratio in Horton's law of stream number. Trans. Amer, Geophys. Union. 36: 520. 1955.

MELLO, H.M.C.F.; CINTRA, J.P. Erros associados à digitalização de mapas. In: CONFERÊNCIA LATINOAMERICANA DE INFORMAÇÃO GEOGRÁFICA, 7. Simpósio Brasileiro de Geoprocessamento, 2. São Paulo, julho de 1993. p29-46. 
MOIK, J.G. Digital processing of remotely sensed images. NASA public. SP-431, Goddard Space Flight Center, 1980. 330p.

MONTGOMERY, G.E.; SCHUCH, H.C. GIS data conversion handbook. Fort Collins: GIS world, 1993. 292p.

MORIMOTO, T. Estudo de efeitos atmosféricos sobre as radiações percebidas pelos sensores a bordo de plataformas orbitais (ERTS/LANDSAT). INPE. São José dos Campos, 1980. (INPE-1689-TDL/021). (Tese de Mestrado em Meteorologia).

NICHOLS, D. Digital Hardware. In: Manual of Remote Sensing. 2ed. v.1. Cap.20. American Society of Photogrammetry. Falls church, Virginia. 1983.

NOGUEIRA, F.P. Utilização de fotografias aéreas em três escalas no estudo da rede de drenagem, em diferentes unidades de solo. Piracicaba, 1979. 110p. Dissertação (Mestrado) - Escola Superior de Agricultura "Luiz de Queiroz", Universidade de São Paulo.

NOVO, E.M.L. DE M. Sensoriamento Remoto: princípios e aplicações. 2ed. São Paulo: Edgard Blucher, 1995. 308p.

OLIVEIRA, C. Curso de cartografia moderna. Rio de Janeiro, IBGE, 1988. 152p.

OLIVEIRA, J.B.; ALFONSI, R.R.; PEDRO JUNIOR, M.J. Regimes hídricos e térmicos dos solos do Estado de São Paulo. In: CONGRESSO BRASILEIRO DE CIÊNCIA DO SOLO, 15., Campinas. Anais. Campinas: SBCS, 1976. p.359-362. 
OLIVEIRA, J.B.; JACOMINE, P.K.T.; CAMARGO, M.N. Classes gerais de solos do Brasil: Guia auxiliar para seu reconhecimento. 2.ed. Jaboticabal: FUNEP, 1992. $201 \mathrm{p}$.

PARADELLA, W.R. Introdução ao processamento digital de imagens de sensores remotos aplicado a geologia. São José dos Campos: INPE, 1990. 45p. (INPE-5023RPE/616).

PARADELLA, W.R.; DUTRA, L.V. Filtragens digitais de imagens Landsat como técnica de auxílio visual na fotointerpretação geológica. São José dos Campos: INPE, 1980. 7p. (INPE-1823-RPE/189).

PARISE, F.J.O. Análise temporal de uso da terra em uma microbacia hidrográfica no município de Piracicaba, SP, por meio de técnicas de geoprocessamento. Piracicaba, 1999. 114p. Dissertação (Mestrado) - Escola Superior de Agricultura “Luiz de Queiroz", Universidade de São Paulo.

PARVIS, M. Drainage pattern significance in airphoto identification of soils and bedrocks. Photogrammetric Engineering, Falls Church, v.16, n.3, p.387-408, 1950.

PFEIFER, R.M. Aplicabilidade de produtos de sensores remotos na caracterização fisiográfica para mapeamento de solos. Piracicaba, 1995. 202p. Tese (Doutorado) Escola Superior de Agricultura "Luiz de Queiroz", Universidade de São Paulo.

PIMENTEL GOMES, F. Curso de Estatística Experimental. 11.ed. Piracicaba: Nobel, 1985. 466p. 
PISSARRA, T.C.T. Avaliação quantitativa das características geomórficas de microbacias hidrográficas de $1^{\mathrm{a}}$ ordem de magnitude em quatro posições di sistema de drenagem - Região de influência de Ilha Solteira, SP. Jaboticabal, 1998. 126p. Dissertação (Mestrado) - Faculdade de Ciências Agrárias e Veterinária do Campus de Jaboticabal/UNESP.

POLITANO, W. Estudo comparativo sobre a morfometria das áreas de dois solos Podzólicos Vermelho-Amarelos. Piracicaba, 1980. 167p. Tese (Doutorado) - Escola Superior de Agricultura "Luiz de Queiroz", Universidade de São Paulo.

QUINTANILHA, J.A. Processamento de imagens digitais. In: SIMPÓSIO BRASILEIRO DE GEOPROCESSAMENTO. São Paulo, 1990. São Paulo: USP/Escola Politécnica, 1990. p.37-52.

QUINTANILHA, J.A. Erros em bases digitais de dados espaciais para uso em sistemas de informação geográfica. São Paulo, 1996. 236p. Tese (Doutorado) - Escola Politécnica, Departamento de Engenharia de Transportes, Universidade de São Paulo.

RABEN, E.L. Fundamentals of Photo Interpretation. AMERICAN SOCIETY OF PHOTOGRAMMETRY. Manual of Photographic Interpretation. Falls Church, 1960. cap.3, p.99-186.

RANIERI, S.B.L.; SPAROVEK, G.; SOUZA, M.P.; DOURADO NETO, D. Aplicação de índice comparativo na avaliação do risco de degradação das terras. Revista Brasileira de Ciência do Solo, 22, p.751-760, 1998.

RANZANI, G. Subsídio à Geografia de Piracicaba. Instituto Histórico e Geográfico de Piracicaba: Editora Franciscana, 1976. 79p. 
RANZANI, G.; FREIRE, O.; KINJO, T. Carta de solos do Município de Piracicaba. Piracicaba: ESALQ-USP, 1966. 85p.

RAY, R.G. Fotografias aéreas na interpretação e mapeamento geológico. Trad. de J. Felicíssimo Júnior. São Paulo: IGG, 1963. 162p.

RAY, R.G.; FISCHER, W.A. Quantitative photography: a geologic research tool. Photogrammetric Engineering, v.26, n.1, p.143-150, 1960.

RICCI, M.; S. PETRI. Princípios de Aerofotogrametria e Interpretação Geológica. São Paulo: Editora Nacional, 1965. 226p.

ROURKE, J.D.; AUSTIN, M.E. The use of airphotos for soil classification and mapping in field. Photogrammetric Engineering, v.17, p.738-741, 1951.

SÃo PAULO (Estado). Plano Cartográfico do Estado de São Paulo. São Paulo: Secretaria de Economia e Planejamento, Coordenadoria de Ação Regional, Divisão de Geografia, 1978. Escala 1:10.000.

SÃO PAULO (Estado). Plano Cartográfico do Estado de São Paulo. São Paulo: Secretaria de Economia e Planejamento, Coordenadoria de Ação Regional, divisão de Geografia, 1979. Escala 1:10.000.

SCHOBBENHOUSE, C.; CAMPOS, D.A.; DERZE, G.R.; ASMUS, H.E. Geologia do Brasil, Brasília: Departamento Nacional de Produção Mineral, 1984.

SCHUMM, S.A. Evolution of drainage systems na slopes in badlands at Perth Ambory. Bull. Geol. Soc. Am., v.67, p.597-646, 1956. 
SILVA. L.C.F. Fotointerpretação de redes de drenagem de dois solos do município de São Pedro - SP. Piracicaba, 1977. 114p. Dissertação (Mestrado) - Escola Superior de Agricultura "Luiz de Queiroz", Universidade de São Paulo.

SILVA, D.A. Fotointerpretação de amostras circulares de redes de drenagem dos solos do Parque Estadual Carlos Botelho - SP. Silvicult. S. P., v.20/22, p.14-24, 1986.

SMITH, K.G. Standards for grading texture of erosional topography. American Journal of Science, v.248, p.655-668, 1950.

SIMONSON, R.W. Use of aerial photographic in soil survey. Photogrammetric Engineering, v.16, n.2, p.308-315, 1950.

SOARES, A.F. Sensoriamento remoto e geoprocessamento aplicados na caracterização dos solos e da cobertura vegetal na bacia hidrográfica do Rio Carandiru-Açu - PA. Piracicaba, 1994. 139p. Dissertação (Mestrado) - Escola Superior de Agricultura "Luiz de Queiroz", Universidade de São Paulo.

SOUZA, L.C.P. Utilização de dados digitais TM/Landsat e análise de agrupamentos na delimitação de unidades de solos da planície de inundação do Rio Ivai - PR. Piracicaba, 1997. 143p. Tese (Doutorado) - Escola Superior de Agricultura "Luiz de Queiroz", Universidade de São Paulo.

SOUZA, M.L.P. Fotointerpretação das redes de drenagem de três solos com horizonte B latossólico ocorrentes no município de Ponta Grossa - PR.. Piracicaba, 1975. 135p. Dissertação (Mestrado) - Escola Superior de Agricultura "Luiz de Queiroz", Universidade de São Paulo.

STRAHLER, A.N. Hypsometric analysis of erosinal topography. Bulletin Geological of Society American, v.63, p.1117-1142, 1952. 
STRAHLER, A.N. Quantitative analysis of watershed geomorphology. Transactions American Geophysical Union, v.38, n.6, p.913-920, 1957.

SUMMERSON, C.H. A philosophy for photointerpreters. Photogrammetric Engineering, v.20, p.396-7, 1954.

TERAMOTO, E.R. Relações solo, substrato geológico e superfícies geomórficas na microbacia do Ribeirão Marins (Piracicaba-SP). Piracicaba, 1995. 141p. Dissertação (Mestrado) - Escola Superior de Agricultura "Luiz de Queiroz", Universidade de São Paulo.

THAPA, K.; BOSSLER, J. Accuracy of spatial data used in geographic information systems. Photogrammetric Engineering and Remote Sensing, v.58, n.6, p.835841, jun. 1992.

VALÉRIO FILHO, M.; HIGA, N.T.; CARVALHO, V.C. Avaliação das imagens orbitais (LANDSAT-1) como base para levantamento de solos. São José dos Campos: INPE, 1976. 276p. (INPE-912-TPT/030).

VALÉRIO FILHO, M. Parâmetros da drenagem e do relevo na caracterização de solos e suas relações fotointerpretativas em imagens de pequena escala. Piracicaba, 1984. 141p. Tese (Doutorado) - Escola Superior de Agricultura "Luiz de Queiroz", Universidade de São Paulo.

VASQUES FILHO, J. Critérios morfométricos aplicados à fotointerpretação de redes de drenagem em três unidade de solos no município de Piracicaba (SP). Piracicaba, 1972. 113p. Tese (Doutorado) - Escola Superior de Agricultura "Luiz de Queiroz", Universidade de São Paulo. 
VETTORAZZI, C.A. Fotointerpretação de bacias hidrográficas e redes de drenagem em cinco solos da região do rio Ribeira de Iguape no estado de São Paulo. Piracicaba, 1985. 151p. Dissertação (Mestrado) - Escola Superior de Agricultura "Luiz de Queiroz"/,Universidade de São Paulo.

VETTORAZZI, C.A. Interpretação de imagens TM/LANDSAT-5, em duas escalas, na caracterização fisiográfica para mapeamento de solos. Piracicaba, 1988. 184p. Tese (Doutorado) - Escola Superior de Agricultura "Luiz de Queiroz", Universidade de São Paulo.

WALSH, S.J.; COOPER, J.W.; VON ESSEN, I.E.; GALLAGER, K.R. Image inhancement of Landsat Thematic Mapper data and GIS data integration for evaluation of resource characteristics. Photogrammetric Engineering, v.56, n.8, p.1135-1141, aug. 1990.

WOLF, P.R. Elements of Photogrammetry. New York: McGraw-Hill book Companny, 1983. 628p. 